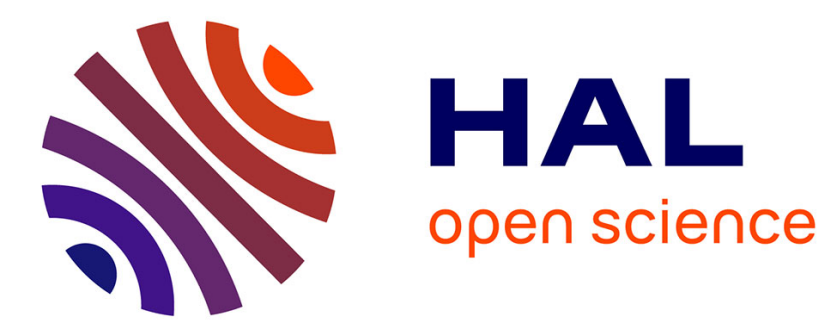

\title{
Helium mobility in advanced nuclear ceramics
}

Shradha Agarwal

\section{To cite this version:}

Shradha Agarwal. Helium mobility in advanced nuclear ceramics. Materials Science [cond-mat.mtrlsci]. Université Paris Sud - Paris XI, 2014. English. NNT : 2014PA112197 . tel-01138454

\section{HAL Id: tel-01138454 \\ https://theses.hal.science/tel-01138454}

Submitted on 2 Apr 2015

HAL is a multi-disciplinary open access archive for the deposit and dissemination of scientific research documents, whether they are published or not. The documents may come from teaching and research institutions in France or abroad, or from public or private research centers.
L'archive ouverte pluridisciplinaire $\mathbf{H A L}$, est destinée au dépôt et à la diffusion de documents scientifiques de niveau recherche, publiés ou non, émanant des établissements d'enseignement et de recherche français ou étrangers, des laboratoires publics ou privés. 

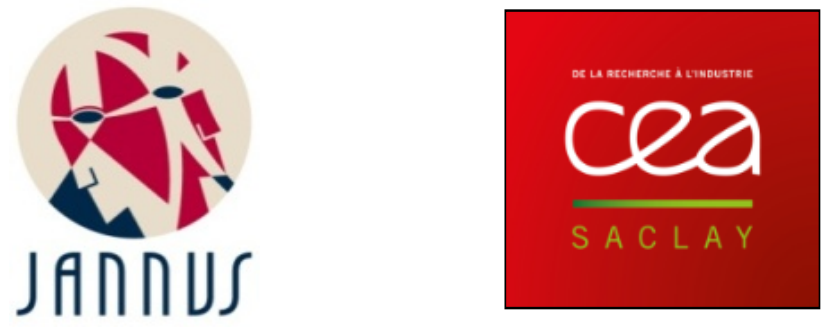

\section{UNIVERSITE PARIS-SUD}

ÉCOLE DOCTORALE : Modélisation et Instrumentation en Physique, Energies, Géosciences et Environnement (MIPEGE)

\section{Laboratoire JANNUS, DEN, SRMP, CEA-Saclay \\ Sciences des Matériaux}

\section{THÈSE DE DOCTORAT}

soutenue le 22/09/2014

par

\section{Shradha AGARWAL}

\section{Helium mobility in advanced nuclear ceramics}

Directeur de thèse :

Composition du jury :

Rapporteurs :

Examinateurs :
Patrick TROCELLIER Ingénieur de Recherche (CEA Saclay)

Nathalie MONCOFFRE Directeur de Recherche CNRS (IPN Lyon)

Guy TERWAGNE Professeur (Université de Namur)

Frédérico GARRIDO Professeur (Université Paris-Sud Orsay)

Ian VICKRIDGE Directeur de Recherche CNRS (INSP Jussieu)

Bernard BONIN Directeur de Recherche CEA (Saclay) 


\section{Acknowledgement}

I would never have been able to finish my dissertation without the guidance of my laboratory members, help from friends, and support from my family. The contributions of many different people, in their different ways, have made this possible. I would like to extend my appreciation especially to the following.

I would like to express my deepest gratitude to my advisor, Dr. Patrick Trocellier, for his excellent guidance, patience, and providing me with an excellent atmosphere for doing research. I would like to thank Sylvain Vaubauillon, who helped me in performing ion beam analysis experiments. This research would have not been possible without his help. I would also like to thank Dr. Thomas Jourdan and Dr. Alain Barbu for helping me in explaining the results from theoritical point of view. Special thanks to my friends Daniel Brimbal and Arunodaya Bhattacharya, from whom I learnt to use transmission electron microscope (TEM). It was impossible for me to obtain, interpret and understand TEM results without their help. I would like to thank Dr. Sandrine Miro, who gave her best suggestions related to the use of AGEING Code. Many thanks to Yves Serruys, Frederic Lepretre, Herve Martin and Eric Bordas for their availability and suggestions during irradiation experiments. Thanks for being with me from beginning until now. Special thanks also goes to Thomas Loussouarn, Gihan Velisa and Daniel Brimbal for keeping very friendly and lively ambiance in the office. It would have been lonely without them. I would highly acknowledge Emilie Jouanny, who gave her best to obtain results from Raman spectroscopy. I would also like to express my gratitude to Patrick Bonnaille and Sylvie Poissionnent for their help in scanning electron microscopy and nano-indentation experiments.

I would also like to thank Jean Luc Bechade and his team from SRMA (CEA) for their availability and help in various scientific issues. I would also like to thank Mario Le Flem from DMN (CEA) for providing excellent quality samples to us. I would also like to thank Frederico Garrido from CSNSM (CNRS-Orsay) for various scientific discussions and annealing experiments. I would also like to thank Hicham Khodja from LEEL (CEA) for $\mu$ - NRA experiments. 
I would also like to thank Mr. Pascal Yvon, Head of Department of Nuclear Materials (DMNCEA), Mr. François Willaime, Head of Physical Metallurgy Research Unit (SRMP-CEA), Mme Lucile Beck, Head of Jannus Laboratory (CEA) to provide this opportunity to me. The experience has been an interesting and rewarding one. My very special thanks to François Willaime for sending me to various conferences and also for helpimg me finding a post-doctoral position. I would not forget to thank Patricia Matysiak and Martin Loge from SRMP who have always helped me regarding administrative issues.

Last but not least, I would thank God for the wisdom and perseverance. I would also like to thank my parents and brothers. They were always supporting and encouraging me with their best wishes. I would also like to thank Mr. Scateena George, my landlord for providing comfortable and friendly atmosphere during my stay for three years. Finally, I would like to thank my best friend, Arunodaya Bhattacharya for his unconditional support. He was always there cheering me up and stood by me through the good and bad times. My research would not have been possible without you all. 


\section{Table of Contents}

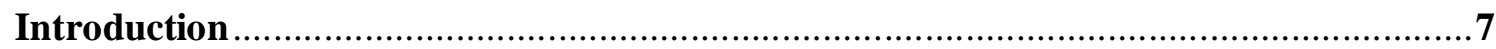

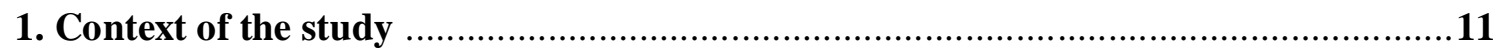

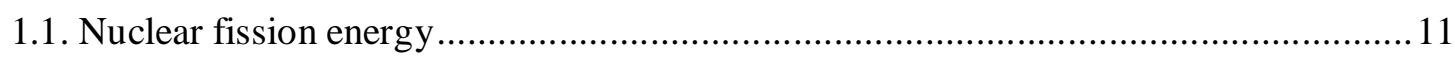

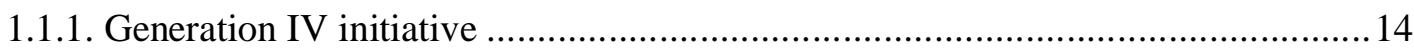

1.1.2. Use of advanced nuclear ceramics in GEN IV reactors ................................... 16

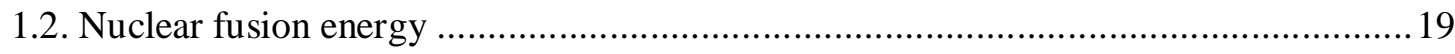

1.2.1. Use of advanced nuclear ceramics in fusion reactors ......................................2 20

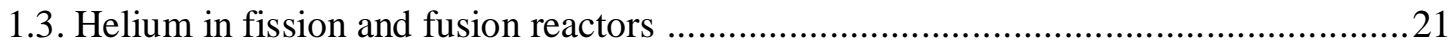

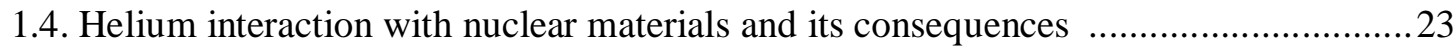

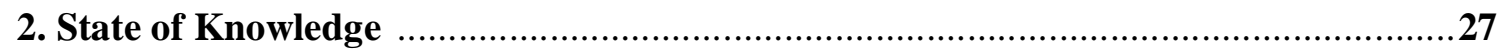

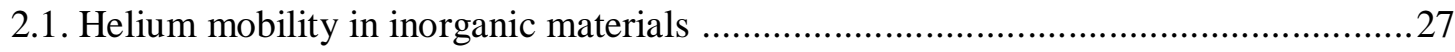

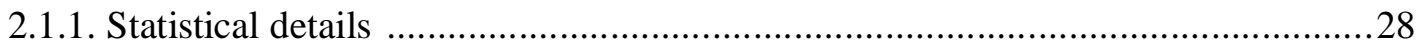

2.1.2. Experimental methods for the study of helium behavior ................................. 31

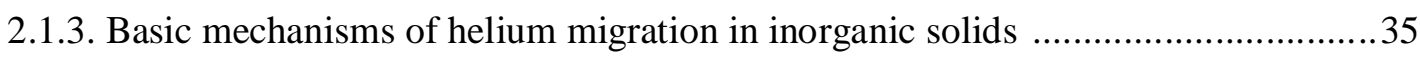

2.1.4. Main experimental data on helium migration in metallic substrates ....................37

2.1.5. Main experimental data on helium migration in non-metallic substrates ..............40

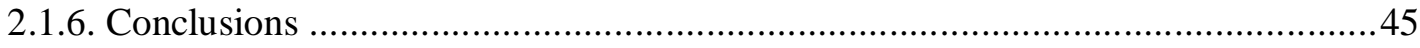

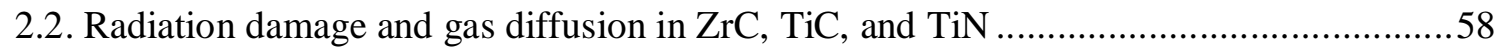

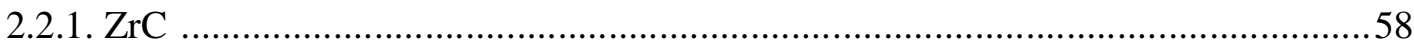

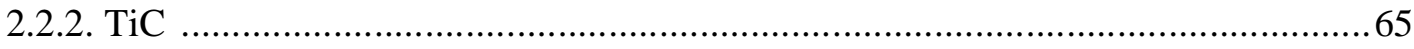

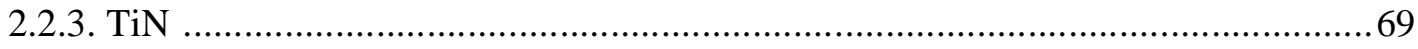

3. Properties of Transition Metal Carbides and Nitrides .........................................75

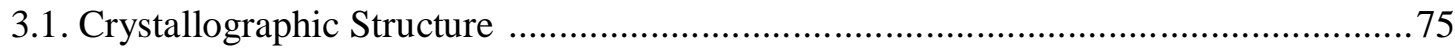

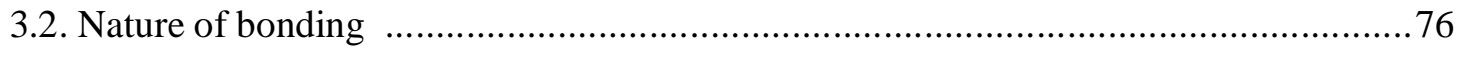

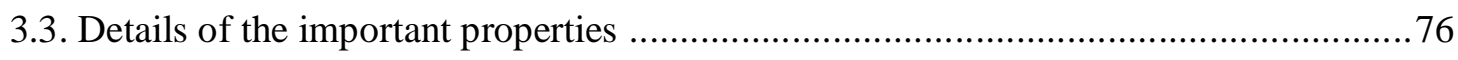

3.4. Variation of properties with M-to-X ratio (M: Ti or Zr \& X: C or N) ........................ 80

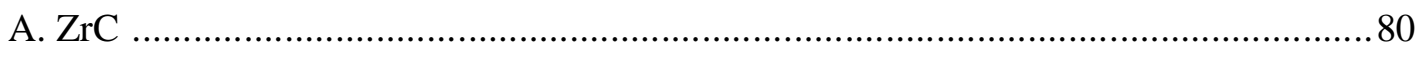

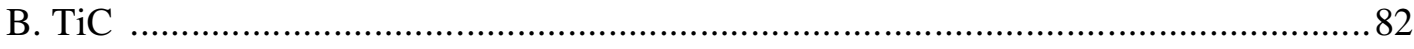




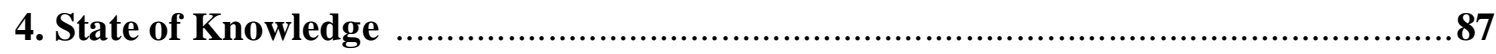

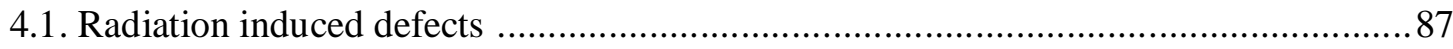

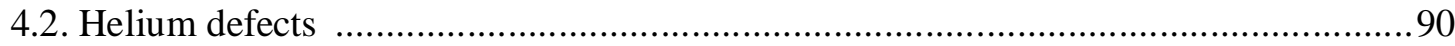

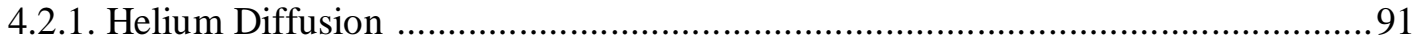

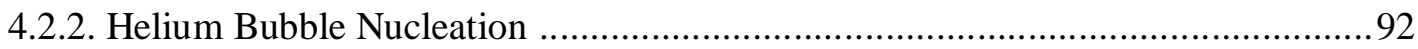

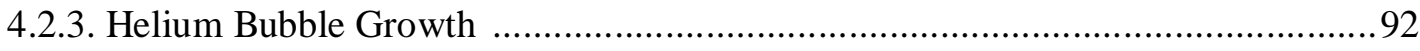

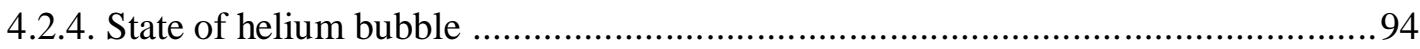

4.2.5. Helium bubble nucleation at extended defects ............................................. 98

4.2.6. Homogeneous vs. heterogeneous nucleation .................................................99

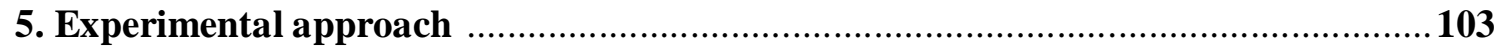

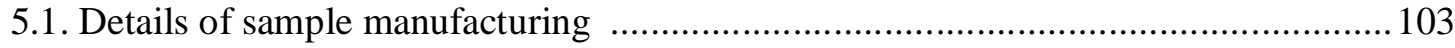

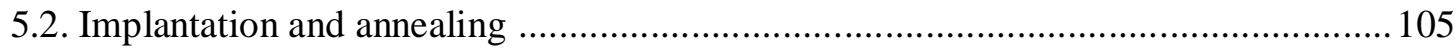

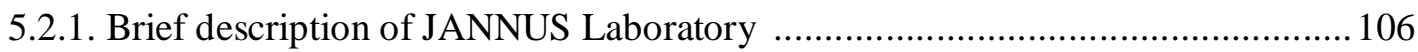

5.2.2. Experimental details for the first set of experiment ..................................... 108

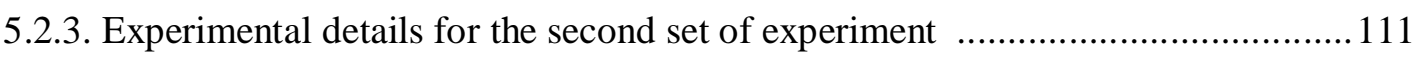

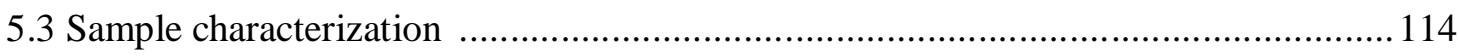

5.3.1. Nuclear Reaction Analysis with stationary $1 \mathrm{~mm}$ size deuteron beam .............. 115

5.3.2. Nuclear reaction analysis with the scanning of $1 \mu \mathrm{m}$ size deuteron beam .......... 123

5.3.3. Transmission Electron Microscopy (TEM) ............................................... 126

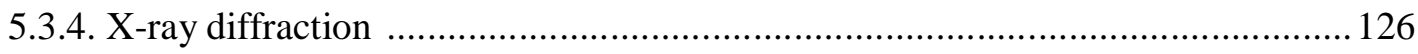

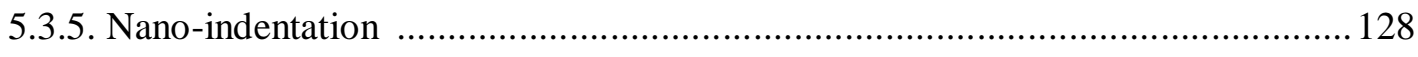

5.3.6. Scanning Electron Microscopy (SEM) and Electron Microprobe ...................... 128

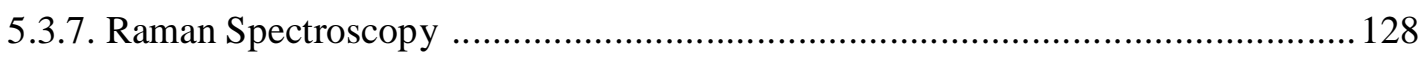

6. Helium behavior under thermal environment .................................................. 131

6.1. Helium behavior under thermal environment in $\mathrm{TiC}$.......................................... 131

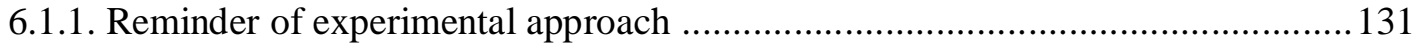




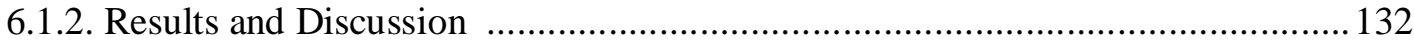

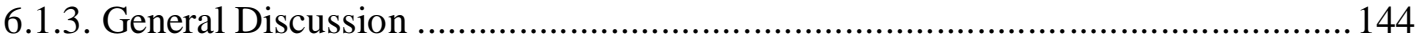

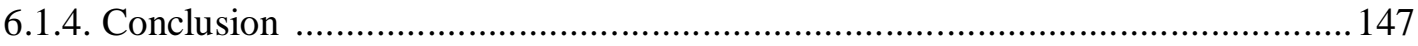

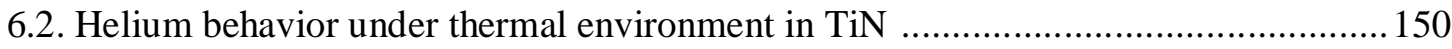

6.2.1. Reminder of the experimental approach ...................................................... 150

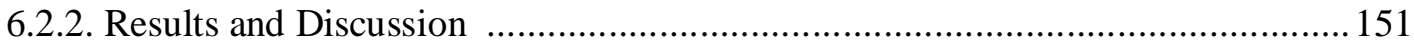

6.2.2.1. Specimens implanted with fluence $F_{1}$ and annealed at various $T_{a} \ldots \ldots \ldots \ldots 151$

6.2.2.2. Comparison study between specimens with fluence $F_{1}, F_{2} \& F_{3} \quad \ldots \ldots \ldots \ldots . . . .171$

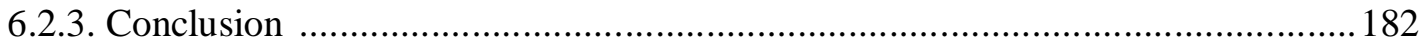

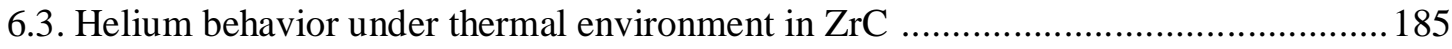

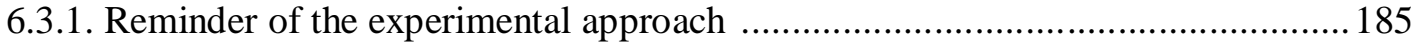

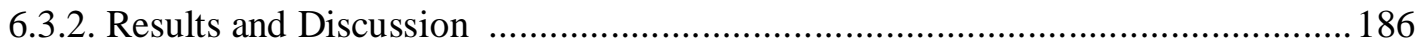

6.3.2.1. Specimens implanted with fluence $F_{1}$ and annealed at various $T_{a} \ldots \ldots \ldots \ldots . . . .186$

6.3.2.2. Comparison study between specimens with fluence $F_{1}, F_{2} \& F_{3} \ldots \ldots \ldots \ldots \ldots . . . . .194$

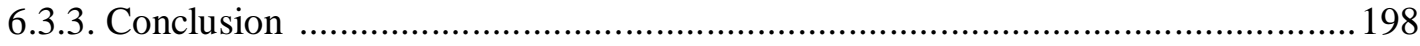

7. Helium behavior under radiation environment.................................................... 199

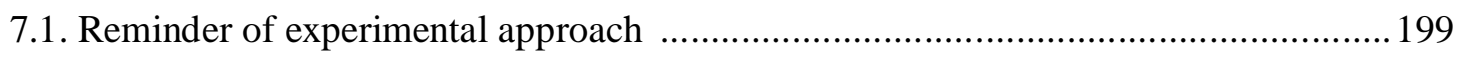

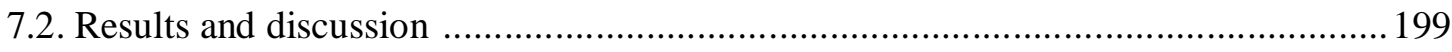

7.2.1. Results of sample characterization after damaging the samples ........................199

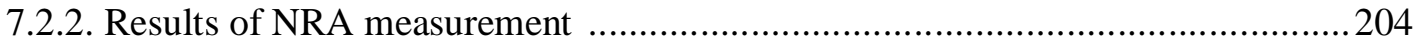

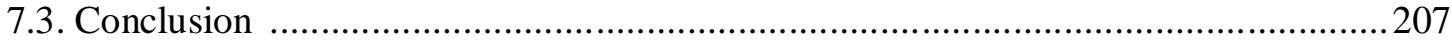

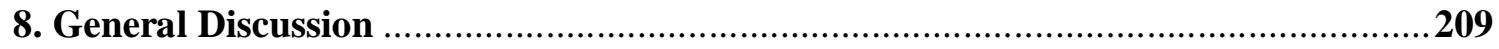

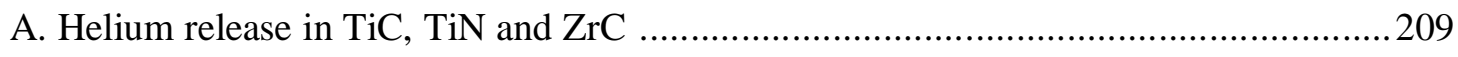

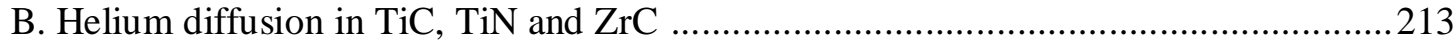

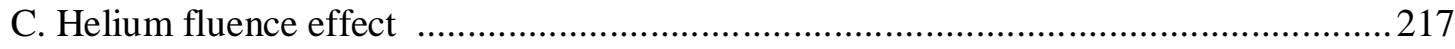

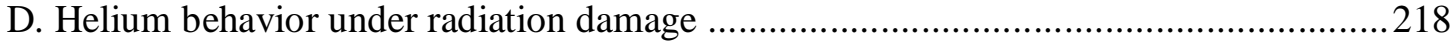

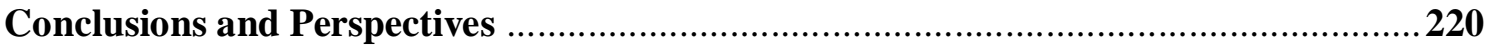

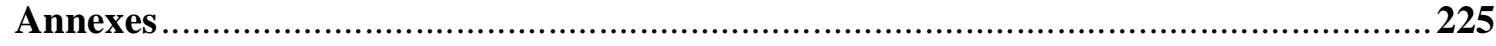




\section{Introduction}

Access to reliable, sustainable and affordable energy is viewed as crucial to worldwide economic prosperity and stability. Given that nuclear power has very low carbon emission and that energy generation currently accounts for $66 \%$ of worldwide greenhouse gas emissions, nuclear energy is considered an important resource in managing atmospheric greenhouse gases and associated climate change.

While the current second and third generation nuclear plant designs provides an economically, technically, and publicly acceptable electricity supply in many markets, further advances in nuclear energy system design can broaden the opportunities for the use of nuclear energy. The fourth generation of nuclear reactors is under development. These new reactors are designed with the following objective in mind: sustainability, safety and reliability, economics, proliferation resistance. Out of six Generation IV systems namely, Gas-Cooled Fast Reactor (GFR), Lead-cooled fast reactor (LFR), Molten Salt Reactor (MSR), Sodium-Cooled Fast Reactor (SFR), Supercritical-Water-Cooled Reactor (SCWR), Very-High-Temperature Reactor (VHTR), this work is dedicated to identify specific fuel type that is compatible with gas-cooled fast reactor (GFR) in-core service conditions and could be extended to diagnose potential cladding material for SFR. The French strategy is mainly oriented towards the development of sodium-cooled fast reactors (SFR) and very slightly focused on GFR.

This dissertation is focused on the study of transition metal ceramics which are candidates for fuel coatings in GFR and have been considered as potential cladding materials for SFR. The specific fuel type in GFR should consists of spherical fuel particle made up of UC or UN, surrounded by a ceramic coating which provides structural integrity and containment of fission products. The most promising candidates for ceramic coatings are $\mathrm{ZrN}, \mathrm{ZrC}$, $\mathrm{TiN}, \mathrm{TiC} \& \mathrm{SiC}$ due to a combination of neutronic performance, thermal properties, chemical behavior, crystal structure, and physical properties.

It is obvious that these ceramics (to be used as fuel particle coating for GFR or as cladding for SFR) would be exposed to energetic fission products from fuel such as heavy ions and neutrons. These high-energy neutron will knock the atoms in the surrounding materials and can induce $(n, \alpha)$ reactions, thus producing high concentration of helium atoms during and after reactor 
operation. The helium atoms produced are energetic and can easily penetrate into the surrounding material.

Helium atoms are considered to be highly insoluble in previously studied structural nuclear materials. The accumulation of helium into solid matrix, can lead to the formation of bubbles, cavity, swelling, embrittlement etc. Helium can strongly induce grain boundary cavitation that can produce formation of inter-granular channels, which may serve as pathways for release of radioactive elements to the environment or lead to grain-boundary weakening and de-cohesion. Particularly in ceramics, large quantities of helium can also lead to dimensional changes and cracks due to over-pressurized helium bubbles. Therefore, study of helium behavior in advanced nuclear ceramics under high operating temperatures and extreme radiation conditions predicted for GFRs and SFRs is viewed as crucial by R\&D team involved in the deployment of Generation IV energy systems.

This study can also be extended to fusion energy systems due to the presence of helium in fusion reactors and the use of $\mathrm{TiC} \& \mathrm{TiN}$ as coatings on materials used for permeation barrier against tritium. This thesis focuses on the study of helium mobility in transition metal ceramics under thermal and radiation environment and is mostly dedicated to investigate transition metal ceramics ( $\mathrm{TiC}, \mathrm{TiN}, \mathrm{ZrC}$ ). Due to the broad range of historic and novel nuclear applications of $\mathrm{SiC}$ such as advanced nuclear fuel forms, structural components for fission reactor systems, blanket structures for fusion energy systems and the immobilization of nuclear waste, $\mathrm{SiC}$ has been very widely studied in last two decades. Thanks to the abundantly available literature on $\mathrm{SiC}$, a comparison between $\mathrm{SiC}$ and other transition metal ceramics has been drawn at the end of the thesis.

With the emergence of single, dual and triple ion beam irradiation facilities around the world, it is possible to simulate the radiation environment inside the reactors. It is possible to simultaneously implant gases (such as $\mathrm{He}, \mathrm{Ar}, \mathrm{Kr}, \mathrm{Xe}$ etc.) and to damage material by one or two ions with different energy and masses. Along with this, it is also possible to heat (or cool) the material (with temperature ranging from $0 \mathrm{~K}$ to $800 \mathrm{~K}$ ), thus allowing replication of real operating conditions inside the reactor. Exposing materials under this environment and their characterization, allows predicting material ageing, defect properties, microstructural evolution and structure-property relationship. 
In this thesis, ion-implantation technique and material characterization techniques are used to study diffusion of helium in transition metal ceramics under thermal and extreme irradiation environments. Our main aim during this thesis is:

- To calculate diffusion and migration energies of helium under different experimental conditions by applying theoretical models on experimental data.

- To investigate the microstructural evolution due to helium accumulation and conversely, identifying the role of microstructure such as grain boundaries, native vacancies and porosity on helium accumulation.

- To know the role of helium introduction conditions on helium diffusion.

- To establish and validate an approach to calculate pressure built by helium gas inside the bubbles and to verify if the pressure approaches mechanical stability limit.

- To understand "when and how ion beam analysis (IBA) could be more effective than transmission electron microscopy (TEM)' to study helium behavior in materials.

- To compare the helium effects in different ceramics (such as $\mathrm{TiC}, \mathrm{ZrC}$ and $\mathrm{TiN}$ ) for their possible use in BISO (Bistructural-isotropic) or TRISO (Tristructural-isotropic) fuel forms for Gen IV reactors.

Following state-of-art material characterization tools are used namely, (1) IBA (Ion beam analysis), primarily $N R A$ (nuclear reaction analysis) and $R B S$ (Rutherford backscattering spectrometry) to know the positioning of helium atoms and other matrix atoms, (2) Raman spectroscopy to determine different phases and to see the evolution of phases after implantation and annealing, (3) TEM (transmission electron microscopy) to observe the microstructure evolution at nano-metric scale, (4) X-ray diffraction to determine the lattice swelling and other crystallographic information, (5) SEM (scanning electron microscopy) to analyze surfaces, (6) Nano-indentation to test material hardness after irradiation, (7) Laser profilometry to measure macroscopic swelling, (8) FIB (focused ion beam), electro polishing, PIPS (precision ion polishing system) to prepare electron transparent thin foils $(\sim 100 \mathrm{~nm})$.

This thesis work has already led to three publications and other three publications are under process. They are planned to submitted by the end of this year. The predominant part of the thesis is based on learning to use various state-of-art material characterization tools, irradiation experiment, analyzing data and applying theoretical models for data interpretation.

This thesis is divided into eight chapters:

Chapter one: In this chapter context of the thesis is provided. 
Chapter two: Our state of knowledge on helium mobility in inorganic materials and radiation effects in transition metal ceramics is presented.

Chapter three: In this chapter, properties of transition metal ceramics are detailed.

Chapter four: Theoretical approach followed during this thesis is detailed.

Chapter five: Experimental approach followed during this thesis is detailed.

Chapter six: Results on helium mobility in transition metal ceramics under thermal environment are presented and discussed.

Chapter seven: Results on helium mobility in transition metal ceramics under radiation environment are presented and discussed.

Chapter eight: Finally, general discussion and conclusions are presented.

It is important to point out that the reference is provided at the end of each chapter. In chapter number two and six, reference is provided at the end of each sub-section. 


\section{Chapter 1}

\section{Context of the study}

\subsection{Nuclear fission energy}

Nuclear power currently provides about $13 \%$ of electrical power worldwide, and has emerged as a reliable base load source of clean and economical electrical energy. In 2011, there were 435 nuclear reactors in operation worldwide, producing $370 \mathrm{GW}_{\mathrm{e}}$ of electricity. Another 108 units or $108 \mathrm{GW}_{\mathrm{e}}$ of electricity are forthcoming (under construction or on order), for a total of 543 units and $478 \mathrm{GW}_{\mathrm{e}}$ of electrical capacity. Given that nuclear power has very low carbon emission and that energy generation currently accounts for $66 \%$ of worldwide greenhouse gas emissions, nuclear energy is considered an important resource in managing atmospheric greenhouse gases and associated climate change [1].

Nuclear fission involves splitting a heavier nucleus into two lighter nuclei. The most common used fuel in most reactors is U-235. The spontaneous fission rate of U-235 is very slow; too slow to be of any use in a nuclear reactor. Therefore, a neutron is made to hit U-235 to induce fission and if a single U-235 nucleus fissions, the emitted neutrons can induce a fission in two or more U-235 nuclei, which each in turn can produce two or more, etc. If enough U-235 nuclei are close together, the process can increase rapidly, producing a lot of energy in a short time. This chain reaction can be described as:

$$
{ }_{0}^{1} n+{ }_{92}^{235} U \rightarrow X+Y+k{ }_{0}^{1} n+Q_{T h}
$$

$\mathrm{k}$ is the number of neutrons released, generally between $2 \& 3$, and $\mathrm{Q}_{\mathrm{th}}$ is the energy generated in the form of heat which is equal to $\sim 200 \mathrm{MeV}$. This energy is distributed among the fission products $\mathrm{X}$ and $\mathrm{Y}, \mathrm{k}$ number of neutrons, and radiation which is in the form of gamma rays and neutrinos. 
The typical power densities in commercial nuclear reactor cores are $\sim 50-75 \mathrm{MW}_{\text {th }} \mathrm{m}^{-3}$, which is nearly two orders of magnitude higher than the average power density in the boiler furnace of a large-scale coal power plant [1].

To maintain the constant rate of fission, control rods which are generally made of $\mathrm{B}_{4} \mathrm{C}$ are used to absorb the neutrons. The reactor vessel contains the core (i.e., the uranium fuel) and water. The heated water in the reactor flows to a steam generator. The steam goes to the turbine causing that to rotate which then turns a generator, thus producing electricity. On the exit side of the turbine is a condenser. This condenser cools the steam and sends it to the environment. Nuclear plants are about 35 to $40 \%$ efficient; i.e., 35 to $40 \%$ of the heat generated in the reactor ends up as electricity; the rest is lost in the environment.

The neutrons produced by the fission process are too energetic to induce fission reaction of $U$ 235 with a small cross section ( $\sigma_{\text {fast }} \approx 1.95$ barns against $\sigma_{\text {thermal }} \approx 580$ barns). Therefore, with this energy of neutrons and with natural uranium as fuel (with only $0.7 \%$ fissile nuclei), a steady rate of reaction is difficult to achieve. However, a constant rate of fission can be maintained if either total number of U-235 atoms (by enrichment of fuel) are increased or the energy of neutrons are bought closer to the energy of thermal neutrons to increase the cross section of absorption (by using moderators). Therefore, in a reactor, where the fast neutrons are moderated by elastic collisions with heavy water or light water and are thermalized is known as thermal reactors. However, a nuclear reactor in which the fission chain reaction is sustained by fast neutrons is known as fast reactor. Such a reactor needs no neutron moderator, but must use fuel that is relatively rich in fissile material when compared to that required for a thermal reactor. Over all, there are two main types of nuclear reactor in operation, characterized by the speed of the neutrons which induce fission:

a) Thermal reactors: These are the predominant kind, using slower neutrons to induce fission, the basic fissile nuclide being U-235. Mainly, they include:

1. light water reactor (LWR)

2. boiling water reactor (BWR)

3. pressurized heavy water reactor (PHWR)

4. light water graphite-moderated reactor (LWGR)

5. gas-cooled reactor (GCR) 
b) Fast reactors. In these less-common reactors, the fast neutrons are used directly to create (breed) fissile nuclides from fissionable nuclides; most commonly $\mathrm{Pu}-239$ is bred from U238. Pu-239 is also used in nuclear weapons. It mainly includes:

1. fast-neutron breeder reactor (FBR)

All type of reactors are loosely grouped into generations describing the time period in which they were first used. Figure 1.1 shows time ranges correspond to the design and the first deployments of different generations of reactors and are discussed below:

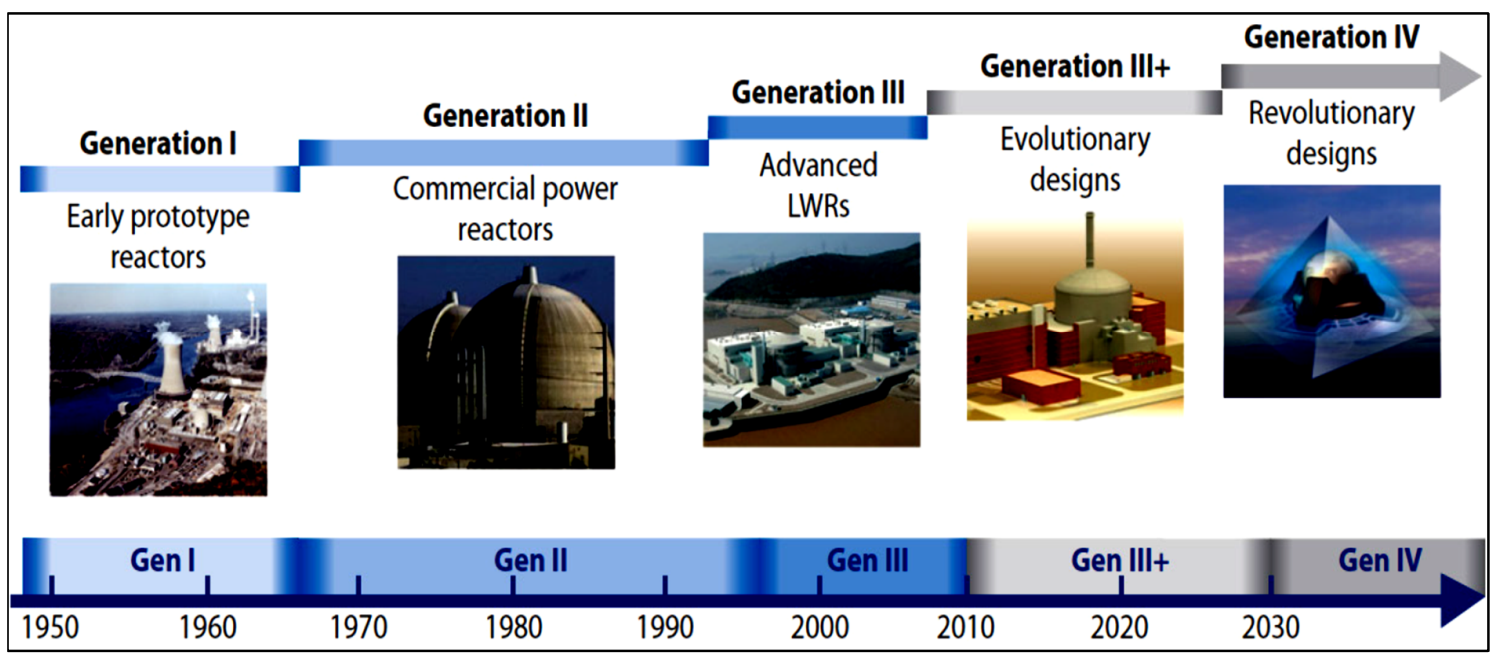

Figure 1.1. Time ranges correspond to the design and the first deployment of different generations of reactors [2].

In the next paragraph, a brief description of each generation of reactor has been provided:

1) First generation: The first power generation was introduced during the period 1950-1970 and included early prototype reactors such as Shipping port, Dresden, Fermi I in the USA and the Magnox reactors in the UK.

2) Second generation: The second generation includes commercial power reactors built during 1970-1990 such as LWRs, BWRs, and PWRs. In Canada, it includes the CANadian Deuterium Uranium heavy water moderated and natural uranium fuelled known as CANDU reactors. In Russia, this was the era of pressurized water reactor VVER-1000 and the RBMK-1000 of Chernobyl accident notoriety. 
3) Third generation: The third generation started being deployed in the 1990s and is composed of the Advanced Boiling Water Reactor (ABWR) and Advanced Light Water Reactor (ALWR) and the system 80+. These were primarily built in East Asian countries. New designs that are expected to be deployed by 2010-2030 include the Advanced Passive AP 600 and AP 1000 . These are considered as evolutionary designs offering improved safety and economics.

4) Fourth generation: While the current second and third generation nuclear plant designs provides an economically, technically, and publicly acceptable electricity supply in many markets, further advances in nuclear energy system design can broaden the opportunities for the use of nuclear energy. The fourth generation of nuclear reactors is expected to start being deployed in 2030. These new reactors are designed with the following objective in mind: sustainability, safety and reliability, economics, proliferation resistance.

\subsubsection{Generation IV initiative}

The Generation IV International Forum (GIF) was created in January 2000 by 9 countries and today has 13 members, all of which are signatories of its founding document, the GIF Charter. Argentina, Brazil, Canada, France, Japan, the Republic of Korea, South Africa, the United Kingdom and the United States signed the GIF Charter in July 2001. It was subsequ-ntly signed by Switzerland in 2002, Euratom1 in 2003, and the People's Republic of China and Russian Federation in 2006.

\section{A. Generation IV goals}

The following goals were defined in the original GIF Charter:

\section{1) Sustainability}

- Generate energy sustainably and promote long-term availability of nuclear fuel.

- Minimise nuclear waste and reduce the long term stewardship burden.

\section{2) Safety and reliability}


- Excel in safety and reliability.

- Have a very low likelihood and degree of reactor core damage.

- Eliminate the need for offsite emergency response.

\section{3) Economics}

- Have a life cycle cost advantage over other energy sources.

- Have a level of financial risk comparable to other energy projects.

\section{4) Proliferation resistance and physical protection}

- Be a very unattractive route for diversion or theft of weapon-usable materials, and provide increased physical protection against acts of terrorism.

\section{B. The Technology Roadmap}

The Technology Roadmap (2002), defined and planned the necessary R\&D and associated timelines to achieve these goals and allow deployment of Generation IV energy systems after 2030. This road mapping exercise was a two-year effort by more than 100 international experts to select the most promising nuclear systems. In 2002, GIF selected the six systems listed below, from nearly 100 concepts, as Generation IV systems:

\section{1) Gas-Cooled Fast Reactor (GFR)}

The GFR system is a high-temperature helium-cooled fast-spectrum reactor with a closed fuel cycle. It combines the advantages of fast-spectrum systems for long-term sustainability of uranium resources and waste minimization. The advantages of the gas coolant are that it is chemically inert (allowing high temperature operation without corrosion and coolant radiotoxicity) and single phase (eliminating boiling), and it has low neutron moderation.

\section{2) Lead-cooled fast reactor (LFR)}

LFRs are $\mathbf{P b}$ or $\mathbf{P b}$-Bi-alloy-cooled reactors operating at atmospheric pressure and at high temperature because of the very high boiling point of the coolant (upto $1743{ }^{\circ} \mathrm{C}$ ). The core is characterized by a fast-neutron spectrum due to the scattering properties of lead.

\section{3) Molten Salt Reactor (MSR)}


A molten salt reactor (MSR) is a class of nuclear fission reactors in which the primary coolant, or even the fuel itself, is a molten salt mixture. MSRs run at higher temperatures than water-cooled reactors for higher thermodynamic efficiency, while staying at low vapor pressure, liquid-fuelled MSR has been focused on fast spectrum.

\section{4) Sodium-Cooled Fast Reactor (SFR)}

The SFR is a Generation IV reactor project to design an advanced fast neutron reactor with the objective of producing a fast-spectrum, liquid sodium-cooled reactor. It allows a lowpressure coolant system and high-power-density operation with low coolant volume fraction in the core.

\section{5) Supercritical-Water-Cooled Reactor (SCWR)}

SCWRs are high temperature, high-pressure, light water reactors that operate above the thermodynamic critical point of water $\left(374^{\circ} \mathrm{C}, 22.1 \mathrm{MPa}\right)$. The reactor core may have a thermal or a fast-neutron spectrum, depending on the core design.

\section{6) Very-High-Temperature Reactor (VHTR)}

The VHTR is a next step in the evolutionary development of high-temperature gas-cooled reactors. It is a graphite-moderated, helium-cooled reactor with thermal neutron spectrum.

\subsubsection{Use of advanced nuclear ceramics in GEN IV reactors}

Out of the above selected Generation IV systems, the use of advanced nuclear ceramics has been validated for GFR, SFR and VHTR.

The French strategy is mainly oriented towards the development of sodium-cooled fast reactors and in a less extent towards GFR option [3]. Then, refractory ceramics have been considered as potential cladding materials for SFR [4].

Identification of a specific fuel type and fuel element/fuel assembly that is compatible with gas-cooled fast reactor GFR in-core service conditions is a key part of the overall goal of developing a practical version of a gas-cooled fast reactor. Current gas reactor fuel technology is not adaptable to a gas-cooled fast reactor. The categories of fuel with the highest potential 
for success are carbide and nitride-base composite-type fuels. These fuels consist of a fissile phase dispersed within a refractory matrix.

The most promising candidates for GFR fuel matrix materials are $\mathrm{ZrN}, \mathrm{ZrC}$, TiN, and $\mathrm{TiC}$, $\mathrm{SiC}$ due to a combination of neutronic performance, thermal properties, chemical behavior, crystal structure, and physical properties. These advanced ceramics are also considered as potential cladding material for SFR.

Normally, an advanced BISO (Bistructural-isotropic) fuel particle is considered for GFRs. This type of fuel form has a fuel kernel and two ceramic outer layers. The central kernel consists of a spherical fuel particle (consists of $\mathrm{UC}$ or $\mathrm{UN}$ ) surrounded by a ceramic coating (TiC, $\mathrm{ZrC}$, $\mathrm{TiN}, \mathrm{ZrN}$ or $\mathrm{SiC}$ ) which provides structural integrity and containment of fission products. In between the coating and the fuel, there is a buffer layer, which is also supposed to be made of ( TiC, $\mathrm{ZrC}, \mathrm{TiN}, \mathrm{ZrN}$ or $\mathrm{SiC}$ ). Buffer allows for changes in thermal expansion, swelling, and fission gas release pressure without creating an unacceptable amount of stress on the outer containment coating [5]. The fuel particle layers are shown schematically in figure 1.2.

The buffer layer is porous in order to reduce its stiffness and the resulting pressure on the coating and to accommodate released fission gases. It is composed of the same material as the coating. By using the same material for the buffer as the coating, there is reduced expansion mismatch and less chance of chemical incompatibilities. These advanced BISO fuel particles can be utilized by placing them in a ceramic matrix composed of the same material as the BISO fuel particles' outer ceramic coating. With this design, there is only one major interface of different materials: the fuel and the buffer.

The new BISO micro fuel particle materials must meet a variety of criteria. Coatings with significant neutron absorption cross-sections cannot be used, thus excluding many candidates. The potential coatings must have high melting points (excess of $2000^{\circ} \mathrm{C}$ ), adequate thermal conductivity $(>10 \mathrm{~W} / \mathrm{m}-\mathrm{K})$ and toughness $\left(>12 \mathrm{MPa}-\mathrm{m}^{1 / 2}\right)$, and acceptable response to high dose neutron damage (swelling $<2 \%$ over service life ( $\sim 80 \mathrm{dpa})$ ). Thus, the categories of materials with the highest potential for success for the GFR are carbide and nitride based ceramics $[5,6]$. The similar criteria is also expected for the candidates of cladding material in SFR. 


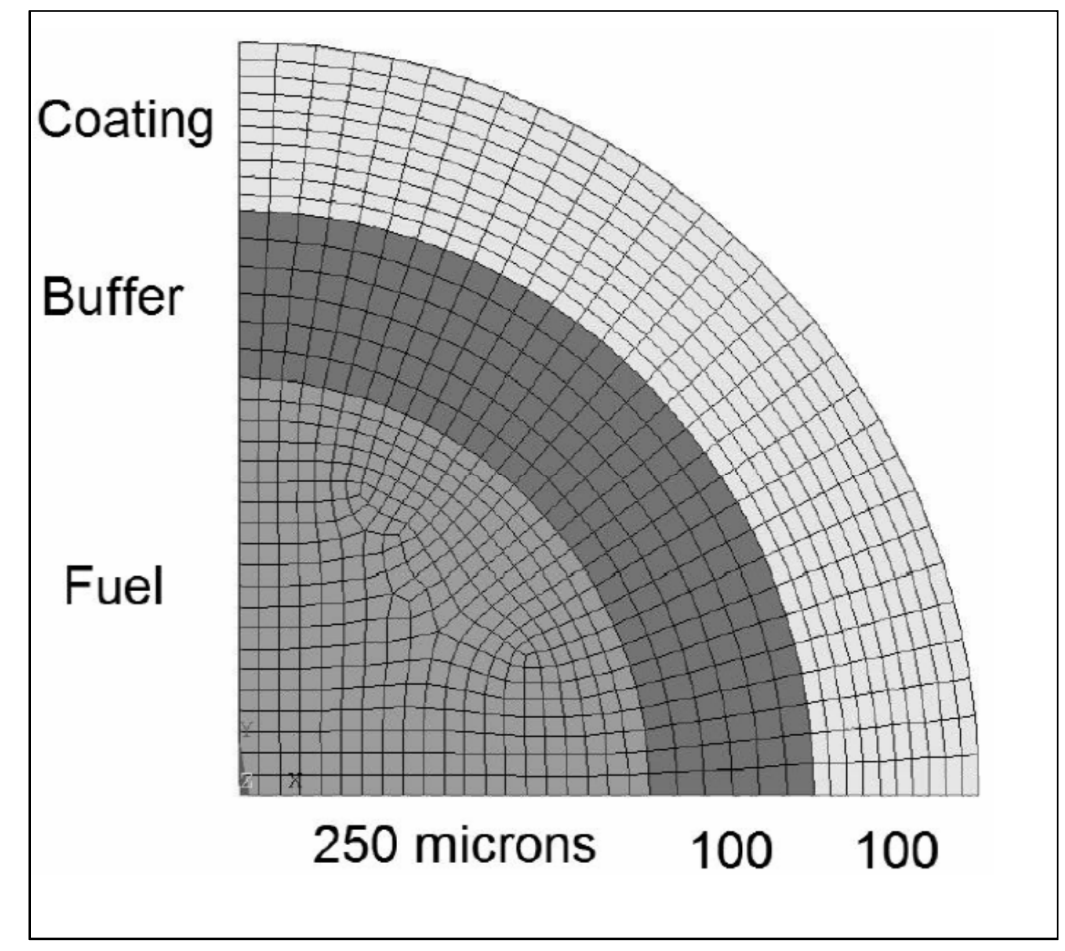

Figure 1.2. One quarter of the cross section showing the layers of a BISO micro fuel particle [5].

For VHTR reactor, use of TRISO fuel has been considered. Tristructural-isotropic (TRISO) fuel is a type of micro fuel particle which consists of a fuel kernel composed of $\mathrm{UO}_{\mathrm{x}}$ (sometimes UC or UCO) in the center, coated with four layers of three isotropic materials. The four layers are a porous buffer layer made of carbon, followed by a dense inner layer of pyrolytic carbon (PyC), followed by a ceramic layer of $\mathrm{SiC}$ to retain fission products at elevated temperatures and to give the TRISO particle more structural integrity, followed by a dense outer layer of PyC (see figure 1.3). In VHTRs (TRISO) fuel, $\mathrm{ZrC}$ will perhaps replace SiC. ZrC enables an increase in power density and total power level with the same coolant outlet temperature. Under accident conditions, historical data suggest that the $\mathrm{ZrC}$-TRISO fuel may be more robust than traditional SiC-TRISO fuel, however lot of research projects are planned in near future to conclude this. 

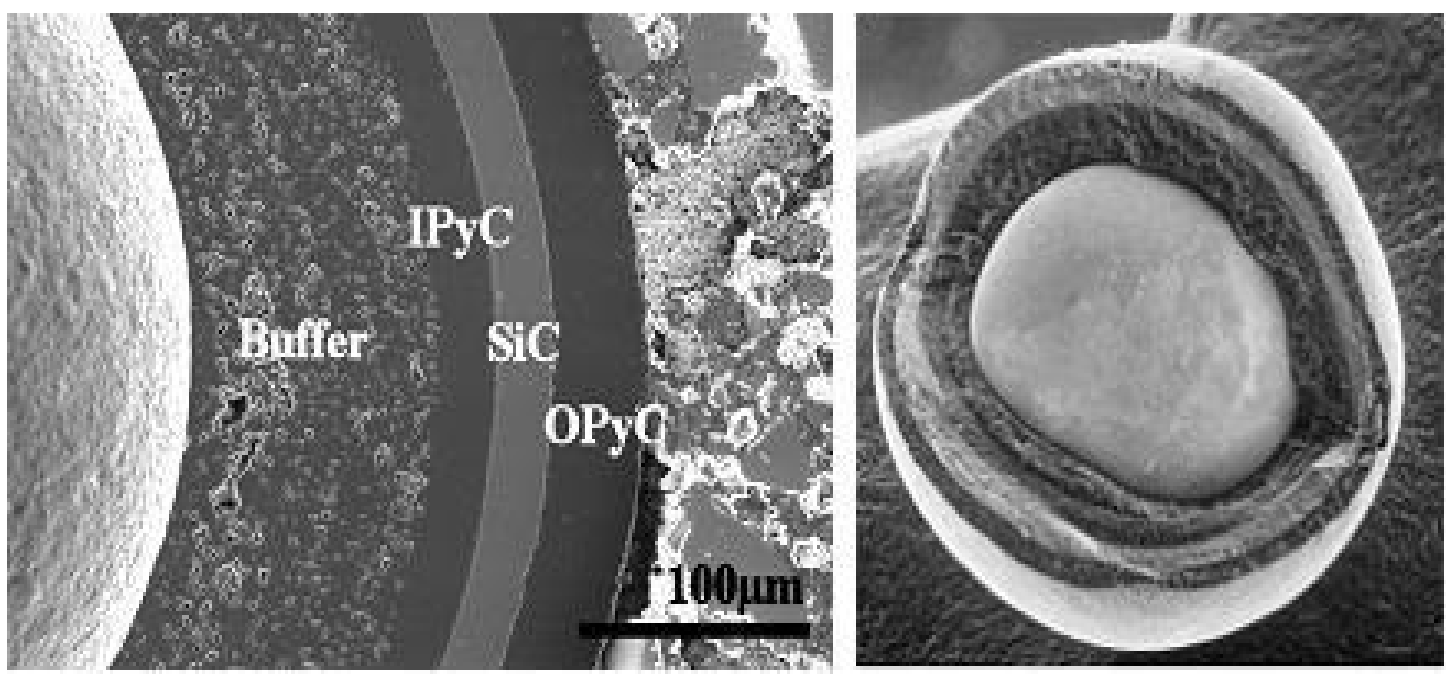

Figure 1.3. TRISO fuel particle showing fuel as well as ceramic coating [7].

\subsection{Nuclear fusion energy}

Fusion power is the power generated by nuclear fusion processes. Fusion happens when two (or more) nuclei come close together and forms a heavier one. In light fusion reactions, some of the mass is lost in this process. It is converted into energy through Einstein's mass-energy equivalence formula $\mathrm{E}=\mathrm{mc}^{2}$.

To fuse atoms, it is necessary to overcome the repulsive Coulomb force. To overcome this "Coulomb barrier", the atoms must slam together at high speeds with high kinetic energy. The easiest way to do this, is to heat the atoms. Once an atom is heated above its ionization energy, its electrons are stripped away, leaving just the bare nucleus: the ion.

Most fusion experiments use a hot cloud of ions and electrons. This cloud is known as a plasma. Most fusion reactions produce neutrons, which can be detected and degrade materials.

The fuel for fusion reactors will be a combination of deuterium and tritium. The reaction of deuterium with tritium produces alpha-particles and $14.1 \mathrm{MeV}$ neutrons by the following equation:

$$
{ }_{1}^{2} D+{ }_{1}^{3} T \rightarrow{ }_{2}^{4} \mathrm{He}+{ }_{0}^{1} n+\text { Energy }(14 \mathrm{MeV})
$$


where $\mathrm{D}$ and $\mathrm{T}$ are deuterium and tritium respectively. The leading designs for controlled fusion research use magnetic (tokomak design) or inertial (laser) confinement of a plasma. Both approaches are still under development and are years away from commercial operation in which heat from the fusion reaction is used to operate a steam turbine which drives electrical generators, as in existing fossil fuel and nuclear fission power stations.

\subsubsection{Use of advanced nuclear ceramics in fusion reactors}

Tritium as a fuel is difficult to handle and transport. During the tritium breeding and fusion reaction, there is the potential for permeation of the tritium through the materials containing it and for its release to the environment. Therefore, materials with a low permeability for tritium are being considered as barriers to prevent the loss of tritium from fusion plants. There are a few metals with relatively small values of permeability, but as a whole, metals themselves are not good barriers to the transport of tritium. Ceramics, on the other hand, are typically very good barriers if they are not porous. In most cases, the low permeation is due to extremely low solubility of hydrogen isotopes in ceramic materials. Carbides, nitrides, aluminides, oxides are studied very extensively to be used as barrier to tritium transport.

Bulk ceramics, such as silicon carbide, may one day be used as tritium permeation barriers, but most of the current barrier development is for coatings of oxides, nitrides, or carbides of the metals themselves [8]. TiN coatings are one of the most researched barriers because of their good adhesion and the ease of deposition. Titanium carbide has also been tested as a permeation barrier. Due to adhesion problems with direct deposition on steel, titanium nitride was used as an intermediate layer between the steel and titanium carbide. These carbides and nitrides are low-activation, temperature-resistant, and radiation damage tolerant compared to most materials. This consideration as barrier was also due to the presence of light element carbon and nitrogen in $\mathrm{TiC}, \mathrm{SiC}$ and $\mathrm{TiN}$. The collisions of the plasma with low mass carbon and nitrogen atoms help in less dissipation of heat, and thus maintains high temperature inside the plasma $[9,10,11]$.

Last but not least, oxide-dispersed strengthened (ODS) alloys contains dispersed oxide carbide and nitride nanoparticles. ODS alloys exhibit very interesting thermo-mechanical properties and a promising radiation tolerance due to the multiplication of interfaces within the matrix $[12,13,14,15]$. 


\subsection{Helium in fission and fusion reactors}

There is large production of helium atom in fusion reactors due to tritium decay. Apart from this, neutrons are produced in both fission and fusion reactors by their respective nuclear reactions (see equation 1.1 and 1.2). These high-energy neutron will knock the atoms in the surrounding materials and induce $(n, \alpha)$ reactions such as:

$$
{ }_{Z}^{A} M+{ }_{0}^{1} n \rightarrow{ }_{Z-2}^{A-3} M+{ }_{2}^{4} \mathrm{He}(\text { several } \mathrm{MeV})
$$

Consequently, the surrounding materials in both fusion and fission reactor are expected to contain a high concentration of helium atoms during and after operation.

Most reactions between neutrons (n) and nucleus (M) are energy dependent. The reaction rate (here for $(n, \alpha)$ reaction) in a thermal reactor is a product of the average fission flux cross section (i.e. on the probability that a nuclear reaction $(n, \alpha)$ would occur) and the equivalent fission flux (here neutron flux). Many $(n, \alpha)$ reactions are exothermic, that is, they can be caused by neutrons of all energies down to thermal. It has been recognized in recent years that, because of the importance of helium production rates in reactor internals, lot of investigation have been done in order to find better cross section data. Table 1.1 presents the crossection data for $(n, \alpha)$ reactions to measure directly the helium content for the principle elements found in stainless steel.

\begin{tabular}{|c|c|c|}
\hline & $\begin{array}{c}\text { Principle elements of stainless } \\
\text { steel }\end{array}$ & $\begin{array}{c}\text { Cross section of (n, } \alpha) \text { reaction in the } \\
\text { elements (milli-barn) }\end{array}$ \\
\hline 1. & Chromium & $0.2 \mathrm{mb}$ \\
\hline 2. & Iron & $0.23 \mathrm{mb}$ \\
\hline 3. & Nickel & $4.5 \mathrm{mb}$ \\
\hline
\end{tabular}

Table 1.1. The values of cross section of $(n, \alpha)$ reaction for few elements [16]. 
In fusion, the issue of gas production is likely to be a more significant problem than in fission because of the higher neutron fluxes and higher average neutron energies. For example, in figure 1.4 where a fission spectrum for a fuel assembly of a $3.8 \mathrm{GWt}$ (gigawatts of thermal power) LWR-P4 reactor in Paluel, France, is compared to a fusion spectrum computed for the first wall (FW) of the 3.0 GWt DEMO concept reactor, the fluxes of neutrons per lethargy interval are greater in the fusion spectrum at all energies instead of thermal energies [17].

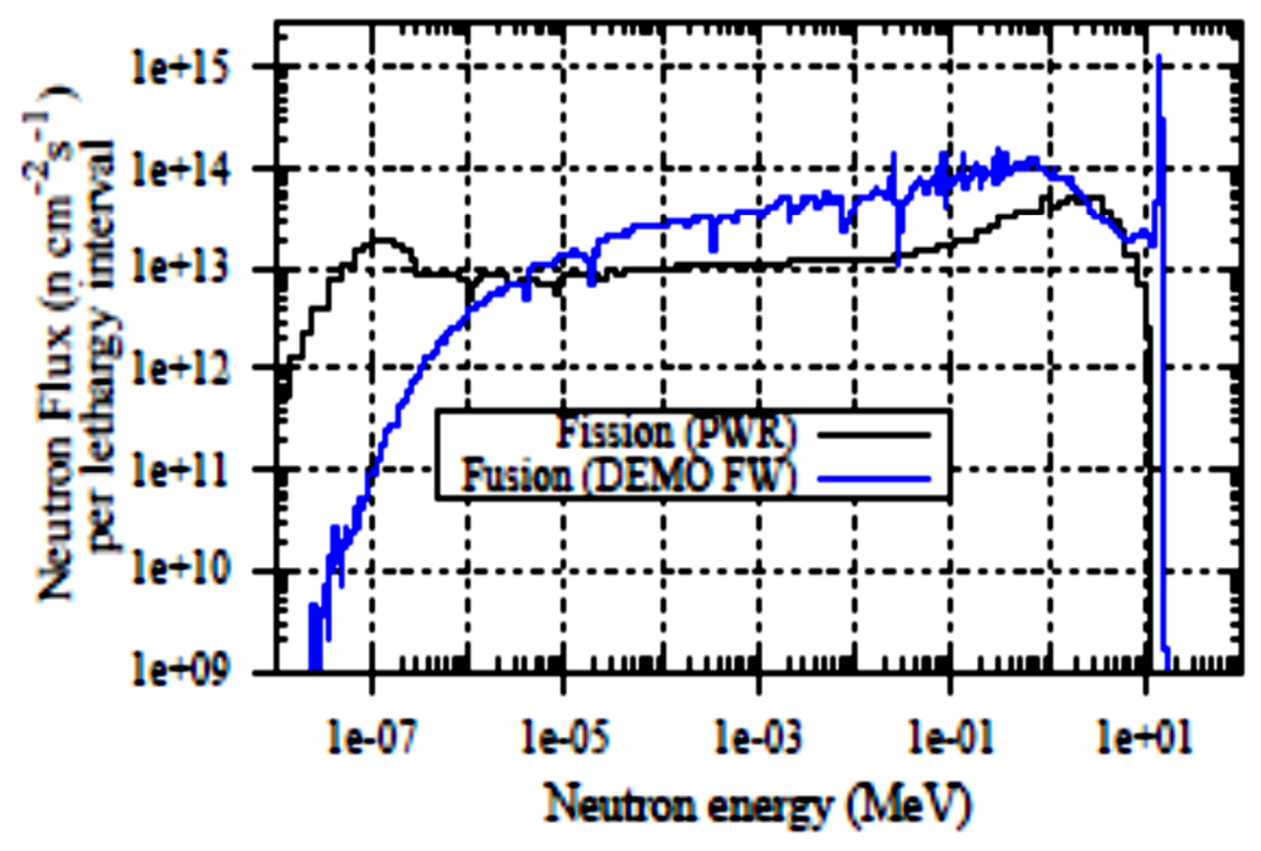

Figure 1.4. Comparison of the neutron-energy spectra in fission and fusion reactors. For fission the average neutron spectrum in the fuel-assembly of a PWR reactor is shown, while the equatorial spectrum for the DEMO model of fusion reactor is shown [17].

Furthermore, whereas the bulk neutron energy in fission is in the $2 \mathrm{MeV}$ range, for every deuterium-tritium fusion reaction in the plasma, a 14.1 MeV neutron is produced. And most of the gas-producing nuclear reactions exhibit a cross section threshold, which means that for incident neutrons below a particular energy the reaction either does not occur or has a very low probability. 
Thus, in fusion, while the higher neutron fluxes compared to fission would increase the total number of reactions in irradiated components, the larger fraction of neutrons at higher energies would also tend to raise the proportion of those reactions which lead to helium gas production. For fusion reactor, the value of helium per dpa i.e. $(\mathrm{He} / \mathrm{dpa} \approx 10)$ where as in fast fission reactors $\mathrm{He} / \mathrm{dpa} \ll<1$. Here, dpa is displacement per atom.

But, in the present work, the energy of helium is kept around $3 \mathrm{MeV}$ to simulate the energy of neutrons in fission reactors due to the predominant candidature of transition metal carbides and nitrides as coating or cladding material in GEN IV reactors. However, the information on helium migration parameter for fusion reactor conditions can be derived very easily from this work.

\subsection{Helium interaction with nuclear materials and its consequences}

The primary characteristic of He, which makes it significant to a wide range of irradiation damage phenomena, is that it is essentially insoluble in solids. Hence, in the temperature range where it is mobile, He diffuses in the matrix and precipitates to initially form bubbles, typically at various microstructural trapping sites. The bubbles can serve as nucleation sites of growing voids in the matrix and creep cavities on grain boundaries (GBs), driven by displacement damage and stress, respectively. Helium can severely degrade the material's properties and an example is explained below.

Figure 1.5 shows the effects of high $\mathrm{He}$ as a function of lifetime-temperature limits in a fusion first wall structure for various irradiation-induced degradation phenomena [18]. 


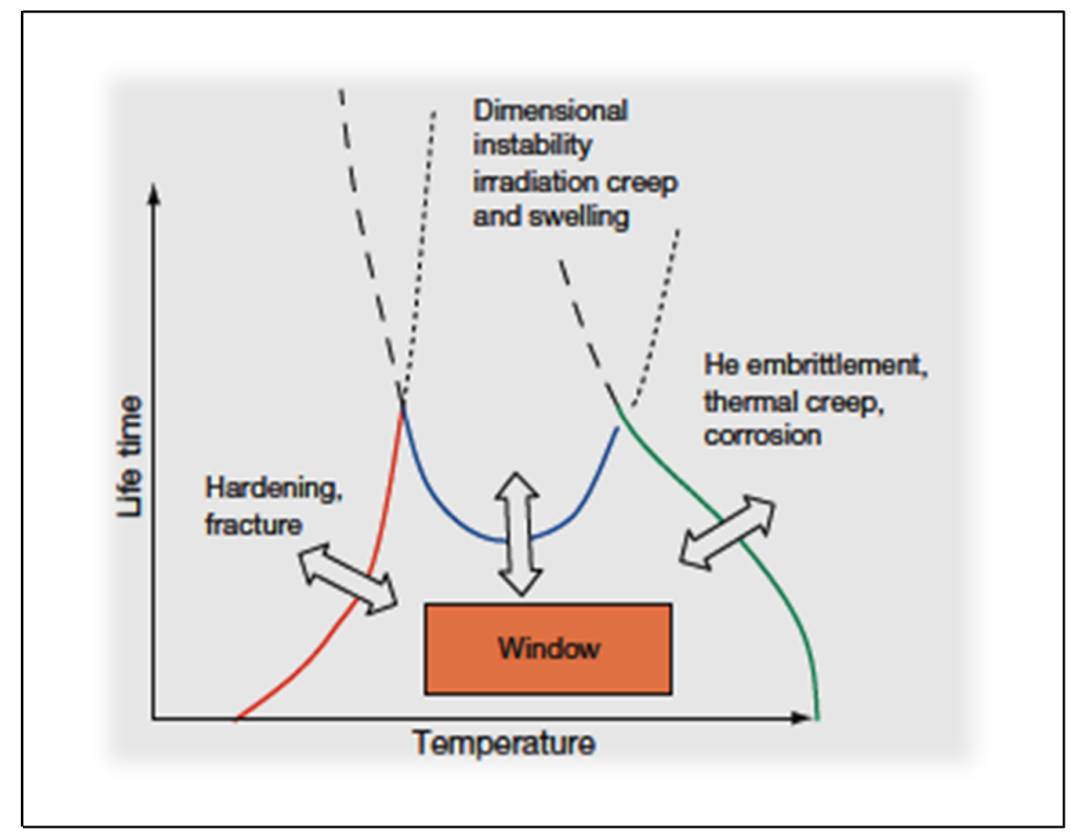

Figure 1.5. Illustration of the materials design window for the fusion energy environment, as a function of temperature [18, 19].

The above sketch shows a very broad-brush, qualitative description of some of the important He effect. On increasing temperature, helium degrades the material properties by precipitating into small bubbles followed by void swelling and further by grain boundary cavitation. With time, material properties under reactor condition (or strong irradiation condition) as a function of temperature deteriorate as follows:

At lower temperatures (red curve), irradiation hardening and loss of tensile uniform ductility are severe, leading to low-temperature fast fracture embrittlement phenomenon. This is believed to be primarily the result of- He-induced grain boundary weakening, manifested by a very brittle intergranular (IG) fracture path, interacting synergistically with irradiation hardening.

At intermediate temperatures (blue curve), the incubation time prior to the onset of rapid swelling is controlled by growing voids form on He bubbles, and He accumulation.

At high temperatures, (green curve) are primarily dictated by chemical compatibility, fatigue, thermal creep, creep rupture, and creep-fatigue limits. In this regime, He can further 
degrade the tensile ductility and the other high temperature properties, primarily by enhancing grain boundary cavitation.

The above behavior is mostly noted in structural alloys. There are very few papers in the literature on helium behavior in transition metal ceramics. But mostly, surface changes like blister formation and similar bubble (or cavity) development leading to swelling and also crack formation in extreme conditions have been reported in these ceramics material. Precise details from bibliography on helium behavior in transition metal ceramics are presented in next chapter.

\section{References}

[1] S. J. Zinkle, G.S. Was Acta Materialia 61 (2013) 735-758.

[2] Technology Roadmap Update For Generation IV Nuclear Energy Systems - January 2014 issued by the OECD Nuclear Energy Agency for the Generation IV International Forum.

[3] Clefs CEA 172, Juillet - Août 2012, pp. 12 - 21.

[4] M. Le Flem, Advanced Materials for Fuel Cladding in Sodium Fast Reactors: From Metals to Ceramics, 2011, www.neutron.kth.se/oldsite/MATGEN.../Le_Flem.pdf.

[5] A. Nosek, J. Conzen, H. Doescher, C. Martin, J. Blanchard, J. Nucl. Mater. 371 (2007) 288303.

[6] Jian Gan, Mitchell K. Meyer, Robert C. Birtcher, Todd R. Allen, Journal Of Astm International, April 2006, Vol. 3, No. 4.

[7] http://eddiehonorato.wordpress.com/tag/triso-coated-fuel-particle/

[8] D.L. Smith, J. Konys, T. Muroga, V. Evitkhin, J. Nucl. Mater. 307-311 (2002) 1314-1322.

[9] G.R. Hopkins, R.J. Price, Nuclear Engineering And Design/Fusion 2 (1985) I 11-143.

[10] J. Luthin, H. Plank, J. Roth, Ch. Linsmeier, Nucl. Instrum. Meth. Phys. Res. B 182 (2001) 218-226.

[11] Tritium Barriers And Tritium Diffusion In Fusion Reactors R. A. Causey, R. A. Karnesky, C. San Marchi, Sandia National Laboratories, Livermore, CA, USA 2012 Elsevier Ltd.

[12] A. A. Popovich, J. Alloys Compounds 215 (1994) 169-173.

[13] Cheng-Guo Wang, Bao-Sen Qi, Yu-Jun Bai, Jun Wu, Jun-Fa Yang, Mater. Sci. Engin. A308 (2001) 292-294.

[14] C.Y. Chen, H. W. Yen, F. H. Kao, W. C. Li , C. Y. Huang, J. R. Yang, S. H. Wang, Mater. Sci. Engin. A 499 (2009) 162-166. 
[15] P. Berthod, Mater. Sci. Technol. 25 (2009) 1003-1008.

[16] I. R. Birss, J. Nucl. Mater. 34 (1970) 241.

[17] M.R. Gilbert, S.L. Dudarev, S. Zheng, L.W. Packer, J.-Ch. Sublet Ccfe-Pr (12) 02.

[18] A. Molvik, A. Ivanov, G. L. Kulcinski, et al. Fusion Sci. Technol. 57 (2010) 369-394.

[19] Y. Dai, G. R. Odette and T. Yamamoto, The Effects of Helium in Irradiated Structural Alloys, 2012, Elsevier Ltd. 


\section{Chapter 2}

\section{State of Knowledge}

To start with the investigation on helium mobility in transition metal ceramics. It appeared important to study the available literature on two topics; firstly on helium mobility in materials to understand 'in general the behavior of helium in materials', secondly on understanding 'the response of transition metal ceramics on gas implantation and ion irradiation'. Therefore, a very broad literature survey was conducted on these two topics before planning the experiments.

Our state of knowledge on helium mobility in materials (particularly in inorganic materials) has led to the publication of a review paper. This paper presents the review of more than 250 papers. This review paper can be obtained from the citation given below:

A review on helium mobility in inorganic materials, $P$. Trocellier, S. Agarwal, S. Miro, Journal of Nuclear Materials 445 (2014) 128-142.

This chapter is divided into two parts:

Part 1: In the first section of the chapter, important features on helium mobility in inorganic materials from our recently published review paper have been mentioned. It is important to know that only important points from the publication are mentioned in this section.

Part 2: In the second section of the chapter, our state of knowledge on transition metal ceramics has been presented.

\section{Part 1}

\subsection{Helium mobility in inorganic materials}

This part of the chapter reviews the available literature devoted to the study of helium migration in inorganic solids from both the experimental and the theoretical point of view. The 
available literature devoted to the study of helium migration in solids first contains some pioneering review papers published during the time period 1963-1996 [1-23].

\subsubsection{Statistical details}

Our broad survey of the literature devoted both to experimental and theoretical studies of helium migration in inorganic materials lead us to select a high number of interesting papers. All inorganic materials can be easily divided into metallic and non-metallic material. Among them, four main classes can be identified:

- Class I: experimental investigations on pure metals and alloys [24-80];

- Class II: experimental investigations on non-metallic compounds [81-156];

- Class III: theoretical calculations on metallic materials [45, 157-181, 182-211];

- Class IV: theoretical calculations on non-metallic compounds [212-224].

\section{A. Class I: Experimental investigations on pure metals and alloys}

Helium diffusion was investigated in a large number of metallic materials. It includes Be [27], $\mathrm{C}$ [30], Mg [28], Al [29,31,32], Si [33], Ti [28,34], V [35-39], Fe [40-47], Ni [40,48-54], Cu [55,56], Zr [40], Nb [37,56], Mo [57,58], Pd [59], Ag [25], Ta [60], W [61-66], Pt [67], Au [25], Ag/Au alloy [79], Fe-based alloys [40,48,68-77], and nickel-based alloys [48,78]. Papers from Thomas [24], Sciani [25], and Jung [26,27] published in the eighties and at the beginning of the nineties give an overview of experimental helium diffusion data obtained in fcc and other metals from Be to $\mathrm{U}$.

The frequency distribution is plotted and shown in figure 2.1. This distribution obtained after wide literature survey shows that among all the studied metallic material for He effects, almost $55 \%$ of studied metallic material are Fe, Fe alloys, $\mathrm{Ni}$ (shown by red color in figure 2.1). 


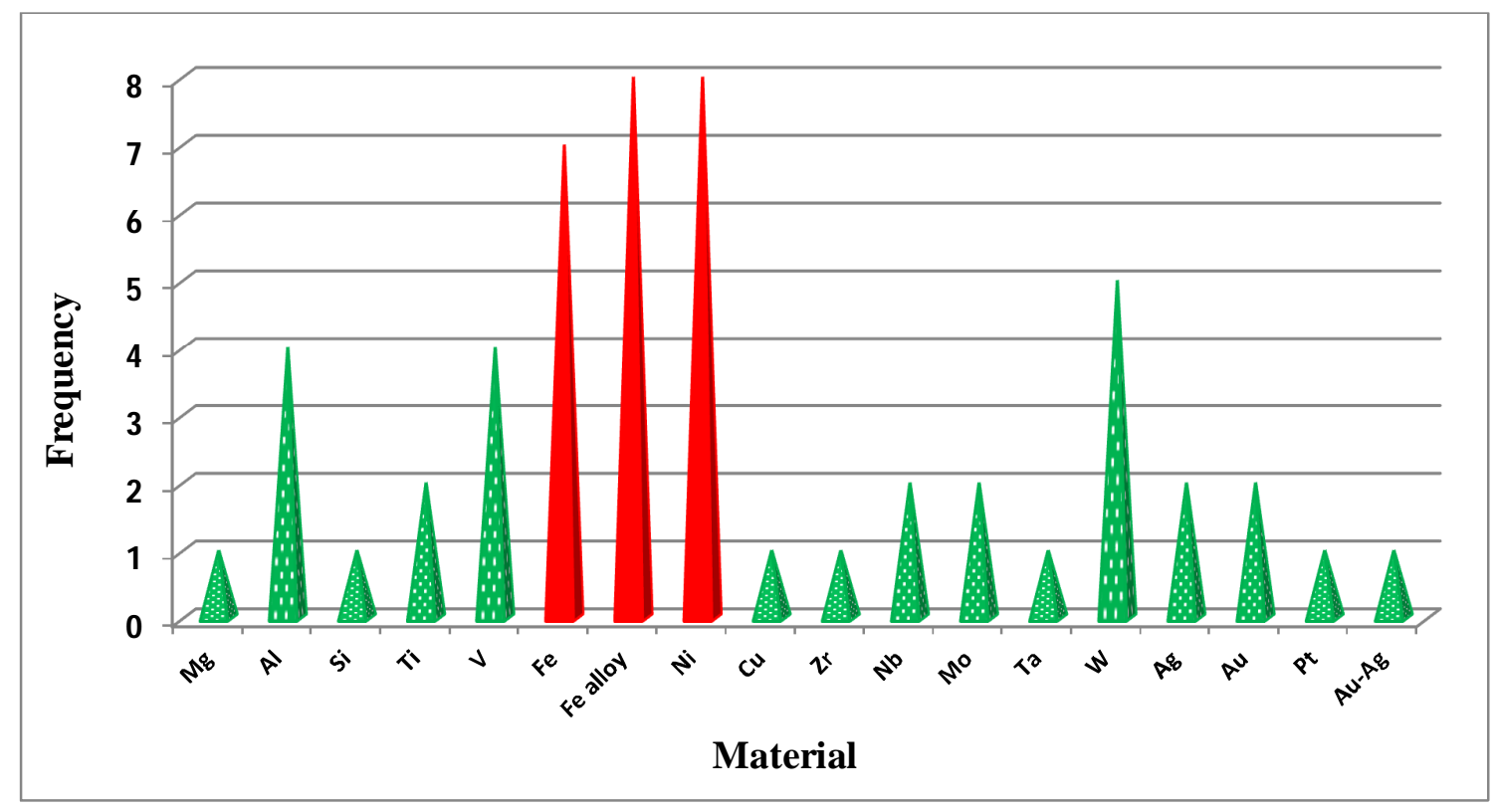

Figure 2.1. Results of the literature survey conducted on the experimental study of helium migration in metals and alloys.

\section{B. Class II: Experimental investigations on non-metallic compounds}

Studies of helium diffusion in non-metallic materials include natural and industrial glasses [81-106], crystalline and amorphous silica and quartz [33,107,108,140,141], silicon carbide [142-147], beryllium oxide [134,135], graphite and diamond [136,137], alumina [135], rutile [151], titanite or sphene $\left(\mathrm{CaTiSiO}_{5}\right)[150,151]$, hydroxyapatite or fluorapatite $\left(\mathrm{Ca}_{10}\left(\mathrm{PO}_{4}\right)_{6} \mathrm{X}_{2}\right.$ with $\mathrm{X}=\mathrm{OH}$ or $\mathrm{F})$, and britholite $\left(\mathrm{Ca}_{4} \mathrm{Nd}_{6}\left(\mathrm{SiO}_{4}\right)_{6} \mathrm{X}_{2}\right)$ [109-125], monazite (rare earth phosphate) [125], thorium phosphate [126], zirconia [117,118,152], spinel $\left(\mathrm{MgAl}_{2} \mathrm{O}_{4}\right)$ [138], zircon $\left(\mathrm{ZrSiO}_{4}\right)$ [121], olivine $\left((\mathrm{Mg}, \mathrm{Fe})_{2} \mathrm{SiO}_{4}\right)$ [148,149], garnet $\left(\mathrm{Ba}_{3} \mathrm{Al}_{2}\left(\mathrm{SiO}_{4}\right)_{3}\right)$ [155], aeschynite $\left((\mathrm{Y}, \mathrm{Ca}, \mathrm{Fe})(\mathrm{Ti}, \mathrm{Nb})_{2}(\mathrm{O}, \mathrm{OH})_{6}\right) \quad[111]$, zirconolite $\left(\mathrm{CaZr}_{2} \mathrm{O}_{7}\right)$, and pyrochlore $\left(\mathrm{Gd}_{2} \mathrm{Zr}_{2} \mathrm{O}_{7}\right)$ [117,118,153], zirconium nitride [154], uraninite $\left(\mathrm{UO}_{2}\right)$ [127-133], plutonium oxide [129]. Figure 2.2 illustrates this repartition.

Most of the above studied materials are classified as nuclear waste ceramics, glasses, nuclear fuels and inert fuel matrices. These four classes represent $70 \%$ of the above studied material.

They are represented as green, red, blue and yellow for nuclear waste matrix, glasses, nuclear fuel and inert fuel matrix, respectively. 


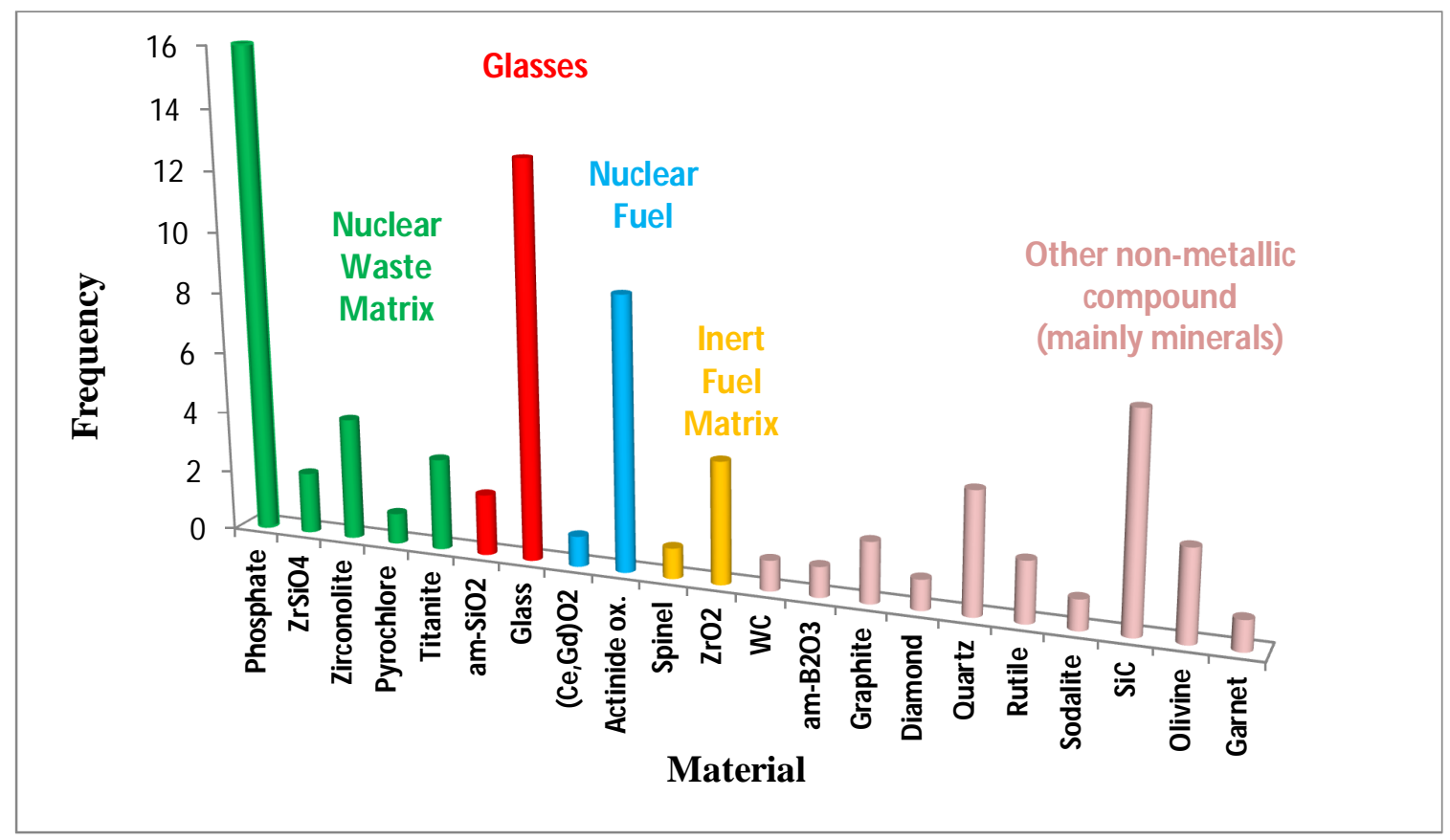

Figure 2.2. Results of the literature survey conducted on the experimental study of helium migration in non-metallic materials.

\section{Class III \& IV: Theoretical calculations on metallic and non-metallic materials}

Modeling studies related to metallic materials mainly concern pure iron and iron-based alloys, i.e. more than thirty papers over fifty six.

Theoretical calculations on non-metallic compounds are rather present very little, i.e. thirteen papers. This rate corresponds to less than $15 \%$ of the total number of papers related to nonmetallic materials and less than $19 \%$ of the total number of papers related to modeling.

They are mainly focused on binary or ternary compounds: $\mathrm{SiC}[215,218], \mathrm{UC}$ [216], $\beta$-ErH $\mathrm{E}_{2}$ [219], $\mathrm{UO}_{2}$ [220], $\mathrm{ZrSiO}_{4}$ [221], $\mathrm{Ti}_{3} \mathrm{AlC}_{2}$ [223], and more scarcely to complex substrate such as sodalite $\left(\mathrm{Na}_{8} \mathrm{Al}_{6} \mathrm{Si}_{6} \mathrm{O}_{24} \mathrm{Cl}_{2}\right)$ [213] or nanostructured materials such as metal/oxide interface [222].

Figure 2.3 gives a statistical distribution on modeling studies devoted to helium migration in both metallic and non-metallic materials. 


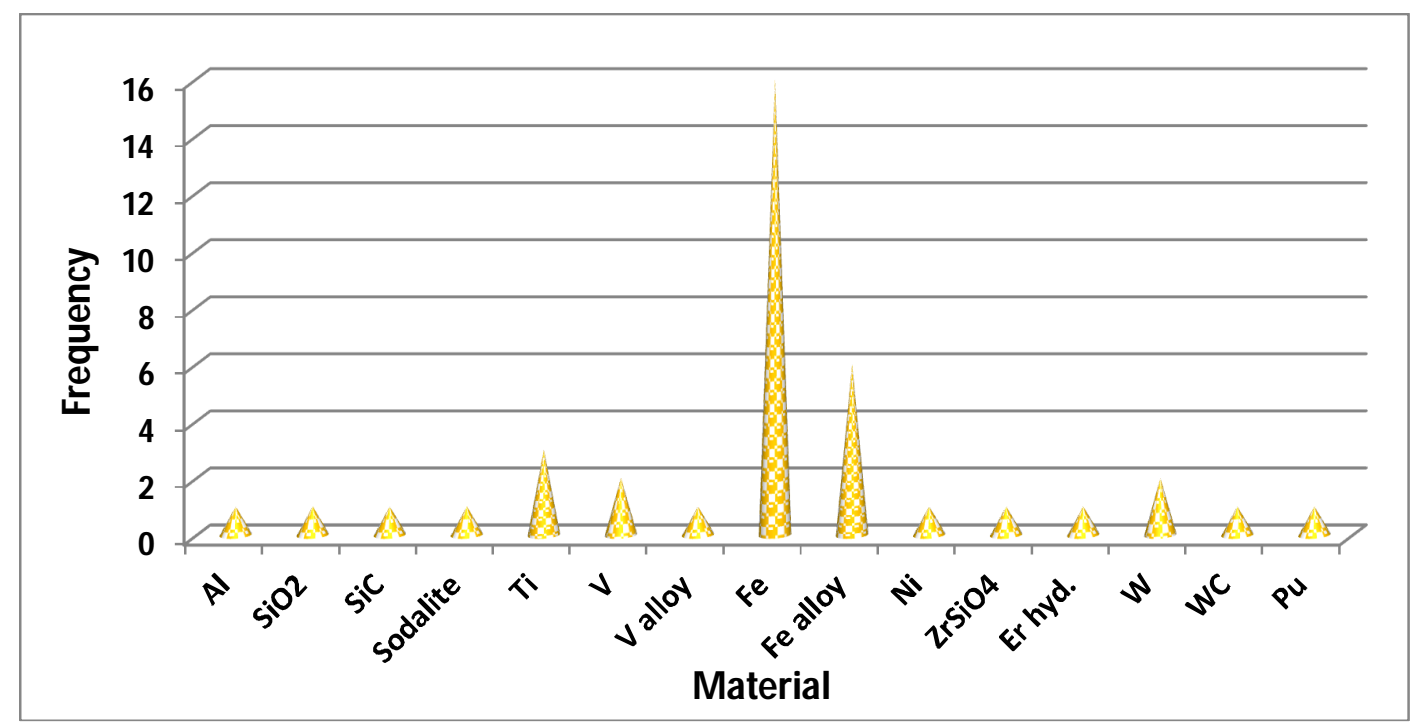

Figure 2.3. Results of the literature survey conducted on the modeling of helium migration in inorganic materials.

\subsubsection{Experimental methods for the study of helium behavior}

The experimental configuration applied for the study of helium behavior in the near surface region of solids generally follows a three step approach:

(1) Helium incorporation in the material;

(2) Thermal annealing under fully controlled conditions;

(3) Helium measurement.

Table 2.1 (presented on the next page) displays the most commonly adopted experimental conditions and gives the corresponding references. A brief summary will be given in the four following sub-sections in order to describe each of the three steps mentioned above.

\section{Helium incorporation}

Four options have been considered to introduce helium in bulk solids:

(1) Presence of radiogenic helium in natural minerals containing $\beta$-emitters as $U$ or Th [150]; 
(2) Interaction between the solid surface and a He gas atmosphere up to saturation using thermal equilibration process or permeation through a porous membrane $[82,102,103]$;

(3) Long term interaction of the solid surface with tritium. The $\beta$-decay of tritium produces ${ }^{3} \mathrm{He}$ [77];

(4) Ion irradiation/implantation: This method is used in about $60 \%$ of the published experimental papers. It includes:

- Direct helium ion implantation (near the surface or in depth) $[110,121,147]$,

- High energy proton irradiation to produce helium by $(\mathrm{p}, \alpha)$ spallation reactions $[3,140,238]$,

- ${ }^{10} \mathrm{~B}$ doping of the substrate followed by neutron irradiation to produce ${ }^{4} \mathrm{He}$ according to the nuclear reaction ${ }^{10} \mathrm{~B}\left(\mathrm{n},{ }^{4} \mathrm{He}\right){ }^{7} \mathrm{Li}[31,144,145]$,

- ${ }^{244} \mathrm{Cm}$ doping in order to detect its $\alpha$-decay [153].

\section{Thermal annealing step}

After helium incorporation, thermal annealing is generally conducted ex-situ using a high temperature furnace $[24,52]$.

In the case of the application of Thermal Helium Desorption Spectrometry (THDS), annealing is conducted within the characterization device [57, 138].

\section{Helium measurement}

The most widely used characterization methods for helium measurement are mass spectrometry in conventional or THDS modes for nearly $50 \%$ of the published experimental papers [47,95], and Ion Beam Analysis (IBA) for more than $30 \%$ of the published experimental papers [53]. Section IV gives more detail about IBA. Some special characterization configurations have also been developed and applied, for example:

- Atom probe field ion microscopy investigations by Amano on W [61];

- Resistivity recovery measurements by Vassen on Pt [67];

- Chemical etching associated to gas chromatography by Chang-An Chen on stainless steel [77]; 
Table 2.1. Summary of experimental approaches developed to study helium migration in the near surface region of inorganic solids.

\begin{tabular}{|c|c|c|c|c|}
\hline Material & Step 1 & Step 2 & Step3 & Reference \\
\hline $\mathrm{Al}$ & Spallation & Thermal annealing & Conventional mass spectrometry & [29] \\
\hline $\mathrm{V}$ & He ion implantation & Thermal annealing & Alpha particle elastic scattering & [35] \\
\hline $\begin{array}{c}\mathrm{Mg}, \mathrm{Ti} \\
\text { Body centered cubic metals }\end{array}$ & He ion implantation & \multicolumn{2}{|c|}{ Thermal helium desorption spectrometry } & $\begin{array}{l}{[26]} \\
{[28]}\end{array}$ \\
\hline $\mathrm{W}$ & He ion implantation & Thermal annealing & Atom probe field ion microscopy & [61] \\
\hline $\mathrm{Pt}$ & He ion implantation & Thermal annealing & Resistivity measurement & [67] \\
\hline Stainless steel & Long term tritium storage & Thermal annealing & Chemical etching + gas chromatography & {$[77]$} \\
\hline $\mathrm{W}$ & He ion implantation & Thermal annealing & Positron annihilation spectroscopy & [63] \\
\hline $\mathrm{Fe}$ and $\mathrm{Fe}-\mathrm{Cr}$ alloy & He ion implantation & Thermal annealing & $\begin{array}{l}\text { Thermodesorption coupled with transmission electron } \\
\text { microscopy }\end{array}$ & {$[44]$} \\
\hline Silica glass & Permeation & Thermal annealing & Conventional mass spectrometry & $\begin{array}{l}{[83-94} \\
102,103]\end{array}$ \\
\hline Graphite & He ion implantation & Thermal annealing & Proton elastic scattering & [136] \\
\hline $\begin{array}{l}\text { Diamond } \\
\text { Apatite }\end{array}$ & Native ${ }^{4} \mathrm{He}$ & Thermal annealing & Conventional mass spectrometry & $\begin{array}{l}{[137]} \\
{[109]}\end{array}$ \\
\hline Obsidian, basaltic glass & Gas saturation & Thermal annealing & Conventional mass spectrometry & [95] \\
\hline Spinel & He ion implantation & \multicolumn{2}{|c|}{ Thermal helium desorption spectrometry } & [138] \\
\hline $\mathrm{ZrO}_{2}$, britholite & He ion implantation & Thermal annealing & Deuteron-induced nuclear reaction analysis & $\begin{array}{c}{[114,115,} \\
117-119, \\
124,147 \\
152]\end{array}$ \\
\hline $\begin{array}{l}\text { Zircon, apatite, rutile, } \\
\text { titanite, monazite }\end{array}$ & He ion implantation & Thermal annealing & Deuteron-induced nuclear reaction analysis & $\begin{array}{r}{[121,125,} \\
149,151]\end{array}$ \\
\hline Fluorapatite & He ion implantation & Thermal annealing & Heavy ion-induced elastic recoil detection analysis & [110] \\
\hline $\mathrm{SiC}$ & ${ }^{10} \mathrm{~B}+$ neutron irradiation & \multicolumn{2}{|c|}{ Thermal helium desorption spectrometry } & [144] \\
\hline Zirconolite, pyrochlore & ${ }^{244} \mathrm{Cm}$ doping & Thermal annealing & Conventional mass spectrometry & [153] \\
\hline Fluorapatite, britholite, $\mathrm{SiC}$ & He ion implantation & Thermal annealing & Deuteron-induced nuclear reaction analysis & {$[120,147]$} \\
\hline $\begin{array}{c}\mathrm{UO}_{2} \\
\text { Nuclear glasses }\end{array}$ & He ion implantation & Thermal annealing & $\begin{array}{l}\text { Deuteron-induced nuclear reaction analysis in } \\
\text { coincidence }\end{array}$ & $\begin{array}{c}131,132, \\
146] \\
{[104,105]}\end{array}$ \\
\hline Thorium phosphate & Radiogenic ${ }^{4} \mathrm{He}$ & Thermal annealing & High sensitivity $\beta$-spectrometry & [126] \\
\hline Apatite & Radiogenic ${ }^{4} \mathrm{He}$ & Thermal annealing & $\begin{array}{l}\text { Laser ablation depth profiling coupled with mass } \\
\text { spectrometry }\end{array}$ & [123] \\
\hline
\end{tabular}


- THDS and Transmission Electron Microscopy (TEM) coupling by Ono on pure iron and FeCr alloys [44];

- Positron Annihilation Spectroscopy (PAS) by Debelle on W [63];

- High sensitivity $\alpha$-spectrometry by Özgümüs on thorium phosphate [126];

- UV laser ablation depth profiling coupled with mass spectrometry by van Soest on Durango apatite [123].

\section{Ion beam methods applied to helium migration study}

The technique is based on high energy proton irradiation to produce helium via a spallation process and also consists in doping the material with ${ }^{10} \mathrm{~B}$ and then submitting to neutron irradiation. The required large scale facilities are, however, of limited access.

The main advantage of helium ion implantation $\left({ }^{3} \mathrm{He}\right.$ or $\left.{ }^{4} \mathrm{He}\right)$ lies in its versatility.

- One can modulate the implantation depth from the near surface (a few hundred of nanometers) to larger depth (several micrometers) by simply varying the energy.

- It is also possible to modulate the ion dose, for example in the range $5.0 \times 10^{19}-1.0 \times 10^{21}$ ions $/ \mathrm{m}^{2}$.

Nevertheless, the main drawback of ion implantation arises from the defect distribution introduced in the sample that may cause helium trapping and undesired deviations in the final helium measurements.

Ion Beam Analysis techniques have been applied to determine helium depth profiles in the near surface region of solids since the middle of the seventies. Four methods have been successfully considered:

(1) The deuteron-induced nuclear reaction ${ }^{3} \mathrm{He}(\mathrm{d}, \mathrm{p}) \alpha[34,114,115,121,226,227,230,231]$;

(2) The proton elastic scattering ${ }^{3} \mathrm{He}(\mathrm{p}, \mathrm{p}){ }^{3} \mathrm{He}$ and ${ }^{4} \mathrm{He}(\mathrm{p}, \mathrm{p}){ }^{4} \mathrm{He}[136,228,229]$;

(3) The high energy ${ }^{4} \mathrm{He}$ elastic scattering ${ }^{4} \mathrm{He}(\mathrm{p}, \mathrm{p}){ }^{4} \mathrm{He}$ coupled with coincidence spectrometry [35];

(4) The high energy Heavy Ion induced Elastic Recoil Detection Analysis (HI-ERDA) [110, 239]. 
High-energy alpha particle elastic scattering requires the use of a cyclotron to produce the incident helium ion beam (50 to $70 \mathrm{MeV}$ ). High energy Heavy Ion induced Elastic Recoil Detection Analysis requires high energy heavy ion beam with a kinetic energy about 1 $\mathrm{MeV} / \mathrm{mass}$ unit [235,236,242].

${ }^{3} \mathrm{He}$ and ${ }^{4} \mathrm{He}$ depth profiling can achieve relatively good depth resolution (less than $50 \mathrm{~nm}$ ) typically on implantation depth of $1 \mu \mathrm{m}$ [237]. Specific detection devices must be implemented both to improve the analyzed depth profile and to discriminate the contributions from the different target components to the resulting ERDA spectrum [237].

Deuteron-induced nuclear reaction on ${ }^{3} \mathrm{He}$ is the most useful and widespread method. Helium depth profiling is based either on the detection of the emitted protons or alpha particles through the ${ }^{3} \mathrm{He}(\mathrm{d}, \mathrm{p})^{4} \mathrm{He}$ nuclear reaction as a function of the incident deuteron energy. The Q-value of this reaction is very high, namely $18.354 \mathrm{MeV}$. The depth profile obtained by proton elastic scattering is affected by the scattering response of all the other elements contained in the target that are superimposed in the measured spectra.

\subsubsection{Basic mechanisms of helium migration in inorganic solids}

\section{A. Irradiation damage}

The basic mechanisms of material damage build-up under irradiation such as point defects, defect clusters, and helium accumulation effects are carefully detailed in recent review papers by McHargue, Zinkle, Chroneos, and Dai [244-247]. A good knowledge of the properties of single helium atoms and small clusters in a metal or a ceramic lattice is the basis for any fundamental understanding of helium effects. The next step is the nucleation and growth of bubbles which then finally lead to the macroscopically observable material deteriorations.

Looking at advanced nuclear materials (metallic alloys, ceramics and composites) for applications to Generation IV fission reactors and fusion energy systems, all will be facing the same radiation degradation phenomena: low temperature hardening and embrittlement; radiation-induced segregation or precipitation; radiation-induced phase stability; void swelling; irradiation creep; high temperature helium embrittlement; surface blistering and exfoliation; and irradiation-assisted corrosion or stress corrosion cracking [8,14,244,245]. 


\section{B. Mechanisms of helium migration in metallic materials}

In metallic substrates, helium migration mainly occurs by the following physical mechanism [246]:

(1) The migration of interstitial helium atoms occurs generally with very low migration energy, less than $0.1 \mathrm{eV}$;

(2) Substitutional helium atoms may diffuse by a conventional vacancy-exchange mechanism. This vacancy mechanism can be considerably influenced by the vacancies and interstitials produced by the atomic displacements. The measured activation energy is generally close to 1 $\mathrm{eV}$;

(3) Substitutional helium atoms may also migrate by dissociation mechanism. In this case the associated activation energy is higher than $2.0 \mathrm{eV}$.

\section{Mechanisms of helium migration in non-metallic materials}

In most ceramic systems, three main mechanisms to describe atom diffusion are similar to metallic system. The mechanism of atomic helium diffusion are [245]:

(1) The interstitial mechanism in which an interstitial atom jumps from one interstitial site to a neighboring one;

(2) The vacancy mechanism in which a substitutional atom jumps to a neighboring vacancy;

(3) A mechanism in which an interstitial atom displaces an atom from its normal substitutional site. Then, the substitutional atom moves to a free interstitial site.

The major physical mechanisms able to affect helium migration are overall the same, i.e. trapping/detrapping processes by/from point or extended defects; interactions with grain boundaries, and growth of bubbles.

However, irradiation-assisted corrosion or stress corrosion cracking will only be of concern in metallic systems. And radiation-induced amorphization only concerns ceramic materials such as silicon carbide or $\mathrm{SiC}_{\mathrm{f}} / \mathrm{SiC}$ composite, waste immobilization matrix, coating layer and ceramic nanophases embedded in metallic substrate such as ODS (Oxide Dispersion Strengthened alloys).

Helium embrittlement effects are common to metallic and non-metallic materials. 


\subsubsection{Main experimental data on helium migration in metallic substrates}

According to the reviewed literature concerning the mobility of helium in metals and alloys, activation energy data are gathered in figure 2.4 and diffusion coefficient values are gathered in figure 2.5. It is important to note that the experimental configurations adopted by the different research groups may vary to a large extent in terms of temperature range explored, helium content introduced in the substrate, chemical composition and microstructure of the substrate. We have plotted the values extracted from studies having different experimental configuration on the same material. For eg., in figure 2.4. red, yellow, green, purple represents nickel, iron, vanadium and $\mathrm{Fe}-\mathrm{Cr}$, respectively.

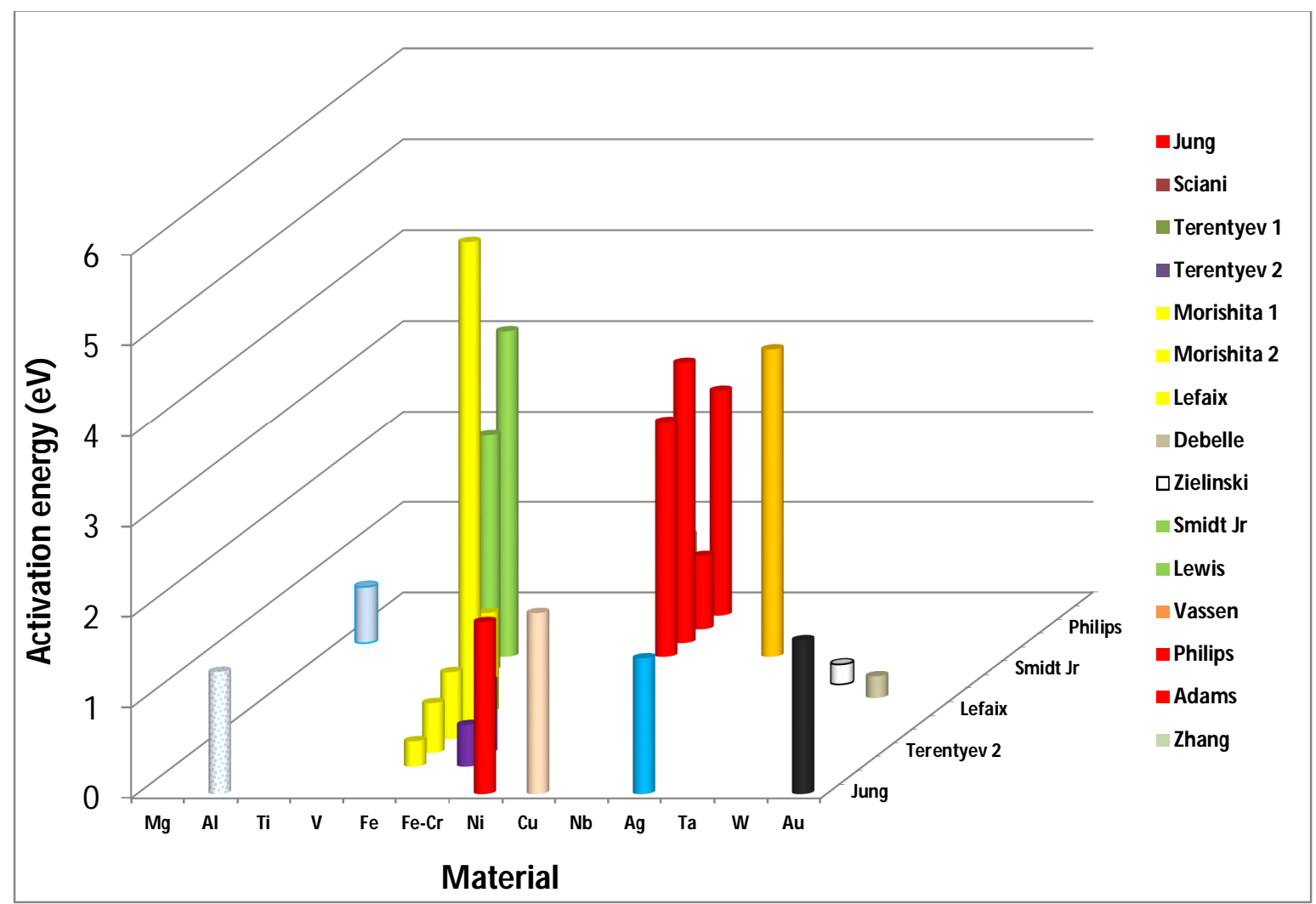

Figure 2.4. Overview of activation energy values determined for migration of helium in metals and alloys. Here, red, yellow, green, purple represents nickel, iron, vanadium and $\mathrm{Fe}-\mathrm{Cr}$, respectively. 


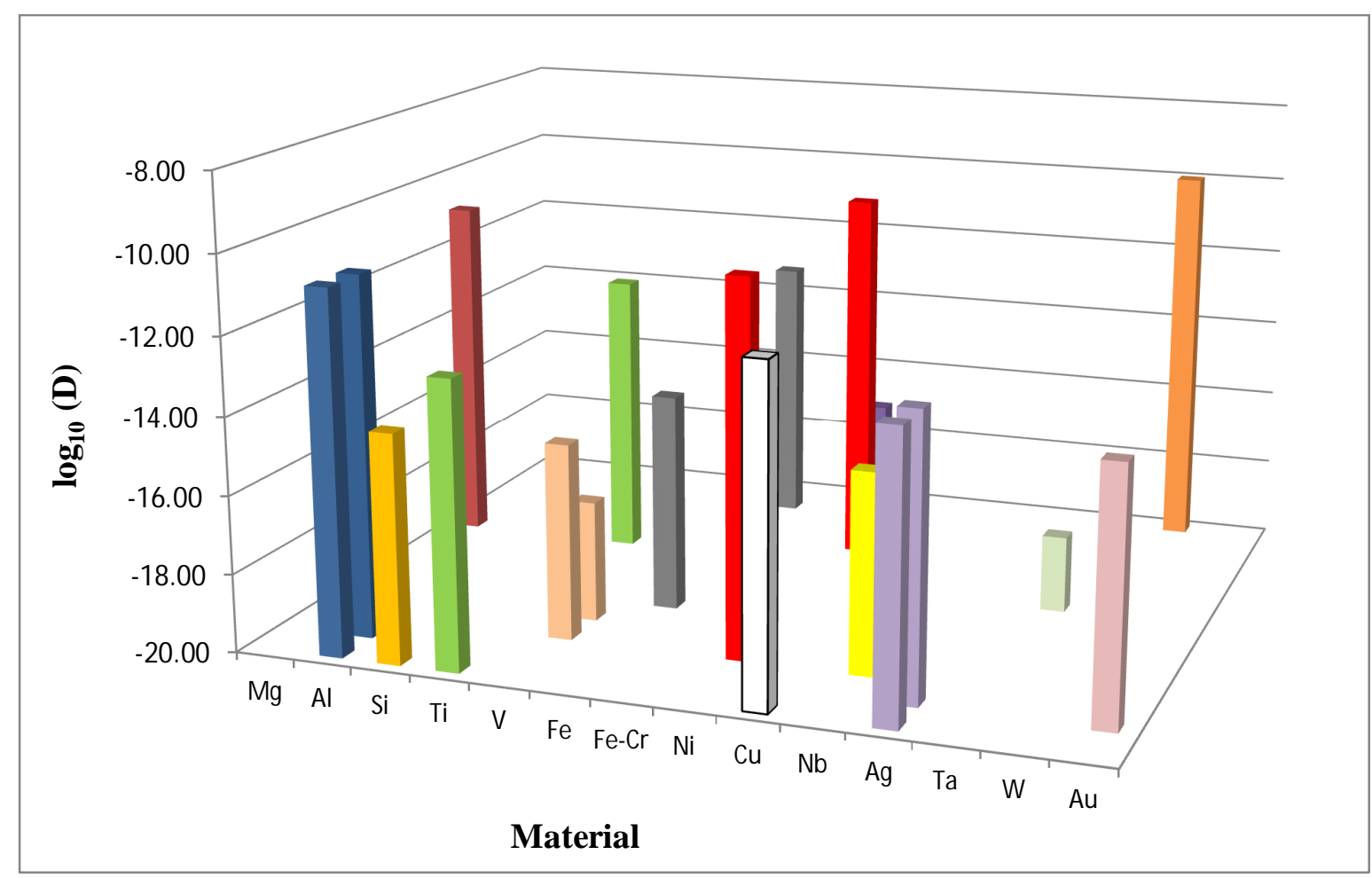

Figure 2.5. Overview of diffusion coefficient values determined for migration of helium in metals and alloys.

\section{A. Pure iron and iron-based alloys}

A very detailed work based on THDS measurement by Morishita allows the discrimination of the different trapping sites in pure iron and to determine their energy parameters [42]. Several features were identified on the THDS spectrum for a pure iron sample implanted at $8 \mathrm{keV}$ and they appeared to be dose dependent:

- A sharp peak at $450 \mathrm{~K}$ corresponds to helium atoms desorbed from single vacancy located near the surface. It is characterized by a dissociation energy about $1.6 \mathrm{eV}$;

- A broad peak located in the interval $750-800 \mathrm{~K}$ associated with helium atom desorption from small $\mathrm{He}_{\mathrm{n}}-\mathrm{V}_{\mathrm{m}}$ clusters with a typical dissociation energy of $2.7 \mathrm{eV}$;

- A broad peak located in the interval $800-1000 \mathrm{~K}$ present at high helium dose $\left(>5 \times 10^{17} \mathrm{~m}^{-}\right.$ $\left.{ }^{2}\right)$. It is attributed to helium atoms desorbed from $\mathrm{He}_{\mathrm{n}}-\mathrm{V}_{\mathrm{m}}$ clusters. The calculated dissociation energy varies in the range 2.2-3.0 eV;

- A sharp peak at $1100 \mathrm{~K}$ corresponding to the desorption of helium from a single vacancy. The corresponding dissociation energy is $3.8 \mathrm{eV}$; 
- The peaks located at temperature higher than $1250 \mathrm{~K}$. They are attributed to helium atoms desorbed from bubbles.

In addition, for helium ion implantation at $150 \mathrm{eV}$ the presence of a new sharp peak located around $550 \mathrm{~K}$ is detected at high doses $\left(>6 \times 10^{18} \mathrm{~m}^{-2}\right)$. All these allocations have been rather well supported by molecular dynamics and Kinetic Monte Carlo calculations.

Very recently, thermal helium desorption spectrometry was coupled with nuclear reaction analysis to study the helium release kinetics in pure $\alpha$-iron [47]. Lefaix and co-workers implanted pure $\alpha$-iron pellets with either $8 \mathrm{keV}{ }^{4} \mathrm{He}$ ions or $3 \mathrm{MeV}^{3} \mathrm{He}$ ions. THDS was used for samples implanted near the surface and nuclear reaction analysis for samples implanted more deeply. Activation energies for every trapping site (mono-vacancies, clusters) have been determined from conventional reaction models and the authors derived the following values: $\mathrm{D}_{0}=4.9 \times 10^{-15} \mathrm{~m}^{2} \cdot \mathrm{s}^{-1}$ and $\mathrm{E}_{\mathrm{a}}=1.13 \mathrm{eV}$. Preliminary observations indicated that a fraction of nearly $50 \%$ of the He remained trapped while helium bubbles migrated in the bulk from the end of ion range (i.e. $5.6 \mu \mathrm{m})$.

\section{B. Nickel and nickel-based alloys}

The first application of deuteron induced nuclear reaction analysis for helium depth profiling is due to Lewis [53]. $200 \mathrm{keV}$ helium-3 ions were implanted from room temperature and up to $1063 \mathrm{~K}$ in high purity ( $<50$ at. ppm impurity) polycrystalline thick nickel disks. The implantation dose was about $1.1 \times 10^{20}$ ions $/ \mathrm{m}^{2}$. The alpha particles emitted from the nuclear reaction ${ }^{3} \mathrm{He}(\mathrm{d}, \alpha)^{1} \mathrm{H}$ were analyzed at an angle of 65 or $70^{\circ}$ from the incident deuteron direction. A new deconvolution technique was specially developed by Lewis in 1981 for the data processing based on Taylor's expansion to take into account energy straggling and multiple scattering effects [234]. Helium loss was shown to occur at a critical temperature equal to 973 $\mathrm{K}$. An effective migration energy of approximately $2.6 \mathrm{eV}$ was found to be consistent with the set of diffusion equations previously proposed by Ghoniem [20].

The behavior of helium in nickel has been intensively studied [48-54]. Figure 2.4 summarizes the major part of the data obtained for the activation energy for helium thermal migration in nickel (see red bars in figure 2.4). Values are in the range $0.11-2.5 \mathrm{eV}$ for temperatures varying from 80 to $1523 \mathrm{~K}$. As we have mentioned above, due to large discrepancies between various experimental configurations adopted by various authors, the direct comparison of results become difficult. 


\section{Tungsten}

The development of research programs for nuclear fusion applications have vastly increased the number of experimental studies related to helium effects in tungsten [61 -66].

Debelle and co-workers have investigated the desorption mechanisms of ${ }^{3} \mathrm{He}$ implanted tungsten at low fluence and low energy [66]. Helium desorption has been observed only from $\sim 1500 \mathrm{~K}$, suggesting a helium trapping at mono-vacancies. Only $\sim 75 \%$ of the implanted helium has been released after the annealing during $1 \mathrm{~h}$ at high temperature $(1873 \mathrm{~K})$; besides, the desorption rate decreased from $1673 \mathrm{~K}$. The presence of a second type of helium trapping site is likely to explain this $25 \%$ helium retention, presumably large $\mathrm{He}_{\mathrm{n}}-\mathrm{V}_{\mathrm{m}}$ complexes. Moreover, an effect of the grain boundaries on this strong helium trapping is suggested.

\section{Other metals}

Among the other metallic materials in which helium behavior has been intensively studied, vanadium and vanadium alloys are most widely studied due to their specific properties which makes them interesting for fusion applications [35-39].

Ryazanov and co-workers have performed a very detailed study on the behavior of helium in vanadium alloys in order to explain the presence of some release peaks not well understood during the deformation and embrittlement processes [39]. Two limiting cases were investigated: slow and fast strain rates. The authors suggested a sweep out mechanisms of helium atoms and helium bubbles by moving dislocations. A different temperature dependence was found for both mechanisms. The total helium amount that comes out to the surface through dislocationdynamic diffusion has weak dependence on temperature and helium transported by dislocations a strong one.

\subsubsection{Main experimental data on helium migration in non-metallic substrates}

According to the investigated literature concerning the mobility of helium in non-metallic solids (ceramics, glasses, minerals), activation energy data are gathered in figure 2.6 and diffusion coefficient values are plotted in figure 2.7. Taking into account the same remark made in the previous section, the direct comparison of data obtained on the same material from different research groups requires particular attention. 


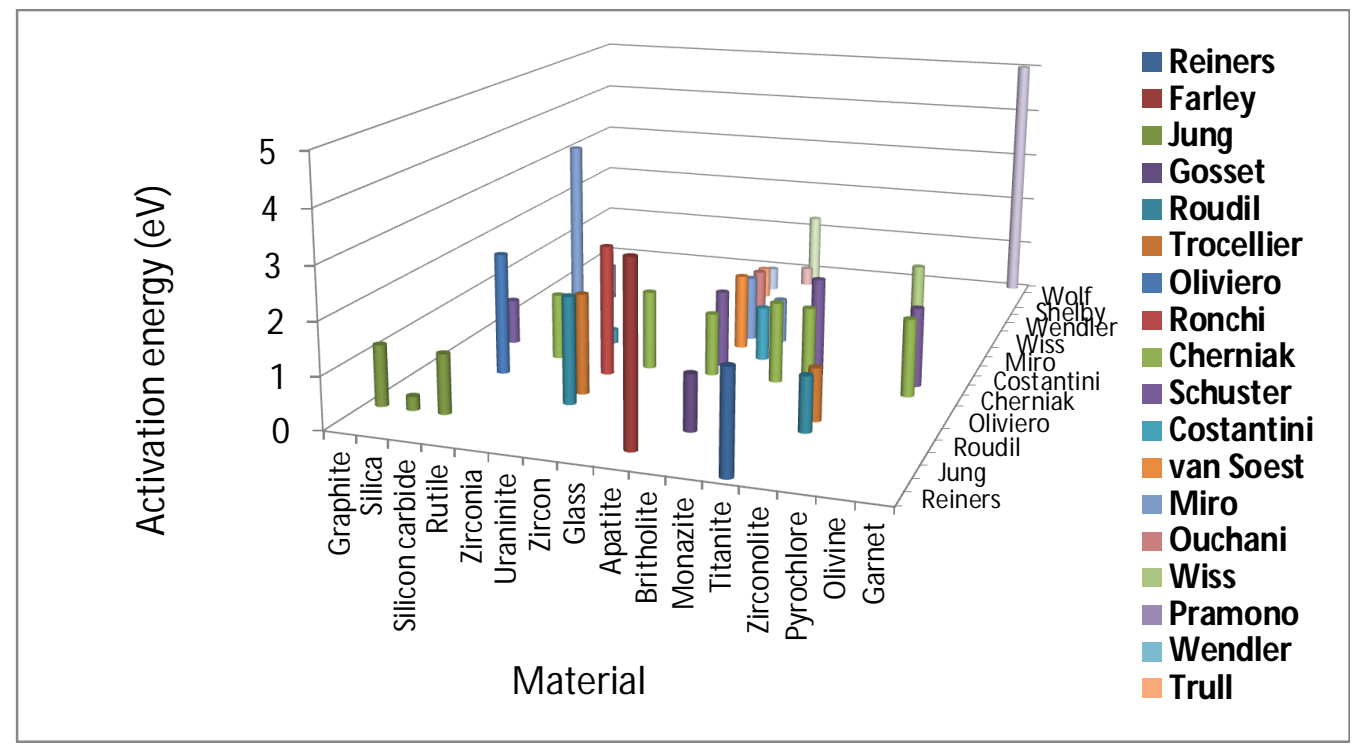

Figure 2.6. Overview of activation energy values determined for migration of helium in ceramics and minerals.

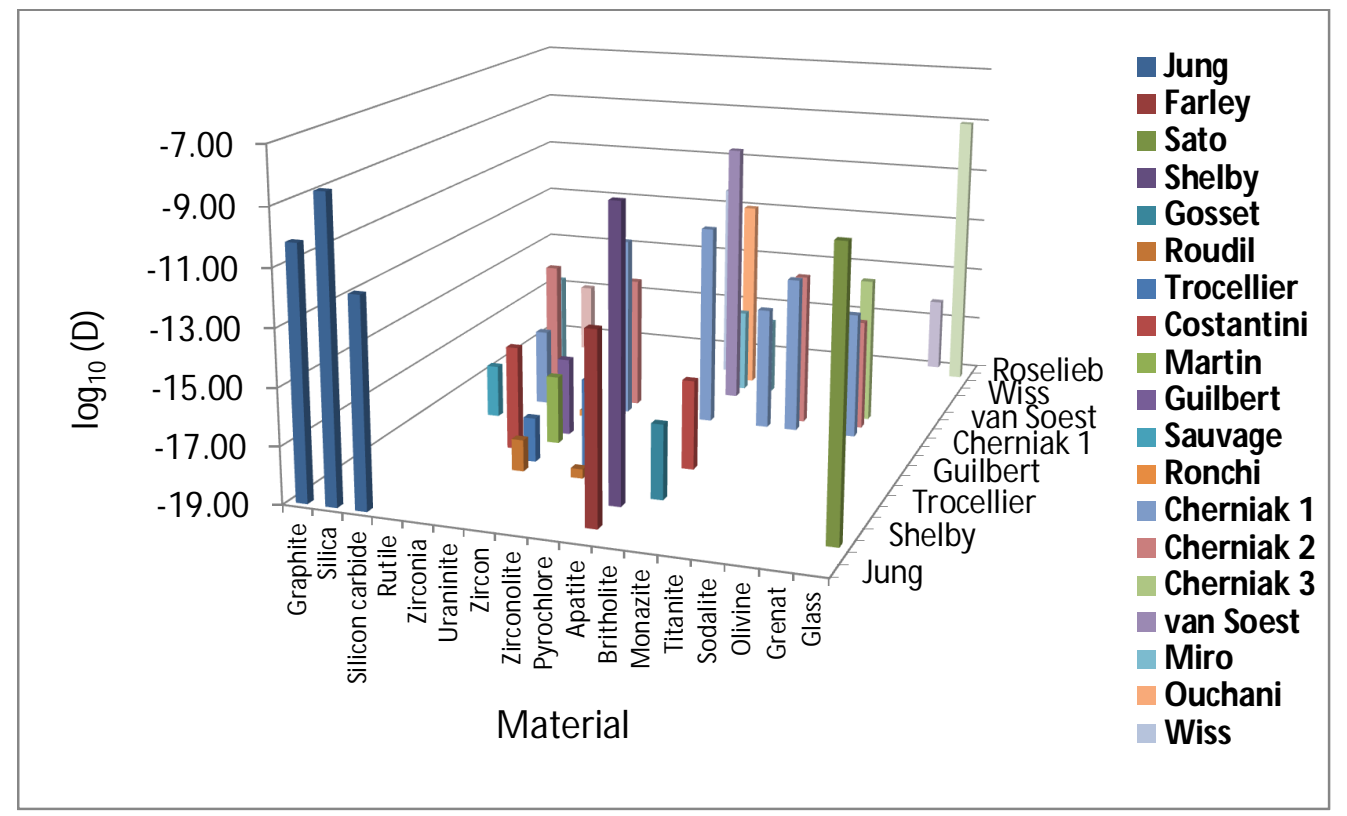

Figure 2.7. Overview of diffusion coefficient values determined for migration of helium in ceramics and minerals. 


\section{A. Inert matrix fuels}

Three materials have been mainly selected, thanks to their properties as potential matrices for long-live radionuclide transmutation, i.e. cubic zirconia [118,152], $\mathrm{Mg}-\mathrm{Al}$ spinel $[117,138]$ and $\mathrm{MgO}[117]$.

Due to the $\alpha$-decays, the helium content could reach large values (>1 at. \%) for long term ageing. Since the solution energy of helium in solids is large (around $3 \mathrm{eV}$ ), He atoms tend to coalesce and form bubbles inducing detrimental modifications of the material structure and mechanical properties [152].

Results have been obtained on polycrystalline $\alpha-\mathrm{ZrO}_{2}$ ceramics and yttria-stabilized-cubic (YSZ) single crystals implanted with $3-\mathrm{MeV}{ }^{3} \mathrm{He}$ ions at a depth around $7 \mu \mathrm{m}$ then isochronously annealed in air at temperatures between 200 and $1100{ }^{\circ} \mathrm{C}$. In $\alpha-\mathrm{ZrO}_{2}$, no change of the depth profile is found up to $800{ }^{\circ} \mathrm{C}$. In contrast, two regimes are found in YSZ:

(i) below $800^{\circ} \mathrm{C}$, diffusion is controlled by helium trapping at native oxygen vacancies $(\sim 10$ at.\%),

(ii) above $800^{\circ} \mathrm{C}$, helium escapes out of the profile, with almost complete outgassing at 1100 ${ }^{\circ} \mathrm{C}$.

Neeft and co-workers have followed the helium release from implanted (100) spinel single crystals by thermal desorption spectrometry. Two series of samples were investigated:

- the first series corresponds to an implantation of $30 \mathrm{keV}{ }^{3} \mathrm{He}$ ions at room temperature with high doses $6.2,16,20$ and $53 \times 10^{19}$ ions $\mathrm{m}^{-2}$,

- the second series corresponds to an irradiation of $4.5 \mathrm{MeV}{ }^{4} \mathrm{He}$ with a low dose $1.3 \times 10^{16}$ ions $\mathrm{m}^{-2}$.

At a very low helium concentration (about $0.0288 \mathrm{appm}$ around $12.4 \mu \mathrm{m}$ ), helium release is dominated by helium interstitial diffusion with an activation energy of $1.8 \mathrm{eV}$. In the case of high dose implantation (about 1.74 at.\% around $100 \mathrm{~nm}$ ), helium is released from He-vacancy clusters with an activation energy of $2.35 \mathrm{eV}$. 


\section{B. Nuclear fuel matrices}

One of the main consequence arising from the presence of actinides in nuclear fuel matrices as $\mathrm{UO}_{2}$ or $(\mathrm{U}, \mathrm{Pu}) \mathrm{O}_{2}$ is the formation of a large quantity of helium produced by $\alpha$-disintegration. Due to its low solubility in this type of ceramics, He can lead in particular to microscopic and macroscopic swelling that may result in cracking of the material $[127,128]$.

In 2004, Roudil and co-workers published a paper in which they reported experimental measurement of helium thermal diffusion coefficient in depleted uranium dioxide matrix [128]. Using ${ }^{3} \mathrm{He}$ implantation followed by fully controlled thermal annealing, and deuteron-induced nuclear reaction spectrometry, they succeeded to discriminate two types of behavior between 1123 and $1273 \mathrm{~K}$, depending on the fluence, with a common activation energy of $2 \mathrm{eV}$ (see table 2.2).

\begin{tabular}{|c|c|c|c|}
\hline $\begin{array}{c}{ }^{3} \text { He fluence } \\
\left(\mathbf{i o n s} / \mathbf{c m}^{2}\right)\end{array}$ & $\mathbf{T}\left({ }^{\circ} \mathbf{C}\right)$ & Annealing duration $(\mathbf{h})$ & $\mathbf{D}\left(\mathbf{m}^{2} / \mathbf{s}\right)$ \\
\hline $0.3 \times 10^{16}$ & 1000 & 4 & $2.3-2.9 \times 10^{-17}$ \\
\hline $0.3 \times 10^{16}$ & 900 & 30 & $3.8-4.8 \times 10^{-18}$ \\
\hline $0.3 \times 10^{16}$ & 850 & 48 & $2.2-2.4 \times 10^{-18}$ \\
\hline $3 \times 10^{16}$ & 1000 & 4 & $1.0-2.8 \times 10^{-18}$ \\
\hline $3 \times 10^{16}$ & 950 & 8 & $3.0-7.8 \times 10^{-19}$ \\
\hline $3 \times 10^{16}$ & 900 & 30 & $1.6-4.2 \times 10^{-19}$ \\
\hline $3 \times 10^{16}$ & 850 & 48 & \\
\hline
\end{tabular}

Table 2.2. Helium diffusion coefficient in $\mathrm{UO}_{2}$ evaluated by NRA measurement [108].

\section{High level nuclear waste matrices}

Dimensioning of actinide waste packages for long term storage has to be taken into account helium production from natural decay and release rates from the material [119]. 
Costantini and co-workers measured helium diffusion coefficients from $\mathrm{Nd}$-britholite in the temperature range $200-400{ }^{\circ} \mathrm{C}$ [114]. The deduced activation energy is about $(1.05 \pm 0.03) \mathrm{eV}$. The values published in the entire literature related to helium migration in apatite and/or britholite are rather consistent.

In their study on helium diffusion in britholite, a mineral matrix considered for actinide immobilization, Gosset and co-workers were the first to demonstrate the existence of two distinct He populations [119]. They succeeded to fit successfully the experimental ${ }^{3} \mathrm{He}$ depth profile obtained after a thermal annealing conducted at $400^{\circ} \mathrm{C}$ to two Gaussian curves: a narrow component associated with helium atoms implanted near the end of range, and a broad component slightly shifted towards the surface. The second component was then attributed to anisotropic, intragranular diffusion along the channels of the hexagonal structure of apatite. The respective apparent diffusion coefficients were $4.17 \times 10^{-17}$ and $2.88 \times 10^{-16} \mathrm{~m}^{2} \mathrm{~s}^{-1}$. In the latter case, a second helium population was produced by the microstructure of the material under investigation. A similar situation may occur if the material suffers a certain degree of damage from the irradiation. This case was discussed by Schuster in Durango apatite [122]. The second helium population was attributed to helium atoms trapped within irradiation defects (vacancies or vacancy clusters).

Many models were proposed to describe the migration mechanisms of helium in inorganic media, generally based on Fick's laws. Miro and co-workers compared different models in the case of fluorapatite and Nd-britholite within the framework of the simulation code AGEING [120] giving an average $D$ value of $4.13 \times 10^{-17} \mathrm{~m}^{2} \mathrm{~s}^{-1}$ at $325^{\circ} \mathrm{C}$ for Nd-britholite; model 2 leads to the following data set: $\mathrm{D}=3.44 \times 10^{-17} \mathrm{~m}^{2} \mathrm{~s}^{-1}, \mathrm{v}=0.05 \mu \mathrm{m} / \mathrm{h}$ and $\mathrm{f}=9 \%$.

Titanate and zirconate-based matrices as zirconolite and pyrochlore have also been investigated. Data processing methods, lead to helium diffusion coefficient and associated activation energy of $1.05 \mathrm{eV}$ in the zirconolite. The helium diffusion coefficient in zirconolite is 1 to 100 million times higher than uranium dioxide matrix [127].

\section{Other non-metallic compounds}

Jung investigated the diffusion of helium in silicon carbide by coupling implantation of high energy $\alpha$-particles $(5-28 \mathrm{MeV})$ at current densities from 0.8 to $40 \times 10^{14} \mathrm{He} \mathrm{m}^{-2} \mathrm{~s}^{-1}$ to doses of typically $10^{17} \mathrm{~m}^{-2}$ at temperatures up to $1100 \mathrm{~K}$ and mass spectrometry [30]. The corresponding diffusion coefficients are given by: 


$$
\mathrm{D}\left(\mathrm{m}^{2} / \mathrm{s}\right)=1.1 \times 10^{-6} \exp \left(-1.14 / \mathrm{k}_{\mathrm{B}} \mathrm{T}\right) \text { for } 800 \leq \mathrm{T}(\mathrm{K}) \leq 1050
$$

He applied the same approach to pyrolitic graphite and found:

$$
\mathrm{D}\left(\mathrm{m}^{2} / \mathrm{s}\right)=5.0 \times 10^{-5} \exp \left(-1.17 / \mathrm{k}_{\mathrm{B}} \mathrm{T}\right) \text { for } 750 \leq \mathrm{T}(\mathrm{K}) \leq 1050
$$

Recently, using the same experimental approach as developed for fluorapatite and $\mathrm{Nd}$ britholite, Miro and co-workers studied the thermally assisted migration of helium in $4 \mathrm{H}-$ and $6 \mathrm{H}-\mathrm{SiC}$ single crystals [147]. They demonstrated for the first time an exchange process between two distinct helium populations. A part of ${ }^{3} \mathrm{He}$ remained trapped in the ${ }^{3} \mathrm{He}$ ion end-of-range region (population 1), while another part of ${ }^{3} \mathrm{He}$ atoms is detrapped from a zone located close to the surface (population 2).

The use of ${ }^{3} \mathrm{He}$ to study the migration behavior of helium in a given material raises the following question: what about the difference in mobility between ${ }^{3} \mathrm{He}$ and ${ }^{4} \mathrm{He}$ ? As discussed by Trull [101] in his paper on helium migration in basaltic glasses, the conventional assumption is to consider the square root of the isotope mass ratio to deduce the respective diffusion coefficients $\left(\mathrm{D}_{4 \mathrm{He}} / \mathrm{D}_{3 \mathrm{He}}=\sqrt{ }\left(\mathrm{m}_{3 \mathrm{He}} / \mathrm{m}_{4 \mathrm{He}}\right)=0.868\right)$.

The first experimental measurements to discriminate between these diffusion coefficients were performed by Schuster and co-workers on Durango apatite [116]. They show that the best fit for their entire data set is $\mathrm{D}_{4 \mathrm{He}} / \mathrm{D}_{3 \mathrm{He}}=1.03$. Considering this result, a refined procedure was developed to correct for the (U-Th)/He ages and for partial diffusive loss $[3,4]$.

\subsubsection{Conclusions}

This bibliographic review allows us to conclude that for any material, helium migration kinetics can be affected by a great number of physical and chemical factors:

- helium content [He], 
- temperature $\mathrm{T}$,

- thermal annealing regime (rate of temperature increase),

- nature and content of impurity atoms,

- microstructure (grain size and grain boundary density) of the substrate, crystalline orientation,

- presence of native vacancies due to non-stoichiometry,

- presence of a defect distributions produced by complex microstructural processes in the material or induced by irradiation damage.

Diffusion is a process assisted by defects and controlled by their volumetric distribution. The main difference that can be distinguished between ceramics and metallic materials are as under:

- In terms of atomic diffusion: In the case of ceramics, owing to the co-existence of two separated sublattices, cation and anion diffusion processes can be considered to occur independently without any cation/anion exchange. In the case of self-diffusion processes, it must be noticed that atom transport can be faster by several order of magnitude in one of the sublattices.

- In terms of the occurrence of unstable charged defects: Moreover, according to the work by Ryazanov, a second major difference would be the occurrence of unstable charged defects in ceramics due to ionization and covalent chemical bonding, for example point defects (vacancies and self-interstitial atoms, small clusters and dislocation loops) [224,225]. The instability of charged defects may cause the multiplication of $1 \mathrm{D}$ and 2D defects and consequently an increase in defect density. Then, helium migration mechanisms can be affected by this increasing density of trapping site.

The research related to helium migration/retention mechanisms in alloys and ceramics are now oriented towards advanced nuclear materials developed for Generation IV reactors and fusion applications. For example: 
- In the first field, new fuel concepts such as (U,Pu) $\mathrm{O}_{2}$ [11], oxide dispersion strengthened steels [239,250], ceramic-ceramic composites as silicon carbide reinforced by silicon carbide fibers $\left(\mathrm{SiC}_{\mathrm{f}} / \mathrm{SiC}\right)[254,255]$.

- In the second field, very strong efforts are now under development [254-263]. The main issue is related to the fact that deuterium, tritium and helium effects determine the long-term stability of the selected materials. The most investigated materials are tungsten and tungsten alloys [253,256,259], and Fe and ferritic-martensitic steels [257,260,262]. For this area, nuclear reaction analysis reveals itself to be a very powerful tool because specific reactions exist for almost every isotope ${ }^{2} \mathrm{H}(\mathrm{D}),{ }^{3} \mathrm{H}(\mathrm{T})$ and ${ }^{3} \mathrm{He}$ namely: (1) $\mathrm{D}\left(\mathrm{d}, \mathrm{p}_{0}\right){ }^{3} \mathrm{He}$ or $\mathrm{D}\left({ }^{3} \mathrm{He}, \mathrm{p}_{0}\right){ }^{4} \mathrm{He},(2) \mathrm{T}(\mathrm{d}$, n) ${ }^{4} \mathrm{He}$, and $(3)^{3} \mathrm{He}\left(\mathrm{d}, \mathrm{p}_{0}\right)^{4} \mathrm{He}$.

Carrying-over the helium-3 studies discussed in this review paper has been yet successfully applied to deuterium depth profiling in the area of fusion related material researches [260,262]. For studies related to ${ }^{4} \mathrm{He}$ behavior, THDS [258] and HI-ERDA [238,240,241] keep their advantages and capabilities.

Finally, from this broad literature survey, it was tempting to conclude that activation energy for helium migration energy in most of the inorganic materials lies in a very broad range from 0.1 to more than $5.0 \mathrm{eV}$. High activation energy values indicate that helium is immobile within the material. However, these values strongly depend on material nature as well as on the experimental conditions under which material has been studied. 


\section{References}

[1] D.W. Graham, W.J. Jenkins, M.D. Kurz, R. Batiza, Helium isotope disequilibrium and geochronology of glassy submarine basalts, Nature $326(1987) 384-386$

[2] J.G. Du, J.Z. Zhang, M.L. Sun, Y.L. Zhang, isotopic composition of helium in eclogite from the Dabie Mountains, central China and its geological significance, Chinese Science Bulletin 43(1998)1362-1366.

[3] D.L. Schuster, K.A. Farley, ${ }^{4} \mathrm{He} /{ }^{3} \mathrm{He}$ thermochronometry, Earth Planet. Sci. Lett. 217(2003)1-17.

[4] P. Burnard, Diffusive fractionation of noble gases and helium isotopes during mantle melting, Earth Planet. Sci. Lett. 220(2004)287-295.

[5] X.B. Zhang, Y.C. Yu, M.L. Sun, K.M. Cheng, W.H. Liu, X.F. Li, L.Y. Ma, Discovery and its geological significance of the mantle-derived helium inclusions of the Ordovician oil-bearing reservoir rocks in the Huanghua depression, China, Science in China Series D-Earth Sciences 47(2004)23-29.

[6] N. Morikawa, K. Kazahaya, H. Masuda, M. Ohwada, A. Nakama, K. Nagao, H. Sumino, Relationship between geological structure and helium isotopes in deep ground-water from the Osaka basin: Application to deep ground-water hydrology, Geochem. J. 42(2008)61-74.

[7] Zhaoli Li, Jingsui Yang, Zhiqin Xu, Tianfu Li, Xiangzhen Xu, Yufeng Ren, Helium isotope composition and its geological significance of the eclogites in the Lasha Terrane, Tibet, Geochim. Cosmochim. Acta 74(2010)A599.

[8] H. Trinkaus, B.N. Singh, Helium accumulation in metals during irradiation - where do we stand?, J. Nucl. Mater. 323(2003)229-242.

[9] N. Yamamoto, Y. Murase, J. Nagakawa, An evaluation of helium embrittlement resistance of reduced activation martensitic steels, Fusion Engin. Design 81(2006)1085-1090.

[10] E. Gaganidze, C. Petersen, J. Aktaa, Study of helium embrittlement in boron doped EUROFER97 steels, J. Nucl. Mater. $386-$ $388(2009) 349-352$.

[11] Y. Pipon, C. Raepsaët, D. Roudil, H. Khodja, The use of NRA to study thermal diffusion of helium in $(\mathrm{U}, \mathrm{Pu}) \mathrm{O}_{2}, \mathrm{Nucl}$. Instrum. Meth. Phys. Res. B 267 (2009) 2250-2254.

[12] S. Nogami, A. Hasegawa, T. Tanno, K Imasaki, K. Abe, High-temperature helium embrittlement of 316FR steel, J. Nucl. Sci. Technol. 48(2011)130-134.

[13] M.R. Gilbert, S.L. Dudarev, S. Zheng, L.W. Packer, J.C. Sublet, An integrated model for materials in a fusion power plant: Transmutation, gas production, and helium embrittlement under neutron irradiation, Nucl. Fusion 52(2012)083019.

[14] S.J. Zinkle, Effect of $\mathrm{H}$ and He irradiation cavity formation and blistering in ceramics, Nucl. Instrum. Meth. Phys. Res. B286(2012)4-19.

[15] R.S. Barnes, D.J. Mazey, The migration and coalescence of inert gas bubbles in metals, Proc. Royal Soc. A 275(1963)47-57.

[16] D.J. Reed, A review of recent theoretical developments in the understanding of the migration of helium in metals and its interaction with lattice defects, Radiation Effects 31(1977)129-147.

[17] N.L. Peterson, Self-diffusion in pure metals, J. Nucl. Mater. 69 \& 70(1978)3-37.

[18] W. Schilling, Diffusion of helium in metals, in Point Defects and Defect Interactions in Metals, edited by Jin-Ichi Takamura, Maseo Doyama and Michio Kitani, University of Tokyo Press, North Holland Publishing Company, Amsterdam, 1982, pp. 303-308.

[19] H. Ullmaier, Helium in metals, Radiation Effects 78(1983)1-10.

[20] N.M. Ghoniem, S. Sharafat, J.M. Williams, L.K. Mansur, Theory of helium transport and clustering in materials under irradiation, J. Nucl. Mater. 117(1983)96-105.

[21] H. Ullmaier, The influence of helium on the bulk properties of fusion reactor structural materials, Nucl. Fusion 24(1984)1039-1083.

[22] S.E. Donnelly, The density and pressure of helium in bubbles in implanted metals: A critical review, Radiation effects 90(1985)1-47.

[23] J.H. Evans, A. van Veen, Gas release processes for high concentrations of helium bubbles in metals, J. Nucl. Mater. 233-237(1996)11791183.

[24] G.J. Thomas, Experimental studies of helium in metals, Radiation Effects 78(1983)37-51.

[25] V. Sciani, P. Jung, Diffusion of helium in fcc metals, Radiation Effects 78(1983)87-99.

[26] P. Jung, K. Schroeder, Diffusion and agglomeration of helium in fcc metals, J. Nucl. Mater. 155-157(1988)1137-1141.

[27] P Jung in Diffusion of Helium and Tritium in Nuclear Materials, Diffusion Processes in Nuclear Materials, edited by R.P. Agarwala, 1992, Elsevier Science Publishers, pp. 235-269. 
[28] R. Vassen, H. Trinkaus, P. Jung, Diffusion of helium in magnesium and titanium before and after clustering, J. Nucl. Mater. 183(1991)18.

[29] H.R. Glyde, K.I. Mayne, Helium diffusion in aluminum, Phil. Mag. 12(1965)997-1003.

[30] P. Jung, Diffusion and retention of helium in graphite and silicon carbide, J. Nucl. Mater. 191-194(1992)377-381.

[31] B. Glam, D. Moreno, S. Eliezer, D. Eliezer, Experimental investigation of helium migration in an fcc aluminum matrix, J. Nucl. Mater. 393(2009)230-234.

[32] X. Xiang, C.A. Chen, K.Z. Liua, L.X. Peng, Y.C. Rao, Effect of Fe and C doping on the thermal release of helium from aluminum, Fusion Engineering Design 85(2010)2086-2089.

[33] P. Jung, Diffusion of implanted helium in $\mathrm{Si}$ and $\mathrm{SiO}_{2}$, Nucl. Instrum. Meth. Phys. Res. B91(1994)362-365.

[34] M.B. Lewis, Evidence for helium trapping to oxygen sites in titanium, Nucl. Instrum. Meth. Phys. Res. B22(1987)499-503.

[35] F.A. Smidt Jr, A.G. Pieper, Studies of the mobility of helium in vanadium, J. Nucl. Mater. 51(1974)361-365.

[36] R.S. Blewer, R.A. Langley, Depth distribution and migration of helium in vanadium at elevated temperatures, J. Nucl. Mater. 63(1976)337346.

[37] M.B. Lewis, Diffusion of ion-implanted helium in vanadium and niobium, J. Nucl. Mater. 152(1988)114-122.

[38] R. Vassen, H. Trinkaus, P. Jung, Helium desorption from V and Fe by atomic diffusion and bubble migration, Phys. Rev. B 44(1991)42064213 .

[39] A. Ryazanov, H. Matsui, A.V. Kazaryan, Physical mechanisms of helium release during deformation of vanadium alloys doped with helium atoms, J. Nucl. Mater. 271\&272(1999)356-359.

[40] M.B. Lewis, K. Farrell, Migration behavior of helium under displacive irradiation in stainless steel, nickel, iron and zirconium, Nucl. Instrum. Meth. Phys. Res. B16(1986)163-170.

[41] K. Morishita, B.D. Wirth, T. Diaz de la Rubia, A. Kimura, Effects of helium on radiation damage processes in iron, $4^{\text {th }}$ Pacific Rim International conference on "Advanced Materials and Processing", Honolulu, HI, December 2001, The Japan.Institute of Metals, Report UCRL-JC-144458.

[42] K. Morishita, R. Sugano, H. Iwakiri, N. Yoshida, A. Kimura, Thermal helium desorption from $\square$-iron, $4^{\text {th }}$ Pacific Rim International conference on "Advanced Materials and Processing", Honolulu, HI, December 2001, Edited by S. Hanada, Z. Zhong, S.W. Nam and R.N. Wright, The Japan.Institute of Metals 2001, pp. 1395-1398.

[43] R. Sugano, K. Morishita, A. Kimura, Helium accumulation behavior in iron based model alloys, Fusion Sci. Technol. 44(2003)446-449.

[44] K. Ono, M. Miyamoto, K. Arakawa, Dynamical interaction of helium bubbles with grain boundaries in Fe and Fe-9Cr ferritic alloy, J. Nucl. Mater. 367-370(2007)522-526.

[45] V.A. Borodin, P.V. Vladimirov, Diffusion coefficients and thermal stability of small helium-vacancy clusters in iron, J. Nucl. Mater. 362(2007)161-166.

[46] Donghua Xu, B.D. Wirth, Post-implantation thermal desorption of helium from poly- and single-crystalline iron, J. Nucl. Mater. 386388(2009)395-399.

[47] H. Lefaix-Jeuland, S. Miro, F. Legendre, Helium behavior in Fe-base materials: Thermal desorption and nuclear reaction analyses, Defects and Diffusion Forum 323-325(2012)221-226.

[48] D.S. Whitmell, R.S. Nelson, The thermal release of helium injected into nickel, stainless steels and nimonic PE16, Radiation Effects $14(1972) 249-255$.

[49] D. Edwards Jr, E.V. Kornelsen, The kinetics of the desorption of helium implanted into a nickel (100) crystal, Surface Science 44(1974)110 .

[50] G.J. Thomas, W.A. Swansiger, M.I. Baskes, Low temperature helium release in nickel, J. Appl. Phys. 50(1979)6942-6947.

[51] D.B.Poker, J.M. Williams, Low temperature release of implanted helium from nickel, Appl. Phys. Lett 40(1982)851-853.

[52] V. Phillips, K. Sonnenberg, J.M. Williams, Diffusion of helium in nickel, J. Nucl. Mater. 107(1982)271-279.

[53] M.B. Lewis, Diffusion and trapping of ion-implanted helium in nickel, J. Nucl. Mater. 149(1987)143-149.

[54] X.Z. Cao, Q. Xu, K. Sato, T. Yoshiee, Thermal desorption of helium from defects in nickel, J. Nucl. Mater. 412(2011)165-169.

[55] T. Yamauchi, S. Yamanaka, M. Miyake, Thermal release behavior of helium implanted into copper at high fluencies, J. Nucl. Mater. 174(1990)53-59.

[56] J. Roth, S.T. Picraux, W. Eckstein, J. Bottiger, R. Behrisch, Temperature dependence of He trapping in niobium, J. Nucl. Mater. 63(1976)120-125. 
[57] W.Th. M. Buters, A. Van Den Beukel, Thermal helium desorption spectrometry on plastically deformed molybdenum, J. Nucl. Mater. $137(1985) 57-62$.

[58] W.Th.M. Buters, A. Van Den Beukel, Helium pipe diffusion along dislocations in molybdenum observed with thermal helium desorption spectrometry, J. Nucl. Mater. 141-143(1986)253-257.

[59] A. N. Zhiganov, A. Ya. Kupryazhkin, Grain-boundary diffusion and solubility of helium in submicrocrystalline palladium, Technical Physics 50(2005)1026-1033.

[60] F. Zielinski, J-M. Costantini, J. Haussy, F. Durbin, Helium depth-profiling in tantalum after ion implantation and high-temperature annealing, J. Nucl. Mater. 312(2003)141-145.

[61] J. Amano, D.N. Seidman, Diffusivity of ${ }^{3} \mathrm{He}$ atoms in perfect tungsten crystals, J. Appl. Phys. 56(1984)983-992.

[62] Z. Fu, N. Yoshida, H. Iwakiri, Z. Xu, Thermal desorption and surface modification of He ${ }^{+}$implanted into tungsten, J. Nucl. Mater. 329$333(2004) 692-696$

[63] A. Debelle, M-F. Barthe, T. Sauvage, R. Belamhawal, A. Chelgoum, P. Desgardin, H. Labrim, Helium behavior and vacancy defect distribution in helium implanted tungsten, J. Nucl. Mater. 362(2007)181-188.

[64] A. Debelle, M.F. Barthe, T. Sauvage, First temperature stage evolution of irradiation-induced defects in tungsten studied by positron annihilation spectroscopy, J. Nucl. Mater. 376(2008)216-221.

[65] Li Yang, Hankui Liu, Xiaotao Zu, First-principles study of the migration of helium in tungsten, International Journal of Modern Physics B 23(2009)2077-2082.

[66] A. Debelle, P.E. Lhuillier, M-F. Barthe, T. Sauvage, P. Desgardin, Helium desorption in ${ }^{3}$ He implanted tungsten at low fluence and low energy, Nucl. Instrum. Meth. Phys. Res. B268(2010)223-226.

[67] R. Vassen, P. Jung, Interstitial migration of hydrogen and helium in platinum, Phys. Rev. B 37(1988)2911-2917.

[68] H. Wiedersich, J.J. Burton, J.L. Katz, Effect of mobile helium on void nucleation in materials during irradiation, J. Nucl. Mater. 51(1974)287-301.

[69] H. Schroeder, P.F.P. Fichner, On the coarsening mechanisms of helium bubbles - Ostwald ripening versus migration and coalescence, J. Nucl. Mater. 179-181(1991)1007-1010.

[70] A.M. Brass, A. Chanfreau, J. Chene, Helium 3 precipitation in AISI 316L stainless steel induced by radioactive decay of tritium: Microstructural study of helium bubble precipitation, Metallurgical and Materials Transactions A25(1994)2117-2130.

[71] A. Chanfreau, A.M. Brass, C. Haut, J. Chene, Helium 3 precipitation in AISI 316L stainless steel induced by radioactive decay of tritium: Growth mechanism of helium bubbles, Metallurgical and Materials Transactions A25(1994)2131-2143.

[72] C.H. Zhang, K.Q. Chen, Y.S. Wang, J.G. Sun, Thermal stability of small He-vacancy clusters in 316L stainless steel irradiated with 2.5 $\mathrm{MeV}$ He ions at $550^{\circ} \mathrm{C}$, Nucl. Instrum. Meth. Phys. Res. B 135 (1998) 256-259.

[73] K. Ono, K. Arakawa, H. Shibasaki, H. Kurata, I. Nakamichi, N. Yoshida, Release of helium from irradiation damages in Fe-9Cr ferritic alloy, J. Nucl. Mater. 329-333(2004)933-937.

[74] A. Kimura, R. Sugano, Y. Matsushita, S. Ukai, Thermal helium desorption behavior in advanced ferritic steels, J. Phys. Chem. Solids 66(2005)504-508.

[75] G. Dobmann, S.N. Korshunov, M. Kroening, Yu.V. Martynenko, I.D. Skorlupkin, A.S. Surkov, Helium and radiation defect accumulation in metals under stress, Vacuum 82 (2008) 856-866.

[76] K. Ono, M. Miyamoto, K. Arakawa, R.C. Birtcher, Dynamical interaction of helium bubbles with cascade damage in Fe-9Cr ferritic alloy, J. Nucl. Mater. 386-388(2009)177-180.

[77] Chang-An Chen, Ying Sun, Zhiyong Huang, Congxian Liu, Sheng Wu, The diffusion of tritium and helium-3 in 21-6-9 stainless steel during the storage of tritium at high pressure and room temperature, Physica Scripta T103(2003)97-100.

[78] K. Ünlü, D.H. Vincent, Helium-3 behavior in some nickel-based amorphous alloys, Nucl. Sci. Engin. 110(1992)386-393.

[79] J.L. Flament, F. Zielinski, S. Saudé, R.I. Grynszpan, Helium diffusion in metals investigated by nuclear reaction analysis, Nucl. Instrum. Meth. Phys. Res. B216(2004)161-166.

[80] Yu. A. Shukolyukov, O. V. Yakubovich, S. Z. Yakovleva, E. B. Sal'nikova, A. B. Kotov, E. Yu. Rytsk, Geothermochronology based on noble gases: III. Migration of radiogenic He in the crystal structure of native metals with applications to their isotopic dating, Petrology 20(2012)1-20.

[81] W.A. Rogers, R.S. Buritz, D. Alpert, Diffusion coefficient, solubility, and permeability for helium in glass, Journal of Applied Physics 25(1954)868-875.

[82] J.H. Reynolds, Rare gases in tektites, Geochimica et Cosmochimica Acta 20(1960)101-114. 
[83] J.E. Shelby, Temperature dependence of He diffusion in vitreous $\mathrm{SiO}_{2}$, J. Amer. Ceram. Soc. 54(1971)125-126.

[84] J.E. Shelby, Helium migration in glass-forming oxides, J. Appl. Phys. 43(1972)3068-3072.

[85] J.E. Shelby, Helium migration in $\mathrm{TiO}_{2}-\mathrm{SiO}_{2}$ glasses, J. Amer. Ceram. Soc. 55(1972)195-197.

[86] J.E. Shelby, Helium migration in alkali borate glasses, J. Appl. Phys. 44(1973)3880-3888.

[87] J.E. Shelby, Effect of phase separation on helium migration in sodium silicate glasses, J. Amer. Ceram. Soc. 56(1973)263-266.

[88] J.E. Shelby, Effect of structural relaxation on helium diffusion and solubility in vitreous $\mathrm{B}_{2} \mathrm{O}_{3}$, J. Non Cryst. Solids 14(1974)288-299.

[89] J.E. Shelby, Helium, deuterium, and neon migration in a common borosilicate glass, J. Appl. Phys. 45(1974)2146-2149.

[90] J.E. Shelby, Helium migration in borogermanate glasses, J. Appl. Phys. 46(1975)4510-4514.

[91] J.E. Shelby, R.J. Eagan, Helium migration in sodium aluminosilicate glasses, J. Amer. Ceram. Soc. 59(1976)420-425.

[92] J.E. Shelby, Pressure dependence of helium and neon solubility in vitreous silica, J. Appl. Phys. 47(1976)135-139.

[93] J.E. Shelby, Helium migration in alkali germanate glasses, J. Appl. Phys. 50(1977) 276-279.

[94] J.E. Shelby, Helium migration in lithium aluminosilicate glasses, J. Appl. Phys. 48(1979) 1497-1502.

[95] A. Jambon, J.E. Shelby, Helium diffusion and solubility in obsidians and basaltic glass in the range $200-300^{\circ} \mathrm{C}$, Earth \& Planetary Science Letters 51(1980)206-214.

[96] J.E. Shelby, Helium migration in alkali-galliosilicate glasses, J. Non Cryst. Sol. 45(1981)411-418.

[97] S.Sato, H. Furuya, K. Morikawa, M. Sugisaki, Y. Inagaki, Behavior of helium release from simulated radioactive waste glasses, J. Nucl. Sci. Technol. 27(1990)343-349.

[98] J.E. Shelby, J.C. Lapp, Helium and deuterium migration in alkali silicate glasses, Phys. Chem. Glasses 34(1993)227-231.

[99] M. Wendler, H. Krüner, G.H. Frischat, Gas bubbles in glass melts under microgravity. Part 3. A further helium diffusion experiment, Phys. Chem. Glasses 36(1995)109-113.

[100] J.C. Lapp, J.E. Shelby, Helium permeation, diffusion and solubility in sodium galliosilicate glasses, Phys. Chem. Glasses 38(1997)256259.

[101] T.W. Trull, M.D. Kurz, Isotopic fractionation accompanying helium diffusion in basaltic glasses, J. Molecular Struct. 485-486(1999)555567.

[102] M.G. Mesko, K. Newton, J.E. Shelby, Helium solubility in sodium silicate glasses and melts, Phys. Chem. Glasses 41(2000)111-116.

[103] M.G. Mesko, J.E. Shelby, Helium solubility in ternary soda-lime-silica glasses and melts, Phys. Chem. Glasses 43(2002)91-96.

[104] F. Chamssedine, T. Sauvage, S. Peuget, DiaDDHEM set-up: New IBA facility for studying the helium behavior in nuclear glasses, Nucl. Instrum. Meth. Phys. Res. B268(2010)1862-1866.

[105] F. Chamssedine, T. Sauvage, S. Peuget, T. Fares, G. Martin, Helium diffusion coefficient measurements in R7T7 nuclear glass by ${ }^{3}$ He(d, $\alpha)^{1} \mathrm{H}$ nuclear reaction analysis, J. Nucl. Mater. 400(2010)175-181.

[106] J.F. Shackelford, Gas solubility in glasses: Principles and applications, Int. J. Appl. Glass Sci. 2(2011)85-95.

[107] D.E. Swets, R.W. Lee, R.C. Frank, Diffusion coefficients of helium in fused quartz, The Journal of Chemical Physics 34(1961)17-22.

[108] K.A. Farley, P.W. Reiners, V. Nenow, An apparatus for high-precision helium diffusion measurements from minerals, Anal. Chem. 71(1999)2059-2061.

[109] R.A. Wolf, K.A. Farley, L.T. Silver, Helium diffusion and low-temperature thermochronometry of apatite, Geochimica et Cosmochimica Acta 60(1996)4231-4240.

[110] S. Ouchani, J.C. Dran, J. Chaumont, Exfoliation and diffusion following helium ion implantation in fluorapatite: implications for radiochronology and radioactive waste disposal, Appl. Geochem. 13(1998)707-714.

[111] W.L. Gong, L.M. Wang, R.C. Ewing, L.F. Chen, W. Lutze, Transmission electron microscopy study of a-decay damage in aeschynite and britholite, Mat. Res. Soc. Symp. Proc. 465(1997)649-656.

[112] M.A. House, K.A. Farley, B.P. Kohn, An empirical test of helium diffusion in apatite: Borehole data from the Otway basin, Australia, Earth Planet. Sci. Lett. 170(1999)463-474.

[113] K.A. Farley, Helium diffusion from apatite: General behavior as illustrated by Durango fluorapatite, J. Geophys. Res. 105 B2 (2000)29032914. 
[114] J-M. Costantini, P. Trocellier, J. Haussy, J-J. Grob, Nuclear reaction analysis of helium diffusion in britholite, Nucl. Instrum. Meth. Phys. Res. B195(2002)400-407.

[115] D. Gosset, P. Trocellier, Y. Serruys, Determination of the helium diffusion coefficient in nuclear waste storage ceramics by a nuclear reaction analysis method, J. Nucl. Mater. 303(2002)115-124.

[116] D.L. Schuster, K.A. Farley, J.M. Sisterson, D.S. Burnett, Quantifying the diffusion kinetics and spatial distribution of radiogenic ${ }^{4}$ He in minerals containing proton-induced ${ }^{3} \mathrm{He}$, Earth Planet. Sci. Lett. 217(2003)19-32.

[117] P. Trocellier, D. Gosset, D. Simeone, J-M. Costantini, X. Deschanels, D. Roudil, Y. Serruys, R.I. Grinszpan, S. Saudé, M. Beauvy, Application of nuclear reaction spectrometry for ${ }^{3} \mathrm{He}$ depth profiling in nuclear ceramics, Nucl. Instrum. Meth. Phys. Res. B206(2003)10771082.

[118] P. Trocellier, D. Gosset, D. Simeone, J-M. Costantini, X. Deschanels, D. Roudil, Y. Serruys, R.I. Grinszpan, S. Saudé, M. Beauvy, ${ }^{3}$ He thermal diffusion coefficient measurement in crystalline ceramics by $\mu$ NRA depth profiling, Nucl. Instrum. Meth. Phys. Res. B210(2003)507512 .

[119] D. Gosset, P. Trocellier, Determination of the helium thermal diffusion coefficient in britholite using a NRA method: New results, J. Nucl. Mater. 336(2005)140-144.

[120] S. Miro, F. Studer, J-M. Costantini, J. Haussy, Ph. Trouslard, J-J. Grob, Effect of composition on helium diffusion in fluorapatites investigated with nuclear reaction analysis, J. Nucl. Mater. 355(2006)1-9.

[121] D.J. Cherniak, E.B. Watson, J.B. Thomas, Diffusion of helium in zircon and apatite, Chem. Geol. 268(2009)155-166.

[122] D.L. Schuster, K.A. Farley, The influence of artificial radiation damage and thermal annealing on helium diffusion kinetics in apatite, Geochimica and Cosmochimica Acta 73(2009)183-196.

[123] M.C. van Soest, B.D. Monteleone, K.V. Hodges, J.W. Boyce, Laser depth profiling studies of helium diffusion in Durango apatite, Geochimica and Cosmochimica Acta 75(2011)2409-2419.

[124] S. Miro, J.M. Costantini, J. Haussy, D. Chateigner, E. Balanzat, Damage and helium migration induced in fluorapatite sinters by swift heavy ion irradiations, J. Nucl Mater. 423(2012)120-126.

[125] D.J. Cherniak, E.B. Watson, Helium diffusion in accessory minerals, Geochimica and Cosmochimica Acta 74(2010)Supplement A173.

[126] A Özgümüs, E. Gilabert, N. Dacheux, C. Tamain, B. Lavielle, Study of radiogenic helium diffusion in the $\square$-thorium phosphate diphosphate ceramic, J. Nucl. Mater. 373(2008)112-118.

[127] D. Roudil, X. Deschanels, P. Trocellier, F. Jommard, A. Boutry, C. Jégou, S. Peuget, D. Gosset, P. Nivet, Thermal diffusion of helium and volatile fission products in $\mathrm{UO}_{2}$ and zirconolite nuclear ceramics, Mat. Res. Soc. Symp. Proc. 824(2004)CC8.5.1-7.

[128] D. Roudil, X. Deschanels, P. Trocellier, C. Jégou, S. Peuget, J-M. Bart, Helium thermal diffusion in a uranium dioxide matrix, J. Nucl. Mater. 325(2004)148-158.

[129] C. Ronchi, J.P. Hiernaut, Helium diffusion in uranium and plutonium oxides, J. Nucl. Mater. 325(2004)1-12.

[130] S. Guilbert, T. Sauvage, P. Garcia, G. Carlot, M-F. Barthe, P. Desgardin, G. Blondiaux, C. Corbel, J-P. Piron, J-M. Gras, Helium migration in implanted $\mathrm{UO}_{2}$ sintered disks, J. Nucl. Mater. 327(2004)88-96.

[131] T. Sauvage, H. Erramli, S. Guilbert, L. Vincent, M-F. Barthe, P. Desgardin, G. Blondiaux, C. Corbel, J.P. Piron, F. Labohm, A. Van Veen, Profile measurements of helium implanted in $\mathrm{UO}_{2}$ sintered pellets by using the ${ }^{3} \mathrm{He}(\mathrm{d}, \square)^{1} \mathrm{H}$ nuclear reaction analysis technique, J. Nucl. Mater. 327(2004)159-164.

[132] G. Martin, P. Garcia, H. Labrim, T. Sauvage, G. Carlot, P. Desgardin, M-F. Barthe, J-P. Piron, A NRA study of temperature and heavy ion irradiation effects on helium migration in sintered uranium dioxide, J. Nucl. Mater. 357(2006)198-205.

[133] P. Garcia, G. Martin, P. Desgardin, G. Carlot, T. Sauvage, C. Sabathier, E. Castellier, H. Khodja, M-F. Barthe, A study of helium mobility in polycrystalline uranium dioxide, J. Nucl. Mater. 430(2012)156-165.

[134] D. Stöver, P.G. Fischer, H.D. Röhrig, Das freisetzungsverhalten von helium aus neutronenbestrahlten BeO-sinterkörpen, berylliumoxid als modellsubstanz zür untersuchung bestrahlungsindizierter diffusionsvorgänge, J. Nucl. Mater. 47(1973)317-322.

[135] C. Filleux, M. Morgeli, W. Stetller, P. Eberhardt, J. Geiss, Trapping of low-energy helium ions in polycrystalline Al and Pt and in BeO and anodic $\mathrm{Al}_{2} \mathrm{O}_{3}$ films at room temperature, Rad. Eff. 46(1980)1-6.

[136] R.A. Langley, R.S. Blewer, J. Roth, Behavior of implanted D and He in pyrolitic graphite, J. Nucl. Mater. 76 \& 77(1978)313-321.

[137] S. Zashu, H. Hiyagon, Degassing mechanisms of noble gases from carbonado diamonds, Geochimica et Cosmochimica Acta 59(1995)1321-1328.

[138] E.A.C. Neeft, R.P.C. Schram, A. van Veen, F. Labohm, A.V. Fedorov, Helium irradiation effects in single crystals of $\mathrm{MgAl}_{2} \mathrm{O}_{4}, \mathrm{Nucl}_{\text {. }}$ Instrum. Meth. Phys. Res. B 166-167(2000)238-243.

[139] A. van Veen, R.J.M. Konings, A.V. Fedorov, Helium in inert matrix dispersion fuels, J. Nucl. Mater 320 (2003) $77-84$. 
[140] D.L. Schuster, K.A. Farley, Diffusion kinetics of proton-induced ${ }^{21} \mathrm{Ne},{ }^{3} \mathrm{He}$ and ${ }^{4} \mathrm{He}$ in quartz, Geochimica and Cosmochimica Acta 69(2005)2349-2359.

[141] G Szakács, E. Szilágyi, F. Pászti, E. Kótai, Determination of migration of ion-implanted helium in silica by proton backscattering spectrometry, Nucl. Instrum. Meth. Phys. Res. B266(2008)1382-1385.

[142] E. Oliviero, A. Van Veen, A.V. Fedorov, M-F. Beaufort, J-F. Barbot, Helium implantation defects in SiC studied by thermal helium desorption spectrometry, Nucl. Instrum. Meth. Phys. Res. B186(2002)223-228.

[143] E. Oliviero, M-F. Beaufort, J-F. Barbot, A. Van Veen, A.V. Fedorov, Helium implantation defects in SiC: A thermal helium desorption spectrometry investigation, J. Appl. Phys. 83(2003)231-238.

[144] Y. Pramono, K. Sasaki, T. Yano, Release and diffusion rate of helium in neutron-irradiated SiC, J. Nucl. Sci. Technol. 41(2004)751-755.

[145] Y. Pramono, T. Yano, Helium release and diffusion mechanism in SiC containing B4C, J. Nucl. Mater. 329-333(2004)1170-1174.

[146] T. Sauvage, G. Carlot, G. Martin, L. Vincent, P. Garcia, M-F. Barthe, A. Gentils, P. Desgardin, Helium behavior in $\square-S i C$ ceramics investigated by NRA technique, Nucl. Instrum. Meth. Phys. Res. B257(2007)231-235.

[147] S. Miro, J-M. Costantini, J. Haussy, L. Beck, S. Vaubaillon, S. Pellegrino, C. Meis, J-J. Grob, Y. Zhang, W.J. Weber, Nuclear reaction analysis of helium migration in silicon carbide, J. Nucl. Mater. 415(2011)5-12.

[148] S.R. Hart, Helium diffusion in olivine, Earth and Planetary Science Letters 70(1984)297-302

[149] D.J. Cherniak, E.B. Watson, Diffusion of helium in olivine at 1 atm. and 2.7 GPa, Geochimica and Cosmochimica Acta 84(2012)269279 .

[150] P.W. Reiners, K.A. Farley, Helium diffusion and (U-Th)/He thermochronometry of titanite, Geochimica et Cosmochimica Acta 63(1999)3845-3859.

[151] D.J. Cherniak, E.B. Watson, Helium diffusion in rutile and titanite, and consideration of the origin and implications of diffusional anisotropy, Chem. Geol. 288(2011)149-161.

[152] J-M. Costantini, J-J. Grob, J. Haussy, P. Trocellier, Ph. Trouslard, Nuclear reaction analysis of helium migration in zirconia, J. Nucl. Mater. 321(2003)281-287.

[153] T.A.G. Wiss, J.P. Hiernaut, P.M.G. Damen, S. Lutique, R. Fromknecht, W.J. Weber, Helium behavior in waste conditioning matrices during thermal annealing, J. Nucl. Mater. 352(2006)202-208.

[154] G.W. Egeland, J.A. Valdez, S.A. Maloy, K.J. McClellan, K.E. Sickafus, G.M. Bond, Heavy-ion irradiation defect accumulation in ZrN characterized by TEM, GIXRD, nanoindentation, and helium desorption, J. Nucl. Mater. 435(2013)77-87.

[155] K. Roselieb, O. Dersch, H. Büttner, F. Rauch, Diffusivity and solubility of He in garnet: An exploratory study using nuclear reaction analysis, Nucl. Instrum. Meth. Phys. Res. B244(2006)412-418.

[156] M.A. Kovalenko, A. Ya. Kupryazkhin, V.V. Ivanov, Mass-spectrometric analysis of diffusion and solubility of helium in ceriumgadolinium ceramics with a submicrocrystalline structure, Technical Physics 55(2010)137-140.

[157] G.A. Cottrell, Void migration in fusion materials, J. Nucl. Mater. 302(2002)220-223.

[158] G.A. Cottrell, Void migration, coalescence and swelling in fusion materials, Fus. Engin. Design 66-68(2003)253-257.

[159] L. Yang, X.T. Zu, F. Gao, Ab initio study of formation, migration and binding properties of helium-vacancy clusters in aluminum, Physica B Condensed Matter 403(2008)2719-2724.

[160] J.H. Evans, Mechanisms of void coarsening in helium implanted silicon, Nucl. Instrum. Meth. Phys. Res. B 196(2002)125-134.

[161] De-Shun Long, Hui-Zhong Xu, Yan-Sen Wang, Guo-Qing Zhao, Shu-Ming Peng, Peng-Ji Zhao, Zhi-Lei Xu, Calculation of diffusion barriers for helium atom in metals, Acta Phys. Sin. 8(1999)746-753.

[162] T. Seletskaia, Yu.N. Osetsky, R.E. Stoller, G.M. Stocks, First-principles theory of the energetics of He defects in bcc transition metals, Phys. Rev. B 78(2008)134103.

[163] X. T. Zu, L. Yang, F. Gao, S. M. Peng, H. L. Heinisch, X. G. Long, R. J. Kurtz, Properties of helium defects in bcc and fcc metals investigated with density functional theory, Phys. Rev. B 80(2009)054104.

[164] Chao-Zhuo Liu, Zhu-Ying Zhou, Li-Qun Shi, Bao-Yi Wang, Xiao-Peng Hao, Guo-Qing Zhao, Annealing behaviour of helium bubbles in titanium films by thermal desorption spectroscopy and positron beam analysis, Chin. Phys. Lett. 24(2007)2357-2360.

[165] Min Chen, Qing Hou, Jun Wang, Tieying Sun, Xinggui Long, Shunzhong Luo, Anisotropic diffusion of He in titanium: A molecular dynamics study, Solid State Comm. 148(2008)178-181

[166] Min Chen, Qing Hou, Influence of defects on the coalescence of helium in titanium: An atomistic simulation, Acta Physica Sinica 59(2010)1185-1189. 
[167] Yong-Fang Lu, Li-Qun Shi, Wei Ding, Xing-Gui Long, First-principles study of hydrogen impact on the formation and migration of helium interstitial defects in hcp titanium, Chinese Physics letters 29(2012)013102.

[168] V.M. Chernov, V.A. Romanov, A.O. Krutskikh, Atomic mechanisms and energetic of thermally activated processes of helium redistribution in vanadium, J. Nucl. Mater. $271 \& 272(1999) 274-279$.

[169] Pengbo Zhang, Jijun Zhao, Ying Qin, Bin Wen, Stability and migration property of helium and self defects in vanadium and V-4Cr-4Ti alloy by first-principles, J. Nucl. Mater. 413(2011)90-94.

[170] K. Ono, K. Arakawa, K. Hojou, Formation and migration of helium bubbles in Fe and Fe-9Cr ferritic alloy, J. Nucl. Mater. 307311(2002)1507-1512.

[171] K. Morishita, R. Sugano, B.D. Wirth, T. Diaz de la Rubia, Thermal stability of helium-vacancy clusters in iron, Nucl. Instrum. Meth. Phys. Res. B202(2003)76-81.

[172] K. Morishita, R. Sugano, B.D. Wirth, MD and KMC modeling of growth and shrinkage mechanisms of helium-vacancy clusters in Fe, J. Nucl. Mater. 323(2003)243-250.

[173] C.C. Fu, F. Willaime, Ab initio study of helium in alpha-Fe: Dissolution, migration, and clustering with vacancies, Phys. Rev. B 72(2005)064117.

[174] T. Seletskaia, Yu.N. Osetsky, R.E. Stoller, G.M. Stocks, Calculation of helium defect clustering properties in iron using a multi-scale approach, J. Nucl. Mater. 351(2006)109-118.

[175] L. Yang, X.T. Zu, H.Y. Xiao, F. Gao, H.L. Heinisch, R.J. Kurtz, K.Z. Liu, Atomistic simulation of helium-defect interaction in alphairon, Appl. Phys. Lett. 88(2006)091915.

[176] L. Ventelon, B.D. Wirth, C. Domain, Helium-self-interstitial atom interaction in alpha-iron, J. Nucl. Mater. 351(2006)119-132.

[177] F. Gao, H.L. Heinisch, R.J. Kurtz, Diffusion of He interstitials in grain boundaries in $\alpha$-Fe, J. Nucl. Mater. 351(2006)133-140.

[178] H.L. Heinisch, F. Gao, R.J. Kurtz, E.A. Le, Interaction of helium atoms with edge dislocations in alpha-Fe, J. Nucl. Mater. 351(2006)141148.

[179] K. Morishita, R. Sugano, Modeling of He-bubble migration in bcc Fe, Nucl. Instrum. Meth. Phys. Res. B 255(2007)52-56.

[180] C. S. Deo, M. A. Okuniewski, S.G. Srivilliputhur, S.A. Maloy, M.I. Baskes, M.R. James, J.F. Stubbins, Helium bubble nucleation in bcc iron studied by kinetic Monte Carlo simulations, J. Nucl. Mater. 361(2007)141-148.

[181] M.J. Caturla, C.J. Ortiz, Effect of self-interstitial cluster migration on helium diffusion in iron, J. Nucl. Mater. 362(2007)141-145.

[182] V.A. Borodin, P.V. Vladimirov, Diffusion coefficients and thermal stability of small helium-vacancy clusters in iron, J. Nucl. Mater. 362(2007)161-166.

[183] H.L. Heinisch, F. Gao, R.J. Kurtz, Atomistic modeling of helium interacting with screw dislocations in alpha-Fe, J. Nucl. Mater. $367(2007) 311-315$

[184] J.H. Shim, S.C. Kwon, W.W. Kim, B.D. Wirth, Atomistic modeling of the interaction between self-interstitial dislocation loops and He in bcc Fe, J. Nucl. Mater. 367(2007)292-297.

[185] C.C. Fu, F. Willaime, First principles calculations in iron: structure and mobility of defect clusters and defect complexes for kinetic modeling, CR Phys. 9(2008)335-342.

[186] M.J. Caturla, C. Ortiz, Chu-Chun Fu, Helium and point defect accumulation: (ii) Kinetic modeling, CR Phys. 9(2008)401-408.

[187] D. Terentyev, N. Juslin, K. Nordlund, N. Sandberg, Fast three dimensional migration of He-clusters in bcc Fe and Fe-Cr alloys, J. Appl. Phys. 105(2009)103509.

[188] Donghua Xu, B. D. Wirth, Spatially dependent rate theory modeling of thermal desorption spectrometry of helium-implanted iron, Fusion Sci. Technol. 56(2009)1054-1068.

[189] D. Terentyev, X. He, Dimensionality of interstitial He migration in $<110>$ tilt grain boundaries in alpha-Fe, Computational Mater. Sci. 49(2010)858-864.

[190] Donghua Xu, B. D. Wirth, Modeling spatially dependent kinetics of helium desorption in bcc iron following He ion implantation, J. Nucl. Mater. 403(2010)184-190.

[191] W. Hao, W.T. Geng, Impeding effect of Ce on He bubble growth in bcc Fe, Nucl. Instrum. Meth. Phys. Res. B 280 (2012) $22-25$.

[192] Lei Zhang, Chu-Chun Fu, Guang-Hong Lu, Energetic landscape and diffusion of He in $\square$-Fe grain boundaries from first principles, Phys. Rev. B 87(2013)134107.

[193] X. He, D. Terentyev, Y. Lin, W. Yang, Interstitial helium diffusion mechanisms in < $110>$ tilt grain boundaries in bcc FeCr alloys: A atomistic study, J. Nucl. Mater. (2013), http://dx.doi.org/10.1016/j.jnucmat.2012.12.040. 
[194] A. Ryazanov.,, D. Braski, H. Schroeder, H. Trinkaus, H. Ullmaier, Modeling the effect of creep on the growth of helium bubbles in metals during annealing, J. Nucl. Mater. 233-237(1996)1076-1079.

[195] K. Ono, K. Arakawa, M. Oohashi, H. Kurata, K. Hojou, N. Yoshida, Formation and migration of helium bubbles in Fe-16Cr-17Ni austenitic alloy at high temperature, J. Nucl. Mater. 283(2000)210-214.

[196] C.H. Zhang, K.Q. Chen, Z.Y. Zhu, Diffusion and agglomeration of helium in stainless steel in the temperature range from RT to $600^{\circ}$ C, Nucl. Instrum. Meth. Phys. Res. B169(2000)64-71.

[197] S.I. Golubov, R.E. Stoller, S.J. Zinkle, A.M. Ovcharenko, Kinetics of coarsening of helium bubbles during implantation and postimplantation annealing, J. Nucl. Mater. 361(2007)149-159.

[198] R.J. Kurtz, H.L. Heinisch, F. Gao, Modeling of He-defect interactions in ferritic alloys for fusion, J. Nucl. Mater. 382(2008)134-142.

[199] E. Martinez, Chu-Chun Fu, Cr interactions with He and vacancies in dilute Fe-Cr alloys from first principles, Phys. Rev. B 84(2011)014203.

[200] J.B. Adams, W.G. Wolfer, On the diffusion mechanisms of helium in nickel, J. Nucl. Mater. 158(1988)25-29.

[201] V.N. Chernikov, H. Trinkaus, H. Ullmaier, Helium bubbles in nickel annealed at T > 0.7Tm, J. Nucl. Mater. 250(1997)103-110.

[202] J.H. Evans, Breakaway bubble growth during the annealing of helium bubbles in metals, J. Nucl. Mater. 334(2004)40-46.

[203] J.H. Evans, R. Escobar Galindo, A. van Veen, A description of bubble growth and gas release during thermal annealing of helium implanted copper, Nucl. Instrum. Meth. Phys. Res. B 217(2004)276-280.

[204] Yu-Wei You, Xiang-Shan Kong, Xue-Bang Wu, Q.F. Fang, Jun-Ling Chen, G.-N. Luo, C.S. Liu, Effect of vacancy on the dissolution and diffusion properties of hydrogen and helium in molybdenum, J. Nucl. Mater. 433(2013)167-173.

[205] Jixing Xia, Wangyu Hu, Jianyu Yang, Bingyun Ao, Xiaolin Wang, A comparative study of helium atom diffusion via an interstitial mechanism in nickel and palladium, Phys. Status Solidi B243(2006)579-583.

[206] C.S. Becquart, C. Domain, Migration energy of He in W revisited by ab initio calculations, Phys. Rev. Lett. 97(2006)196402.

[207] L. Yang, H.K. Liu, X.T. Zu, First-principles study of the migration of helium in tungsten, International J. Modern Phys. B 23(2009)20772082.

[208] C.S. Becquart, C. Domain, An object Kinetic Monte Carlo simulation of the dynamics of helium and point defects in tungsten, J. Nucl. Mater. 385 (2009) 223-227.

[209] C.S. Becquart, M.F. Barthe, A. de Backer, Modelling radiation damage and He production in tungsten, Phys. Scripta T145(2011)014048.

[210] J. Wang, Y.L. Zhou, M. Li, Q. Hou, Atomistic simulations of helium behavior in tungsten crystals, J. Nucl. Mater. 427(2012)290-296.

[211] S.E. Donnelly, R.C. Birtcher, C. Templier, V. Vishnyakov, Response of helium bubbles in gold to displacement-cascade damage, Phys. Rev. B 52(1995)3970-3976.

[212] V. Dremov, P. Sapozhnikov, A. Kutepov, V. Anisimov, M. Korotin, A Shorikov, D.L. Preston, M.A. Zocher, Atomistic simulations of helium dynamics in a plutonium lattice, Phys. Rev. B 77(2008)224306.

[213] M.J. Murphy, G.A. Voth, A.L.R. Bug, Classical and quantum transition state theory for the diffusion of helium in silica sodalite, J. Phys. Chem. B 101(1997)491-503.

[214] T. Ono, T. Kawamura, T. Kenmotsu, Y. Yamamura, Simulation study on retention and reflection from tungsten carbide under high fluence of helium ions, J. Nucl. Mater. 290-293(2001)140-143.

[215] R.M. Van Ginhoven, A. Chartier, C. Meis, W.J. Weber, L.R. Corralès, Theoretical study of helium insertion and diffusion in 3C-SiC, J. Nucl. Mater. 348(2006)51-59.

[216] A. Chartier, L. Van Brutzel, Modeling of point defects and rare gas incorporation in uranium mono-carbide, Nucl. Instrum. Meth. Phys. Res. B 255(2007)146-150.

[217] M. Reich, R.C. Ewing, T.A. Ehlers, U. Becker, Low-temperature anisotropic diffusion of helium in zircon: Implications for zircon (UTh)/He thermochronometry, Geochimica et Cosmochimica Acta 71(2007)3119-3130.

[218] S. Leclerc, M. F. Beaufort, A. Declémy, J. F. Barbot, Evolution of defects upon annealing in He-implanted 4H-SiC, Appl. Phys. Lett. 93(2008)122101.

[219] R.R. Wixom, J.F. Browning, C.S. Snow, P.A.Schultz, D.R. Jennison, First principles site occupation and migration of hydrogen, helium, and oxygen in beta-phase erbium hydride, J. Appl. Phys. 103(2008)123708.

[220] Younsuk Yun, O. Eriksson, P. M. Oppeneer, Hanchul Kim, Kwangheon Park, First-principles theory for helium and xenon diffusion in uranium dioxide, J. Nucl. Mater. 385(2009)364-367.

[221] I. Saadoune, N.H. de Leeuw, A computer simulation study of the accomodation and diffusion of He in uranium- and plutonium-doped zircon $\left(\mathrm{ZrSiO}_{4}\right)$, Geochimica et Cosmochimica Acta 73(2009)3880-3893. 
[222] P. Erhardt, A first-principles study of helium storage in oxides and at oxide-iron interfaces, J. Appl. Phys. 111(2012)113502.

[223] Jingren Xiao, Chenxu Wang, Tengfei Yang, Shuyan Kong, Jianming Xue, Yugang Wang, Theoretical investigation on helium incorporation in Ti3AlC2, Nucl. Instrum. Meth. Phys. Res. B 304(2013)27-31.

[224] A.I. Ryazanov, K. Yasuda, C. Kinoshita, A.V. Klaptsov, Growth and instability of charged dislocation loops under irradiation in ceramic materials, J. Nucl. Mater. 307-311(2002)918-923.

[225] A.I. Ryazanov, A.V. Klaptsov,K. Yasuda, C. Kinoshita, Determination of effective charge states for point radiation defects in fusion ceramic materials, J. Nucl. Mater. 329-333(2004)97-102.

[226] P.P. Pronko, J.G. Pronko, Depth profiling of ${ }^{3} \mathrm{He}$ and ${ }^{2} \mathrm{H}$ in solids using the ${ }^{3} \mathrm{He}(\mathrm{d}, \mathrm{p}){ }^{4} \mathrm{He}$ resonance, Phys. Rev. B 9(1974)2870-2878.

[227] R.A. Langley, S.T. Picraux, F.L. Vook, Depth distribution of deuterium and ${ }^{3}$ He, J. Nucl. Mater. 53(1974)257-261.

[228] R.S. Blewer, Some practical aspects of depth profiling gases in metals by proton backscattering: Application to helium and hydrogen isotopes, in Ion Beam Surface Layer Analysis, volume 1, edited by O. Meyer, G. Linker and F. Käppeler, Plenum Press, New York, 1975, pp. 185-199.

[229] R.A. Langley, Depth profiling of deuterium and helium in metals by elastic proton scattering: A measurement of the enhancement of the elastic scattering cross section over Rutherford scattering cross section, in Ion Beam Surface Layer Analysis, volume 1, edited by O. Meyer, G. Linker and F. Käppeler, Plenum Press, New York, 1975, pp. 201-210.

[230] M. Hufschmidt, V. Heintze, W. Möller, D. Kamke, The density profile of implanted ${ }^{3} \mathrm{He}$ measured by means of the ${ }^{3} \mathrm{He}(\mathrm{d}, \mathrm{p}){ }^{4} \mathrm{He}$ nuclear reaction, Nucl. Instrum. Meth. 124(1975)573-577.

[231] W. Möller, M. Hufschmidt, D. Kamke, Large depth profile measurements of D, ${ }^{3} \mathrm{He}$, and ${ }^{6} \mathrm{Li}$ by deuteron induced nuclear reactions, Nucl. Instrum. Meth. 140(1977)157-165.

[232] E.V. Kornelsen, A.A. Van Gorkum, Quantitative thermal-desorption spectrometry of ionically implanted inert-gases. 2. Technical requirements, Vacuum 31(1981)99-111.

[233] A.A. Van Gorkum, E.V. Kornelsen, Quantitative thermal-desorption spectrometry of ionically implanted inert-gases. 1. Fundamental aspects, Vacuum 31(1981)89-98.

[234] M.B. Lewis, A deconvolution technique for depth profiling with nuclear microanalysis, Nucl. Instrum. Meth. 190(1981)605-611.

[235] S. Grigull, R. Behrisch, U. Kreissig, M. Harz, Simultaneous analysis of low-Z impurities in the near-surface region of solid materials by heavy ion elastic recoil detection (HIERD), Fresenius J. Anal. Chem. 353(1995)578-581.

[236] G. Dollinger, M. Boulouednine, A. Bergmaier, T. Faestermann, C.M. Frey, Limits in elastic recoil detection analysis with heavy ions, Nucl. Instrum. Meth. Phys. Res. B118(1996)291-300.

[237] J. Tirira, Y. Serruys, P. Trocellier, Forward Recoil Spectrometry, Plenum Publishing Corporation, New York, 1996.

[238] D. Hilscher, C.-M. Herbach, U. Jahnke, V. Tishchenko, M. Enke, D. Filges, F. Goldenbaum, R.-D. Neef, K. Nünighoff, N. Paulk, H. Schaal, G. Sterzenbach, A. Letourneau, A. Böhm, J. Galin, B. Lott, A. Péghaire, L. Pienkowski, Helium production for $0.8-2.5 \mathrm{GeV}$ proton induced spallation reactions, damage induced in metallic windows, J. Nucl. Mater. 296(2001)83-89.

[239] D. Pantelica, L. Thomé, S.E. Enescu, F. Negoita, P. Ionescu, I. Stefan, A. Gentils, Ion-beam characterization of He implanted into nuclear matrices, Nucl. Instrum. Meth. Phys. Res. B 219-220 (2004) 373-378.

[240] A. Kimura, R. Sugano, Y. Matsushita, S. Ukai, Thermal helium desorption behavior in advanced ferritic steels, J. Phys. Chem. Solids 66(2005)504-508.

[241] D. Pantelica, A. Isbasescu, F. Negoita, H. Petrascu, M. Petrascu, P. Ionescu, N. Scintee, Identification of hydrogen and helium in elastic recoil detection measurements using a compact $\left(\square \mathrm{E}\right.$ - $\mathrm{E}_{\mathrm{r}}$ ) ionization chamber, Nucl. Instrum. Meth. Phys. Res. B149(2006)504-508.

[242] E. Markina, M. Mayer and H. T. Lee, Measurement of He and H depth profiles in tungsten using ERDA with medium heavy ion beams, Nucl. Instrum Meth. Phys. Res. B269(2011)3094-3097.

[243] J. F. Ziegler, SRIM-2013, http://www.srim.org.

[244] C.J. McHargue, Ion beam modification of ceramics, Mater. Sci. Engin. A253(1998)94-105.

[245] S.J. Zinkle, V.A. Skuratov, D.T. Hoelzer, On the conflicting roles of ionizing radiation in ceramics, Nucl. Instrum. Meth. Phys. Res. B 191 (2002) 758-766.

[246] A. Chroneos, M.J.D. Rushton, R.W. Grimes, Fundamental point defects properties in ceramics, Chapter 1.02 in Comprehensive Nuclear Materials, edited by R.J.M. Konings, 2012, Elsevier, pp. 47-64..

[247] Y. Dai, G.R. Odette, T. Yamamoto, The effects of helium in irradiated structural alloys, Chapter 1.06 in Comprehensive Nuclear Materials, edited by R.J.M. Konings, 2012, Elsevier, pp. 141-193.

[248] I. Charit, K.L. Murty, Structural materials issues for the next generation fission reactors, JOM 62(2010)67-74. 
[249] K.L. Murty, Materials for next-generation nuclear plants: Objectives and challenges, JOM 62(2010)60-61.

[250] B. Raj, M. Vijalayakshmi, Ferritic steels for sodium-cooled fast reactors: Design principles and challenges, JOM 62(2010)75-83.

[251] G.R. Odette, D.T. Hoelzer, Irradiation tolerant nanostructured ferritic alloys : transforming helium from a liability to an assess, JOM 62(2010)84-92.

[252] B.D. Wirth, K. Nordlund, D.G. Whyte, D. Xu, Fusion materials modeling: Challenges and opportunities, MRS Bulletin 36(2011)216222.

[253] S.J. Zinkle, G.S. Was, Materials challenges in nuclear energy, Acta Materialia, 61(2013)735-758.

[254 - 263] New Trends

[254] N. Hashimoto, J.D. Hunn, N. Parikh, S. Gilliam, S. Gidcumb, B. Patnaik, L.L. Snead, Microstructural analysis on helium retention of ion-irradiated and annealed tungsten foils, J. Nucl. Mater. 347(2005)307-313.

[255] T. Taguchi, N. Igawa, S. Jitsukawa, K. Shimura, Effect of implanted helium on thermal diffusivities of SiC/SiC composites, Nucl. Instrum. Meth. Phys. Res. B 242(2006)469-472.

[256] H.T. Keng, S.W. Li, S.W. Wu, Ji-Jung Kai, Fu-Rong Chen, Y. Katoh, A. Kohyama, Cavity formation in Tyranno-SA SiCf/SiC composite irradiated with multiple-ion beam at elevated temperatures, J. Nucl. Mater. 367-370(2007)753-757.

[257] P.E. Lhuillier, M-F. Barthe, P. Desgardin, W. Egger, P. Sperr, Positron annihilation studies on the nature and thermal behavior of irradiation induced defects in tungsten, Physica Status Solidi C 6(2009)2329-2332.

[258] Y. Yamauchi, K. Gotoh, Y. Nobuta, T. Hino, S. Suzuki, M. Akiba, Deuterium retention and desorption behavior of reduced activated ferritic steel with surface damage due to high energy helium ion irradiation, Fusin Engin. Design 85(2010)1838-1870.

[259] X. Xiang, C.A. Chen, K.Z. Liua, L.X. Peng, Y.C. Rao, Effect of Fe and C doping on the thermal release of helium from aluminum, Fusion Engineering Design 85(2010)2086-2089.

[260] H.T. Lee, H. Tanaka, Y. Ohtsuka, Y. Ueda, Ion-driven permeation of deuterium through tungsten under simultaneous helium and deuterium irradiation, J. Nucl. Mater. 415(2011)S696-S700.

[261] Liu Yuan-Dong, Yin Yi-Hui, Tan Yun, Research on tritium and helium-3 content distributions in steel wall of spherical pressure vessel under general boundary condition, Acta Physica Sinica 61(2012)156601

[262] P. Petersson, M. Rubel, G. Possnert, S. Brezinsek, B. Pegourie, Nuclear reaction and heavy ion ERD analysis of wall materials from controlled fusion devices: Deuterium and nitrogen-15 studies, Nucl. Instrum. Meth. Phys. Res. B 273(2012)113-117.

[263] H. Lefaix-Jeuland, S. Moll, T. Jourdan, F. Legendre, Effect of grain microstructure on thermal helium desorption from pure iron, J. Nucl. Mater. 434 (2013) 152-157.

[264] E. Bernard, H. Khodja, J. Chêne, B. Pégourié, C. Martin, C. Pardanaud, Simultaneous deuterium implantation and ion beam microanalyses in CFC NB31: Understanding the in-bulk migration, J. Nucl. Mater. 438(2013)S975-S978. 


\section{Chapter 2}

\section{State of Knowledge}

\section{Part 2}

\subsection{Radiation damage and gas diffusion in $\mathrm{ZrC}$, $\mathrm{TiC}$, and $\mathrm{TiN}$}

In this chapter, a literature review on $\mathrm{TiC}, \mathrm{ZrC}$ and $\mathrm{TiN}$ is presented. We did not find many papers on the behavior of helium in these ceramics under extreme thermal or radiation environment. However, there are few papers available on the microstructure evolution of these ceramics after irradiation which helps us in comparing the microstructure changes solely after irradiation with the microstructure changes on irradiation and helium implantation together. This literature survey also includes the behavior of other gas atoms like xenon, in these materials. This part of the chapter is divided into three sections devoted to each material, respectively. All the text written in each section of this chapter has also been summarized into their respective table. While reading this chapter, one can only refer to the tables for a quick overview.

\subsection{1. $\mathrm{ZrC}$}

Data on the effect of irradiation on thermal, physical, and mechanical properties of $\mathrm{ZrC}$ is extremely limited in the literature. Also, all the available data cannot be compared to present a general conclusion. This is due to the variation in irradiation response caused by different $\mathrm{C} / \mathrm{Zr}$ ratio present in materials having different stoichiometric ratio. The variation of multiple properties with different $\mathrm{C} / \mathrm{Zr}$ ratio are detailed in next chapter. However, due to the presence of many stable stoichiometric variants of $\mathrm{ZrC}$, this section of the chapter features some common conclusions. In each sub-section of the chapter, work from available literature has been arranged in inverse chronological order.

One of the main irradiation effects on the $\mathrm{ZrC}$ includes: 


\section{Changes in density and lattice parameter (or swelling)}

- Recently, Snead et al. [1] reported the effects of fast neutron irradiation on the properties of high purity zone-refined $\mathrm{ZrC}_{0.87}$. The samples were irradiated at a high flux $\sim 1-10 \times 10^{25} \mathrm{n} / \mathrm{m}^{2}$ $(\mathrm{E}>0.1 \mathrm{MeV})$ in the irradiation temperature range of $\sim 910-1750 \mathrm{~K}$. The changes in lattice parameter determined by X-ray diffraction were within the measurement error and the corresponding macroscopic swelling due to lattice expansion was reportedly less than $0.1 \%$ [1].

- Gosset et al. [2] reported the microstructural evolution in hot pressed $\mathrm{ZrC}$ subject to $4 \mathrm{MeV}$ $\mathrm{Au}$ ion irradiation. The ion fluence was between $10^{11}$ and $5 \times 10^{15} / \mathrm{cm}^{2}$ with the irradiation temperature $300 \mathrm{~K}$. Swelling saturation $(0.6 \%)$ was observed at fluence close to $\sim 10^{14} / \mathrm{cm}^{2}$.

- One of the earliest reports of irradiation effect on the physical characteristics of $\mathrm{ZrC}_{0.98}$ was documented by Andrievskii et al. [3]. Carbides of $\mathrm{Nb}$ and $\mathrm{Zr}$ were irradiated to a fast neutron fluence of $1.5 \times 10^{20} \mathrm{n} / \mathrm{cm}^{2}$ at $\sim 425$ and $\sim 1780 \mathrm{~K}$. A decrease in the density with increasing irradiation temperature was recorded. A small change in the lattice parameter was also reported.

- Early works on the effects of neutron irradiation on $\mathrm{ZrC}$ and other transition metal monocarbides were reported by Keilholtz et al. [4], Keilholtz and Moore [5], and Dyslin et al. [6]. Anisotropic swelling of the materials was reported in all the studies. The magnitudes of volumetric saturation swelling of various $\mathrm{ZrC}\left(\mathrm{ZrC}_{1.08-1.27}\right)$ materials during irradiation were reported by Keilholtz [4] to be $\sim 2 \%$ to $\sim 3.5 \%$ at $403-628 \mathrm{~K}$, and $\sim 1 \%$ at $1273-$ $1373 \mathrm{~K}$, as shown in fig. 2.8. Keilholtz et al. [4] also reported the absence of grain boundary separation in $\mathrm{ZrC}$ samples irradiated at temperatures between 570 and $970 \mathrm{~K}$ to fluence between 0.8 and $5.4 \times 10^{21} \mathrm{n} / \mathrm{cm}^{2}$.

Reviewing the available literature, similar to $\mathrm{SiC}, \mathrm{ZrC}$ undergoes temperature dependent lattice swelling at low to intermediate temperatures but exhibits only minor swelling at higher temperatures. The swelling behavior reportedly was similar to the low temperature transient swelling of silicon carbide [7], saturating at doses as low as <1 dpa. 


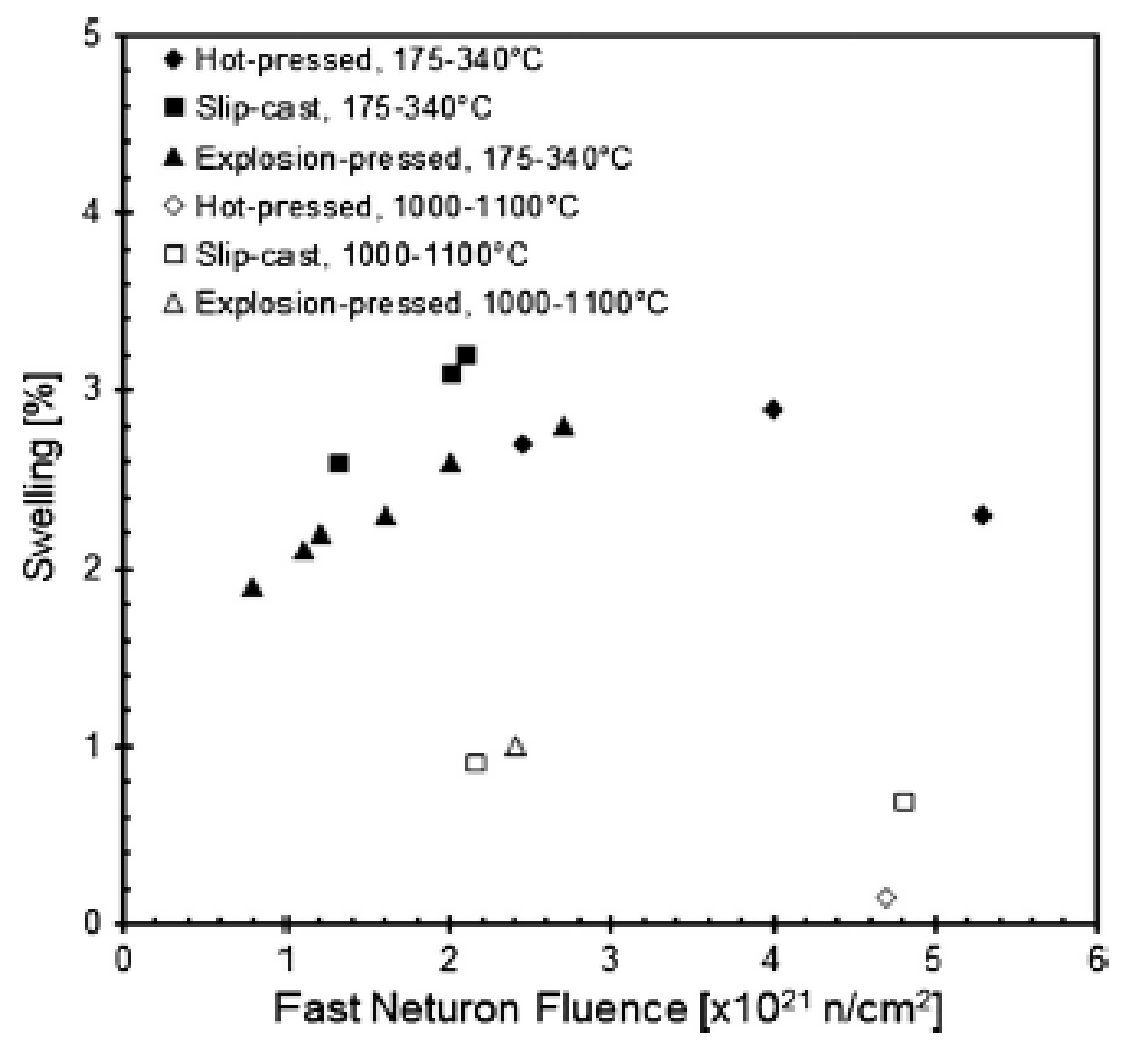

Figure 2.8. Swelling behavior of zirconium carbide during neutron radiation as reported by Keilholtz [4].

\section{Microstructural changes with the formation of dislocation loops}

- Snead et al. [1] recently reported the effects of fast neutron irradiation to the range $\sim 1-10 \mathrm{x}$ $10^{25} \mathrm{n} / \mathrm{m}^{2}(\mathrm{E}>0.1 \mathrm{MeV})$ in the irradiation temperature range of $\sim 910-1750 \mathrm{~K}$. At irradiation temperatures $\sim 910 \mathrm{~K}$ and fast fluence $4 \times 10^{25} \mathrm{n} / \mathrm{cm}^{2}$, small unidentified dislocation loops aligned in a raft-like structure were reported. As the temperature increased to $\sim 1295 \mathrm{~K}$, formation of larger Frank faulted loops was reported. Microstructure of the samples irradiated at $\sim 1530 \mathrm{~K}$ contained both distinct Frank loops and other unidentifiable dislocation loops. As the irradiation temperature increased, a transition from Frank loops to prismatic loops was reported. 
- Gosset et al. [2] reported the microstructural evolution for $4 \mathrm{MeV} \mathrm{Au}$ ion fluence between $10^{11}$ and $5 \times 10^{15} / \mathrm{cm}^{2}$ with the irradiation temperature $300 \mathrm{~K}$. They reported that in the intermediate fluence range $\left(<10^{14} / \mathrm{cm}^{2}\right)$, formation of high density dislocation loops was reported. With fluence $>10^{15} / \mathrm{cm}^{2}$, the growth of these loops led to the formation of a high density dislocation network via loop interactions. Further interactions of this dislocation network with defects were cited as the reason for swelling saturation beyond $10^{14} / \mathrm{cm}^{2}$.

- Yang et al. [8] reported the effect of proton irradiation (2.6 MeV) on the microstructure of $\mathrm{ZrC}_{1.01}$ irradiated to fluence of 0.7 and $1.5 \mathrm{dpa}$ at $\sim 1100 \mathrm{~K}$. Microstructural observations indicated the formation of high density nano-sized dislocation loops with densities increasing with irradiation dose. No irradiation induced voids were reported. Yang also reported a change in the lattice parameter with irradiation dose $(0.09$ and $0.11 \%$ for 0.7 and 1.5 dpa respectively) which was in good agreement with earlier reported data.

- Gan [9] reported the observation of the microstructure of hot-pressed $\mathrm{ZrC}_{1.01}(\sim 100 \%$ theoretical density) irradiated by $2.6 \mathrm{MeV}$ protons up to a fluence of $2.75 \times 10^{19} \mathrm{~cm}^{-2}$ corresponding to $0.71-1.8 \mathrm{dpa}$. The irradiation temperature was $1070 \mathrm{~K}$. TEM observation revealed small size, high density dislocation loops which had not been observed in $\mathrm{ZrC}$ irradiated with $\mathrm{Kr}$ ions in their previous work [10]. However, no voids were observed, that is consistent with the observations recorded for $\mathrm{Kr}$ irradiation experiments. This void suppression was attributed to the strong covalent bonding inherent to $\mathrm{ZrC}$.

All the above work on lattice swelling and microstructural changes has been summarized in table 2.3a. We have already mentioned that we cannot directly compare this work because all the work has been performed on $\mathrm{ZrC}$ having different stoichiometric ratio.

\begin{tabular}{|l|l|c|c|c|c|l|}
\hline Material & Particle & Energy & $\begin{array}{c}\text { Dpa (or Fluence) } \\
\text { \& T (K) during } \\
\text { irradiation }\end{array}$ & $\begin{array}{c}\text { Swelling } \\
\text { Measured }\end{array}$ & Microstructural Changes & Ref \\
\hline
\end{tabular}




\begin{tabular}{|c|c|c|c|c|c|c|}
\hline $\mathrm{ZrC}_{0.87}$ & neutron & $\begin{array}{c}\mathrm{E}>0.1 \\
\mathrm{MeV}\end{array}$ & $\begin{array}{c}1-10 \times 10^{25} \mathrm{n} / \mathrm{m}^{2} \\
\sim 910-1750 \mathrm{~K}\end{array}$ & $<0.1 \%$ & $\begin{array}{l}\text { At } 4 \times 10^{25} \mathrm{n} / \mathrm{cm}^{2} \text { with irradiation } \\
\text { temperature: } \\
\sim 910 \mathrm{~K}: \text { small unidentified } \\
\text { dislocation loops } \\
\sim 1295 \mathrm{~K} \text { : formation of larger Frank } \\
\text { faulted loops } \\
\sim 1530 \mathrm{~K} \text { : contained both distinct } \\
\text { Frank loops and other unidentifiable } \\
\text { dislocation loops }\end{array}$ & {$[1]$} \\
\hline $\mathrm{ZrC}_{0.95}$ & Au ion & $4 \mathrm{MeV}$ & $\begin{array}{c}10^{11}-5.10^{15} / \mathrm{cm}^{2} \\
\sim 300 \mathrm{~K}\end{array}$ & $\begin{array}{l}\text { Swelling } \\
\text { saturation at } \\
0.6 \% \text { close to } \\
10^{14} / \mathrm{cm}^{2}\end{array}$ & $\begin{array}{l}\text { At fluence }<10^{14} / \mathrm{cm}^{2} \text { : formation of } \\
\text { high density dislocation loops was } \\
\text { reported. } \\
\text { At fluence }>10^{15} / \mathrm{cm}^{2} \text { : formation of } \\
\text { a high density dislocation network } \\
\text { via loop interactions was reperted. }\end{array}$ & [2] \\
\hline $\mathrm{ZrC}_{0.98}$ & neutron & $\begin{array}{c}\mathrm{E}>0.1 \\
\mathrm{MeV}\end{array}$ & $\begin{array}{l}1.5 \times 10^{20} \mathrm{n} / \mathrm{cm}^{2} \\
\sim 425 \& \sim 1780 \mathrm{~K}\end{array}$ & $\begin{array}{l}\text {-small change in } \\
\text { lattice parameter } \\
\text {-decrease in the } \\
\text { density }\end{array}$ & Not known & [3] \\
\hline $\mathrm{ZrC}_{1.08-1.27}$ & neutron & $\begin{array}{c}\mathrm{E}>0.1 \\
\mathrm{MeV}\end{array}$ & See figure 2.7 & $\begin{array}{l}\sim 2 \%-3.5 \% \\
\text { at } 403-628 \mathrm{~K} \\
\sim 1 \% \\
\text { at } 1273-1373 \mathrm{~K}\end{array}$ & Not known & {$[4]$} \\
\hline $\mathrm{ZrC}_{1.01}$ & proton & $\begin{array}{c}\mathrm{E}=2.6 \\
\mathrm{MeV}\end{array}$ & $\begin{array}{c}0.7-1.5 \mathrm{dpa} \text { at } \\
\sim 1100 \mathrm{~K}\end{array}$ & $\begin{array}{l}\sim 0.09 \% \text { at } 0.7 \\
\text { dpa. } \\
\sim 0.11 \% \text { at } 1.5 \\
\text { dpa. }\end{array}$ & $\begin{array}{l}\text { Formation of high density nano- } \\
\text { sized dislocation loops with } \\
\text { densities increasing with irradiation } \\
\text { dose. }\end{array}$ & {$[8]$} \\
\hline $\mathrm{ZrC}_{1.01}$ & proton & $\begin{array}{c}\mathrm{E}=2.6 \\
\mathrm{MeV}\end{array}$ & $\begin{array}{c}0.71-1.8 \mathrm{dpa} \text { at } \\
\sim 1070 \mathrm{~K}\end{array}$ & Not known & $\begin{array}{l}\text { TEM observation revealed small } \\
\text { size, high density dislocation loops. }\end{array}$ & [9] \\
\hline
\end{tabular}

Table 2.3a. Summary of the work on lattice swelling and microstructural changes on ZrC after irradiation.

\section{Absence of irradiation induced amorphization in $\mathrm{ZrC}$}

- Recently, Pellegrino et al. [11] reported that the accumulation of defects created by nuclear collisions induced by $\mathrm{MeV} \mathrm{Au}$ ion bombardment leads to amorphization of $\mathrm{SiC}$ at the lowest 
Au fluence used $\left(2.8 \times 10^{14} \mathrm{~cm}^{-2}\right)$, whereas $\mathrm{TiC}$ and $\mathrm{ZrC}$ do not amorphize at the highest $\mathrm{Au}$ fluence used $\left(3.3 \times 10^{15} \mathrm{~cm}^{-2}\right)$.

\section{Irradiation effects on the mechanical properties of $\mathrm{ZrC}$}

Irradiation is known to often cause significant hardening of materials due to, for example, accumulation of matrix defect clusters.

- Snead et al. [1] reported the measurement of room temperature hardness and Young's modulus as determined by the nano-indentation technique and indentation toughness by microVickers indentation for zone-refined $\mathrm{ZrC}_{0.87}$. The room temperature hardness appears to be insensitive to irradiation temperature within the $873-1773 \mathrm{~K}$ for $1-10 \times 10^{25} \mathrm{n} / \mathrm{m}^{2}$ fluence range.

- Yang et al. [8] reported an increase in the micro-hardness ( 15\% at $1.5 \mathrm{dpa})$ and fracture toughness (> 50\% at $1.5 \mathrm{dpa}$ ) of $\mathrm{ZrC}_{1.01}$ after proton irradiation to 0.7 and $1.5 \mathrm{dpa}$ at $1100 \mathrm{~K}$.

- In an early work, Andreivskii et al. [3] found changes in hardness and elastic modulus of $\mathrm{ZrC}_{0.98}$ sintered at $\sim 2900 \mathrm{~K}$, irradiated to a fluence of $1.5 \times 10^{20} \mathrm{n} / \mathrm{cm}^{2}$ at temperatures $\sim 420$ and $\sim 1370 \mathrm{~K}$. An increase of $\sim 1.2 \%$ in the room temperature elastic modulus and $\sim 12 \%$ in the hardness for irradiation at $420 \mathrm{~K}$ were measured. No change in the elastic modulus but an increase of $\sim 7 \%$ in the hardness values were observed for the $1370 \mathrm{~K}$ irradiation, indicating that the effect of irradiation on the mechanical properties was more significant at lower temperatures.

- Kovalchenko and Rogovai [12] reports a $\sim 12 \%$ increase in the hardness of $\mathrm{ZrC}_{0.98}$ irradiated to a fast neutron fluence of $\sim 10^{19} \mathrm{n} / \mathrm{cm}^{2}$ at $\sim 320 \mathrm{~K}$. 
All the work related to irradiation effects on the mechanical properties of $\mathrm{ZrC}$ have been summaried in table $2.3 \mathrm{~b}$.

\begin{tabular}{|c|c|c|c|c|c|}
\hline Material & Particle & Energy & $\begin{array}{l}\text { Dpa (or Fluence) \& } \\
\text { T (K) during } \\
\text { irradiation }\end{array}$ & Change in hardness \& elastic modulus & Ref \\
\hline $\mathrm{ZrC}_{0.87}$ & neutron & $\begin{array}{c}\mathrm{E}>0.1 \\
\mathrm{MeV}\end{array}$ & $\begin{array}{l}1-10 \times 10^{21} \mathrm{n} / \mathrm{cm}^{2} \\
\sim 910-1750 \mathrm{~K}\end{array}$ & $\begin{array}{l}\text { No change in hardness was observed after } \\
\text { irradiation at temperature range ( } 910-1750 \\
\mathrm{~K}) \text {. }\end{array}$ & [1] \\
\hline $\mathrm{ZrC}_{0.98}$ & neutron & $\begin{array}{c}\mathrm{E}>0.1 \\
\mathrm{MeV}\end{array}$ & $\begin{array}{c}1.5 \times 10^{20} \mathrm{n} / \mathrm{cm}^{2} \\
\text { at } \sim 425 \& \sim 1780 \mathrm{~K}\end{array}$ & $\begin{array}{l}\text { At } 420 \mathrm{~K} \text { : } \\
\sim 1.2 \% \text { increase in the room temperature } \\
\text { elastic modulus } \\
\sim 12 \% \text { in the room temperature hardness } \\
\text { for irradiation was measured. } \\
\text { At } 1370 \mathrm{~K} \text { : } \\
\text { No change in the elastic modulus but an } \\
\text { increase of } \sim 7 \% \text { in the hardness values. } \\
\text { It indicates the effect of irradiation on the } \\
\text { mechanical properties was more } \\
\text { significant at lower temperatures. }\end{array}$ & [3] \\
\hline $\mathrm{ZrC}_{1.01}$ & proton & $\begin{array}{c}\mathrm{E}=2.6 \\
\mathrm{MeV}\end{array}$ & $\begin{array}{l}0.7-1.5 \mathrm{dpa} \\
\text { at } \sim 1100 \mathrm{~K}\end{array}$ & $\begin{array}{l}\text { Micro-hardness increases } \\
(\sim 15 \% \text { at } 1.5 \mathrm{dpa}) \\
\text { Fracture toughness } \\
(>50 \% \text { at } 1.5 \mathrm{dpa})\end{array}$ & [8] \\
\hline $\mathrm{ZrC}_{0.98}$ & neutron & $\begin{array}{c}\mathrm{E}>0.1 \\
\mathrm{MeV}\end{array}$ & $\begin{array}{l}\sim 10^{19} \mathrm{n} / \mathrm{cm}^{2} \\
\text { at } \sim 320 \mathrm{~K} .\end{array}$ & $\sim 12 \%$ increase in the hardness & [12] \\
\hline
\end{tabular}

Table 2.3b. Summary of the work on irradiation effects on the mechanical properties of $\mathrm{ZrC}$ after irradiation. 


\section{Interaction of $\mathrm{ZrC}$ with xenon}

- Recently, Gutierrez et al. [13] carried out a study to elucidate the role of temperature on the diffusion of xenon in zirconium carbide. Two batches $\left(\mathrm{ZrC}_{0.95} \mathrm{O}_{0.05}\right)$ and $\left(\mathrm{ZrC}_{80} \mathrm{O}_{20}\right)$ have been studied in order to evaluate the role of the presence of free carbon and zirconia during high temperature annealing. Ions of ${ }^{136} \mathrm{Xe}^{2+}$ have been implanted at an energy of $800 \mathrm{keV}$ corresponding to a mean projected range of $160 \mathrm{~nm}$ and at an ion fluence of $10^{16} \mathrm{~cm}^{-2}$ corresponding to a maximum concentration of 1 at.\%. Thermal annealing has been carried out in a temperature range from 1775 to $2075 \mathrm{~K}$. The xenon distribution profiles have been measured by Rutherford backscattering spectrometry before and after the different treatments. The results show that the presence of residual zirconia induces a strong damage at the surface, however pure $\mathrm{ZrC}$ sintered specimen display less degradation at the surface and better retention capabilities for xenon.

At high temperature $\left(1800{ }^{\circ} \mathrm{C}\right)$, for $\left(\mathrm{ZrC}_{80} \mathrm{O}_{20}\right)$, the limit of oxygen solubility is exceeded, the zirconia is transformed into oxycarbide and constraints generated by this growth induced relaxation of xenon. However, nearly stoichiometric $\left(\mathrm{ZrC}_{0.95} \mathrm{O}_{0.05}\right)$ zirconium carbide showed excellent capacities of xenon retention.

- In 1967, Auskern et al. [14] also studied the release of ${ }^{133} \mathrm{Xe}$ from $\mathrm{ZrC}$ samples (with varying $\mathrm{C} / \mathrm{Zr}$ ratios). He showed that $\mathrm{Xe}$ release varied from $84 \%$ to $30 \%$ for $\mathrm{ZrC}_{0.58}$ to $\mathrm{ZrC}_{0.91}$. The fractional release of ${ }^{133} \mathrm{Xe}$ decreased with increasing carbon content to a minimum of $30 \%$ for $\mathrm{ZrC}_{0.91}$ with an estimated activation energy $\sim 765 \mathrm{~kJ} / \mathrm{mol}(\sim 7.9 \mathrm{eV})$.

\subsubsection{TiC}

Like $\mathrm{ZrC}$, TiC is also stable over a wide stoichiometry in which the $\mathrm{C}$ :Ti ratio is $<1$. Hence this variation of composition influences microstructure and other properties of $\mathrm{TiC}$.

Between 1980-1990, a small number of papers have illustrated the measurement of electric resistivity to determine the damage caused by neutron (or electron) irradiation. The summary of the work in these papers is presented in table 2.4 and is detailed in next paragraph: 
- Matsui and Iseki [15] examined the fast (14 MeV) neutron damage in titanium monocarbide $\left(\mathrm{TiC}_{1-\mathrm{x}}\right)$ by measuring low-temperature electrical resistivity and magnetic susceptibility. Both physical properties changed remarkably with neutron damage. They also noted that damage process dependence on the non-stoichiometry (the amount of the carbon vacancies) of the material. However, they also mentioned that both properties (without damage) are also considerably affected by the non-stoichiometry.

- In situ measurement of electrical resistivity of $\mathrm{TiC}_{\mathrm{x}},(\mathrm{x}=0.56,0.66$ and 0.72$)$ was done at liquid helium temperature under fusion (14 MeV) neutrons up to $1.92 \times 10^{21} \mathrm{n} / \mathrm{m}^{2}$. Matsui et al. [16] clearly showed that resistivity increases almost linearly with the neutron dose except at the beginning of the irradiation runs. The damage rate of $\mathrm{TiC}$, increased with higher carbon content.

In the annealing process, there were several recovery stages to which the migration of inter stitial type defects contributed. Even after an anneal at $340 \mathrm{~K}$, a large unrecovered resistivity remained suggesting that the amount of residual damage depends on the non-stoichiometry of the specimen.

- M. Iseki et al. [17] prepared titanium carbide $\left(\mathrm{TiC}_{0.8}\right)$ by plasma-jet melting and irradiated to an electron dose less than $6 \times 10^{26} \mathrm{e} / \mathrm{mm}^{2}$ from room temperature to $800^{\circ} \mathrm{C}$. The number density and average size of the defect clusters formed at irradiation temperatures below $400^{\circ} \mathrm{C}$ were less than those formed above $600{ }^{\circ} \mathrm{C}$. Since $\mathrm{TiC}_{0.8}$ has an order structure of carbon below around $600{ }^{\circ} \mathrm{C}$, the ordered phase is more resistant to radiation than the disordered one in higher temperatures. The clusters decrease in number density and develop to dislocation loops during post irradiation annealing above $1000^{\circ} \mathrm{C}$.

There were two temperature region for the recovery of the defect clusters. It is conceivable that the first one appeared in the temperature region around $600^{\circ} \mathrm{C}$ caused by migration of carbon vacancies, and the second one appeared above $1000^{\circ} \mathrm{C}$ by migration of titanium vacancies.

- Morillo et al. [18] also measured the electrical resistivities of nearly stoichiometric titanium monocarbides $\left(\mathrm{TiC}_{0.97}\right)$ during fast neutron and $2.5 \mathrm{MeV}$ electron irradiations at $21 \mathrm{~K}$. They found the recovery of defects up to $400 \mathrm{~K}$. 


\begin{tabular}{|c|c|c|c|c|c|}
\hline Material & $\begin{array}{c}\text { Particl } \\
\text { e }\end{array}$ & Energy & $\begin{array}{c}\text { Dpa (or Fluence) } \\
\text { \& T (K) during } \\
\text { irradiation }\end{array}$ & Most remarkable points & Ref \\
\hline $\begin{array}{c}\mathrm{TiC}_{\mathrm{x}} \\
(\mathrm{x}=0.56 \\
0.66 \& \\
0.72)\end{array}$ & neutron & $\mathrm{E}=14 \mathrm{MeV}$ & $\begin{array}{l}1.92 \times 10^{21} \mathrm{n} / \mathrm{m}^{2} \\
\text { (liquid helium } \\
\text { temperature }-269 \\
{ }^{\circ} \mathrm{C} \text { ) }\end{array}$ & $\begin{array}{l}\text { Resistivity increases almost linearly with the neutron } \\
\text { dose (except at the beginning of the irradiation runs). } \\
\text { Damage rate is more in } \mathrm{ZrC} \text { with higher carbon content. } \\
\text { During annealing, the amount of residual damage } \\
\text { depends on the non-stoichiometry of the specimen. }\end{array}$ & {$[16]$} \\
\hline $\mathrm{TiC}_{0.8}$ & electron & $\mathrm{E}=1 \mathrm{MeV}$ & $\begin{array}{l}6 \times 10^{26} \mathrm{e} / \mathrm{mm}^{2} \\
\text { (at room } \\
\text { temperature to } 800 \\
\left.{ }^{\circ} \mathrm{C}\right)\end{array}$ & $\begin{array}{l}\text { Number density and average size of the defect clusters } \\
\text { increases with irradiation temperature. } \\
\text { During post irradiation annealing clusters decrease } \\
\text { in number density and develop to dislocation loops at } \mathrm{T} \\
\geq 1000^{\circ} \mathrm{C} \text {. } \\
\text { Two temperature region for the recovery of the defect } \\
\text { clusters. } \\
\mathrm{I}^{\mathrm{st}} \text { at } \mathrm{T}=600^{\circ} \mathrm{C} \text { due to migration of } \mathrm{C} \text { vacancies, } \\
\mathrm{II}^{\text {nd }} \mathrm{T} \geq 1000^{\circ} \mathrm{C} \text { due to migration of } \mathrm{Ti} \text { vacancies. }\end{array}$ & [17] \\
\hline $\mathrm{TiC}_{0.97}$ & $\begin{array}{l}\text { neutron } \\
\qquad \& \\
\text { electron }\end{array}$ & $\mathrm{E}>0.1 \mathrm{MeV}$ & $\begin{array}{c}1.3 \times 10^{18}-1.4 \times 10^{19} \\
\text { at } 21 \mathrm{~K}\end{array}$ & $\begin{array}{l}\text { Electrical resistivities were measured during } \\
\text { irradiations to measure irradiation effects. } \\
\text { During post implantation annealing, the recovery of } \\
\text { defects at } 400 \mathrm{~K}(60 \% \text { and } 80 \%) \text {. }\end{array}$ & {$[18]$} \\
\hline $\mathrm{TiC}$ & $\mathrm{Kr}^{+}$ & $\mathrm{E}=1 \mathrm{MeV}$ & $\begin{array}{c}10 \mathrm{dpa} \text { and } 70 \mathrm{dpa} \text { at } \\
800{ }^{\circ} \mathrm{C}\end{array}$ & $\begin{array}{l}\text { No signs of amorphization or the presence of faulted } \\
\text { loops, } \\
\text { but perfect loops and dislocation networks were } \\
\text { reported. }\end{array}$ & {$[22]$} \\
\hline $\begin{array}{c}\text { TiC single } \\
\text { crystal }\end{array}$ & $\mathrm{Au}$ & $\mathrm{E}=4 \mathrm{MeV}$ & $\begin{array}{l}\quad 3.3 \times 10^{15} \mathrm{~cm}^{-2} \\
\text { at room temperature }\end{array}$ & No amorphisation of TiC single crystal. & [11] \\
\hline
\end{tabular}

Table 2.4. Summary of the important results on TiC after irradiation.

- Gan et al. damaged $\mathrm{TiC}$ by $1 \mathrm{MeV} \mathrm{Kr}^{+}$at $800{ }^{\circ} \mathrm{C}$ to $10 \mathrm{dpa}$ and $70 \mathrm{dpa}$. They reported no signs of amorphization or the presence of faulted loops, but perfect loops and dislocation networks were reported [22]. 
- Pellegrino et al. [11] observed no amorphisation of TiC single crystal up to the highest $\mathrm{Au}$ fluence used $\left(3.3 \times 10^{15} \mathrm{~cm}^{-2}\right)$.

In the late 80's, few papers were published by Japan Atomic Research Institute to demonstrate the damage evolution in $\mathrm{TiC}$ crystal under He or $\mathrm{H}$ damage by the use of transmission electron microscopy. The essential points mentioned in these papers are mentioned below and are summarized in Table 2.5.

- K. Hojou et al. [19] examined the processes of damage evolution in TiC crystals irradiated with $25 \mathrm{keV} \mathrm{H}^{2+}$ ions at $12 \mathrm{~K}$ and $28 \mathrm{~K}$, and with $25 \mathrm{keV} \mathrm{D}^{2+}$ ions at $18 \mathrm{~K}$ and the effect of annealing after the irradiation by in situ observation with an electron microscope equipped with an ion accelerator.

Amorphization was confirmed in TiC irradiated with $\mathrm{H}^{2+}$ ions to a fluence of about $1 \times 10^{21}$ $\mathrm{H}^{2+/} \mathrm{m}^{2}$ at $12 \mathrm{~K}$, while no amorphization occurred in TiC irradiated with $\mathrm{D}^{2+}$ ions to a fluence of $4.5 \times 10^{21} \mathrm{D}^{2+/} \mathrm{m}^{2}$ at $18 \mathrm{~K}$.

No amorphization in $\mathrm{D}^{2+}$ irradiation is considered to be due to the difficulty of producing chemical bonding species which suppress the recovery of irradiation induced defects in comparison to $\mathrm{H}^{2+}$ irradiation.

- K. Hojou et al. [20] observed bubble formation and growth in TiC during $20 \mathrm{keV}$ helium ion irradiation over the wide range of irradiation temperatures from 12 to $1523 \mathrm{~K}$. No amorphization occurred over this temperature range. The bubble densities and sizes were almost independent of irradiation temperatures from 12 to $1273 \mathrm{~K}$. Remarkable growth and coalescence occurred during irradiation at high temperature above $1423 \mathrm{~K}$ and during annealing above $1373 \mathrm{~K}$ after irradiation. 
- K. Hojou et al. [21] irradiated TiC polycrystal with $10 \mathrm{keV}$ helium ions with the flux of $3 \mathrm{x}$ $10^{16}$ ions $\mathrm{m}^{2} \mathrm{~s}^{-1}$, a number of dislocation loops were produced at the initial stage of irradiation. They became tangled as the irradiation proceeded and saturated in density. Neither an amorphous zone nor cavities were formed up to the irradiation fluence of $3 \times 10^{22}$ ions $/ \mathrm{m}^{2}$.

\begin{tabular}{|c|c|c|c|}
\hline Material & Irradiation condition & Most remarkable points & Ref \\
\hline $\mathrm{TiC}$ & $\begin{array}{l}1 \times 10^{21} \mathrm{H}^{2+/} \mathrm{m}^{2}, 25 \mathrm{keV}, \mathrm{H}^{2+} \text { ions at } 12 \mathrm{~K} \text { and } 28 \\
\qquad \mathrm{~K}, \\
\text { and with } 4.5 \times 10^{21} \mathrm{D}^{2+/} \mathrm{m}^{2}, 25 \mathrm{keV} \mathrm{D}^{2+} \text { ions at } 18 \\
\mathrm{~K}\end{array}$ & $\begin{array}{l}\text { Amorphization on irradiation with } \mathrm{H}^{2+} \text { ions to a } \\
\text { fluence of about } 1 \times 10^{21} \mathrm{H}^{2+/} \mathrm{m}^{2} \text { at } 12 \mathrm{~K} \text {, } \\
\text { No amorphization on irradiation with } \mathrm{D}^{2+} \text { ions to a } \\
\text { fluence of } 4.5 \times 10^{21} \mathrm{D}^{2+/} \mathrm{m}^{2} \text { at } 18 \mathrm{~K} \text {. } \\
\text { No amorphization in } \mathrm{D}^{2+} \text { irradiation due to the } \\
\text { difficulty of producing chemical bonding as compared } \\
\text { to } \mathrm{H}^{2+} \text { irradiation }\end{array}$ & [19] \\
\hline $\mathrm{TiC}$ & $\begin{array}{l}20 \mathrm{keV} \text { helium ion irradiation } \\
\text { Irradiation temperatures from } 12 \text { to } 1523 \mathrm{~K} \text {. }\end{array}$ & $\begin{array}{l}\text { Remarkable bubble growth and coalescence occurred: } \\
\text { during irradiation at high temperature above } 1423 \mathrm{~K} \text {. } \\
\text { during annealing above } 1373 \mathrm{~K} \text { after irradiation. }\end{array}$ & {$[20]$} \\
\hline $\mathrm{TiC}$ & $\begin{array}{l}10 \mathrm{keV} \text { helium ions with the flux } \\
\text { of } 3 \times 10^{16} \text { ions } \mathrm{m}^{2} \text { to obtain net fluence of } 3 \times 10^{22} \\
\text { ions } / \mathrm{m}^{2} \text { at room temperature. }\end{array}$ & $\begin{array}{l}\text { Number of dislocation loops produced at the initial } \\
\text { stage of irradiation became tangled as the irradiation } \\
\text { proceeded and saturated in density. } \\
\text { Neither an amorphous zone nor cavities were formed } \\
\text { perhaps because the irradiations were done at room } \\
\text { temperature. }\end{array}$ & {$[21]$} \\
\hline
\end{tabular}

Table 2.5. Summary of the important points on the damage evolution in TiC crystal under He or H damage by the use of transmission electron microscopy.

\subsubsection{TiN}

After the broad literature survey, it was concluded that very less research have been carried out in the past to study irradiation damage and inert gas behavior in TiN. But during last 10 years, some groups have studied TiN for Gen IV application and have reported following points which are also summarized in table 2.6: 
- Xue et al. [23] recently published paper about improving the radiation damage tolerance of titanium nitride ceramics by the introduction of vacancy defects. They irradiated $\mathrm{TiN}$ and $\mathrm{TiN}_{0.7}$ using a $100 \mathrm{keV}$ Ar-ion beam at $600{ }^{\circ} \mathrm{C}$ to target doses of $3 \times 10^{17}$ ions $\mathrm{cm}^{-2}$ and performed SRIM estimation, GIXRD and fluorescence analysis to evaluate the effect of pre-existing vacancy defect on the radiation tolerance.

The lattice parameter of TiN increased after irradiation due to interstitial atoms and vacancies in as-irradiated TiN. In contrary, the lattice parameter decreased for as-irradiated $\mathrm{TiN}_{0.7}$, which indicates that the nitrogen atom vacancies in $\mathrm{TiN}_{0.7}$ acted as sinks for displacement atoms generated by irradiation to limit interstitial atoms existing.

The intensity of peaks in fluorescence spectrum of as-irradiated TiN was higher than that of asirradiated $\mathrm{TiN}_{0.7}$ attributing to the presence of color centers formed by Frenkel defects in asirradiated TiN. All of the results indicate that introducing vacancy defect in materials would offer capability to realize self-heal of irradiation damage.

- Xue et al. [24] also studied lattice expansion and microstructure evaluation of Ar ionirradiated titanium nitride. They irradiated TiN ceramic using a $100 \mathrm{keV}$ Ar ion beam at $600{ }^{\circ} \mathrm{C}$ and at target fluences of $3 \times 10^{17}$ ions $\mathrm{cm}^{-2}$, corresponding to 115 displacements per atom (dpa). $\mathrm{X}$-ray diffraction and transmission electron microscopy were performed to evaluate the irradiation damage in TiN. The lattice parameter increased and the lattice expanded by $0.19 \%$ after irradiation due to interstitial atoms and vacancies in Ar-irradiated TiN. Hills, bubbles and dislocations were observed. It is noteworthy that many TiN grains pulled out after irradiation and that amorphization of oxide grain boundaries was observed using high-resolution transmission electron microscopy, which indicates that the oxygen-containing impurities are potentially fatally dangerous to the radiation resistance property of TiN and other candidate materials.

- Gan et al. [22] also published a report on ion irradiation study on microstructure stability of GFR ceramics. They irradiated TEM disc samples of hot-pressed TiN using $1 \mathrm{MeV} \mathrm{Kr}$ ions at $800^{\circ} \mathrm{C}$. The irradiations were conducted at a dose rate of approximately $3.0 \times 10^{-3} \mathrm{dpa} / \mathrm{s}$ with doses up to $70 \mathrm{dpa}$. Post-irradiation examination reveals the changes in microstructure due to 
$\mathrm{Kr}$ ion irradiation. No evidence of faulted loops or amorphization is found in TiN. Dislocation networks and perfect loops are found in TiN.

- Bes et al. [25] has shown that Xe introduced by ion implantation in sintered TiN tends to be release as a result of annealing, due to a transport mechanism towards the sample surface. They found that the xenon concentration which is sufficient to form bubbles in TiN matrix is lower than 0.4 at.\%. These bubbles were found unpressurised at $15 \mathrm{~K}$. Their size increases due to temperature and local xenon concentration. For the highest xenon concentrations, a mechanism involving the formation of a Xe interconnected bubble network is proposed to explain $\mathrm{Xe}$ massive release observed by Rutherford backscattering spectrometry experiments. 


\begin{tabular}{|c|c|c|c|}
\hline Material & Irradiation condition & Most remarkable points & Ref \\
\hline $\begin{array}{l}\text { TiN \& } \\
\operatorname{TiN}_{0.7}\end{array}$ & $\begin{array}{c}\text { Ar-ion beam at } 600{ }^{\circ} \mathrm{C}, \\
\text { Fluence }=3 \times 10^{17} \text { ions } \mathrm{cm}^{-2}\end{array}$ & $\begin{array}{l}\text { For TiN: lattice parameter increased due to } \\
\text { interstitial atoms and vacancies in as-irradiated } \\
\text { TiN. } \\
\text { For } \mathrm{TiN}_{0.7} \text { : In contrary lattice parameter } \\
\text { decreased on as-irradiated } \mathrm{TiN}_{0.7} \text {, the } \mathrm{N} \text { atom } \\
\text { vacancies in TiN }{ }_{0.7} \text { acted as sinks for } \\
\text { displacement atoms generated by irradiation. } \\
\text { Conclusion: Introducing vacancy defect in } \\
\text { materials would help in self-healing of } \\
\text { irradiation damage. }\end{array}$ & $\begin{array}{l}{[23]} \\
\end{array}$ \\
\hline TiN & $\begin{array}{l}100 \mathrm{keV} \text { Ar ion at } 600{ }^{\circ} \mathrm{C} \text { with fluence of } \\
3 \times 10^{17} \text { ions } \mathrm{cm}^{-2} \text {, corresponding to } 115 \mathrm{dpa}\end{array}$ & $\begin{array}{l}\text { Lattice expanded by } 0.19 \% \text {. } \\
\text { Bubbles and dislocations were observed. }\end{array}$ & {$[24]$} \\
\hline TiN & $\begin{array}{c}1 \mathrm{MeV} \mathrm{Kr} \text { ions, } 800^{\circ} \mathrm{C} \\
3.0 \times 10^{-3} \mathrm{dpa} / \mathrm{s} \text { with doses up to } 70 \mathrm{dpa} \text {. }\end{array}$ & $\begin{array}{l}\text { No evidence of faulted loops. } \\
\text { No amorphization. } \\
\text { Dislocation networks and perfect loops are found } \\
\text { in TiN. }\end{array}$ & {$[$ [22] } \\
\hline $\mathrm{TiN}$ & $\begin{array}{l}800 \mathrm{keV} \mathrm{Xe}, 5.0 \times 10^{15} \text { at. } / \mathrm{cm}^{2} \\
\text { at room temperature } \\
+ \text { Post implantation annealing } \\
\quad\left(1300^{\circ} \mathrm{C}-1600^{\circ} \mathrm{C}\right)\end{array}$ & $\begin{array}{l}\text { Xenon concentration which is sufficient to form } \\
\text { bubbles in TiN matrix is lower than } 0.4 \text { at.\%. } \\
\text { Xe massive release is due to formation of a Xe } \\
\text { interconnected bubble network. }\end{array}$ & \begin{tabular}{|l}
{$[25]$} \\
\end{tabular} \\
\hline
\end{tabular}

Table 2.6. Summary of literature survey on TiN. 


\section{References}

[1] L.L. Snead et al., J. Nucl. Mater. 371 (2007) 329-337.

[2] D. Gosset et al., J. Nucl. Mater. 373 (2008) 123-129.

[3] R.A. Andrievskii et al., Neorg. Meter. 14 (1978) 680-683.

[4] G.W. Keilholtz, R.E. Moore, M.F. Osborne, Nucl. Appl. 4 (1968) 330.

[5] G.W. Keilholtz, R.E. Moore, in: Proc. of the Amer. Nucl. Soc., 1969.

[6] D.A. Dyslin, R.E. Moore, H.E. Robertson, ORNL Report - 4480, 1969, p. 425.

[7] T. Ogawa, K. Ikawa, High Temp. Sci. 22 (1986) 179-192.

[8] Y. Yang et al., J. Nucl. Mater. 378 (2008) 341-348.

[9] J. Gan, Y. Yang, D. Clayton, A. Todd, J. Nucl. Mater. 389 (2009) 317-325.

[10] J. Gan, M.K. Meyer, R.C. Birtcher, T.R. Allen, J. ASTM Int. 3 (2006) 1-7.

[11] S. Pellegrino, L. Thomé, A. Debelle, S. Miro, P. Trocellier, Nuclear Instruments and Methods in Physics Research B 307 (2013) 294-298.

[12] M.S. Kovalchenko, Y.I. Rogovai, Neorg. Mater. 9 (1973) 321.

[13] G. Gutierrez, N. Toulhoat, N. Moncoffre, Y. Pipon, A. Maître, M. Gendre, A. PerratMabilon, Journal of Nuclear Materials 416 (2011) 94-98.

[14] A. Auskern, J. Nucl. Mater. 22 (1967) 257-268.

[15] H. Matsui, M. Iseki, J. Nucl. Mater. 152 (1988) 14-20.

[16] H. Matsui, M.W. Guinan, T. Iida, M. Iseki, J. Nucl. Mater. 133-134 (1985) 718721.

[17] M. Iseki, S. Ushijima, H. Ohashi, T. Kirihara, J. Atomic Energy Soc. Jpn. 26 (1984).

[18] J. Morillo, C.H. de Novion, J. Dural, Radiat. Eff. 55 (1981) 67-77.

[19] K. Hojou, H. Otsu, S. Furuno, N. Sasajima, K. Izui, J. Nucl. Mater. 239 (1996) 279-283.

[20] K. Hojou, H. Otsu, S. Furuno, K. Izui, T. Tsukamoto, J. Nucl. Mater. 212-215 (1994) 281-286.

[21] K. Hojou, S. Furuno, H. Otsu, K. Izui, T. Tsukamoto, J. Nucl. Mater. 155-57 (1988) 298-302. 
[22] J. Gan, INL/EXT-05-00799: Gas-Cooled Fast Reactor (GFR) FY 05 Annual Report: Ion Irradiation Study on Microstructure Stability of GFR Ceramics: $\mathrm{ZrC}, \mathrm{ZrN}, \mathrm{TiC}, \mathrm{TiN}$, and $\mathrm{SiC}$, 2005, pp. 94-125.

[23] Jia-Xiang Xue, Guo-Jun Zhang, Li-Ping Guo, Hai-Bin Zhang, Xin-Gang Wang, Ji Zou, Shu-Ming Peng, Xing-Gui Long, Journal of the European Ceramic Society 34 (2014) 633-639.

[24] Jia-Xiang Xue, Guo-Jun Zhang, Fang-Fang Xu, Hai-Bin Zhang, Xin-Gang Wang, ShuMing Peng, Xing-Gui Long, Nuclear Instruments and Methods in Physics Research B 308 (2013) 62-67.

[25] R. Bès, C. Gaillard, N. Millard-Pinard, S. Gavarini, P. Martin, S. Cardinal, C. Esnouf, A. Malchère, A. Perrat-Mabilon, Journal of Nuclear Materials 434 (2013) 56-64. 


\section{Chapter 3}

\section{Properties of Transition Metal Carbides and Nitrides}

In this chapter, important properties of $\mathrm{TiC}, \mathrm{TiN}$ and $\mathrm{ZrC}$ have been summarized. Our main objective of this chapter is to highlight those properties which helps them to qualify as one of the most promising candidate for nuclear energy application.

\subsection{Crystallographic Structure}

Transition metal carbides (or nitrides) of group IV e.g., TiC, TiN and $\mathrm{ZrC}$ have fcc or $\mathrm{NaCl}$ type structure which provides octahedral sites large enough for $\mathrm{C}$ or $\mathrm{N}$ atoms and in turn gets stabilized by them. Due to the presence of $\mathrm{C}$ or $\mathrm{N}$ atoms on interstitial position, they are also known as interstitial carbide (or nitride). The typical fcc or $\mathrm{NaCl}$ structure representing transition metal carbides and nitrides such as $\mathrm{TiN}, \mathrm{TiC}, \mathrm{ZrC}$ etc. is shown in figure 3.1.

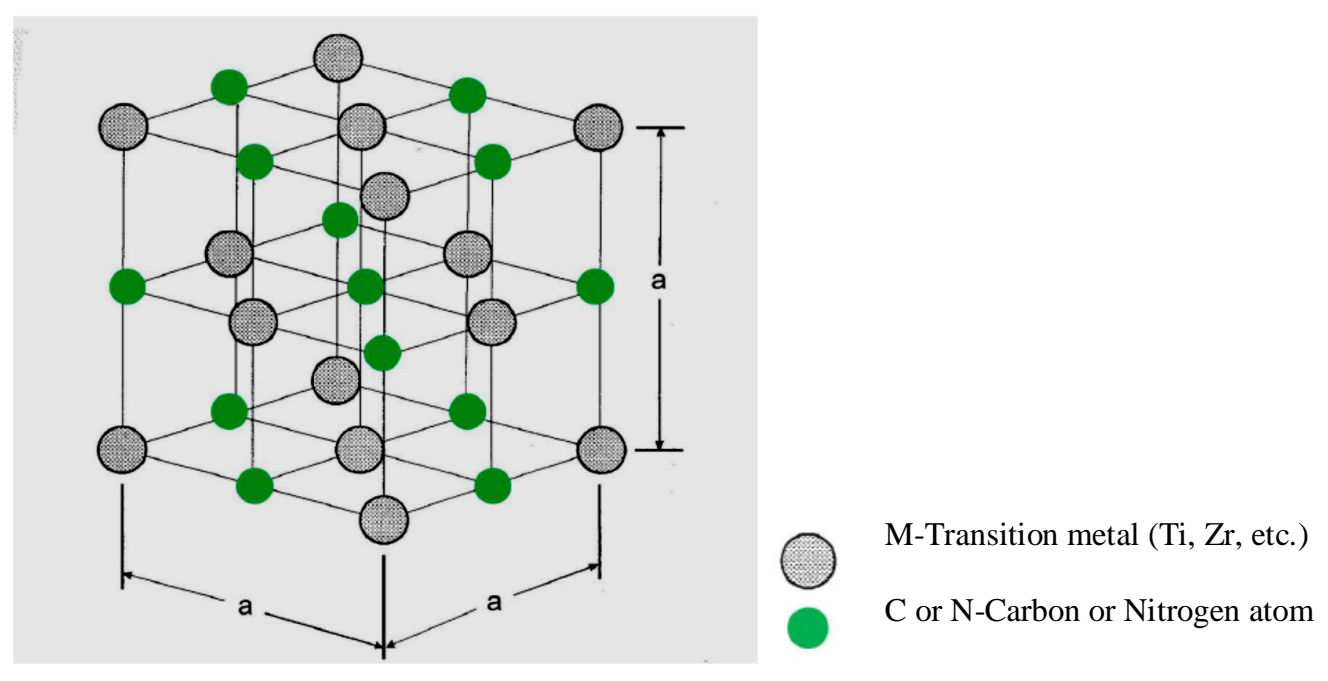

Figure 3.1. Typical NaCl type structure of transition metal carbides.

The shortest M-M distance is about 30\% greater than in the lattice of pure metal for the Group IV and V carbides (or nitrides). 
At $100 \%$ site occupancy, the stoichiometry of the carbide is $\mathrm{MC}_{1.0}$ and nitride is $\mathrm{MN}_{1.0}$, though this situation is rarely realized. The vacancies that result from a nonstoichiometric $\mathrm{M}-\mathrm{C}$ or $\mathrm{M}-$ $\mathrm{N}$ ratio have a great effect on the thermodynamic, mechanical, electronic, and magnetic properties of the metal carbides and nitrides.

\subsection{Nature of bonding}

The carbon atoms in an interstitial carbide can be considered as isolated atoms nesting within the framework of the metal atoms. Essentially, no carbon-to-carbon bond exists since the spacing between carbon atoms is too large for any significant atomic interaction (see figure 3.1). The overall bonding scheme is then limited to metal-to-metal (M-M) and metal-to-carbon (M-C) bonds and combines the three following types of bonding:

1. Ionic bonding resulting from a transfer of electrons from the metal to the carbon atoms, 2. Metallic bonding with a finite density of states at the Fermi-energy level $\mathrm{E}_{\mathrm{f}}$,

3. Covalent bonding between metal d-state and the carbon p-state, with some metal-to-metal interaction.

A similar bonding is expected in transition metal nitrides. Due to this complex bonding, transition metal carbides and nitrides have a unique mixture of properties from metallic and ceramic system.

\subsection{Details of the important properties}

In chapter 1, we mentioned that the structural material for application in Gen IV fission reactors and fusion reactors must have high melting point (exceeding $2000{ }^{\circ} \mathrm{C}$ ), adequate thermal conductivity $(>10 \mathrm{~W} / \mathrm{m}-\mathrm{K})$, toughness $\left(>12 \mathrm{MPa}-\mathrm{m}^{1 / 2}\right)$, and acceptable response to high dose neutron damage (swelling $<2 \%$ over service life ( $~ 80 \mathrm{dpa})$ ). In next paragraph, each of these properties have been discussed and compared for $\mathrm{TiC}, \mathrm{ZrC}$ and $\mathrm{TiN}$.

- High melting point: The transition metal carbides (or nitrides) of Group IV have much a higher melting point than their host metals. These materials have also been compared to SiC. And we noted that among all the materials, $\mathrm{ZrC}$ have the highest melting point. 


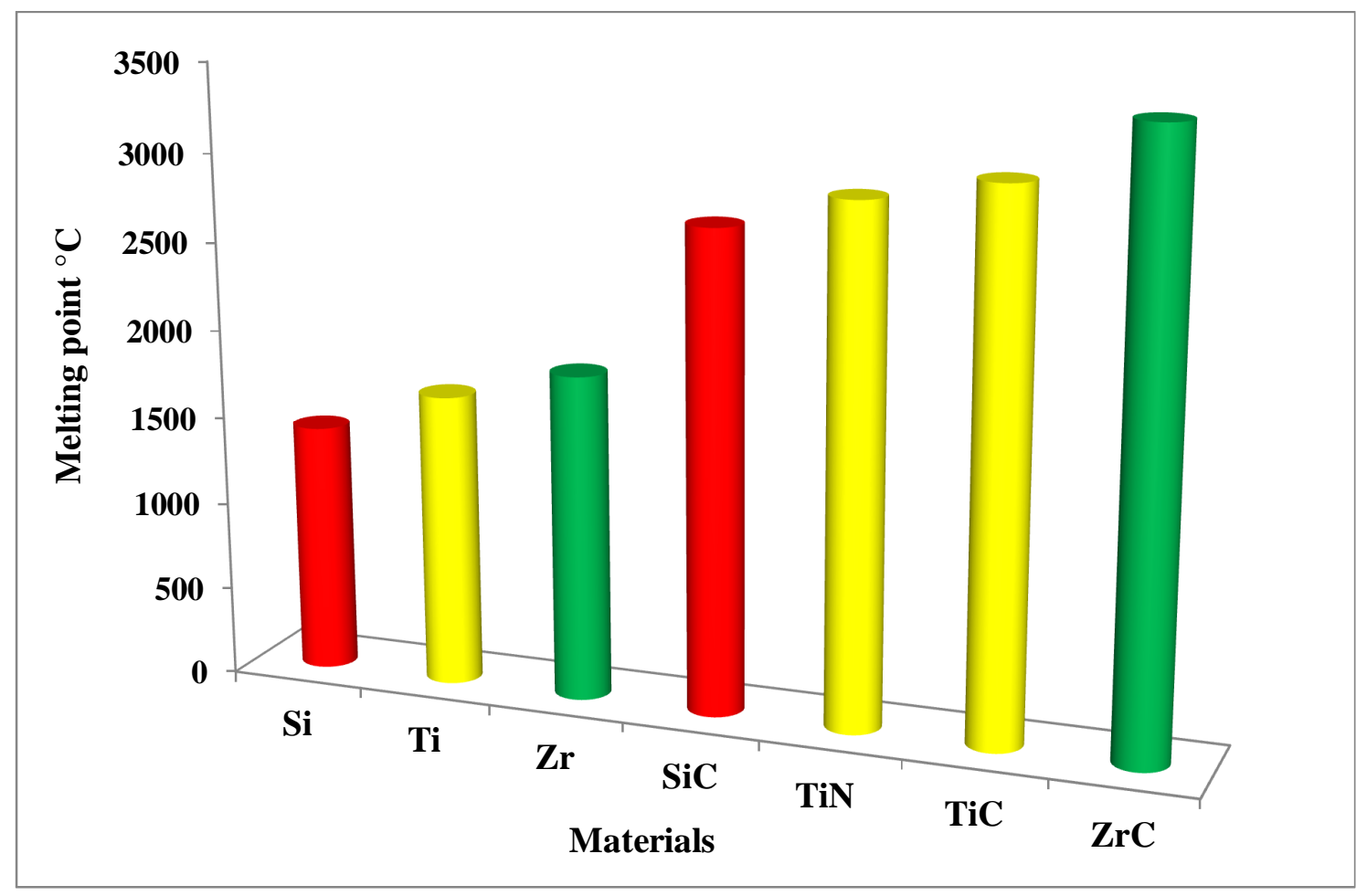

Figure 3.2. Comparison of host metals with their respective carbides in terms of melting temperature, including titanium nitride [1].

- Thermal Conductivity: The thermal conductivity or $k$ (i.e., the time rate of transfer of heat by conduction) of transition metal carbides and nitrides is different from other materials as $k$ increases with the increase in temperature. Figure 3.3a and 3.3b shows the thermal conductivity for transition metal carbides and transition metal nitrides, respectively. It is important to note from figure $3.3 \mathrm{a} \& 3.3 \mathrm{~b}$ that $\mathrm{TiC}, \mathrm{TiN}$ and $\mathrm{ZrC}$ have $k>10 \mathrm{~W} / \mathrm{m}-\mathrm{K}$ at temperature ranging from $0{ }^{\circ} \mathrm{C}$ to $2400{ }^{\circ} \mathrm{C}$. 


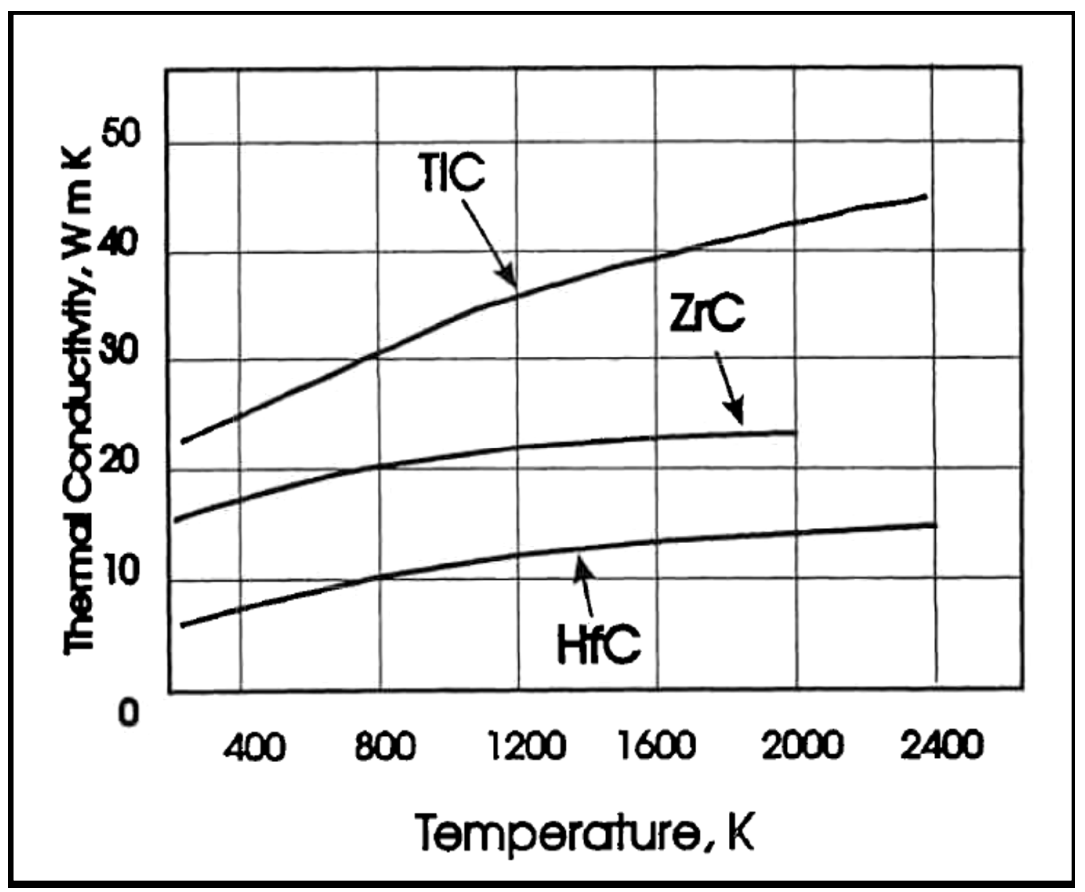

Figure 3.3a. Thermal conductivities of transition metal carbides [1].

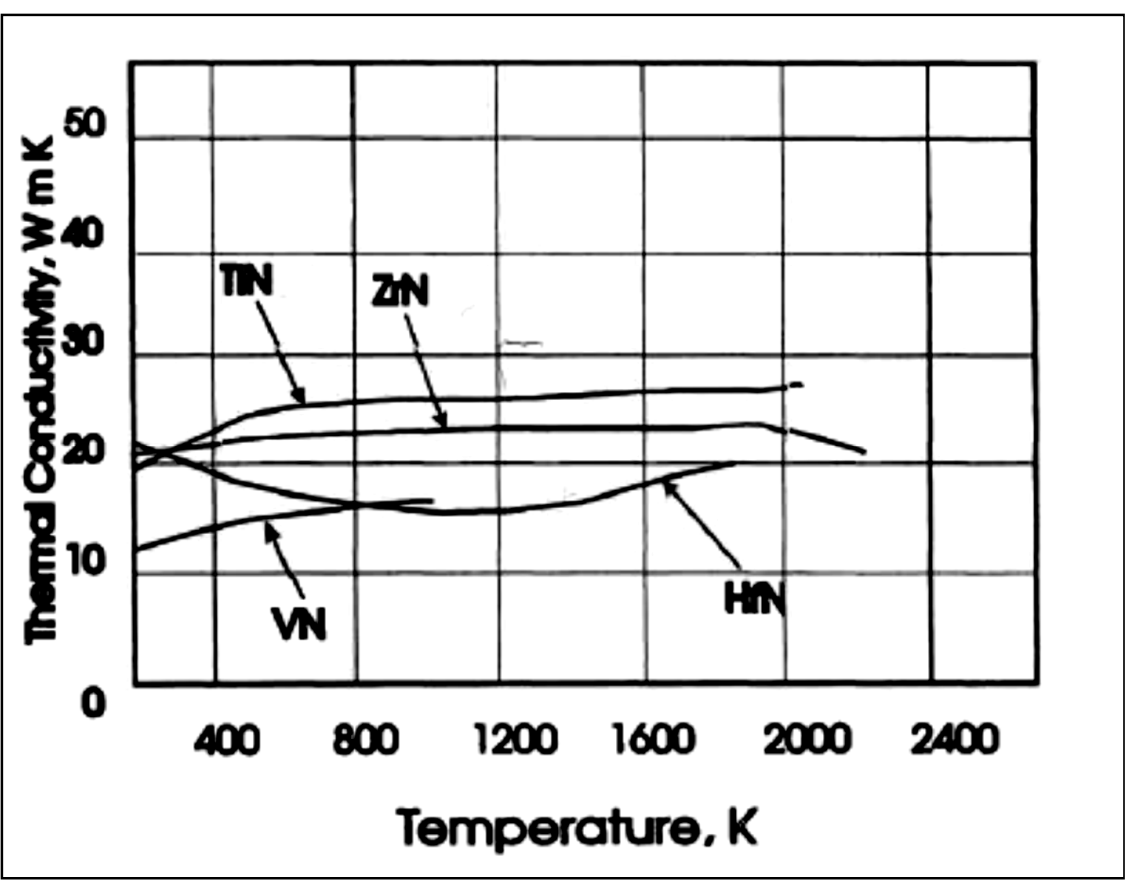

Figure 3.3b. Thermal conductivities of transition metal nitrides [1].

- Hardness: The detailed information on toughness was not available in the literature. However, metal carbides like their host metals lower their hardness on increasing the 
temperature and hence do not fail in response to stress. This property makes them suitable to be used under high temperature environment in GenIV fission reactors and in fusion reactors. Figure 3.4 shows the decreasing hardness of refractory carbides as a function of temperature.

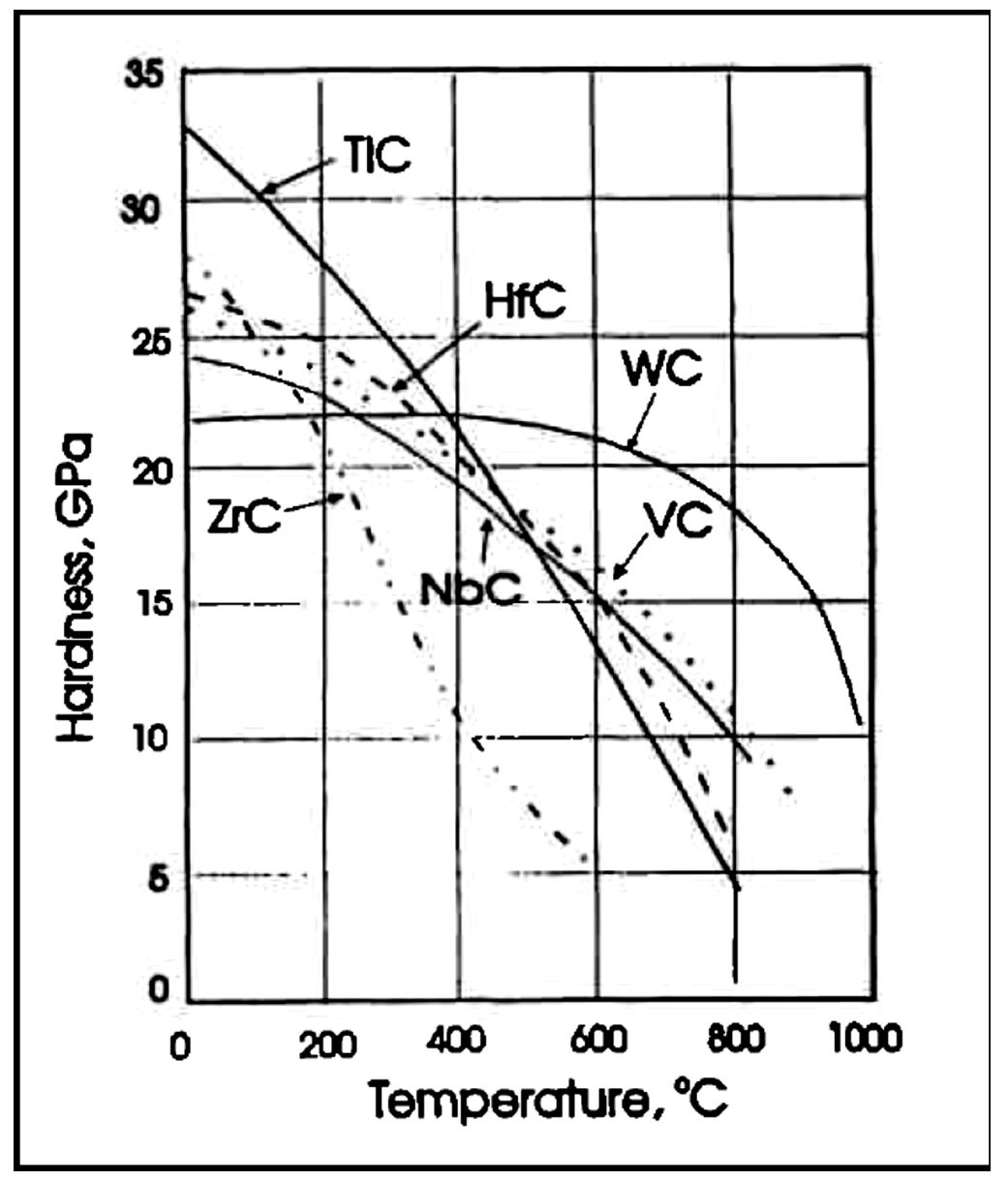

Figure 3.4. Hardness of refractory carbides as a function of temperature [1].

- Radiation tolerance: There is no specific data available for this property, as data for radiation tolerance depends on types of ions used for irradiation and other experimental conditions. We have already discussed about radiation tolerance properties in section 2.2. However, this section is dedicated to the direct comparison of properties, which helps them to qualify as nuclear material. To complete this section we could only find one publication in which the radiation tolerance of $\mathrm{TiN}, \mathrm{TiC}, \mathrm{ZrC}$ and $\mathrm{SiC}$ have been directly compared. Gan et al. [2] published a recent report on irradiation response on these material and showed that $\mathrm{TiN}$ and $\mathrm{TiC}$ lattice expand up to $\sim 2 \%$ whereas $\mathrm{ZrC}$ lattice expands to $\sim 7 \%$ under 70 dpa damage at $800{ }^{\circ} \mathrm{C}$ caused 
by $1 \mathrm{MeV}$ Krypton ions. Under the same condition, SiC lattice do not expand at all, perhaps due to the recrystallisation at high temperature.

They mentioned that voids were only seen under the case of $\mathrm{TiC}$ and contributes to $\sim 0.01 \%$ void swelling. They finally concluded that $\mathrm{SiC}$, TiC and $\mathrm{TiN}$ perform better than $\mathrm{ZrC}$ and $\mathrm{ZrN}$ on microstructural response to $\mathrm{Kr}$ ion irradiation at $800^{\circ} \mathrm{C}$.

\subsection{Variation of properties with $\mathrm{M}$-to-X $\operatorname{ratio}(\mathrm{M}$ : $\mathrm{Ti}$ or $\mathrm{Zr} \& \mathrm{X}$ : $\mathrm{C}$ or $\mathrm{N}$ )}

Transition metal carbides and nitrides are stable on wide range of stoichiometric ratios. Accordingly, it is reasonable to expect a large stability of these materials under ion irradiation due to conservation of their structure with large number of vacancies. The variation of properties with different stoichiometric ratios for each material is described in the next paragraph:

\section{A. $\mathrm{ZrC}$}

Recently Katho and co-workers provided a survey of properties data for $\mathrm{ZrC}$ with a strong focus on the variation of properties based on the stoichiometry of $\mathrm{ZrC}$ [3]. In other words, there are vacancies (or missing atoms) within the lattice. These missing atoms are mostly carbon and very rarely metal vacancies are present. The amount of carbon vacancies can be considerable, reaching $50 \%$ in some cases. Two examples of properties varying with $\mathrm{C} / \mathrm{Zr}$ ratio are given below:

1. As the $\mathrm{C} / \mathrm{Zr}$ ratio increases, the $\mathrm{Zr}-\mathrm{ZrC}$ eutectic melting temperature increases and reaches $3700 \mathrm{~K}$ and drops with further increasing carbon content to form a $\mathrm{ZrC}-\mathrm{C}$ eutectic with a melting point in a range close to $3120 \mathrm{~K}$. This property is shown in figure 3.5. 


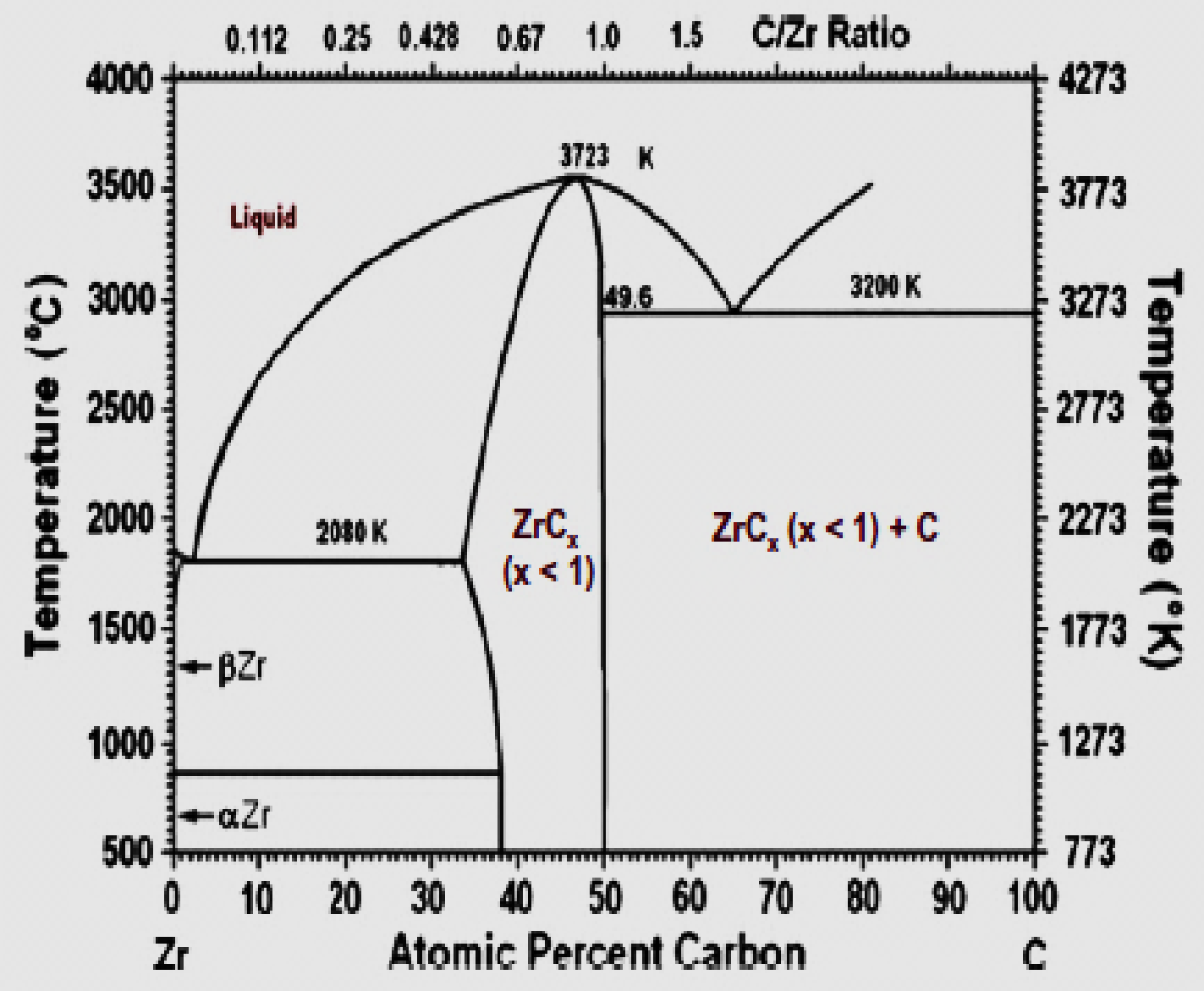

Figure 3.5. Phase diagram of $\mathrm{Zr}$-C as reported in literature [1,3]

2. As the $\mathrm{C} / \mathrm{Zr}$ ratio increases, the ambient lattice parameter of $\mathrm{ZrC}$ increases and approaches a maximum $(\sim 0.4702 \mathrm{~nm})$ with $\mathrm{C} / \mathrm{Zr} \sim 0.83$ beyond which the lattice parameter decreases. In contrast, carbon-rich $\mathrm{ZrC}$ with excess carbon (i.e., $\mathrm{C} / \mathrm{Zr}>1.0$ have small lattice parameter than near-stoichiometric $\mathrm{ZrC}$. This property is shown in figure 3.6. 


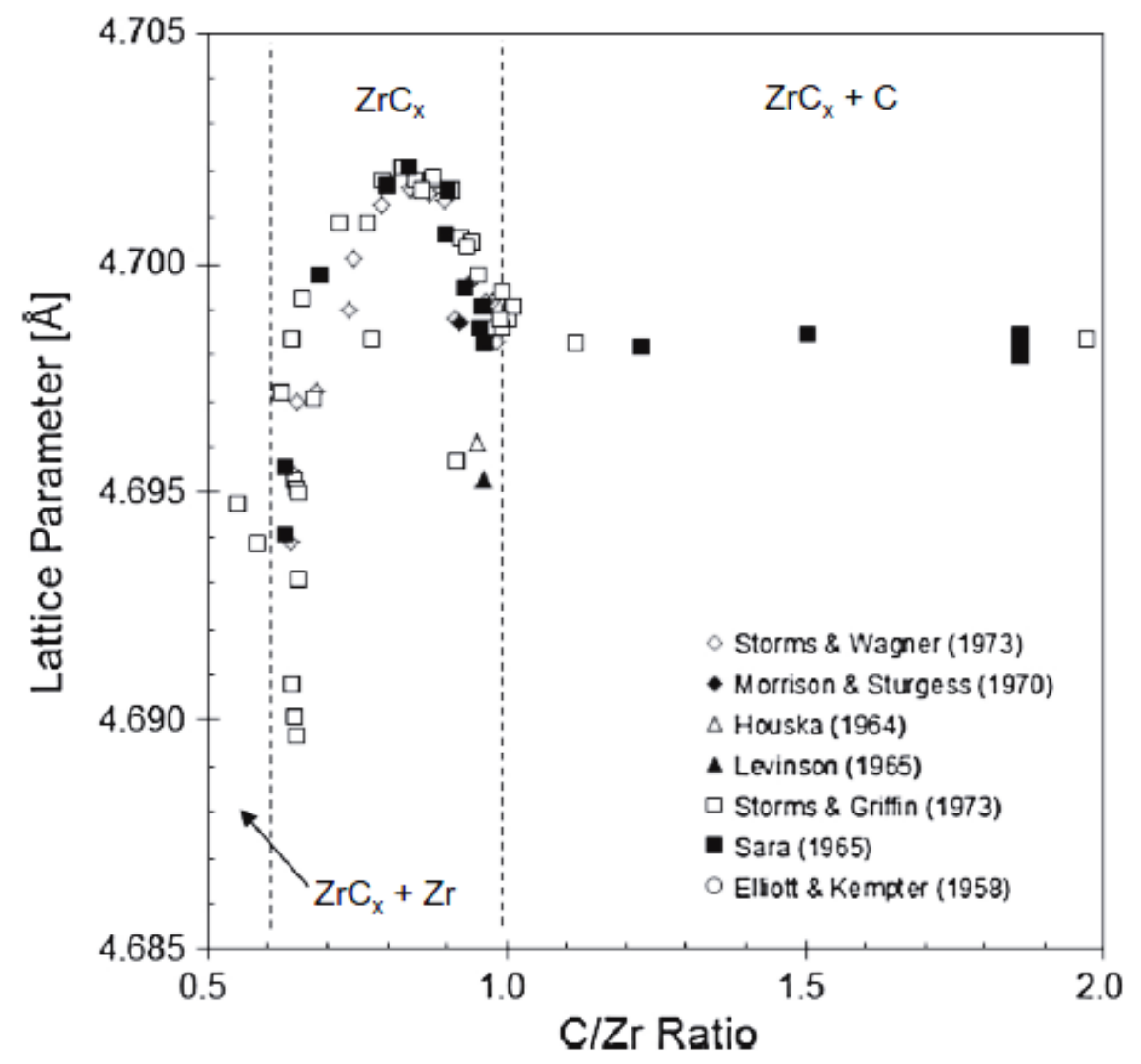

Figure 3.6. Variation of lattice parameter with C/Zr ratio reported in literature [1,3]

\section{B. TiC}

TiC also shows strong variation in property based on stoichiometry. Figure 3.7 and Figure 3.8 shows phase diagram and lattice parameter of TiC, respectively.

Figure 3.7 represents the phase diagram of the binary system Ti-C. The extensive homogeneity range is shown in shaded portion of the diagram. Due to wide range of stable compositions, these carbides are considered as defect structures.

Figure 3.8 illustrates the variation of lattice parameter with the composition in case of TiC. It should be noted that highest value of a 0 occurs at carbon/titanium of approximately 0.85 and not at (1to1) stoichiometry. This is also where melting point is higher. 


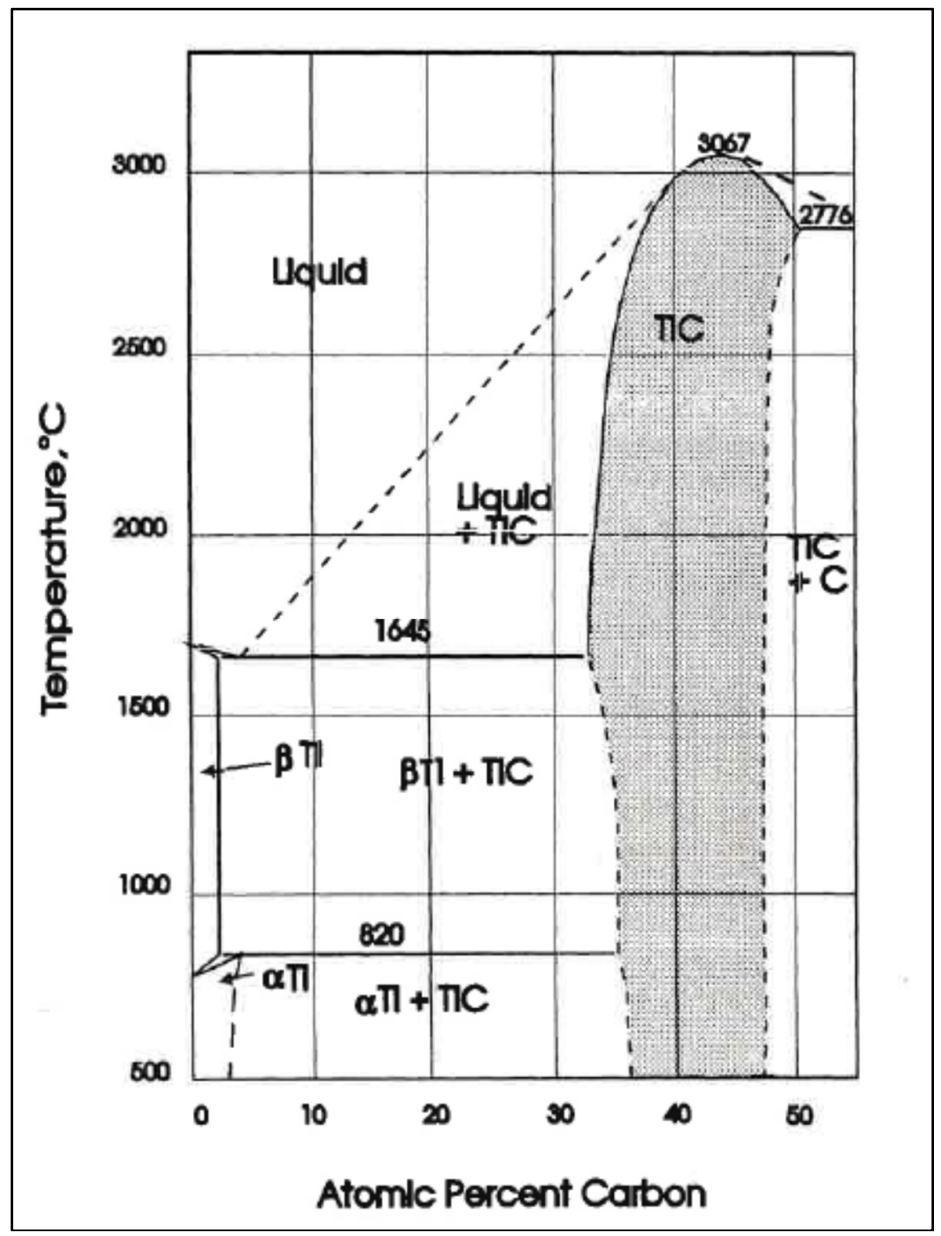

Figure 3.7. Carbon-titanium phase diagram. Homogeneity range shown in shaded section [1]. 


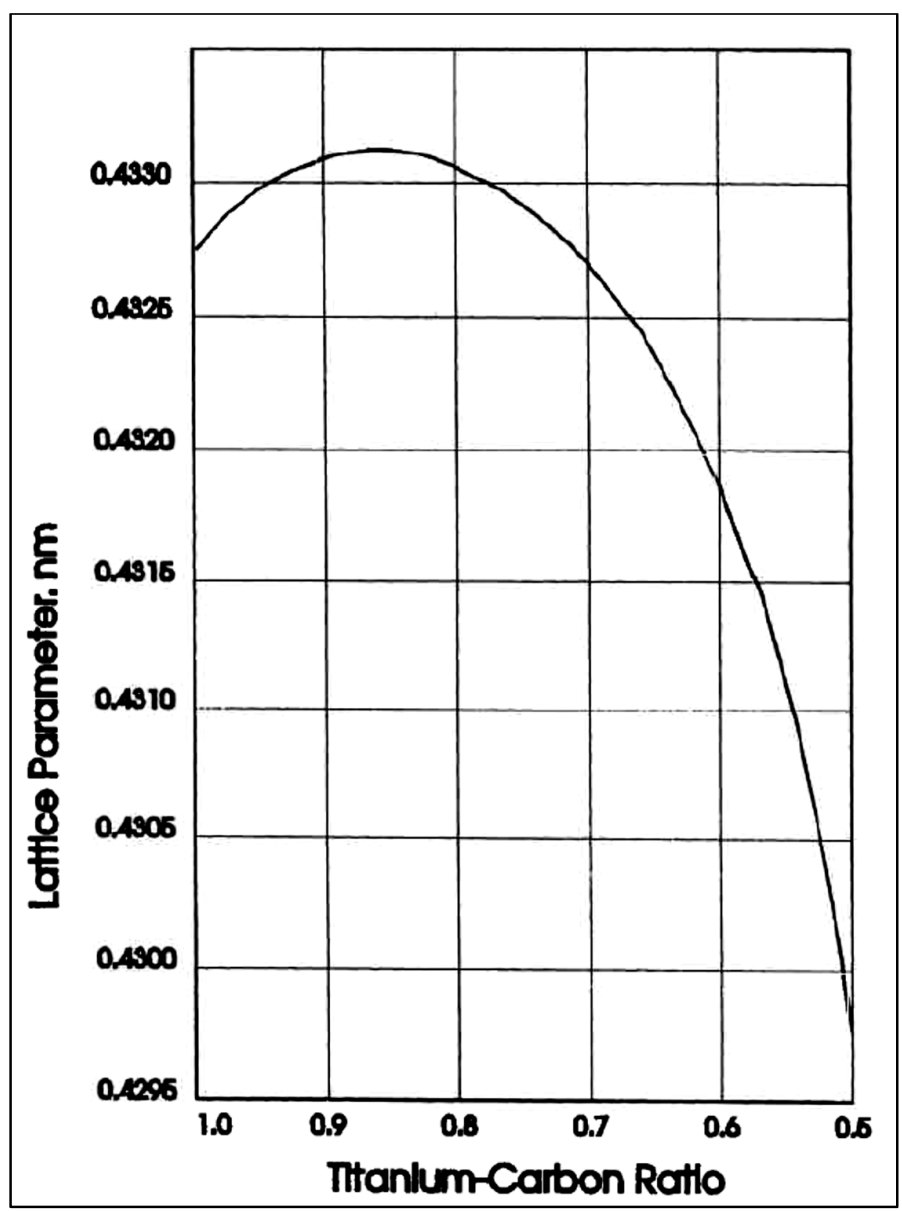

Figure 3.8. Lattice parameter of TiC as a function of composition.

\section{TiN}

Like $\mathrm{ZrC}$ and $\mathrm{TiC}$, TiN is also stable on wide range of stoichiometry between 0.6 and 1.2.

The equilibrium solid phases of the titanium-nitrogen system are shown in figure 3.9 and are defined below:

- the terminal hexagonal close-packed (HCP) solid solution $(\alpha \mathrm{Ti})$, based on titanium below $882{ }^{\circ} \mathrm{C}$, with a wide range of compositions;

- the terminal body-centered cubic (BCC) solid solution ( $\beta \mathrm{Ti}$ ), based on titanium above 882

${ }^{\circ} \mathrm{C}$, also with a wide range of compositions;

- the tetragonal $\mathrm{Ti}_{2} \mathrm{~N}$ phase (also referred to as the $\varepsilon$ phase ); and 
- the face-centered cubic (FCC) TiN phase (also referred to as the $\delta$ phase), with a wide range of compositions.

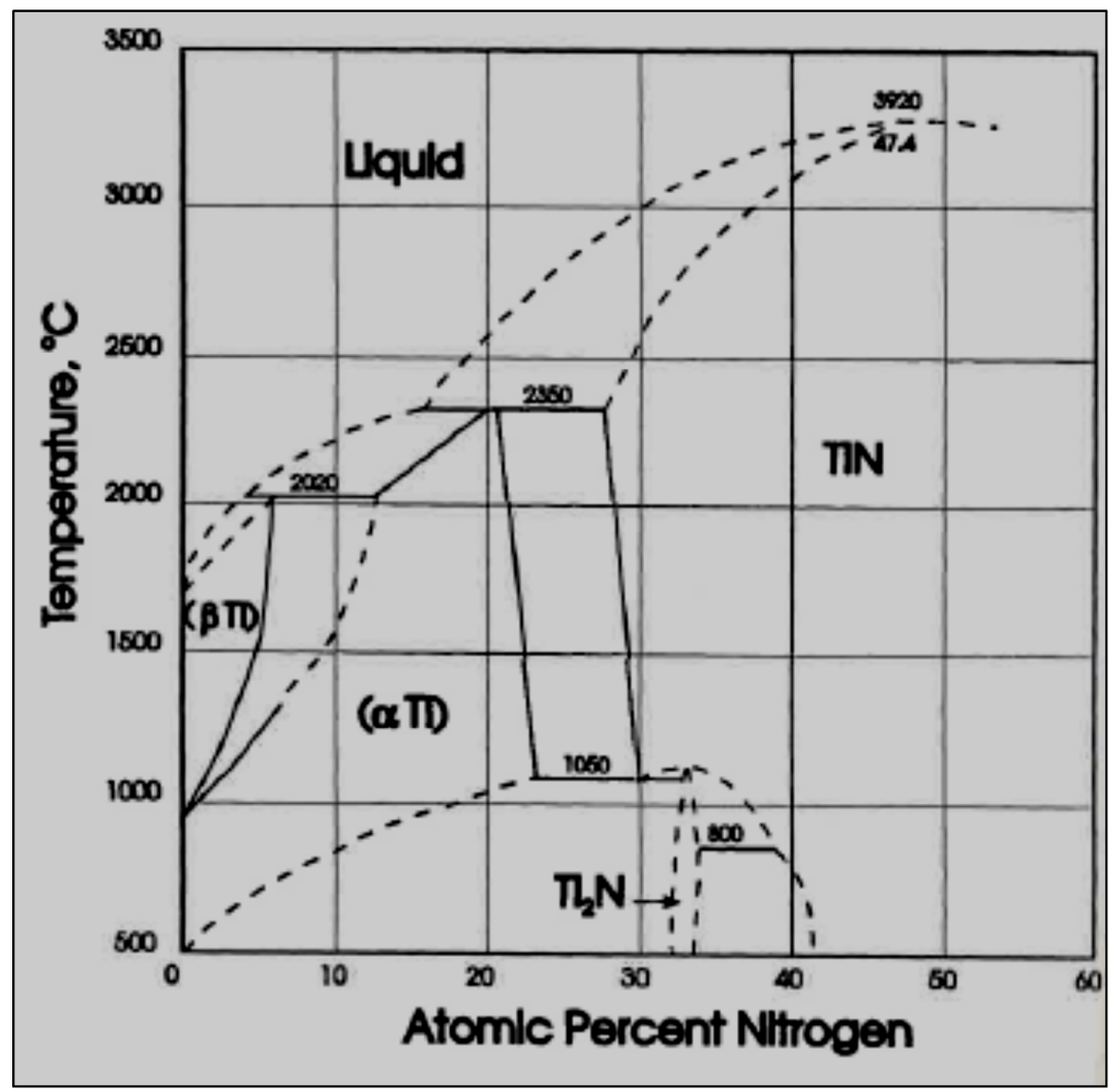

Figure 3.9. Nitrogen-titanium phase diagram [1].

\section{References}

[1] H. Pearson, Handbook of Refractory Carbides and Nitrides, Noyes Publication, Westwood (NJ), 1996

[2] J. Gan, INL/EXT-05-00799: Gas-Cooled Fast Reactor (GFR) FY 05 Annual Report: Ion Irradiation Study on Microstructure Stability of GFR Ceramics: $\mathrm{ZrC}, \mathrm{ZrN}, \mathrm{TiC}, \mathrm{TiN}$, and SiC, 2005, pp. 94-125. 
[3] Properties of zirconium carbide for nuclear fuel applications, Yutai Katoh, Gokul Vasudevamurthy, Takashi Nozawa, Lance L. Snead, Journal of Nuclear Materials 441 (2013) 718-742.

[4] E.K. Storms, The Refractory Carbides, Academic Press, New York, 1967. 


\section{Chapter 4}

\section{Theoretical Approach}

Radiation damage caused by ion implantation is a powerful technique for studying the characteristics of defects because this method can generally control the spatial distribution and amount of lattice defects, and introduce impurities in controlled amounts that may exceed the solubility limits. Using ion implantation, lattice defects, or crystalline defects, of structural materials have been extensively investigated and comprehensive theories of radiation damage were well established in 1950s and 1960s. Helium defects, as a special problem of interest have attracted many systematic experimental and theoretical studies in the past four to five decades. The main difficulty is that helium defect configuration is highly dependent on helium introduction condition. In the next section, a brief summary on formation of radiation induced defects is given. Section 4.2 provides the basic experimental findings of helium defects and related theories.

\subsection{Radiation induced defects}

During irradiation, an energetic incident ion interacts with stationary target atoms into two broad categories: the transfer of energy to electrons (ionization and electronic excitations) and the transfer of energy to atomic nuclei, primarily by ballistic processes involving elastic (billiard-ball-like) collisions. In most of the cases, electronic excitation and ionization are caused by highly energetic ions. The partitioning of the energy transferred into electronic excitations and into elastic nuclear collisions is an important process controlling the effects of radiation.

When an incident ion undergoes an elastic collision with an atom in the target material, a certain amount of kinetic energy, called the primary recoil energy, is transferred to the atom. If the recoil energy is sufficient (above threshold energy about 20 to $50 \mathrm{eV}$ in metals) the atom will be 'permanently' ejected from its original lattice position to an interstitial site, leaving behind a vacancy. This interstitial-vacancy pair is called a Frenkel pair. In many cases the 
primary recoil energy is high enough to create a cascade of atomic collisions by ejecting further atoms from their sites, resulting in more Frenkel pairs.

The initial defects produced during ballistic collisions are most likely to be point defects (vacancy and self-interstitial) that agglomerate to form two or three dimensional defects (dislocations, stacking faults, voids). Electronic excitations can lead to formation of ion tracks and conversely can also induce partial recovery of defects due to the local thermal spike generated by ionizing events. In our study, energy of ions during irradiation is only few $\mathrm{MeV}$ and they interact mainly by ballistic processes.

The spatial distribution of the defects depends on the nature of the incident particles: for electrons with energy of the order of $1 \mathrm{MeV}$ one obtains isolated Frenkel pairs; for proton, neutron and heavy ion irradiations one generally observes collision cascades due to their high mass, which one can imagine as a vacancy rich core surrounded by interstitials along the incident ion track. In this case, it is easier to observe higher dimensional defects because point defects are created so close to each other within the cascade that they can more easily join together to form larger clusters.

The number of displacements per atom and per second $\left(\mathrm{dpas}^{-1}\right)$ characterizes the irradiation. It is equal to the rate of production of Frenkel pairs (not the net production). For instance an atomic fraction of $10^{-3}$ Frenkel pairs is produced per second by an irradiation characterized by $10^{-3} \mathrm{dpas}^{-1}$.

Computer codes such as TRIM (Transport of Ions in Matter) are nowadays available to calculate defect production ( $\left.\mathrm{dpas}^{-1}\right)$ and their spatial distribution. The TRIM [1-3] is included in the SRIM (Stopping and Range of Ions in Matter) software [1-3] to simulate the interactions between in energetic particle and a solid target made up of stationary atoms. This code is based on Monte Carlo statistical approach. To perform calculation, data related to the target (chemical composition, density, displacement threshold energy, binding energies of atoms of the target) and the ion incident (type and energy) must be introduced into the program.

Using stopping power tables and other data, this program determine as a function of depth:

(i) the trajectory of the projectile and all displaced atoms from the target,

(ii) electronic and nuclear energy losses,

(iii) the final resting position of the incident (or implanted) ions,

(iv) the exit of the projectile by the front surface (back-scattering) or by the rear surface 
(transmission),

(v) the displacement of atoms due to cascades.

Following equation is used to determine the number of displaced atoms in the target (dpa):

$$
\mathbf{d p a}=\mathrm{D}_{\mathrm{TRIM}} \frac{\emptyset}{d}
$$

where:

- $\mathrm{D}_{\text {TRIM }}$ is the total number of atoms displaced calculated by the TRIM code (number of displaced atoms per unit surface);

- $\emptyset$ is the irradiation fluence of ions per unit area;

- $\mathrm{d}$ is the atomic density.

However, this value of dpa is only an estimate of the number of isolated defects induced by irradiation. In fact, this code does not take into account the effects of recombination (athermal or thermally activated) mainly dependent properties of the target; therefore gives an estimation of the concentration of point defects created at $0 \mathrm{~K}$, which is generally overestimated compared to experimental results.

In our study, we used this code to determine the electronic and nuclear stopping powers of ions, the ion implantation depth and the number of dpa for each irradiation. To estimate the amount of radiation induced defects by SRIM, the displacement threshold energy $E_{d}$, representing minimum energy necessary to permanently move an atom from its site must be known and should be introduced in the code. This value of $E_{d}$ would differ from one material to another.

There are two type of TRIM calculation available in SRIM code for damage calculation. TRIM allows the user to omit certain aspects of collision kinetics in order to increase the speed of the calculation. "Full Damage Cascades" includes all normal kinetics of the ion penetrating the target. The "Quick" calculation ignores target atom cascades and limits the calculation to the ion trajectories. The "Sputtering" calculation includes special plots related to target atom sputtering. Finally, TRIM may be run in a constrained mode, as explained below for calculating neutron, electron, and photon cascades [1-3]. 
1. "Detailed Calculation with Full Damage Cascades (FDC) option": This option follows every recoil until its energy drops below the lowest displacement energy of any target atom. Hence all collisional damage to the target is analyzed. The one exception is for very rare massive cascades which exceed 2000 atoms. At this point TRIM runs out of memory, and an error message is posted indicating that the limit of 2000 atoms in a single cascade has been exceeded.

2. “Quick Calculation-Kinchen Pease (KP) option”: This option should be used if you don't care about details of target damage or sputtering. The damage calculated with this option will be the quick statistical estimates based on the Kinchin-Pease formalism [3].

The following data will be calculated correctly with Quick Calculation-Kinchen Pease option": Final distribution of ions in the target, ionization energy loss by the ion into the target, energy transferred to recoil atoms, backscattered ions and transmitted ions.

Identical range results for each ion is obtained on using the full damage cascade and KP option, since the random number generator for the ions is separate from that used for the recoils. The main difference between KP and FDC calculation appears during damage calculation (or dpa). FDC gives more precise value to the actual damage into the material as it takes into account the displaced atoms caused by recoil. However, KP does the quick calculation by neglecting the damage caused by recoil and generally used for range, ions distribution and energy losses.

\subsection{Helium defects}

It is important to mention that most of the information provided in this section of the chapter has been taken from the work published by H. Trinkaus. He has published atleast 40 to 50 papers on helium behavior in nuclear materials (primarily metals) between $1979 \& 2003$. Below this, the information which is relevant to this work is provided from his papers [4-7].

Upon introduction into the bulk material, helium atom undergoes three distinct processes: diffusion (or transport), bubble nucleation and bubble growth.

The diffusion of helium atoms is the basic requirement for bubble nucleation and growth. Their diffusion is the result of random jumps from one stable or meta-stable lattice site to another. The most important positions of $\mathrm{He}$ atoms in a lattice are interstitial sites and 
substitutional sites (He atoms in vacancy). The preferred positions and dominant migration modes depend on temperature as well as on the presence of other intrinsic or irradiation induced defects acting as traps, especially vacancies and He-vacancy clusters.

\subsubsection{Helium Diffusion}

The most important basic processes of helium diffusion are described below and shown in figure 4.1.

a) Interstitial migration: The simplest mechanism by which helium atoms transport is the interstitial diffusion mechanism, in which the atoms occupy and move between the interstitial sites.

b) Substitutional migration (vacancy migration): Substitutional helium atoms occupy vacancies. For e.g., in case of TiC, vacancy could be metal-vacancy or carbon-vacancy. However, based on the different paths by which helium atoms transport, the substitutional migration mechanism can be subdivided into two categories:

i) Vacancy mechanism: A transient helium-vacancy complex containing one helium atom and two vacancies is formed in which He atom jumps from one vacancy to the other (see figure 4.1).

ii) Dissociation mechanism: In this mechanism, a He atom in a vacancy is dissociated from its position and diffuses interstitially until re-trapped by another vacancy. Dissociation process can be activated thermally, by recombination of vacancies occupied by helium atoms with selfinterstitial atoms or by irradiation induced displacement.

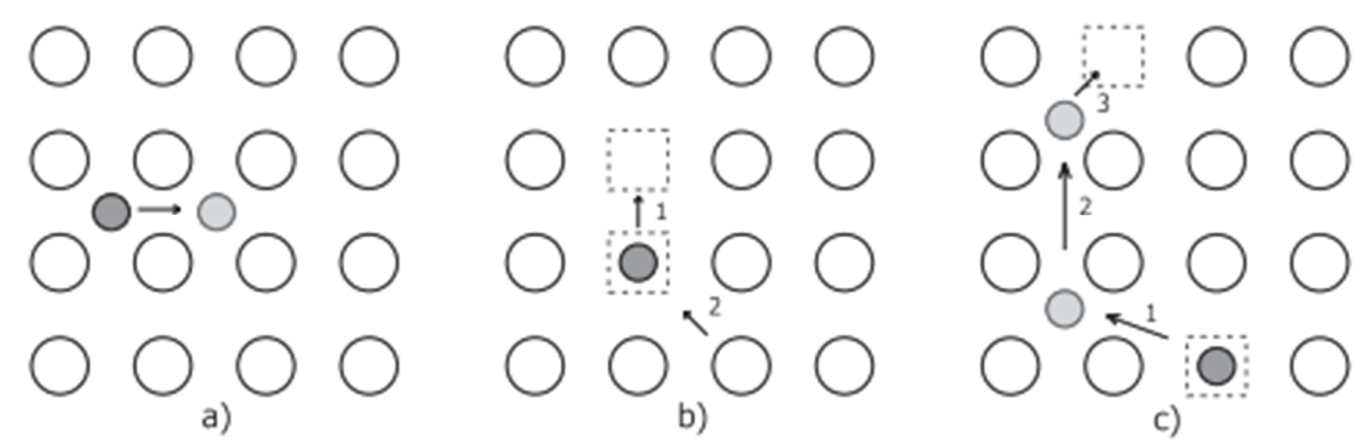

Figure 4.1. Migration mechanisms of He in a crystalline solid. a) Interstitial migration, b) 91 substitutional migration and c) dissociative interstitial diffusion [8]. 
In case of negligible radiation damage, for e.g. in case of helium production by tritium decay, helium atoms are introduced into material matrix without creation of vacancies, helium is transported by interstitial mechanism. However, if energetic helium is introduced into the sample from ion accelerators, it leads to the production of vacancies and self-interstitial atoms along with helium atoms. In this case, helium diffusion through substitutional vacancy mechanism is the dominant mode of diffusion due to the presence of vacancies.

\subsubsection{Helium Bubble Nucleation}

The nucleation of He bubbles within grains of a matrix occurs by the concurrent diffusion and clustering of He atoms, vacancies and self-interstitial atoms. The interactions between the three fundamental defects lead to the formation of small clusters of one to three helium atoms and one to three vacancies, with sizes in the 0.2 to $0.4 \mathrm{~nm}$ range. The tiny clusters formed during the transport stage are in highly non-equilibrium state and are thus very unstable. For example, in case of nickel, a self-interstitial atom can readily replace a trapped helium atom from a vacancy site because the formation energy for a vacancy-interstitial pair is $4.5 \mathrm{eV}$ while the vacancy-helium binding energy has been estimated to be about $3.6 \mathrm{eV}$ in nickel [9]. For heliumfilled cavities to grow, stable $\mathrm{He}-\mathrm{V}$ complexes (HeVCs) must first nucleate. It is estimated that between 3 to 10 defects must be involved for the formation of critical HeVCs [4]. The sizes for critical clusters are in the 0.2 to $1 \mathrm{~nm}$ range.

\subsubsection{Helium Bubble Growth}

Beyond the nucleation stage, $\mathrm{HeVCs}$ are stable up to a temperature that is about 0.3 to 0.4 of the melting temperature, particularly in metals. However, limited data is available in case of ceramics. Thus the next phase constitutes the growth phase of bubbles or He-V complexes. They grow under helium supply and stress- or irradiation-induced vacancy supersaturation. But even in the absence of both, they can grow, either by migration and coalescence, or by Ostwald ripening via helium resolution. 
Fundamentally, under all conditions including annealing, irradiations under heavy ions or during helium implantation, He- $\mathrm{V}$ complexes (or bubbles) can grow in principle by one or all of the three processes [5]:

- it can accept newly created gas atom, injected gas atom or redissolved gas atoms (Ostwald ripening);

- it can accept vacancies either by producing near-Frenkel pairs in the low temperature regime or by absorbing thermal vacancies, if they are mobile at higher temperatures;

- it can migrate until it coalesces with other bubbles (MC).

In the next paragraph, bubble coarsening upon annealing by migration and coalescence (MC) and Ostwald ripening (OR) has been discussed:

- Migration and Coalescence: Coalescence is essentially a collision process between the bubbles; the most important basis for this process lies under migration of bubbles. Bubble migration is due to random rearrangements of the bubble surface by diffusion of matrix atoms. Three routes are available to them: they diffuse via the vapor phase within the bubble; they can migrate around the surface of the bubble; or they can diffuse by a vacancy diffusion mechanism through the lattice near the bubble. Each process has a characteristic dependence on temperature and bubble radius $r$. In most of the cases, surface diffusion is the fastest mechanism (see figure 4.2a).

- Ostwald Ripening: Ostwald ripening is due to thermally activated resolution from (small) and re-absorption of helium atoms by large bubbles. This suggests that the apparent activation energy of bubble density reached by OR is equal to the energy of He dissociation from bubbles. In addition to the dissociation and re-absorption of $\mathrm{He}$ atoms, OR of He bubbles requires the dissociation and re-absorption of vacancies. Accordingly, this basically two-component OR process may be He atom or vacancy dissociation controlled, mainly depending on which of the two dissociation energies is higher (see figure 4.2b).

Figure 4.2 shows schematic illustration of the two main bubble coarsening mechanisms taken from Trinkaus et al. [5]: 
(a) Migration and Coalescence

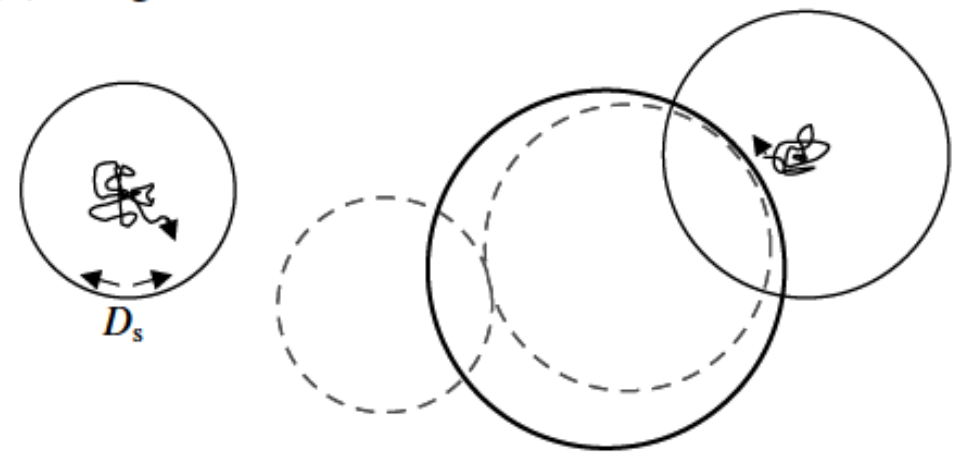

(b) Ostwald Ripening

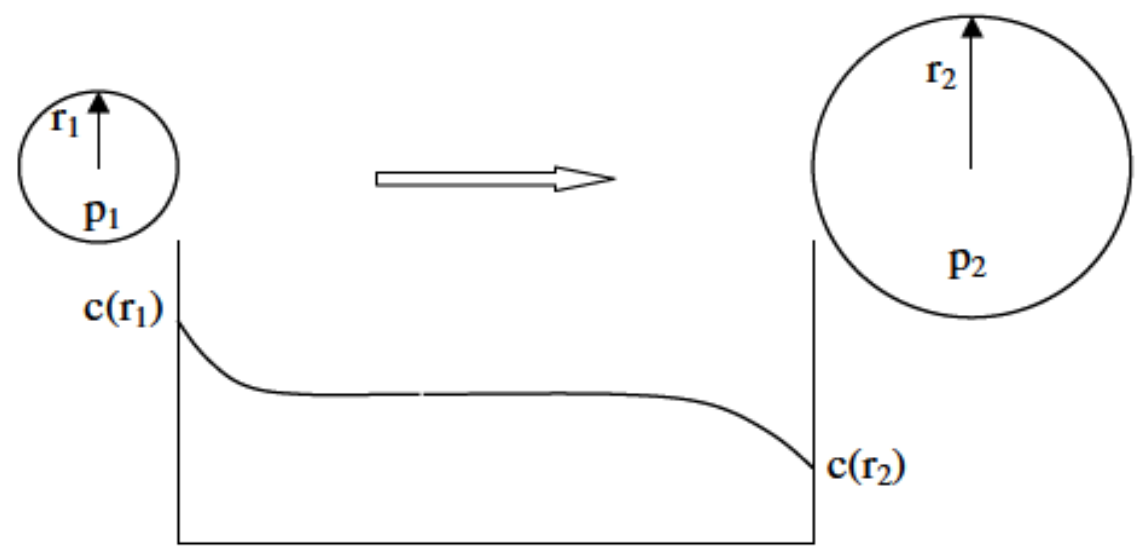

Figure 4.2. Schematic illustration of the two main bubble coarsening mechanisms, (a) migration and coalescence via surface diffusion, (b) Ostwald ripening due to He fluxes driven by differences in the thermal equilibrium He concentrations in the vicinity of small and large bubbles [5].

\subsubsection{State of helium bubble}

The next important concern about helium defects is the development of high pressure inside the bubbles which can reach the mechanical stability limit of the material. The energetic state of a gas bubble is characterized by two quantities: its volume and the gas pressure (or density) in it. The density in gas bubble is defined as ratio of number of He atoms to vacancies. 
The energetic state of bubble depends on the conditions and the stage of the bubble evolution, i.e. on temperature, He production and displacement rates, He concentration and dose, as well as bubble size.

For possible values of the pressure inside a bubble, Trinkaus has defined two distinctly different limiting cases [5]:

(1) The mechanical stability limit at which the matrix would yield by spontaneous plastic deformation, most likely by dislocation loop punching. Calculations have shown that the corresponding upper bound limit of the pressure may be reasonably well represented by:

$$
\mathrm{p} \leq \mathbf{0 . 2 \mu}
$$

where $\mu$ is the shear modulus of the matrix.

(2) The condition of thermodynamic equilibrium yields

$$
\mathbf{p}=\mathbf{2} \Upsilon / \mathbf{r}
$$

where $r$ is the surface free energy.

At high $\mathrm{He}$ to dpa ratio, high He production rate and concentration, where He dominates the bubble evolution since most of the concurrently produced SIAs and vacancies are annihilated at existing bubbles, it is likely that the pressure is close to the limit given by Eq. 4.2. For Ni, and austenitic steels where $\mu=90 \mathrm{GPa}$, this limit is as high as $18 \mathrm{GPa}$.

A sufficient thermal equilibrium vacancy concentration is required to establish thermal equilibrium of bubbles according to Eq. 4.3. which holds around and above T >0.4 Tm.

In small nm-scale bubbles, for instance in $\mathrm{Ni}$ and austenitic steels where $r=2 \mathrm{~N} / \mathrm{m}$, the equilibrium pressure reaches also values in the GPa range, but clearly not as high values as those defined by the mechanical stability limit.

It is emphasized here that at high He to dpa ratio and high He concentrations, the pressure remains significantly above the thermal equilibrium value even above $\mathrm{T}>0.4 \mathrm{Tm}$. 
The most important direct method to determine bubble sizes and volume density is transmission electron microscopy (TEM). To determine the pressure or helium densities in the bubbles, EELS (electron-energy-loss-spectrometry) or UVAS (ultraviolet absorption spectrometry) can be used. However, both these techniques are highly complicated and rarely available, therefore we developed an approach to calculate helium densities and pressure by entering experimental data obtained from TEM into theoretical equation known as equation of state of helium (EOS). These EOS have been clearly illustrated in 1983 by Trinkaus [4].

In the next paragraph, our approach and some equations are briefly outlined.

The state of helium inside the bubbles could be solid as well as fluid. The solid state of helium inside the bubbles is unlikely to occur, because it would generate very high pressure which can be far beyond the mechanical stability limit of the material and practically impossible. Therefore, we have only discussed the fluid state of helium.

A helium bubble may be imagined to be formed in three steps: formation of cavity $\left(F_{B}\right)$, introduction of helium into cavity considered to be rigid $\left(\mathrm{F}_{\mathrm{HeMe}}\right)$, and relaxation of thus formed bubble $\left(\mathrm{F}_{\mathrm{rel}}\right)$.

The formation free energy of the bubble, $\mathrm{F}_{\mathrm{B}}$, consists of the corresponding contributions $\mathrm{F}_{\mathrm{C}}$, $\mathrm{F}_{\mathrm{HeMe}}$ and $\mathrm{F}_{\mathrm{rel}}$, respectively.

$$
\mathbf{F}_{\mathbf{B}}=\mathbf{F}_{\mathbf{C}}+\mathbf{F}_{\mathrm{HeMe}}+\mathbf{F}_{\text {rel }}
$$

In this equation:

- if $r_{B} \geq 1 \mathrm{~nm}, F_{C}={ }_{\curlyvee} S$, where $\Upsilon$ is the specific surface free energy of material.

- $\mathrm{F}_{\mathrm{HeMe}}$ i.e. the energy required for the introduction of helium into the cavity. This can be divided into helium bulk free energy $\left(F_{H e}^{B}\right)$ and various interaction energies, for eg. He-He interaction to the bubble surface $\left(F_{H e}^{S}\right)$, He-metal interaction to the bubble surface $\left(F_{H e M e}^{S}\right)$.

In these terms, what concerns us the most is $F_{H e}^{B}$. Because $F_{H e}^{B}$ depends on the particle density. The density dependence of free energy $F_{H e}^{B}$ can be described by a truncated power series in the particle density $(n=1 / v)$ i.e. number of helium atoms present per unit volume and conversely, $v$ is volume per helium atom (in $\AA^{3}$ ).

It is important to mention that the gas pressure within the clusters of the limiting size $r=10$ $\AA$ is expected to be $4 \times 10^{4} \mathrm{MPa}$ in nickel [4]. This value also corresponds to the mechanical 
stability limit. For such pressure (and temperature below $10^{4} \mathrm{~K}$ ) neither the ideal nor Van der Waals gas law is valid. Therfore, we have to apply other modified gas law in this pressure regime.

Before proceeding further, it is important to recall that compressibility factor $(\boldsymbol{Z})$ is a measure of how much the thermodynamic properties of a real gas deviate from those expected of an ideal gas. Please see annexe I for details on compressibility factor.

Precisely, the ideal gas corrected for non-ideality is defined as: $\mathbf{P V} \mathbf{m}=\mathbf{Z R T}$ where $\mathrm{P}$ is the pressure, $\mathrm{V}_{\mathrm{m}}$ is the molar volume, $\underline{Z}$ is the compressibility factor, $\mathrm{R}$ is the universal gas constant, and $\mathrm{T}$ is the temperature. This law is also known as real gas equation of state (EOS). For ideal gas behavior $\mathrm{Z}=1$ as the gas pressure approaches 0 ; for real gas behavior $\underline{Z}$ could be greater than 1 (for high pressure) or less than 1 (for intermediate pressure).

To be easily understandable, if we are able to find the value of $\mathrm{Z}$ i.e. compressibility factor corresponding to pressure inside the helium bubbles. And, if we put this value of $\mathrm{Z}$ into $\left(\mathrm{PV}_{\mathrm{m}}\right.$ $=$ ZRT), we should be able to extract the value of $\mathrm{P}$ (i.e. pressure inside the bubbles).

Let us see the formulas mentioned by $\mathrm{H}$. Trinkaus [4] to find the value of $\mathrm{Z}$ i.e. compressibility factor.

The compressibility factor from Trinkaus equation of state of helium can be expanded into:

$$
z=(1-\rho)\left(1+\rho-2 \rho^{2}\right)+(1-\rho)^{2} \rho \frac{B}{v_{l}}+(3-2 \rho) \rho^{2} z_{l}+(1-\rho) \rho^{2} z_{l}^{\prime} v_{l}
$$

In equation 4.5:

$\mathrm{B}(\mathrm{T})$ the constant is defined as; $B(\boldsymbol{T})=\mathbf{1 7 0} \boldsymbol{T}^{-1 / 3}-\frac{\mathbf{1 7 5 0}}{\mathrm{T}}\left(\right.$ in $\left.\AA^{3}\right)$

$v_{l}$ the fluid volume upon freezing; $v_{l}=\mathbf{5 6} \boldsymbol{T}_{m}^{-1 / 4} \exp \left(-0.145 T_{m}^{+1 / 4}\right)\left(\boldsymbol{i n} \AA^{3}\right)$

$z_{l}$ the compressibility factor on freezing; $z_{l}=0.1225 v_{l} T_{m}^{0.555}$ 
$z_{l}^{\prime} v_{l}=\left(\frac{\partial z}{\partial} \ln v\right) l \approx-50 ;$ the quasi-harmonic approximation on freezing appears to be rather constant along the melting curve between $100 \mathrm{~K}$ and $1000 \mathrm{~K}$.

Please note that these equations are not explained in order to keep the application simple. Please see reference [4] for details.

We can easily observe from eq. (4.6 to 4.8), value of $\mathrm{T}$ i.e. annealing temperature and $\mathrm{T}_{\mathrm{m}}$ i.e. melting temperature is must for all the equations. Both the values of $\mathrm{T}$ and $\mathrm{T}_{\mathrm{m}}$ are easily known in the experiment.

The only unknown is ' $\rho$ ' in the above equation. The value of reduced particle density ' $\rho=$ $v_{l} / \mathrm{v}$ ' has to be found experimentally with the help of TEM. This would be explained later with the real data in the result part.

Finally once, the value of compressibility factor ' $\mathrm{z}$ ' is obtained by solving above equation 4.5 . This value can be put into real gas law $\left(\mathrm{PV}_{\mathrm{m}}=\mathrm{ZRT}\right)$ to derive the pressure inside the bubbles.

\subsubsection{Helium bubble nucleation at extended defects}

In the preceding section, possible effects of extended defects such as dislocations and grain boundaries (GBs) on bubble nucleation were ignored i.e. it was assumed to occur homogeneously within an otherwise perfect matrix lattice.

The extended defects may play a crucial role in bubble nucleation, bubble growth and interlinking of the bubbles especially at grain boundaries may provide channels to expel helium atoms out of the material. They can also lead to grain boundary weakening and de-cohesion.

Dislocations and GBs act as strong traps for mobile He atoms. The evolution of bubbles at extended defects such as dislocations and GBs is controlled by fluxes of He atoms to such sites (it constitute effective local He production rates at these defects) and these fluxes are controlled by the bubble evolution within the bulk of the matrix as illustrated in figure 4.3. 


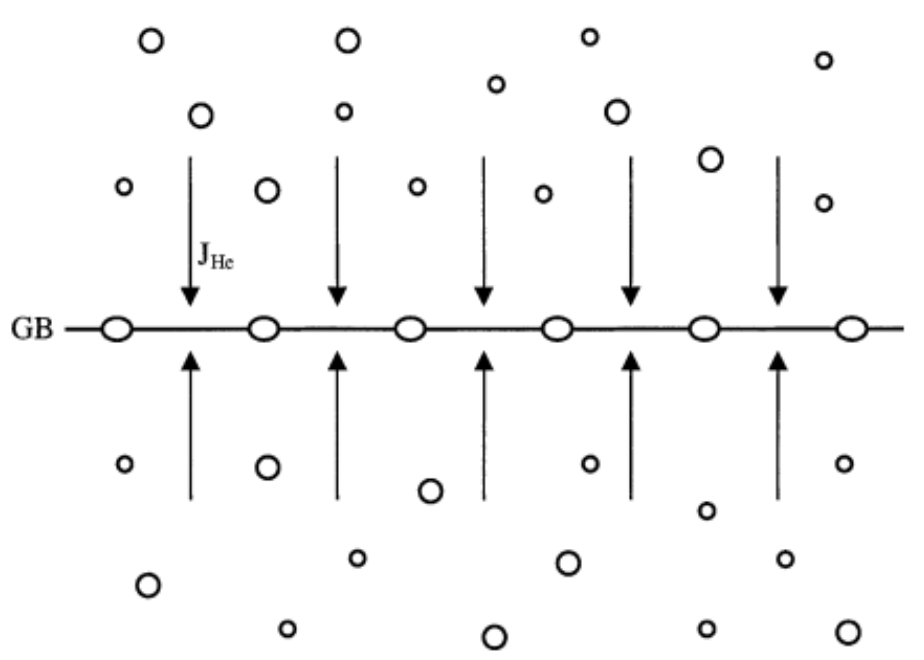

Figure 4.3. Schematic illustration of He fluxes to GBs controlled by the bubble evolution within the bulk of the matrix. These constitute effective local He production rates at GBs. Thus, the bubble evolution at extended defects is strongly coupled to that in the bulk.

There are few features which are important to mention:

(1) Premature bubble nucleation at an extended defect results in a reduction of the $\mathrm{He}$ concentration in the vicinity of grain boundary. This also leads to strongly reduced nucleation probability in their vicinity which manifests itself as bubble denuded zones adjacent to the extended defect. This has been previously observed by transmission electron microscopy.

(2) An extended defect collects a substantial fraction of the He atoms produced in such zones.

\subsubsection{Homogeneous vs. heterogeneous nucleation}

During helium production at various temperatures, extended defects behave differently:

At low temperatures: At low temperatures, where thermal dissociation from He atom traps is negligible, the globally dominant nucleation mode, homogeneous vs. heterogeneous, is 
determined by the relation between the partial sink strengths of bubble nuclei according to homogeneous nucleation and of pre-existing deep traps.

Homogeneous nucleation will be dominant if the sink strength of bubble nuclei, i.e. the product of their density and their size, is larger than the sink strength of other pre-existing traps, for instance the corresponding product of density and size of GBs or precipitates, and vice versa, depending on temperature and He production rate.

At high temperatures: At high temperatures, where thermal dissociation from $\mathrm{He}$ atom traps must be considered, the relation between the partial sink strengths of possible nucleation sites does no longer provide a sufficient criterion for homogeneous vs. heterogeneous nucleation.

In this case, effects of dislocation cores, interfaces and GBs on the thermodynamics of critical bubble nuclei are important.

In figure 4.4 the 'classical' understanding of these interfacial effects on the thermodynamic state of a nucleus of given volume, i.e. on the radius of curvature of its surface, $r$, the corresponding equilibrium gas pressure inside it, $p=2 \Upsilon / r$, where $r$ is the specific surface free energy, and $c^{*}$ mentioned in the figure is the thermal equilibrium He concentration around it.

Figure 4.4a shows the bubble (with radius $\mathrm{r}$ ) in the matrix of the material (or far away from the GB), however figure $4.4 \mathrm{~b}$ shows interfacial equilibrium at the triple junctions surface segments of a bubble and a GB. In triple junction, two surfaces are provided by bubble and other surface is provided by GB. This results in an increase in $r$ and corresponding decrease in pressure and $\mathrm{c}^{*}$.

These relationships suggest that heterogeneous bubble nucleation at interfaces and GBs would occur at lower critical He concentration $\mathrm{c} *$ than homogeneous nucleation (assuming that bubble nucleation would occur at a certain minimum critical nucleus size), and would be reached earlier therefore in the former than in the latter case.

Consequently, a significant reduction of the He concentration by substantial premature heterogeneous nucleation would prevent additional homogeneous nucleation. 
(a)

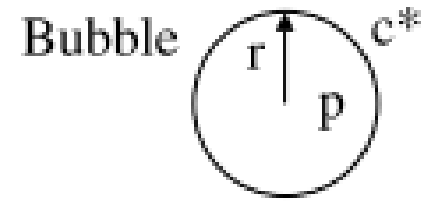

(b)

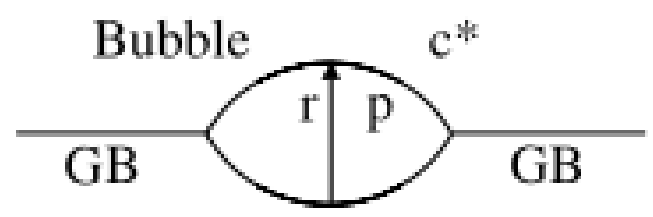

Figure 4.4 Illustration of interfacial effects on cavity nucleation at high temperatures; (a) spherical nucleus in the matrix, (b) lenticular nucleus at a GB. Under this condition, the radius of curvature of the nucleus surface, $r$, increases while the corresponding equilibrium gas pressure inside it, $p=2 r / r$, and the thermal equilibrium He concentration around $i t, c^{*}(p)$, decrease, suggesting that the critical concentration required for bubble nucleation decreases and bubble nucleation becomes easier from configuration (a) to (b).

\section{References}

[1] J. F. Ziegler, http://srim.org/SRIM/SRIM2011.htm.

[2] J.F. (James F.) Ziegler, U. Littmark, J.P. Biersack, The Stopping and Range of Ions in Solids / J.F. Ziegler, J.P. Biersack, U. Littmark, Pergamon, New York, 1985.

[3] SRIM - Lessons and Tutorials, http://www.srim.org/SRIM/Tutorials/Tutorials.htm, 2011.

[4] H. Trinkaus, Radiation effects, 78, 189 (1983).

[5] H. Trinkaus, B.N. Singh, J. Nucl. Mater. 323 (2003) 229-242.

[6] H. Trinkaus, B.N. Singh and A. J. E. Foreman, J. Nucl. Mater. 174 (1990) 80-85.

[7] H. Trinkaus, Point Defects and Defect Interactions in Metals, Yamada Science Foundation, 1982, published by University of Tokyo Press. 
[8] Helium Filled Bubbles in Solids- Nucleation, Growth and Swelling, Odd Runevall

Doctorial Thesis, Royal institute of technology Stockholm, Sweden 2012

[9] S. Sharafat, and N. M Ghoniem, Radiation Effects and Defects in Solids, 113, 331 (1990).

[10] D. Kaletta, Rad. Effects, 1983, Vol. 78, pp. 245-259

[11] Paul Erhart, Jaime Marian, J. Nucl. Mater. 414 (2011) 426-430. 


\section{Chapter 5}

\section{Experimental Approach}

In this chapter, an overall experimental approach followed during this thesis has been detailed.

\subsection{Details of sample manufacturing}

TiC, $\mathrm{ZrC}$ and TiN were manufactured at LTMEX Laboratory, CEA Saclay [1,2]. All the three samples were synthesized using hot isostatic pressing (HIP). Hot isostatic pressing (HIP) is a form of heat treatment that uses high pressure to densify materials and to improve their mechanical properties. Pressure is generally applied by an inert gas, usually argon. Important details on HIP for each material have been summarized in 1-5 rows of Table 5.1.

\begin{tabular}{|c|c|c|c|c|}
\hline & & TiC & $\mathbf{Z r C}$ & $\mathbf{T i N}$ \\
\hline 1. & $\begin{array}{c}\text { Manufacturing } \\
\text { Process }\end{array}$ & Hot Isostatic Pressing & $\begin{array}{l}\text { Hot Isostatic } \\
\text { Pressing }\end{array}$ & Hot Isostatic Pressing \\
\hline 2. & $\mathrm{~T}\left({ }^{\circ} \mathrm{C}\right)$ during HIP & $1600^{\circ} \mathrm{C}$ & $1900^{\circ} \mathrm{C}$ & $1400^{\circ} \mathrm{C}$ \\
\hline 3. & $\mathrm{P}$ (bars) during HIP & 1600 bars & 2000 bars & 1400 bars \\
\hline 4. & HIP Duration & $2 \mathrm{~h}$ & $2 \mathrm{~h}$ & $1 \mathrm{~h}$ \\
\hline 5. & $\begin{array}{l}\text { Chemical additions } \\
\text { during manufacturing }\end{array}$ & $\begin{array}{l}\mathrm{Fe}(<w \mathrm{t} .400 \mathrm{ppm}) \\
\mathrm{W}(<w \mathrm{wt} .6500 \mathrm{ppm}) \\
\mathrm{Co}(<w t .320 \mathrm{ppm})\end{array}$ & - & $\begin{array}{c}\mathrm{O}(<w t .8500 \mathrm{ppm}) \\
\mathrm{Fe}(<w t .1600 \mathrm{ppm}) \\
\mathrm{C}(<w t .800 \mathrm{ppm})\end{array}$ \\
\hline 6. & Density & $99 \%$ & $99 \%$ & $96.4 \%$ \\
\hline 7. & Grain size & $8-10 \mu \mathrm{m}$ & $1-5 \mu \mathrm{m}$ & $10-20 \mu \mathrm{m}$ \\
\hline
\end{tabular}




\begin{tabular}{|c|c|c|c|c|}
\hline 8. & Porosity & $\begin{array}{c}\text { a very low density } \\
(<1 \%) \text { of intra-granular } \\
\text { porosity. }\end{array}$ & $\begin{array}{l}\text { Intergranular } \\
\text { porosity and } \\
\text { low intra- } \\
\text { granular } \\
\text { porosity but } \\
\text { near grain } \\
\text { boundaries }\end{array}$ & $\begin{array}{c}\text { Spherical } \\
\text { intragranular }\end{array}$ \\
\hline 9. & Stoichiometry & $0.94 \pm 0.02$ & $0.92 \pm 0.02$ & $0.99 \pm 0.02$ \\
\hline
\end{tabular}

Table 5.1. Summary of various properties of the samples [1, 2].

Along with the details on material manufacturing, information on density, grain size, porosity and stoichiometry of these samples have been summarized in 6-9 rows of Table 5.1. The stoichiometric ratios have been calculated by calculating the concentration of $\mathrm{C}$ (or $\mathrm{N}$ ) and $\mathrm{Zr}$ (or Ti) by nuclear reaction analysis (NRA) and Rutherford backscattering spectroscopy (RBS), respectively. Moreover, the value of stoichiometric ratio has been verified by obtaining spectrum from Raman spectroscopy and by comparing the position and shape of spectrum with various spectrum given in the literature for different stoichiometric ratio. The pictures of sample's surface from scanning electron microscope (SEM) are provided in Figure 5.2.

$\mathrm{TiC}, \mathrm{ZrC}$ and $\mathrm{TiN}$ were received by us in the form of small rectangles and squares having an average dimensions around $2 \mathrm{~cm}$ x $2 \mathrm{~cm}$ x $0.5 \mathrm{~cm}$. These sample pieces were polished by 0.1 $\mu \mathrm{m}$ silicon carbide disc followed by a chemical polishing with colloidal silica to remove the surface defects. After polishing, the samples were cleaned ultrasonically with distilled water and ethanol.
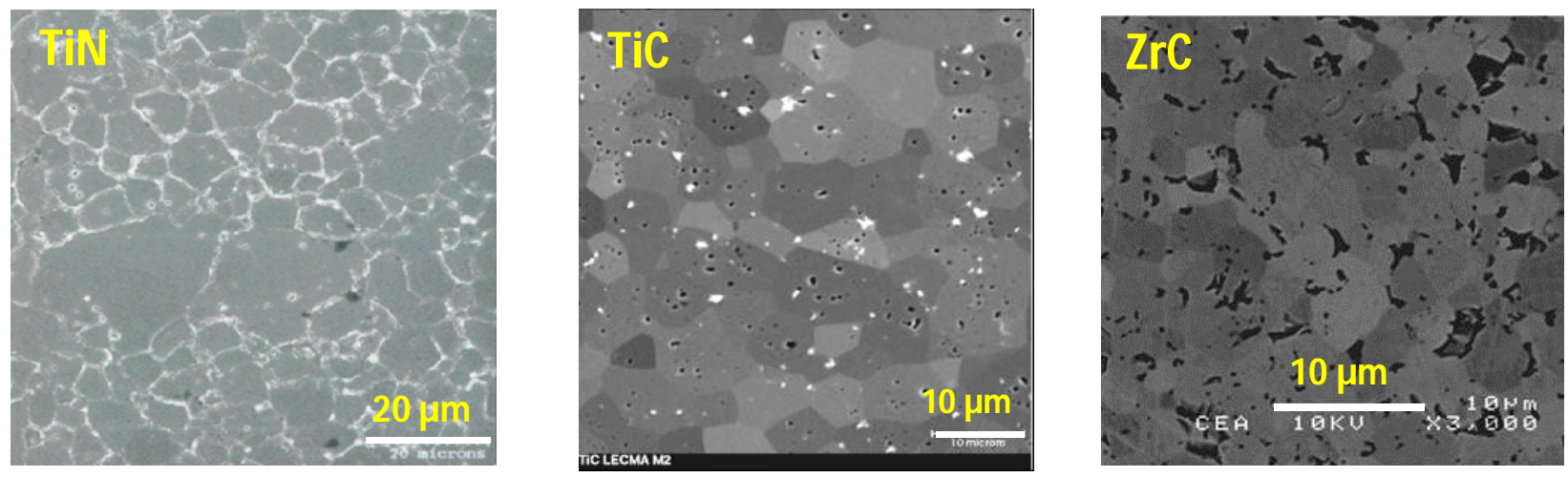

Figure 5.1. Pictures of TiN, TiC and ZrC from scanning electron microscope (SEM). 


\subsection{Implantation and annealing}

The goal of this thesis is to study helium mobility under thermal and radiation environment. To achieve this goal, two sets of experiments were conducted. A brief description of two sets of experiment is given in next paragraph and afterwards a detailed description is provided:

\section{- First set of experiments}

Aim: To study helium mobility under thermal environment.

Approach: He implantation $\rightarrow$ Thermal annealing $\rightarrow$ Sample characterization.

Remark: About $85 \%$ of the thesis work is devoted to conduct and interpret the result of first set of experiment.

This set of experiment is again divided into two sections.

\section{First section:}

Aim: To compare helium mobility under thermal annealing between $\mathrm{TiC}, \mathrm{ZrC}$ and $\mathrm{TiN}$.

Approach: He implantation (the value of implantation fluence is same) $\rightarrow$ Thermal annealing (at 5 different temperatures) $\rightarrow$ Sample characterization.

Remark: TiN, TiC and $\mathrm{ZrC}$ were implanted with same helium fluence and annealed at 5 different temperatures under same conditions to compare helium mobility.

\section{$\underline{\text { Second section: }}$}

Aim: To study the effect of implantation fluence on helium mobility under thermal annealing.

Approach: He implantation (implantation fluence is varied) $\rightarrow$ Thermal annealing (at only 2 temperatures) $\rightarrow$ Sample characterization.

Remark: These experiments were only done on $\mathrm{TiN}$ and $\mathrm{ZrC}$. TiN was implanted with three fluence $\left(F_{1}, F_{2}\right.$ and $\left.F_{3}\right)$ and sample with each fluence was annealed at two temperatures. Similar experiments were done on $\mathrm{ZrC}$.

Among $\mathrm{TiN}, \mathrm{TiC}$ and $\mathrm{ZrC}$, TiN has maximum grain size and close to stoichiometric ratio 1:1, however $\mathrm{ZrC}$ has minimum grain size and stoichiometric ratio is far from 1:1. TiC lies in 
between in terms of grain size and stoichiometric ratio. Therefore, due to limited time, some experiments and some characterization techniques (particularly TEM) were only limited to TiN and $\mathrm{ZrC}$.

\section{- Second set of experiments}

Aim: To study helium mobility under radiation damage.

Approach: Damaging the material by self-ion implantation $\rightarrow$ He implantation $\rightarrow$ Thermal annealing (if required) $\rightarrow$ Sample characterization.

Remark: About $15 \%$ of the thesis work is devoted to conduct and interpret the result of second set of experiment.

Before starting with the detailed description of each set of experiment, it is important to mention that the sample characterization method employed in each set of experiments are same and hence they are described only once at the end of this chapter. Furthermore, all the ion implantations were carried out at Jannus Laboratory, CEA-Saclay, hence a brief description of Jannus facility is provided below.

\subsubsection{Brief description of JANNUS Laboratory}

Figure 5.2 display the complete layout of the multi-irradiation facility at JANNUS Saclay [3].

Three accelerators are coupled: a 3 MV Pelletron ${ }^{\mathrm{TM}}$ named Épiméthée, a 2 MV Pelletron ${ }^{\mathrm{TM}}$ tandem named Japet and a 2.5 MV single ended Van de Graaff named Yvette.

Épiméthée is equipped with an electron cyclotron resonance ion source able to produce multicharged ions. Japet is equipped with a charge exchange ion source operating with Cs vapour able to produce initially single charged negative ions that are then converted into positive ions by a stripping process through a very low pressure argon leak. Yvette includes at its terminal a conventional radiofrequency ion source used to produce protons, deuterons and helium-3 and helium-4 ions. 
The triple beam chamber receives one beam line coming from each of the accelerators, allowing single, dual or triple beam irradiation. This chamber is implemented with a movable array of 7-Faraday mini-cups allowing a periodic control of the ion flux in each beam. The sample holder operates from liquid nitrogen temperature to $850{ }^{\circ} \mathrm{C}$. Three energy degraders constituted by rotating wheels mounted with suitable thin metallic layers give the possibility to broaden the damage profile accumulated into the sample under investigation. Each of the beam line converging towards the triple beam chamber is equipped with a raster scanner unit able to move the beam inside a $2 \times 2 \mathrm{~cm}^{2}$ area onto the sample surface. A second vacuum chamber is linked to Épiméthée. It can be used for single beam irradiation or ion beam analysis. A 5Faraday mini-cups device and a heating/cooling stage sample holder are also available in this chamber. A third vacuum chamber has been implemented on Yvette. It is a multipurpose ion beam analysis chamber equipped with two X-ray detectors, a high purity germanium detector for gamma-ray detection and two surface barrier detectors (100 and $1500 \mu \mathrm{m})$ usable for Rutherford backscattering, elastic recoil detection and nuclear reaction analysis measurements. 


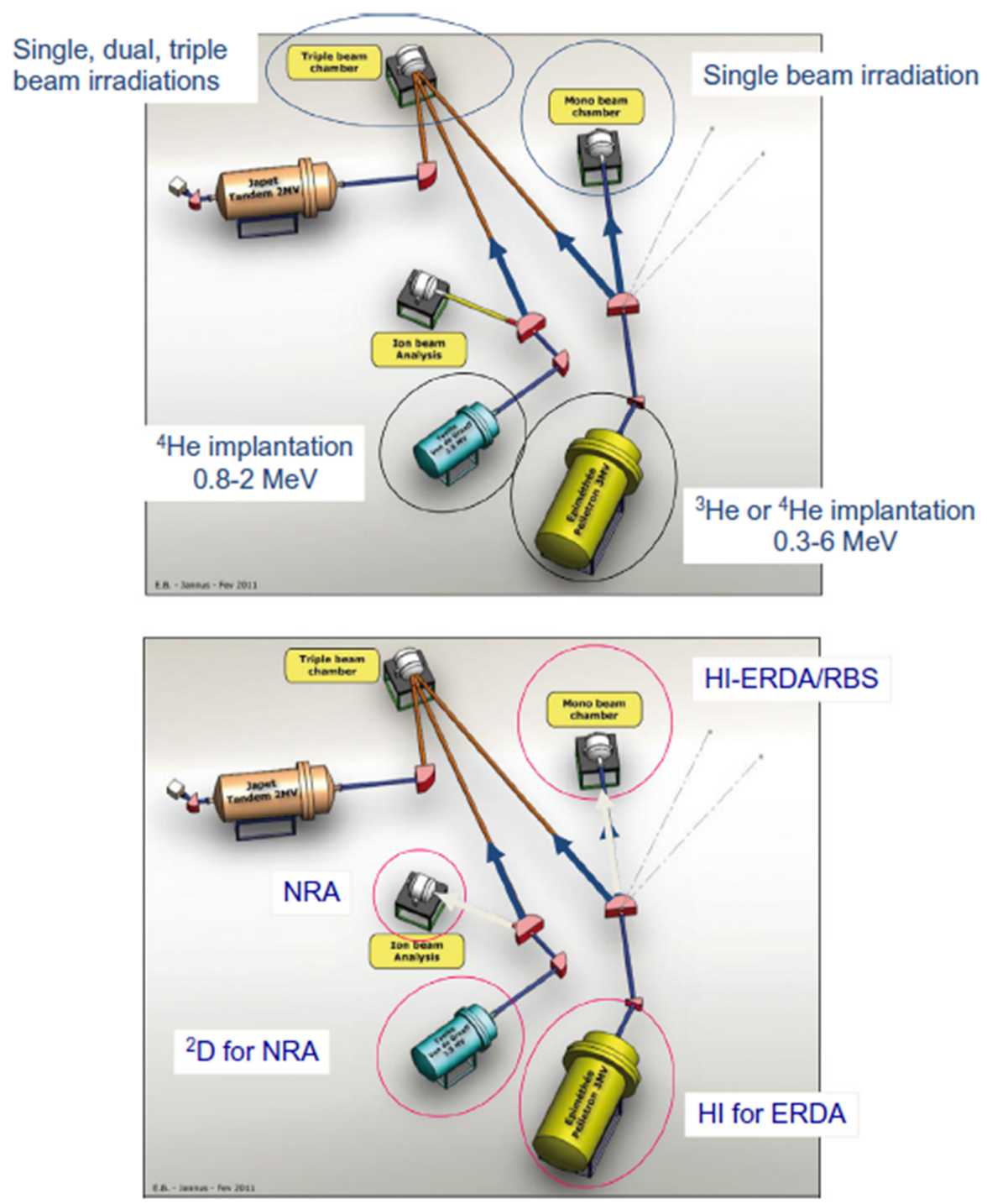

Figure 5.2. Complete layout of Jannus-Saclay facility.

\subsubsection{Experimental details for the first set of experiment}

\section{First section}

- He implantation: Three samples each of $\mathrm{TiC}, \mathrm{TiN}$ and $\mathrm{ZrC}$ were implanted with $3 \mathrm{MeV}$ ${ }^{3} \mathrm{He}^{+}$ions at room temperature. The regular monitoring of temperature during implantation was done using thermocouples and temperature only varied between $28 \pm 10{ }^{\circ} \mathrm{C}$. The beam was scanned on the complete sample holder for the homogeneous implantation of helium. The dose was about $5 \times 10^{16}$ ions $/ \mathrm{cm}^{2}$ with an average dose rate of $4 \times 10^{12}$ ions $/ \mathrm{cm}^{2} / \mathrm{s}$ using $3 \mathrm{MV}$ 
PELLETRON ÉPIMÉTHÉETM at the JANNUS Laboratory CEA Saclay [3]. The values of the projected ion range (see Table 5.2) were around $6.5 \mu \mathrm{m}$ (calculated by SRIM [4]) to avoid undesirable near surface effects.

\begin{tabular}{|c|c|c|c|}
\hline & TiC & TiN & ZrC \\
\hline${ }^{3}$ He energy $(\mathbf{M e V})$ & 3 & 3 & 3 \\
\hline Average ion flux $\left(\mathbf{1 0}^{\mathbf{1 2}} \mathbf{c m}^{-\mathbf{2}} \mathbf{s}^{-\mathbf{1}}\right)$ & $4.75 \pm 0.45$ & $3.56 \pm 0.35$ & $4.75 \pm 0.45$ \\
\hline Average dose $\left.\mathbf{( 1 0}^{\mathbf{1 6}} \mathbf{c m}^{-\mathbf{2}}\right)$ & $5.00 \pm 0.50$ & $5.10 \pm 0.1$ & $5.00 \pm 0.50$ \\
\hline Projected range $(\boldsymbol{\mu m})$ & 6.78 & 6.16 & 6.49 \\
\hline $\boldsymbol{\Delta} \mathbf{R p}(\mathbf{n m})$ & 315 & 289 & 441 \\
\hline $\begin{array}{c}\text { Maximum } \\
\text { (\%) } \mathbf{\%} \text { ) at the Bragg peak }\end{array}$ & 1.8 at. $\%$ & 1.7 at. $\%$ & 1.56 at. $\%$ \\
\hline
\end{tabular}

Table 5.2. Summary of various details during helium implantation [1,2].

- Thermal annealing: After helium implantation, each sample was cut into three (or four) small rectangle pieces with dimension $(0.7 \mathrm{~cm} \times 0.7 \mathrm{~cm} \times 0.5 \mathrm{~cm})$. To avoid contamination during annealing, each small piece was sealed in quartz tube under low argon gas pressure (see figure 5.3).

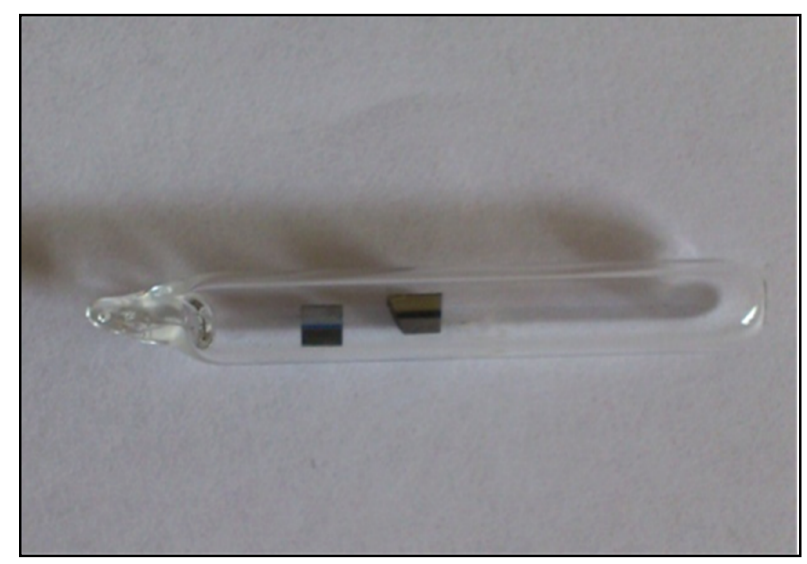

Figure 5.3. Sealed quartz tube containing helium implanted samples and a virgin sample. 
These quartz tubes were annealed at different temperatures ranging from $\mathrm{T}_{\mathrm{a}}=1000{ }^{\circ} \mathrm{C}$ to 1600 ${ }^{\circ} \mathrm{C}$ for 2 hours each in PCI laboratory (Physics and Chemistry of Irradiation) at CSNSM Orsay. The time duration ( $\mathrm{t}$ ) for annealing at each temperature was $2 \mathrm{~h}$. Temperatures in furnaces were monitored with conventional thermocouples. These information have been summarized in table 5.3 .

\begin{tabular}{|c|c|c|c|c|c|}
\hline Sample & $* \mathbf{T}_{\mathbf{a} 1}, \mathbf{t}$ & $* \mathbf{T}_{\mathbf{a} 2}, \mathbf{t}$ & $* \mathbf{T}_{\mathbf{a} 3}, \mathbf{t}$ & $* \mathbf{T}_{\mathbf{a} 4}, \mathbf{t}$ & $* \mathbf{T}_{\mathbf{a} 5}, \mathbf{t}$ \\
\hline $\mathbf{T i C}$ & $1000{ }^{\circ} \mathrm{C}, 2 \mathrm{~h}$ & $1100{ }^{\circ} \mathrm{C}, 2 \mathrm{~h}$ & $1400{ }^{\circ} \mathrm{C}, 2 \mathrm{~h}$ & $1500{ }^{\circ} \mathrm{C}, 2 \mathrm{~h}$ & $1600{ }^{\circ} \mathrm{C}, 2 \mathrm{~h}$ \\
\hline $\mathbf{T i N}$ & $1000{ }^{\circ} \mathrm{C}, 2 \mathrm{~h}$ & $1100{ }^{\circ} \mathrm{C}, 2 \mathrm{~h}$ & $1400{ }^{\circ} \mathrm{C}, 2 \mathrm{~h}$ & $1500{ }^{\circ} \mathrm{C}, 2 \mathrm{~h}$ & $1600{ }^{\circ} \mathrm{C}, 2 \mathrm{~h}$ \\
\hline $\mathbf{Z r C}$ & $1000{ }^{\circ} \mathrm{C}, 2 \mathrm{~h}$ & $1100{ }^{\circ} \mathrm{C}, 2 \mathrm{~h}$ & $1400{ }^{\circ} \mathrm{C}, 2 \mathrm{~h}$ & $1500{ }^{\circ} \mathrm{C}, 2 \mathrm{~h}$ & $1600{ }^{\circ} \mathrm{C}, 2 \mathrm{~h}$ \\
\hline
\end{tabular}

Table 5.3. Summary of details on annealing of helium implanted samples.

${ }^{*} T_{a 1}, T_{a 2}, T_{a 3}, T_{a 4}, T_{a 5}$ represents the first, second, third, fourth and fifth annealing temperature respectively.

Second section:

- He implantation: Two big samples each of $\mathrm{TiN}$ and $\mathrm{ZrC}$ were implanted three times under the same configuration (as first section) with three different fluences. During the three implantations, the He ions were implanted with $3 \mathrm{MeV}$ energy at room temperature using $3 \mathrm{MV}$ PELLETRON ÉPIMÉTHÉETM at the JANNUS Laboratory, CEA Saclay. The values of fluence were $5 \times 10^{16}$ at. $/ \mathrm{cm}^{2}\left(\mathrm{~F}_{1}\right), 0.73 \times 10^{16}$ at. $/ \mathrm{cm}^{2}\left(\mathrm{~F}_{2}\right)$ and $0.23 \times 10^{16}$ at. $/ \mathrm{cm}^{2}\left(\mathrm{~F}_{3}\right)$. The values of the projected ion range (calculated by SRIM [4]) and other details are summarized in table 5.4. It is to be noted that value of fluence $F_{1}$ is same as the value of implantation fluence used in first section. 


\begin{tabular}{|c|c|c|c|}
\hline & Fluence $\mathbf{F}_{1}$ & Fluence $\mathbf{F}_{2}$ & Fluence $\mathbf{F}_{3}$ \\
\hline${ }^{3} \mathrm{He}$ energy (MeV) & 3 & 3 & 3 \\
\hline Sample implanted & $\mathrm{TiN}, \mathrm{ZrC}$ & $\mathrm{TiN}, \mathrm{ZrC}$ & $\mathrm{TiN}, \mathrm{ZrC}$ \\
\hline Fluence $\left(10^{16}\right.$ atoms $\left.\mathrm{cm}^{-2}\right)$ & $5.10 \pm 1.1$ & $0.73 \pm 0.2$ & $0.23 \pm 0.08$ \\
\hline Average ion flux $\left(10^{12} \mathrm{~cm}^{-2} \mathrm{~s}^{-1}\right)$ & $3.56 \pm 0.7$ & $6.56 \pm 1.05$ & $6.04 \pm 1.1$ \\
\hline T $\left({ }^{\circ} \mathbf{C}\right)$ during implantation & $\begin{array}{l}\text { Between } \\
(28-38)^{\circ} \mathrm{C}\end{array}$ & $\begin{array}{c}\text { Between } \\
(20-37)^{\circ} \mathrm{C}\end{array}$ & $\begin{array}{c}\text { Between } \\
(18-23){ }^{\circ} \mathrm{C}\end{array}$ \\
\hline \multirow{2}{*}{$\begin{array}{c}\text { Projected range }(\mu \mathrm{m}), \\
\qquad \Delta \mathrm{Rp}(\AA)\end{array}$} & $\begin{array}{c}\text { TiN: } 6.16 \mu \mathrm{m}, \\
289 \mathrm{~nm}\end{array}$ & $\begin{array}{c}\text { TiN: } 6.16 \mu \mathrm{m}, \\
289 \mathrm{~nm}\end{array}$ & $\begin{array}{c}\text { TiN: } 6.16 \mu \mathrm{m}, \\
289 \mathrm{~nm}\end{array}$ \\
\hline & $\begin{array}{l}\mathrm{ZrC}: 6.49 \mu \mathrm{m}, \\
\quad 441 \mathrm{~nm}\end{array}$ & $\begin{array}{c}\text { ZrC: } 6.49 \mu \mathrm{m}, \\
441 \mathrm{~nm}\end{array}$ & $\begin{array}{c}\mathrm{ZrC}: 6.49 \mu \mathrm{m}, \\
441 \mathrm{~nm}\end{array}$ \\
\hline
\end{tabular}

Table 5.4. Summary of various details during helium implantation [1,2].

- Thermal annealing: After helium implantation, each sample was cut into three (or four) small rectangle pieces with dimension $(0.7 \mathrm{~cm}$ x $0.7 \mathrm{~cm} \times 0.5 \mathrm{~cm})$. To avoid contamination during annealing, each small piece was sealed in quartz tube under low argon gas pressure (see figure 3) and annealed at two temperatures $\mathrm{T}_{\mathrm{a}}=1100{ }^{\circ} \mathrm{C} \& 1500{ }^{\circ} \mathrm{C}$ for 2 hours in PCI laboratory at CSNSM Orsay.

\subsubsection{Experimental details for the second set of experiment}

- Self-ion implantation to damage the material: Before implanting He ions into the samples, $\mathrm{TiN}$ and $\mathrm{TiC}$ samples were damaged by self-ions $\left(\mathrm{Ti}^{6+}\right)$ and $\mathrm{ZrC}$ was damaged by its self-ions $\left(\mathrm{Zr}^{6+}\right)$ by using $2 \mathrm{MV}$ Japet accelerators at the JANNUS Laboratory, CEA Saclay. The energy of self-ions during implantation was kept $14 \mathrm{MeV}$. TiN and TiC were damaged up to $27 \mathrm{dpa}$ (displacement per atom). However, $\mathrm{ZrC}$ was damaged only up to 9 dpa due to large experimental time (around 3 days) required to obtain dpa $>9$ by $\mathrm{Zr}^{6+}$ ions. The ion range calculated by SRIM for each and other details during implantation are summarized in table 5.5. The values of dpa mentioned in this paragraph have been calculated by Full Damage Cascade Calculation (see chapter 4 for details).

An example of ion range and target vacancies created by SRIM is shown in figure 5.4 and figure 5.5 respectively. 


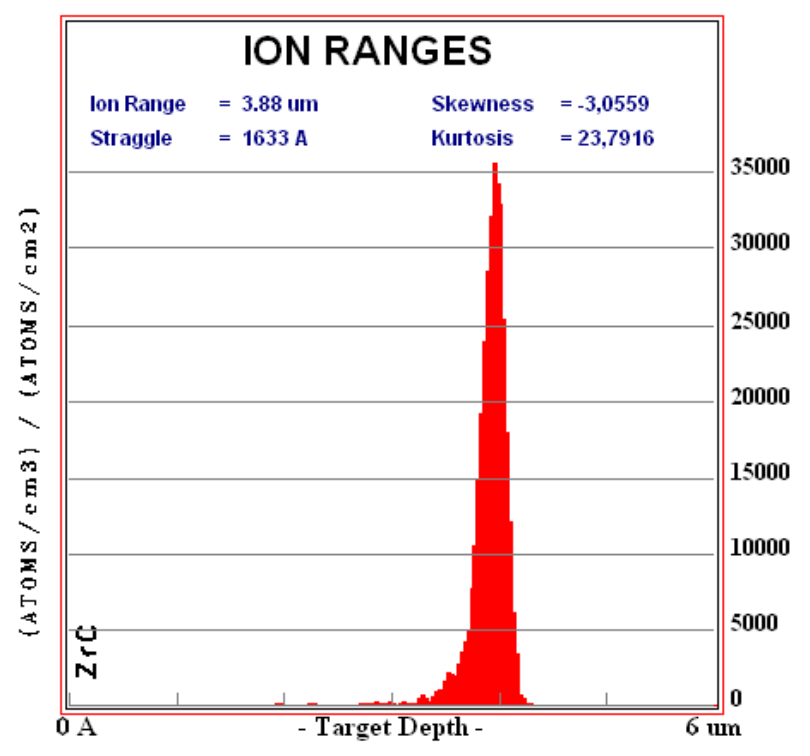

Figure 5.4. Ion ranges of $14 \mathrm{MeV} \mathrm{Zr}^{6+}$ ions in $\mathrm{ZrC}$.

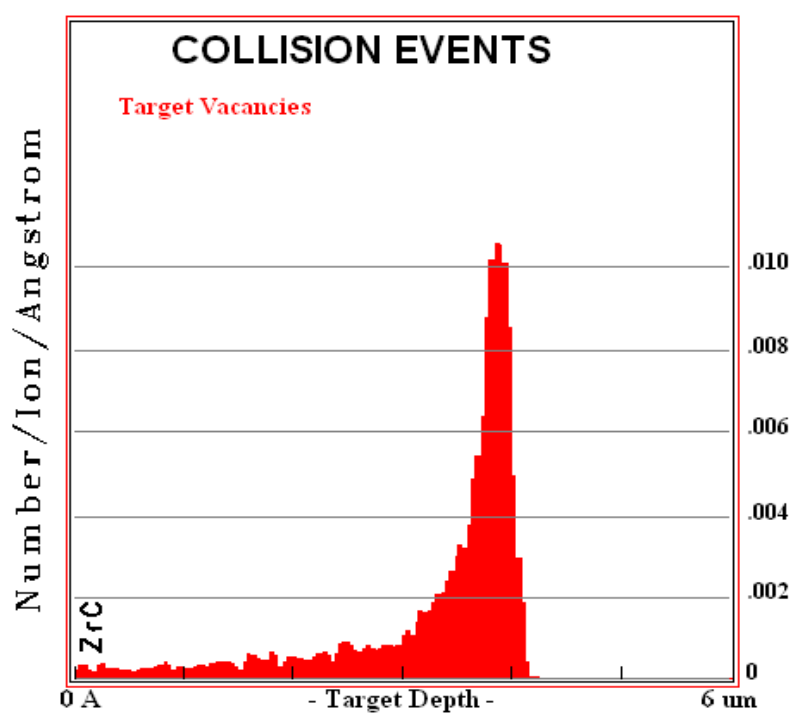

Figure 5.5. Collision events caused by $14 \mathrm{MeV} \mathrm{Zr^{6+ }}$ ion in $\mathrm{ZrC}$ 


\begin{tabular}{|c|l|l|c|c|c|c|c|}
\hline Sample & Ion & $\begin{array}{l}\text { Energy } \\
(\mathbf{M e V})\end{array}$ & $\begin{array}{c}\text { Fluence } \\
(\text { ions/cm }\end{array}$ & $\begin{array}{c}\text { Dpa } \\
(\text { calculated } \\
\text { by FDC } \\
\text { option) }\end{array}$ & $\begin{array}{c}\text { Dpa } \\
(\text { calculated } \\
\text { by KP } \\
\text { option) }\end{array}$ & $\begin{array}{l}\text { Range } \\
(\boldsymbol{\mu m})\end{array}$ & $\begin{array}{c}\Delta \mathbf{R p} \\
(\mathbf{n m})\end{array}$ \\
\hline $\mathrm{TiC}$ & \multirow{2}{*}{$\mathrm{Ti}^{6+}$} & 14 & $1.326 \mathrm{E} 16$ & 9 & 3.7 & 2.83 & 189 \\
\cline { 4 - 8 } & & & $3.84 \mathrm{E} 16$ & 27 & 9.9 & 2.83 & 189 \\
\hline $\mathrm{TiN}$ & $\mathrm{Ti}^{6+}$ & 14 & $1.326 \mathrm{E} 16$ & 9 & 3.7 & 2.66 & 223 \\
\cline { 4 - 8 } & & & $3.84 \mathrm{E} 16$ & 27 & 9.9 & 2.66 & 223 \\
\hline $\mathrm{ZrC}$ & $\mathrm{Zr}^{6+}$ & 14 & $4.93 \mathrm{E} 15$ & 9 & 3.7 & 2.53 & 375 \\
\hline
\end{tabular}

Table 5.5. Summary of implantation details for $\mathrm{Ti}^{6+}$ and $\mathrm{Zr}^{6+}$ ions.

- He implantation: $2 \mathrm{MeV}^{3} \mathrm{He}^{+}$ions were implanted into damaged $\mathrm{TiC}$, TiN and $\mathrm{ZrC}$ with fluence, $2.83 E 16$ at./cm ${ }^{2}$. The range calculated by SRIM was $R_{p}=3.88 \mu \mathrm{m}\left(\Delta R_{p}=1633 \AA\right), R_{p}$ $=3.98 \mu \mathrm{m}\left(\Delta \mathrm{R}_{\mathrm{p}}=1095 \AA\right), \mathrm{R}_{\mathrm{p}}=3.61 \mu \mathrm{m}\left(\Delta \mathrm{R}_{\mathrm{p}}=1641 \AA\right)$ for $\mathrm{ZrC}$, TiC and TiN respectively. Figure 5.6 shows the depth distribution of $\mathrm{Ti}^{6+}$ ions and induced-vacancies in $\mathrm{TiC}$ compared with $2 \mathrm{MeV}^{3} \mathrm{He}$ implantation profile.

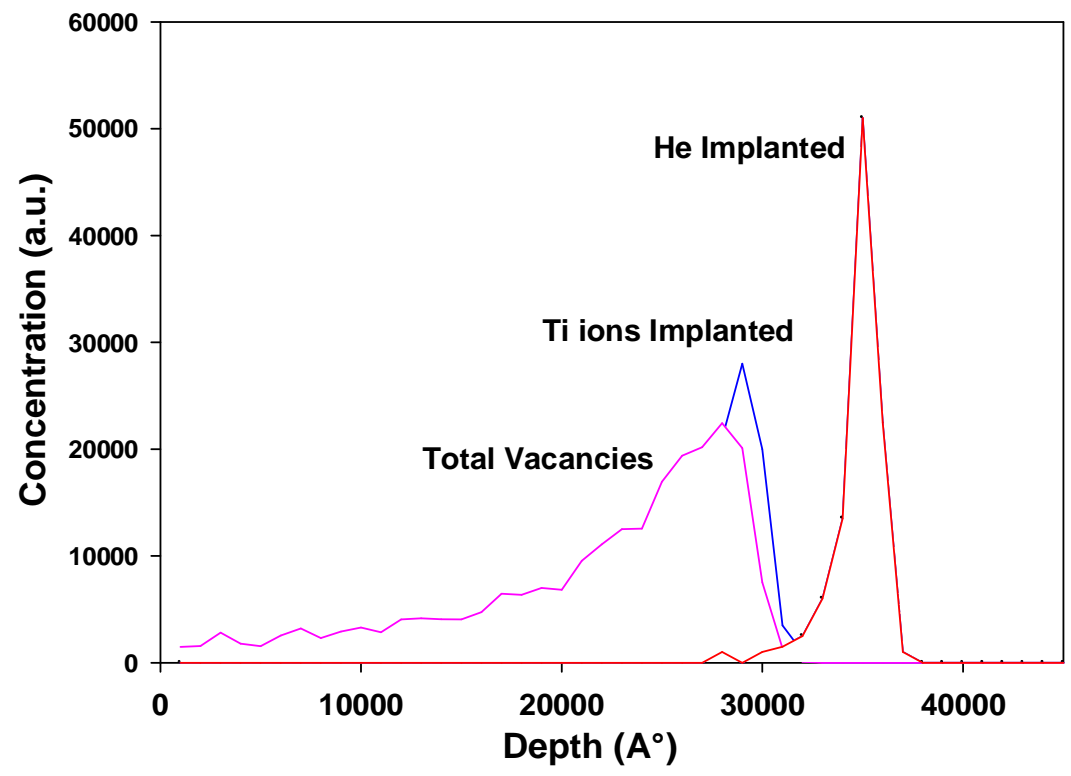

Figure 5.6. Comparison between depth distribution of $\mathrm{Ti}^{6+}$ ions and induced-vacancies in TiC with $2 \mathrm{MeV}^{3} \mathrm{He}$ implantation profile. 
- Thermal annealing: After radiation damage and helium implantation, some samples were annealed at $\mathrm{T}_{\mathrm{a}}=1600{ }^{\circ} \mathrm{C}$ to study the combine effect of damage and annealing.

\subsection{Sample characterization}

Table 5.6 describes the name and purpose of various characterization techniques used during this study. However, Nuclear reaction analysis (NRA) and Transmission electron microscopy (TEM) are the two vastly used techniques for the characterization of material and hence are explained in detail.

\begin{tabular}{|c|c|c|c|}
\hline & Name of the characterizing technique & Purpose of the technique & $\begin{array}{l}\text { Name of the laboratory equipped } \\
\text { with characterizing instrument }\end{array}$ \\
\hline 1. & $\begin{array}{l}\text { Nuclear reaction analysis (NRA) with } \\
\text { stationary deuteron beam ( } 1 \mathrm{~mm} \text { size) }\end{array}$ & $\begin{array}{l}\text { To measure } \mathrm{C} \text { and } \mathrm{N} \text { contents in both } \\
\text { carbides and nitride. } \\
\text { To know He depth distribution along the } \\
\text { depth of the sample. }\end{array}$ & Jannus Laboratory, CEA Saclay \\
\hline 2. & $\begin{array}{l}\text { Nuclear reaction analysis (NRA) with } \\
\text { deuteron beam ( } 1 \mu \mathrm{m} \text { size) by beam } \\
\text { scanning }\end{array}$ & $\begin{array}{l}\text { To know the helium distribution in lateral } \\
(\mathrm{x}, \mathrm{y}) \text { direction. }\end{array}$ & LEEL, CEA Saclay \\
\hline 3. & Rutherford back scattering (RBS) & $\begin{array}{l}\text { To calculate the stoichiometric ratio of } \\
\text { the material in combination with NRA } \\
\text { measurements (see row 1) by knowing } \\
\text { the concentration of heavy elements ( } \mathrm{Ti} \\
\text { or } \mathrm{Zr} \text { ). }\end{array}$ & Jannus Laboratory, CEA Saclay \\
\hline \multirow[t]{2}{*}{3.} & $\begin{array}{l}\text { Transmission Electron Microscopy (TEM) } \\
\text { on cross-section specimen prepared by FIB } \\
\text { (focused ion beam). }\end{array}$ & $\begin{array}{l}\text { TEM: To know the effect of helium on } \\
\text { material's microstructure (for eg. bubble } \\
\text { formation, cavity formation, blisters etc.) }\end{array}$ & SRMP, CEA Saclay. \\
\hline & & $\begin{array}{l}\text { FIB: To prepare cross-section TEM } \\
\text { specimen. }\end{array}$ & IEMN, CNRS, Lille. \\
\hline 4. & X-ray Diffraction & To know lattice swelling. & $\begin{array}{l}\text { LEMHE-ICMMO, University } \\
\text { Paris SUD-11 }\end{array}$ \\
\hline
\end{tabular}




\begin{tabular}{|l|l|l|l|}
\hline 5. & Raman Spectrometry & $\begin{array}{l}\text { To detect different phases and to see the } \\
\text { evolution of phases after implantation and } \\
\text { annealing. }\end{array}$ & Jannus Laboratory, CEA Saclay. \\
\hline 6. & Nano-indentation & $\begin{array}{l}\text { To know hardness of material after } \\
\text { irradiation. }\end{array}$ & SRMP, CEA Saclay. \\
\hline 7. & $\begin{array}{l}\text { Scanning electron microscopy (SEM) and } \\
\text { electron microprobe }\end{array}$ & $\begin{array}{l}\text { To know the elemental concentration and } \\
\text { surface changes after irradiation and } \\
\text { annealing. }\end{array}$ & SRMP, CEA Saclay. \\
\hline
\end{tabular}

Table 5.6. Details of various characterization techniques used.

In the following paragraphs, firstly detailed description of NRA and TEM is provided and other techniques are described later.

\subsubsection{Nuclear Reaction Analysis with stationary $1 \mathrm{~mm}$ size deuteron beam: To determine He distribution along the depth}

To determine the helium depth distribution into the sample, nuclear reaction analysis (NRA) was done. To carry out NRA with ${ }^{3} \mathrm{He}\left(\mathrm{d}, \mathrm{p}_{0}\right)^{4} \mathrm{He}$ nuclear reaction, an energetic deuteron beam is bombarded on the sample pre-implanted with helium. As a result of reaction between deuteron and helium-3, proton and alpha-particles are produced. If helium is implanted deep into the sample, then $\alpha$-particle gets absorb with in the material and hence the chances of its detection are reduced. However, protons are easily detected due to its low mass and carry the information on position and quantity of helium.

The ${ }^{3} \mathrm{He}\left(\mathrm{d}, \mathrm{p}_{\mathbf{0}}\right)^{4} \mathrm{He}$ nuclear reaction has a wide resonance centered on $\mathrm{E}_{\mathrm{d}}=430 \mathrm{keV}$. These measurements were performed on as-implanted and thermally annealed samples by using the 2.5 MV Van de Graff accelerators Yvette at JANNUS Laboratory.

The deuteron milli-beam of $0.5 \mathrm{~mm}$ to $1 \mathrm{~mm}$ spot size with beam energy of $1.3 \mathrm{MeV}$ was used in order to penetrate the depth of $\sim 6.5 \mu \mathrm{m}$ in sample. The protons produced by various $(\mathrm{d}, \mathrm{p})$ and $(d, \alpha)$ reactions along with the backscattered deuterons were detected with a surface barrier detector located at an angle of $150^{\circ}$ with respect to the incident beam. A $29 \mu \mathrm{m}$ thin mylar 
$\left(\mathrm{C}_{10} \mathrm{H}_{8} \mathrm{O}_{4}\right)$ foil was placed in front of the $1500 \mu \mathrm{m}$ thick surface barrier detector to stop all the backscattered deuterons. The solid angle subtended by the detector was $2.44 \mathrm{msr}$. The configuration of nuclear analysis chamber is shown in figure 5.7.

The detected spectrum contains several peaks from various deuteron-induced nuclear reactions e.g., ${ }^{12} \mathrm{C}\left(\mathrm{d}, \mathrm{p}_{0}\right){ }^{13} \mathrm{C},{ }^{16} \mathrm{O}\left(\mathrm{d}, \mathrm{p}_{0}\right){ }^{17} \mathrm{O},{ }^{16} \mathrm{O}\left(\mathrm{d}, \mathrm{p}_{1}\right){ }^{17} \mathrm{O},{ }^{3} \mathrm{He}\left(\mathrm{d}, \mathrm{p}_{0}\right){ }^{4} \mathrm{He}$. The energy of each peak was checked by using the PYROLE code [5]. The proton signal from the ${ }^{3} \mathrm{He}\left(\mathrm{d}, \mathrm{p}_{0}\right)^{4} \mathrm{He}$ nuclear reaction (located at about $13 \mathrm{MeV}$ ) gave us the information about the quantity and position of helium into the sample.

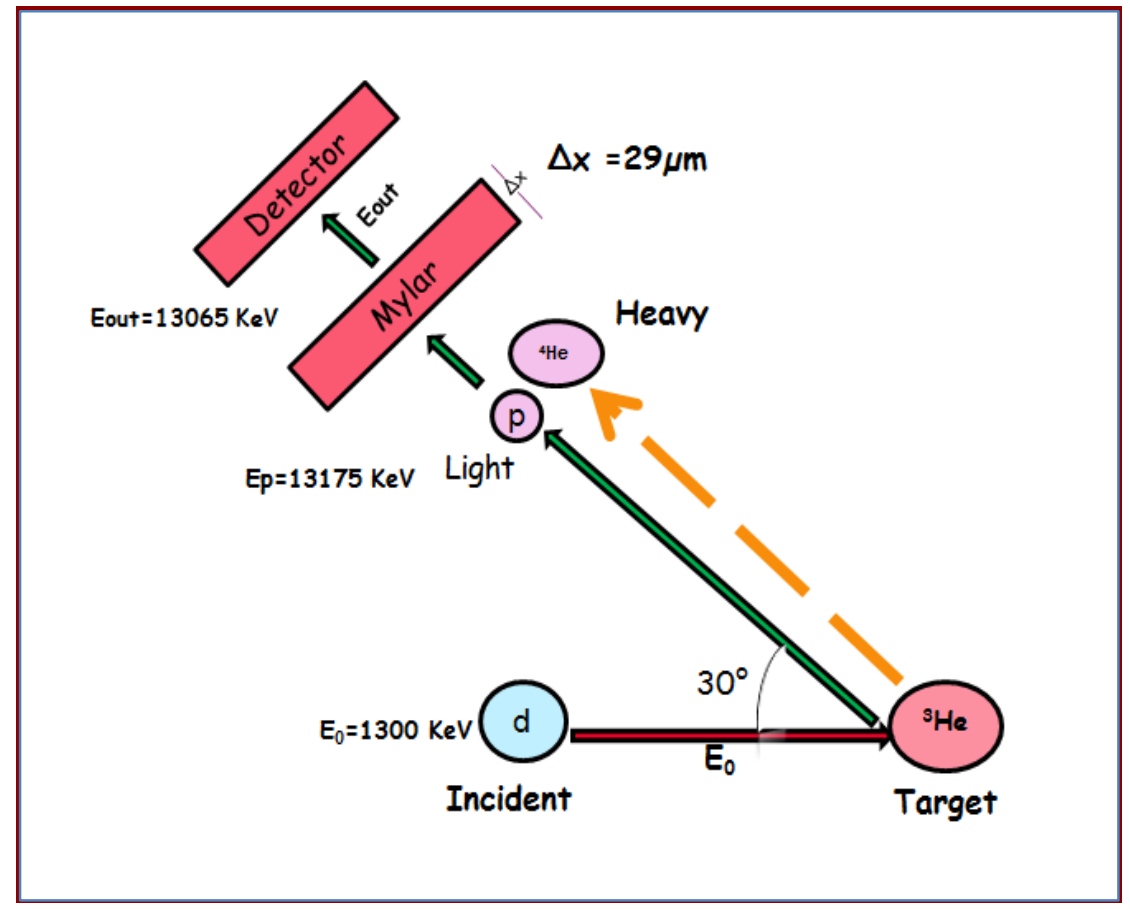

Figure 5.7. Configuration of nuclear analysis chamber at JANNUS Laboratory, CEA, Saclay.

The number of detected protons $\mathrm{N}_{\mathrm{p}}$ for a profile analyzed with a given deuteron beam (having energy $\mathrm{E}_{0}$ and deuteron particle $\mathrm{N}_{\mathrm{d}}$ ) can be determined from equation [6]:

$$
\mathrm{N}_{\mathrm{p}}\left(\mathrm{E}_{0}\right)=\mathrm{N}_{\mathrm{d}}\left(\mathrm{E}_{0}\right) \Omega \int_{x=0}^{\infty}\left(\frac{d \sigma\left(E_{d}(x)\right)}{d \Omega}\right) \rho(x) d x
$$


where $\mathrm{d} \sigma\left(\mathrm{E}_{\mathrm{d}}(\mathrm{x})\right) / \mathrm{d} \Omega$ is the differential cross section for ${ }^{3} \mathrm{He}(\mathrm{d}, \mathrm{p})^{4} \mathrm{He}$ reaction at energy $E_{d}$, which describes the probability of the reaction at this deuteron energy. The deuteron energy $\mathrm{E}_{\mathrm{d}}(\mathrm{x})$ will be attained at some specific depth in the material which depends on the incident deuteron energy $\left(\mathrm{E}_{0}\right)$ and the rate of energy loss for the deuterons with depth within the material. In the above integral, $\rho(x)$ represents the depth distribution of He. The values of the cross section as a function of deuteron energy corresponding to our detector solid angle were calculated using the data from Bosch \& Hale [7]. The cross section of ${ }^{3} \mathrm{He}\left(\mathrm{d}, \mathrm{p}_{0}\right){ }^{4} \mathrm{He}$ nuclear reaction versus deuteron energy with the data mentioned in the paper from Bosch \& Hale has been plotted in figure 5.8.

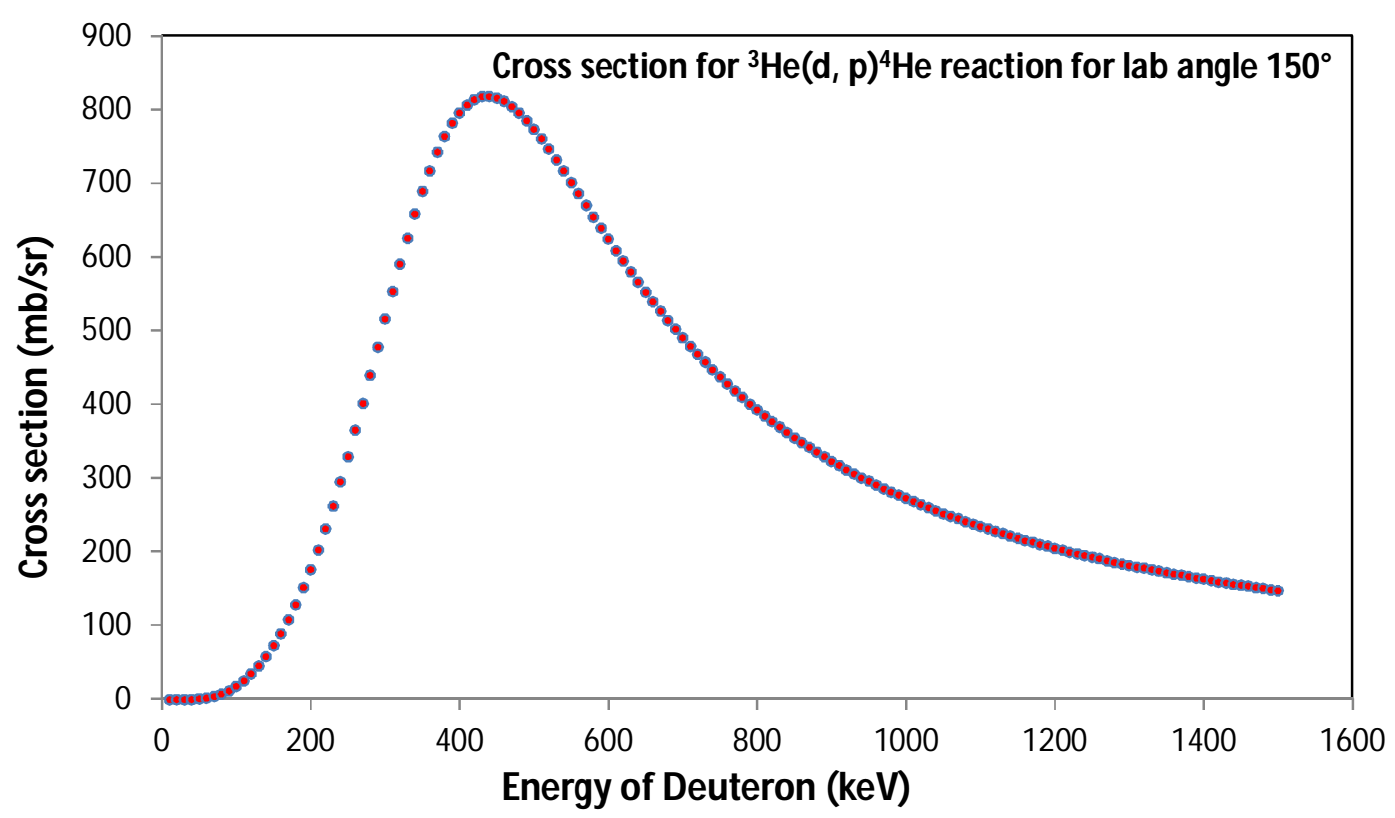

Figure 5.8. The cross section of ${ }^{3} \mathrm{He}\left(d, p_{0}\right)^{4} \mathrm{He}$ nuclear reaction [7].

The energy of deuteron beam was changed from $1.8 \mathrm{MeV}$ to $0.9 \mathrm{MeV}$ using a step size of 0.1 $\mathrm{MeV}$ (or $0.05 \mathrm{MeV}$ ) near the maximum of the reaction yield. This step by step decrease of deuteron beam energy, shifts the maximum of cross section of the ${ }^{3} \mathrm{He}(\mathrm{d}, \mathrm{p})^{4} \mathrm{He}$ reaction towards the surface to cover the complete helium distribution. 
By plotting the variation of incident deuteron energy versus proton count at each energy, an excitation curve is obtained giving us the complete distribution of helium into the sample. In figure 5.9, an example of excitation curve is shown for TiC.

Two possible methods are available to analyze the data from NRA and to obtain helium depth distribution. We can either analyze the proton spectrum at the deuteron energy corresponding to the maximum NRA yield (single deuteron energy method or SDEM) with the SIMNRA program $[8,9]$ or the excitation curve method (ECM) using the AGEING code $[10,11,12]$. We have sometimes used both the methods to determine the helium depth distribution. This double approach of data processing was carried out due to the complex shape of helium implantation profile obtained for some samples. In the next paragraph, we have described both the methods, briefly.

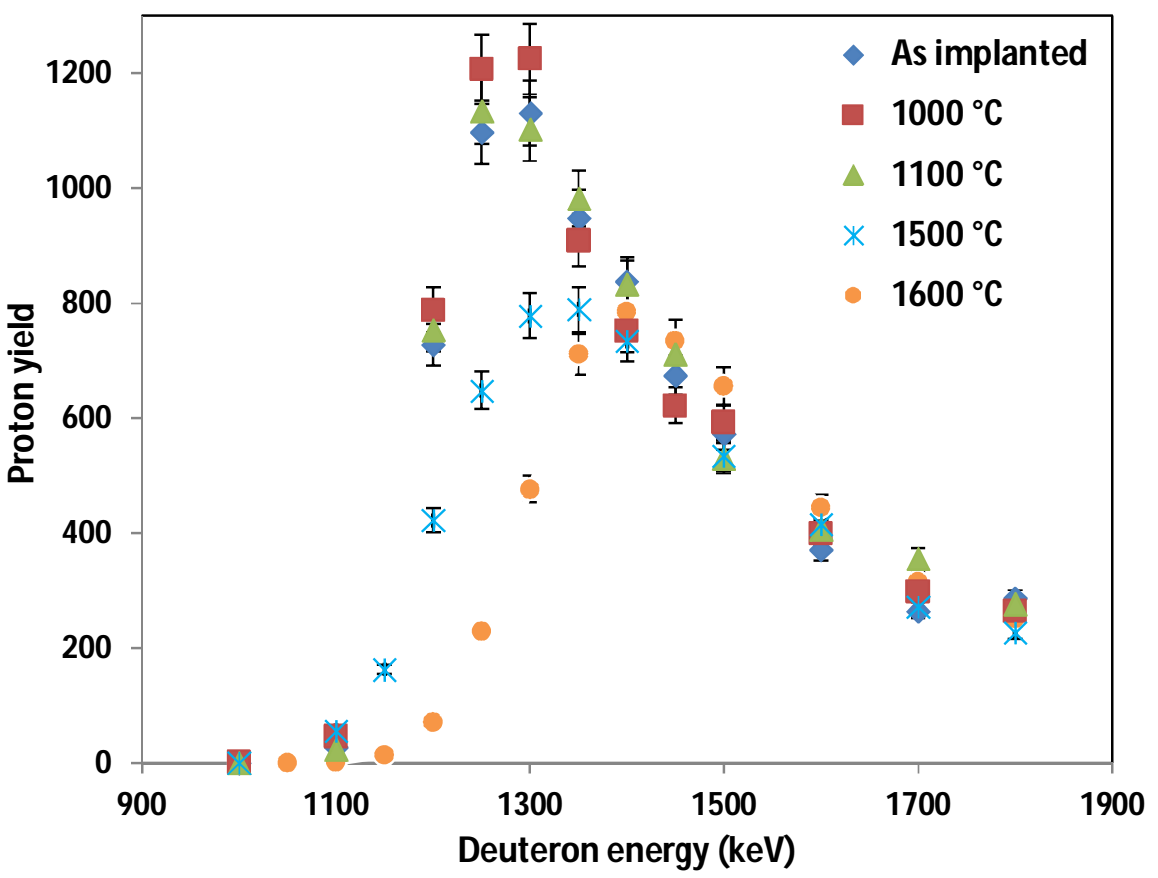

Figure 5.9. Excitation curves (proton yield versus incident deuteron energy) measured for asimplanted and annealed TiC samples. 


\section{A. Single deuteron energy spectrum method: SIMNRA}

The proton energy spectrum obtained were analyzed using SIMNRA simulation code developed by Matej Mayer [8].

The SIMNRA procedure consists in fitting the proton spectrum recorded at the energy corresponding to the maximum NRA yield in order to minimize the error. In our study, the energy spectrum corresponding to $1.3 \mathrm{MeV}$ deuteron energy have been fitted to obtain the helium depth profile of as-implanted and annealed samples of $\mathrm{TiN}, \mathrm{TiC} \& \mathrm{ZrC}$.

In SIMNRA simulation code, complete experimental configuration including the geometry of the experiment, detector energy calibration values, mylar foil thickness, incident beam characteristics and nuclear reaction cross section values are given as an input. The sample (in our case $\mathrm{TiN}, \mathrm{TiC} \& \mathrm{ZrC}$ ) can be defined to be constituted of many layers of different thickness. Each layer can consist of desired elements in which concentration of each element could be entered. For eg., during the simulation of TiC sample containing helium at $6 \mu \mathrm{m}$, sample was divided into approximately 15 layers, out of which first 8 layers contained Ti \& $\mathrm{C}$ to simulate first few $\mu \mathrm{m}$ of the sample containing no helium, then step by step in next layers $\mathrm{He}$ concentration is increased to simulate the helium containing part of the sample. While defining the sample configuration, one can also play with the thickness of each layer.

We divided the sample into layers having same thickness values calculated by code RESNRA (RESolution in NRA) [9]. This code calculates the depth resolution as a function of the distance from the surface of the sample. The depth resolution is maximum at the surface of the sample which degrades with depth due to incident deuteron beam and proton beam straggling. Then, the expected theoretical proton energy spectrum corresponding to initial input condition is obtained.

This theoretical curve was fit to the proton energy spectrum obtained experimentally at the same condition by optimizing the sample configuration in terms of the number and thickness of the layers as well as the helium concentration (see figure 5.10). The helium profile was obtained as an output. 


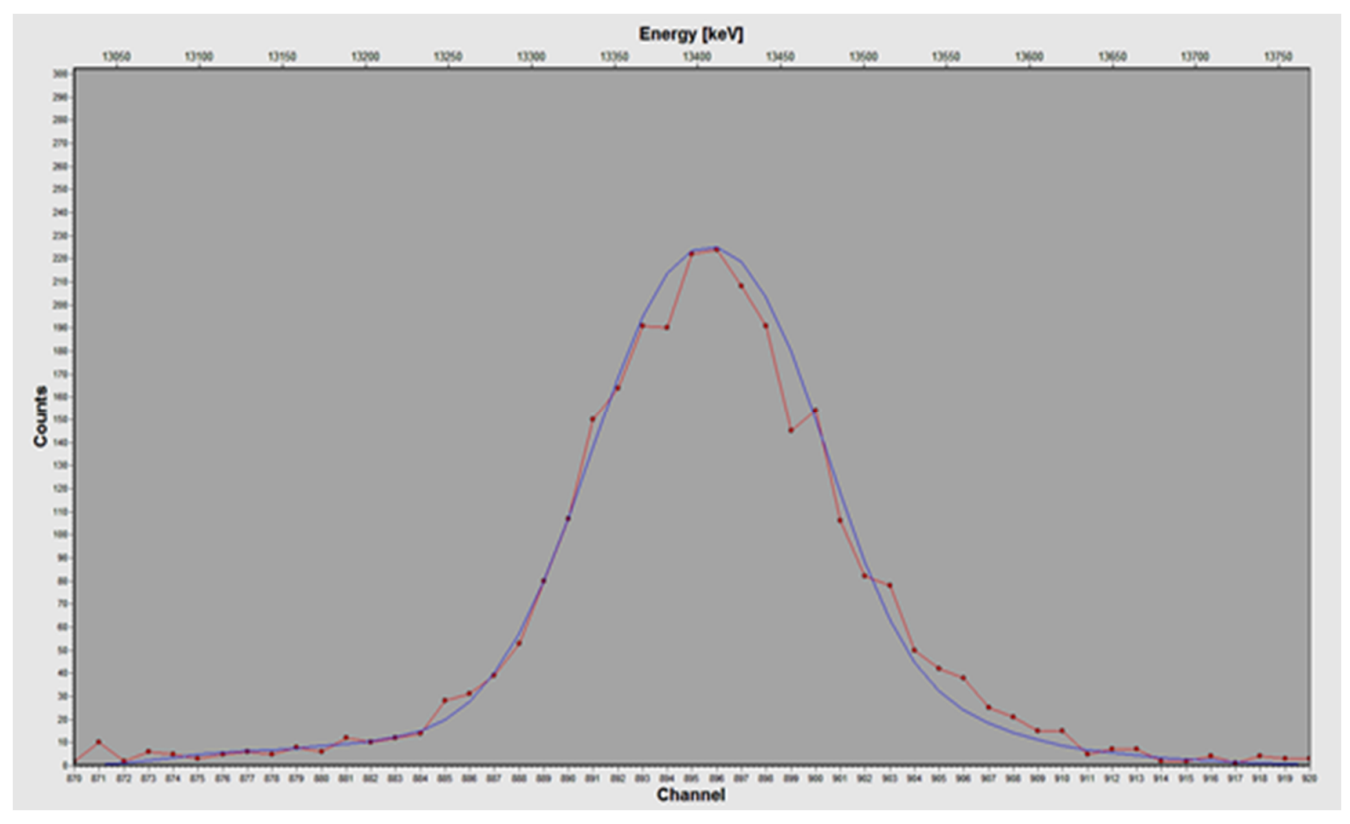

Figure 5.10. Red curve denotes the proton spectrum obtained experimentally by NRA. However, blue curve is the theoretical proton spectrum obtained by SIMNRA and has been fitted to superimpose on experimental curve to extract the helium depth distribution.

In most of the cases, the data (helium atomic fraction versus depth) obtained for helium depth distribution can be fit to a Gaussian function. However in some case, data can only be fit into more than one mathematical function. Therefore for such cases, we assume that the helium depth distribution obtained from SIMNRA code results from the contribution of two mathematical functions.

The accurate decomposition of the helium concentration profile into two components was done using the FITYK software [13]. Then, considering that both the mathematical functions of helium depth profile may obey the following Gaussian approximation (namely G1 and G2):

$$
\rho_{i}(x)=A_{i} \cdot \exp ^{-\left[\frac{\left(x-x_{c i}\right)^{2}}{2 s_{i}^{2}}\right]} \text { with } \int_{0}^{+\infty} \rho_{i}(x) d x=A_{i} \cdot s_{i} \cdot \sqrt{2 \pi}
$$

where $A_{i}$ is the amplitude, $x_{c i}$ is the centroid, $s_{i}$ is the standard deviation, i equals to 1 or 2 for G1 or G2 Gaussian contributions respectively. Here, G1 is the Gaussian fit of the helium distribution which is present at the end-of-range and G2 is the Gaussian fit of the tail which is present near the sample surface (see figure 5.11). 


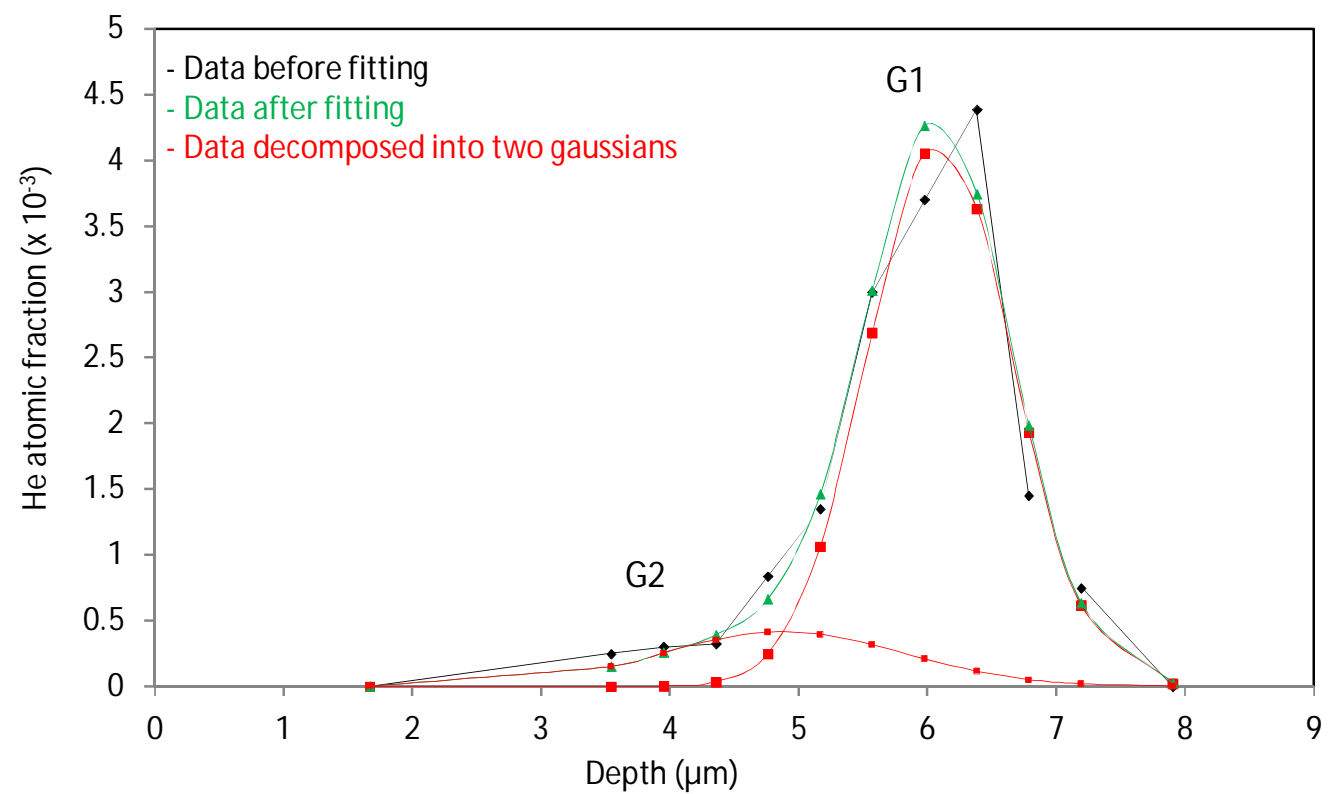

Figure 5.11. Fitting of the implantation profile obtained from SIMNRA by FITYK software into two Gaussian (G1 \& G2).

Furthermore, it was possible to evaluate the broadening of the FWHM (FWHM = 2.355 s) for both the Gaussian peak with temperature and the following classical formula already applied on a wide range of materials [14-18] was used to find diffusion coefficient values:

$$
\mathrm{D}=\left(\mathrm{sT}^{2}-\mathrm{s}_{0}^{2}\right) /(2 \mathrm{t})
$$

where $\mathrm{D}$ is an apparent diffusion coefficient; $\mathrm{s}_{\mathrm{T}}$ and $\mathrm{s}_{0}$ are the standard deviation values corresponding to each component of the helium profile obtained at annealing temperature $\mathrm{T}$ and the helium profile of as-implanted sample, respectively; $t$ is the annealing time. The evolution of the apparent diffusion coefficient with $\mathrm{T}$ can be further interpreted in the frame of the classical Arrhenius assumption to derive an average activation energy value $\left(\mathrm{E}_{\mathrm{a}}\right)$ according to:

$$
\mathrm{D}=\mathrm{D}_{0} \exp \left(-\mathrm{E}_{\mathrm{a}} / \mathrm{k}_{\mathrm{B}} \mathrm{T}\right)
$$

where $\mathrm{D}_{0}$ is a pre-exponential factor and $\mathrm{k}_{\mathrm{B}}$ is the Boltzmann constant. 


\section{B. Excitation curve method: AGEING}

An alternative to the processing of the spectrum coming from a single deuteron energy measurement is to simulate the whole excitation curve by means of the simulation code known as AGEING. This code was written by Haussy at CEA-DAM Ile-de-France $[10,11,12]$. It was developed in PV-wave (Precision Visuals - Workstation Analysis and Visualization Environment)/GUI environment. PV-WAVE is an array-oriented 4GL programming language to build and deploy visual data analysis applications. PV-WAVE employs FORTRAN-like syntax with a huge collection of software libraries of numerical analysis functionality known as IMSL (International Mathematics and Statistics Library).

In AGEING-1 version, the experimentally obtained excitation curves were fitted by a model where the proton yield $\mathrm{N}_{\mathrm{p}}\left(\mathrm{E}_{0}\right)$ at a given incident deuteron energy $\left(\mathrm{E}_{0}\right)$ is the convolution product of the ${ }^{3} \mathrm{He}$ concentration profile $\rho(x)$ with ${ }^{3} \mathrm{He}(\mathrm{d}, \mathrm{p})^{4} \mathrm{He}$ reaction cross section $\sigma(\mathrm{E}(\mathrm{x}))$ as described by equation 5.1. The hypothesis to neglect the angular dependence at greater value of solid angle has been explained by Tesmer et al. [19] and the value of $\left(\mathrm{N}_{\mathrm{d}}\left(\mathrm{E}_{0}\right)\right)$ is constant at each incident energy. Then, with the assumption of $\rho(x)$ being Gaussian distribution, this code tries to search the three parameters $\left(\mathrm{A}, \mathrm{x}_{\mathrm{c}}\right.$ and $\left.\mathrm{s}\right)$ and optimise their value by an IMSL modified Levenberg-Marquardt algorithm (also known as NILNLSQ function) which minimises a normalised quadratic error function between the simulated and experimental curves.

In order to reduce the high error values, a version AGEING-2 code was built by extending AGEING-1 and introducing the new modulus called PDE_MOL. This modulus solves a system of partial differential equations. Therefore, the model of helium migration was written by Costantini $[10,11,12]$, where helium is assumed to have two distinct populations in the form of following two differential equations:

$$
\begin{gathered}
\delta \mathrm{C}_{1} / \mathrm{dt}=\mathrm{D}_{1} \cdot \delta^{2} \mathrm{c}_{1} / \delta \mathrm{x}^{2}-\mathrm{v}_{1} \cdot \delta \mathrm{c}_{1} / \delta \mathrm{x}-\mathrm{g}_{12} \cdot \mathrm{c}_{1} \\
\delta \mathrm{C}_{2} / \mathrm{dt}=\mathrm{D}_{2} \cdot \delta^{2} \mathrm{c}_{2} / \delta \mathrm{x}^{2}-\mathrm{v}_{2} . \delta \mathrm{c}_{2} / \delta \mathrm{x}+\mathrm{g}_{12} \cdot \mathrm{c}_{1}-\mathrm{F}_{2} \cdot \mathrm{c}_{2}
\end{gathered}
$$

These equations describes the different physical mechanisms involved i.e., pure diffusion, atomic transport and exchange coupled with boundary conditions.

Here, equation 5.5 represents the modified Fick's second law applied to population P1 where the concentration $\left(C_{1}\right)$ of helium atom could be diffused (with diffusion coefficient $D_{1}$ ), 
transported (with transport velocity $\mathrm{v}_{1}$ ) and could be de-trapped or leaked to population P2 (with de-trapping coefficient $g_{12}$ ).

Equation 5.6 represents the modified Fick's second law applied to population P2 where the concentration $\left(\mathrm{C}_{2}\right)$ of helium atoms could be diffused (with diffusion coefficient $\mathrm{D}_{2}$ ), transported (with transport velocity $\mathrm{v}_{2}$ ) and could leak out of the sample (with leakage coefficient $\mathrm{F}_{2}$ ). It should be noted that $\mathrm{g}_{12}$ and $\mathrm{F}_{2}$ coefficients denote the rate of de-trapping and rate of leakage having the dimension $\left(\right.$ time $\left.^{-1}\right)$.

In addition to the Gaussian distribution assumption on the implantation profile, a boundary condition $\mathrm{C}_{2}(0, \mathrm{t})=0$ at the sample surface was applied meaning that helium can never accumulate at the sample surface.

However, it should be mentioned that population P1 cannot go out of the sample directly. It first goes to population P2 (having magnitude $\mathrm{g}_{12}$ per unit time) and finally leaves the sample through its surface (having magnitude $\mathrm{F}_{2}$ per unit time). The coefficient $\mathrm{g}_{12}$ is kept constant with time, until the maximum de-trapped helium fraction $\left(1-\mathrm{TP}_{1}\right)$ is reached and finally the helium content in the population $\mathrm{P} 1$ becomes zero. Here, $\mathrm{TP}_{1}$ denotes the population $\mathrm{P} 1$ which is trapped. This model thus consists in fitting seven free parameters $\left(\mathrm{D}_{1}, \mathrm{v}_{1}, \mathrm{~g}_{12}, \mathrm{D}_{2}, \mathrm{v}_{2}, \mathrm{~F}_{2}, \mathrm{TP}_{1}\right)$ using a trial-and-error method, based on the minimization of the same NLINSQ error function between the experimental and calculated excitation curves. The quality of the fitted parameters is always estimated by the minimum error value.

\subsubsection{Nuclear reaction analysis with the scanning of $1 \mu \mathrm{m}$ size deuteron beam: To know the helium distribution in lateral directions.}

NRA $\mu$-analysis was performed at nuclear microprobe of the LEEL at CEA Saclay using the

${ }^{3} \mathrm{He}\left(\mathrm{d}, \mathrm{p}_{0}\right){ }^{4} \mathrm{He}$ nuclear reaction [20]. The principal of NRA with $\mu$-beam is similar to that of NRA with milli-beam. The difference lies in the sizes of deuteron beam which are $1 \mu \mathrm{m}$ and 1 mm for NRA with $\mu$-beam \& NRA with milli-beam, respectively. The other important difference is that for $\mu$-beam NRA, deuteron beam is scanned on the surface of the sample, however, for for milli-beam NRA, deuteron beam is kept stationary on the sample surface.

When the size of deuteron beam is $1 \mathrm{~mm}$ and with energy (for e.g. $\mathrm{E}_{\mathrm{D}}=3 \mathrm{MeV}$ in our case), the information in terms of proton counts comes from the interaction with helium present (6.5 
$\mu \mathrm{m}$ deep in our case) in the sample area of $\sim 1 \mathrm{~mm}$. It is important to note that, $1 \mathrm{~mm}$ of sample area has $\sim 100$ grains (if the size of each grain in the sample is considered to be $10 \mu \mathrm{m}$ ). Therefore, $1 \mathrm{~mm}$ deuteron beam size gives an idea about the average quantity of helium present in approximately 100 grains. And finally, this large statistics in terms of large number of proton counts (coming from interaction of $1 \mathrm{~mm}$ beam size) allows us to derive helium depth distribution.

Whereas, when the size of deuteron beam is reduced to $1 \mu \mathrm{m}$, and this beam is scanned on the surface of the sample. Then, it is possible to separate the information coming from the grains and the information coming from the grain boundary. And finally, it is possible to conclude that whether more helium is trapped in grain interior or in grain boundary and also it is possible to know if the helium distribution within the grain is heterogeneous or homogeneous. Figure (5.12a \& 5.12b) shows the spatial distribution of carbon and helium in non-annealed samples. The color scale starts with white for the lowest counting rate and ends with green for the highest. Figure 5.12a exhibits the distribution of carbon in $\mathrm{TiC}$ with a homogeneous yellow color while Figure 5.12b clearly shows the heterogeneous 3-D helium distribution, i.e. the colour scale now extends from blue to yellow.

The beam was normal to the sample surface and proton detection was performed at $170^{\circ} \mathrm{using}$ an annular $1500 \mu \mathrm{m}$ thick surface barrier silicon detector. The detector solid angle measured with reference samples was $(120 \pm 10)$ msr. Backscattered deuterons were stopped using a 23 $\mu \mathrm{m}$ thick mylar foil in front of the active surface. Samples were imaged by the scanning of $(\sim 1 \mathrm{x} 1) \mu \mathrm{m}^{2}$ beam on $(\sim 50 \times 50) \mu \mathrm{m}^{2}$ area in order to get helium spatial distributions. The energy of incident deuteron beam was $1.3 \mathrm{MeV}$. 


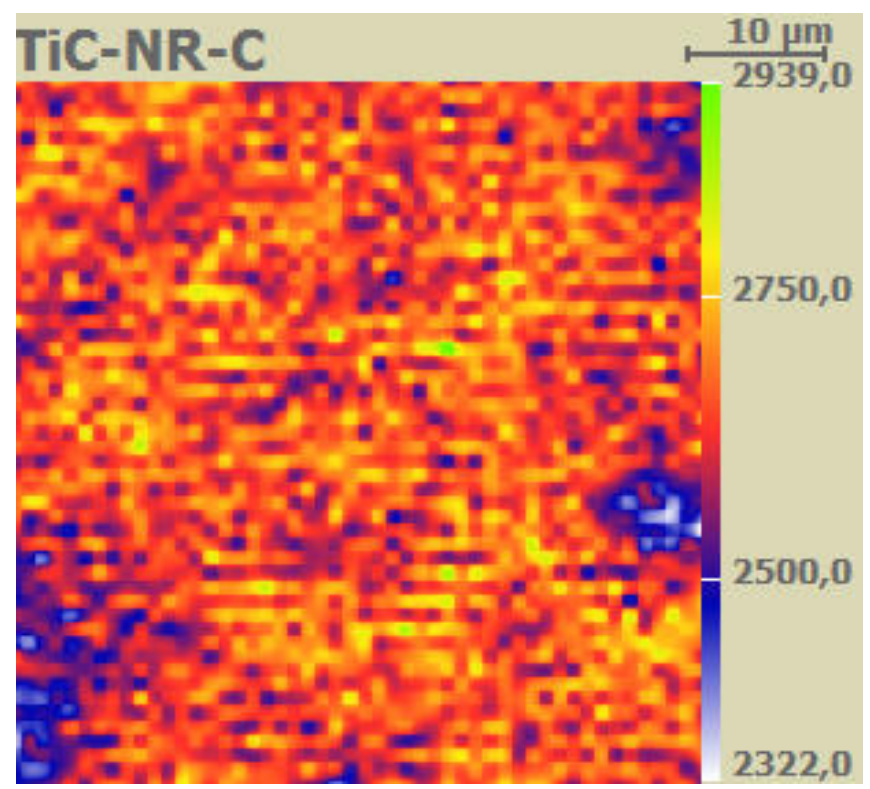

Figure 5.12a. NRA cartography to show carbon lateral distributions by rastering the beam over a $50 \times 50 \mu^{2}$ surface area of TiC sample. This cartography shows the homogeneous distribution of carbon within the grains and on the grain boundaries.

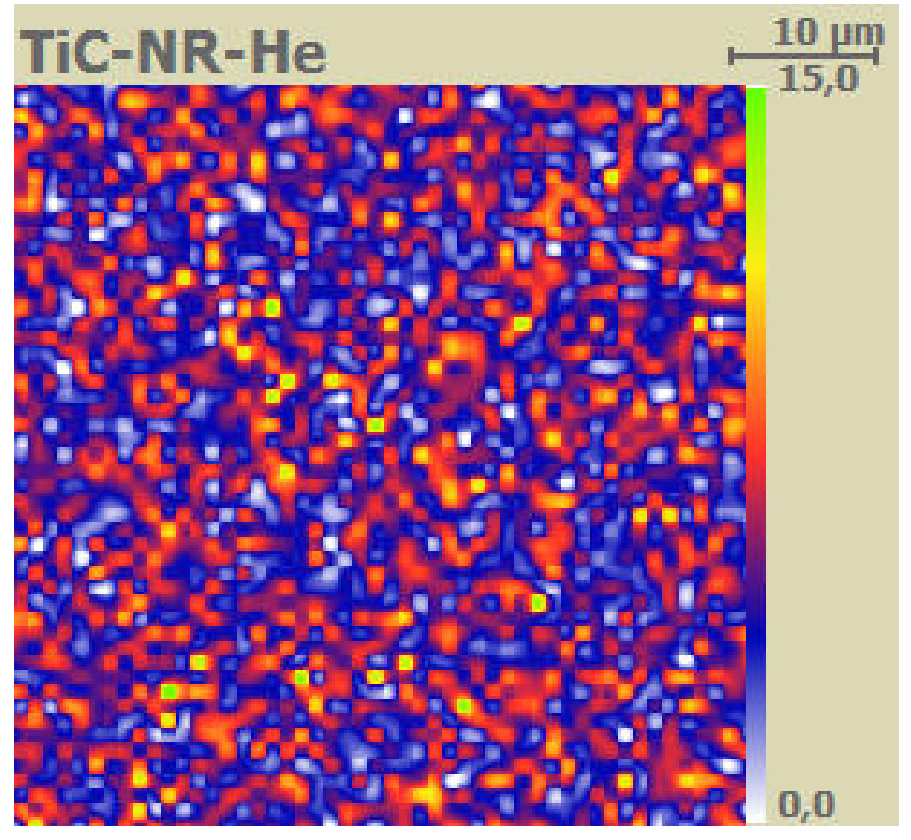

Figure 5.12b. NRA cartography to show helium lateral distributions by rastering the beam over a $50 \times 50 \mathrm{\mu m}^{2}$ surface area of TiC sample implanted with $3 \mathrm{MeV}{ }^{3} \mathrm{He}$ ions. This cartography shows the heterogeneous distribution within the grains. 


\subsubsection{Transmission Electron Microscopy (TEM)}

The cross-sectional TEM specimens were prepared using focused ion beam micro machining (FIB) for implanted and annealed samples. The FIB used a focused ion beam for controlled removal of material by sputtering using $\mathrm{Ga}^{+}$ions. The specimens were investigated in Philips CM-20 microscope operated at $200 \mathrm{keV}$. The main TEM techniques employed were phase contrast for identification of small bubbles. Average bubble radii $r_{B}$ were determined by counting more than 100 bubbles at least three times in three different areas of the zone under analysis. Foil thicknesses needed for volume bubble density measurement were determined by contamination spot separation method [21].

\subsubsection{X-ray diffraction}

$\mathrm{X}$-ray diffraction is a common technique for the study of crystal structures and atomic spacing. $\mathrm{X}$-ray diffraction is based on constructive interference of monochromatic X-rays diffracted from a crystalline sample. These $\mathrm{X}$-rays are generated by a cathode ray tube, filtered to produce monochromatic radiation, collimated to concentrate, and directed toward the sample. The interaction of the incident rays with the sample produces constructive interference of diffracted rays when conditions satisfy Bragg's Law $(n \lambda=2 d \sin \theta)$.

This law relates the wavelength $(\lambda)$ of electromagnetic radiation to the diffraction angle $(\theta)$ and the lattice spacing (d) in a crystalline sample. These diffracted X-rays are then detected, processed and counted. By scanning the sample through a range of $2 \theta$ angles, all possible diffraction directions of the lattice should be attained due to the random orientation of the material. Conversion of the diffraction peaks to d-spacings allows identification of the material because each material has a set of unique d-spacings. Typically, this is achieved by comparison of d-spacing's with standard reference patterns.

All diffraction methods are based on generation of X-rays in an X-ray tube. These X-rays are directed at the sample, and the diffracted rays are collected. A key component of all diffraction is the angle between the incident and diffracted rays.

X-ray diffraction was done using Philips X'Pert Pro Material research diffractometer equipped with copper anti-cathode (8.04 keV and $1.54 \AA)$. More details on the general use of diffractometer and principal of X-ray diffraction can be found in the literature [22, 23]. 
In our study, only the sample implanted with self-ions (for second set of experiments) are studied by using X-ray diffraction. The lattice swelling was calculated for $\mathrm{TiC}, \mathrm{TiN}$ and $\mathrm{ZrC}$. More details on the use of X-ray diffraction to calculate lattice swelling in nuclear materials can also be found in the literature [24]. Figure 5.12 shows an example for non-damaged and damaged TiC (with only two peaks). The peak position of the sample damaged at $9 \mathrm{dpa}$ is little shifted towards left. To satisfy the condition of Bragg's law $(n \lambda=2 d \sin \theta)$ for constructive interference, normally if the value of $\theta$ decreases, the value of $d$ increases. So already, the shift in the peak position of damaged sample towards 'lower value of $\boldsymbol{\theta}$ ' indicates lattice expansion. However, precise information on lattice expansion can be calculated by using mathematical formulas.

The information on the lattice parameter for damage and non-damage sample can be found from equation 5.7 .

$$
d_{h k l}=\left[\frac{1}{a^{2}}\left(h^{2}+k^{2}+l^{2}\right)\right]^{-1 / 2}
$$

where $\mathrm{h}, \mathrm{k}, \mathrm{l}$ are the miller indices, a is the lattice parameter.

The value of $d$ is calculated by Bragg's law by putting the value of $\theta$ from peak position. And after putting the values of $\mathrm{h}, \mathrm{k}, 1$ from literature and calculated $\mathrm{d}$, the values of 'a' (lattice parameter) could be found. And by comparing the lattice parameter value for damaged and nondamaged sample the value of lattice expansion could be found.

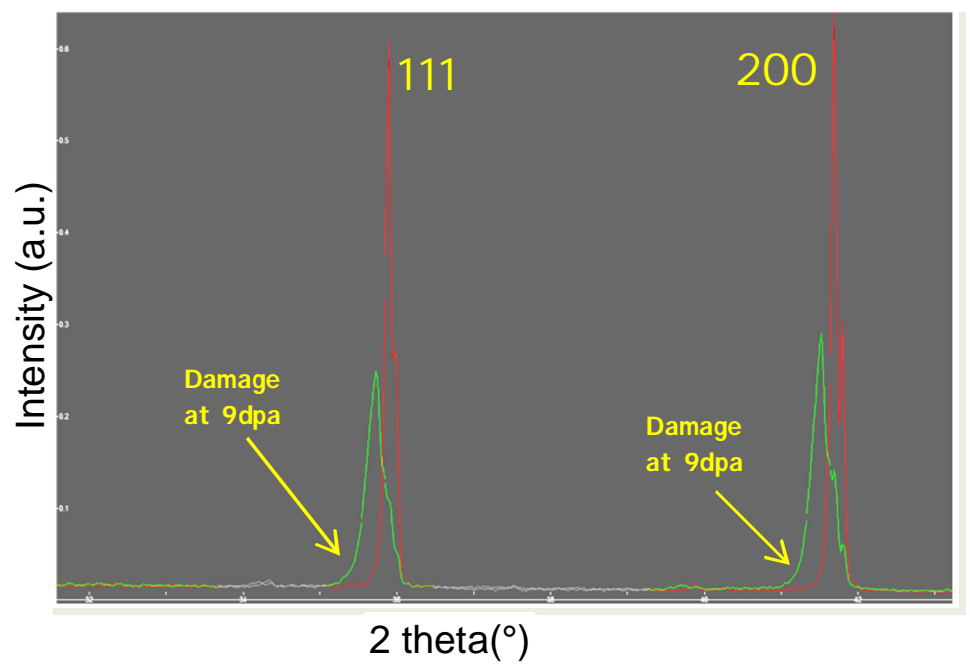

Figure 5.12. X ray-characterization for TiC at 0 dpa and 9 dpa. 


\subsubsection{Nano-indentation}

Nano-indentation is a powerful technique used for assessing mechanical properties at nano/micro-scale. It is used for obtaining material parameters like elastic modulus, hardness, plastic or viscous parameters from experimental readings of indenter load and depth of penetration.

In nano-indentation, an indenter tip, normal to the sample surface, is driven into the sample by applying an increasing load up to some preset value. The load is then gradually decreased until partial or complete relaxation of the material occurs. We have used three-sided pyramid shaped indenter known as Berkovich at SRMP, CEA Saclay to measure the evolution of hardness after damaging the samples by ion-implantation. Forces involved are usually in the milli or micronewton range and the depth in the order of nanometers.

Hardness is defined as the mean contact pressure at the maximum load:

$$
\mathbf{H}=\mathbf{P m a x} / \mathrm{A}
$$

During our experiments, we have repeated the loading many times on one sample to obtain the highest precision possible for hardness measurement.

\subsubsection{Scanning Electron Microscopy (SEM) and Electron Microprobe}

The use of scanning electron microscope (Gemini LEO1525 the FEG) at SRMP, CEA-Saclay allowed us to know the information about the sample's surface and composition. The sample's surfaces before and after irradiation and also, before and after thermal annealing were analyzed using SEM. Along with this, the use of Castaing microprobe (CAMECA SX50) identified the chemical elements present in the material and their distribution at the micron scale.

\subsubsection{Raman Spectroscopy}

The recently installed micro-Raman spectrometer at JANNUS-Saclay is a Renishaw In Via spectrometer coupled with an Olympus microscope containing an $\mathrm{x}-\mathrm{y}-\mathrm{z}$ stage. During experiments by Raman spectrometry, the $532 \mathrm{~nm}$ line of a frequency-doubled Nd-YAG laser was focused on a $1 \mu \mathrm{m}^{2}$ spot and collected through a $100 \mathrm{X}$ objective. 
The virgin $\mathrm{TiN}, \mathrm{TiC}$ and $\mathrm{ZrC}$ were passed under Raman spectroscope to get information on their stoichiometry. And also, damaged and annealed samples were passed under Raman spectroscope to know increase or decrease in the concentration of vacancies.

\section{References}

[1] M. Dormeval, P. Wident, D. Gosset, Technical Report DMN/SRMA/LA2M/2003-2593/A.

[2] M. L. Flem, S. Urvoy, T. Guilbert, F. Onimus, J. Pelé, Technical Report DMN/ SRMA / LA2M/NT/2005-2719/A.

[3] S. Pellegrino, P. Trocellier, S. Miro, Y. Serruys, E. Bordas, H. Martin, N. Chaâbane, S. Vaubaillon, J.P. Gallien, L. Beck, Nucl. Instrum. Meth. Phys. Res. B 273 (2012) 213-217.

[4] J.F. Ziegler, SRIM (2013), <http://www.srim.org>.

[5] P. Trouslard, Rapport CEA-R-5703, 1995.

[6] D.J. Cherniak, E.B. Watson, Chem. Geol. 288 (2011) 149-161.

[7] H.S. Bosch, G.M. Hale, Nucl. Fusion 32 (1992) 611-631.

[8] M. Mayer, SIMNRA’s User Guide, Technical Report IPP 9/113, 1997.

[9] M. Mayer, Nucl. Instrum. Meth. Phys. Res B 266 (2008) 1852.

[10] J.-M. Costantini, P. Trocellier, J. Haussy, J.-J. Grob, Nucl. Instrum. Meth. Phys. Res. B 195 (2002) 400-407.

[11] S. Miro, J.-M. Costantini, J. Haussy, L. Beck, S. Vaubaillon, S. Pellegrino, C. Meis, J.-J. Grob, Y. Zhang, W.J. Weber, J. Nucl. Mater. 415 (2011) 5-12.

[12] S. Miro, J.M. Costantini, J. Haussy, D. Chateigner, E. Balanzat, J. Nucl. Mater. 423 (2012) 120.

[13] M. Wojdyr, Fityk, J. Appl. Crystallogr. 43 (2010) 1126-1128.

[14] P. Trouslard, Rapport CEA-R-5703, 1995.

[15] D. Gosset, P. Trocellier, Y. Serruys, J. Nucl. Mater. 303 (2002) 115-124.

[16] J.-M. Costantini, J.-J. Grob, J. Haussy, P. Trocellier, Ph. Trouslard, J. Nucl. Mater. 321 (2003) 281-287.

[17] P. Trocellier, D. Gosset, D. Simeone, J.-M. Costantini, X. Deschanels, D. Roudil, Y. Serruys, R.I. Grinszpan, S. Saudé, M. Beauvy, Nucl. Instrum. Meth. Phys. Res.B 206 (2003) 1077-1082.

[18] S. Miro, F. Studer, J.-M. Costantini, J. Haussy, Ph. Trouslard, J.-J. Grob, J. Nucl. Mater. 355 (2006) 1-9. 
[19] J. R. Tesmer, M. Nastasi (Eds.), Handbook of Modern Ion Beam Materials Analysis, MRS, Pittsburgh, 1995, p. 159.

[20] H. Khodja, E. Berthoumieux, L. Daudin, J.-P. Gallien, Nucl. Instrum. Meth. Phys. Res. B 181 (2001) 83-86.

[21] G. Fenske, S.K. Das and M. Kaminsky, J. Nucl. Mater. 80 (1979) 373-378.

[22] www.panalytical.com/Xray-diffractometers.htm.

[23] http://www.chem.sc.edu/faculty/zurloye/XRDTutorial_2013.pdf.

[24] B. Ravat, B. Oudot, N. Baclet, Journal of Nuclear Materials 366 (2007) 288-296. 


\section{Chapter 6}

\section{Helium behavior under thermal environment}

In this chapter, important findings on 'helium behavior in transition metal ceramics under thermal environment' would be presented and discussed. It is important to mention that, due to differences in the microstructural properties of $\mathrm{TiC}, \mathrm{TiN}$ and $\mathrm{ZrC}$ in terms of grain size, porosity and stoichiometry, results are presented and discussed separately for three materials in three different sections.

\section{Part 1}

\subsection{Helium behavior under thermal environment in $\mathrm{TiC}$}

Before presenting and discussing results for helium behavior under thermal environment in $\mathrm{TiC}$, we have given a quick reminder of experimental approach. The results shown in this section of the chapter have already been published. This paper can be obtained from the citation given below:

Diffusion and retention of helium in titanium carbide $S$. Agarwal, $P$. Trocellier, $S$. Vaubaillon, S. Miro, Journal of Nuclear Materials 448 (2014) 144-152.

\subsubsection{Reminder of experimental approach}
He implantation in $\mathrm{TiC}$
$\left(3 \mathrm{MeV}, 5 \mathrm{E} 16\right.$ at. $\left./ \mathrm{cm}^{2}, \mathrm{Rp}=6.78 \mu \mathrm{m}\right)$
$\rightarrow \quad$ Thermal annealing
$\left(\mathbf{1 0 0 0}{ }^{\circ} \mathbf{C}, \mathbf{1 1 0 0}{ }^{\circ} \mathbf{C}, \mathbf{1 4 0 0}\right.$
${ }^{\circ} \mathbf{C}, \mathbf{1 5 0 0}{ }^{\circ} \mathbf{C}, \mathbf{1 6 0 0}^{\circ} \mathbf{C}, \mathbf{2}$ h) 


\subsubsection{Results and Discussion}

After helium implantation and annealing at 5 different temperatures, NRA experiments were conducted on as-implanted and annealed samples to determine the position and quantity of helium into the sample. The deuteron milli-beam of $0.5 \mathrm{~mm}$ to $1 \mathrm{~mm}$ spot size with beam energy of $1300 \mathrm{keV}$ was used in order to penetrate to a depth of $6.78 \mu \mathrm{m}$ in the sample. The protons produced by various $(\mathrm{d}, \mathrm{p})$ and $(\mathrm{d}, \alpha)$ reactions along with the backscattered deuterons were detected.

The detected spectrum (see figure 6.1a) contains several peaks from various deuteron-induced nuclear reactions e.g., ${ }^{12} \mathrm{C}\left(\mathrm{d}, \mathrm{p}_{0}\right){ }^{13} \mathrm{C},{ }^{3} \mathrm{He}\left(\mathrm{d}, \mathrm{p}_{0}\right){ }^{4} \mathrm{He}$. Please refer to section 5.3.1 for details on NRA.

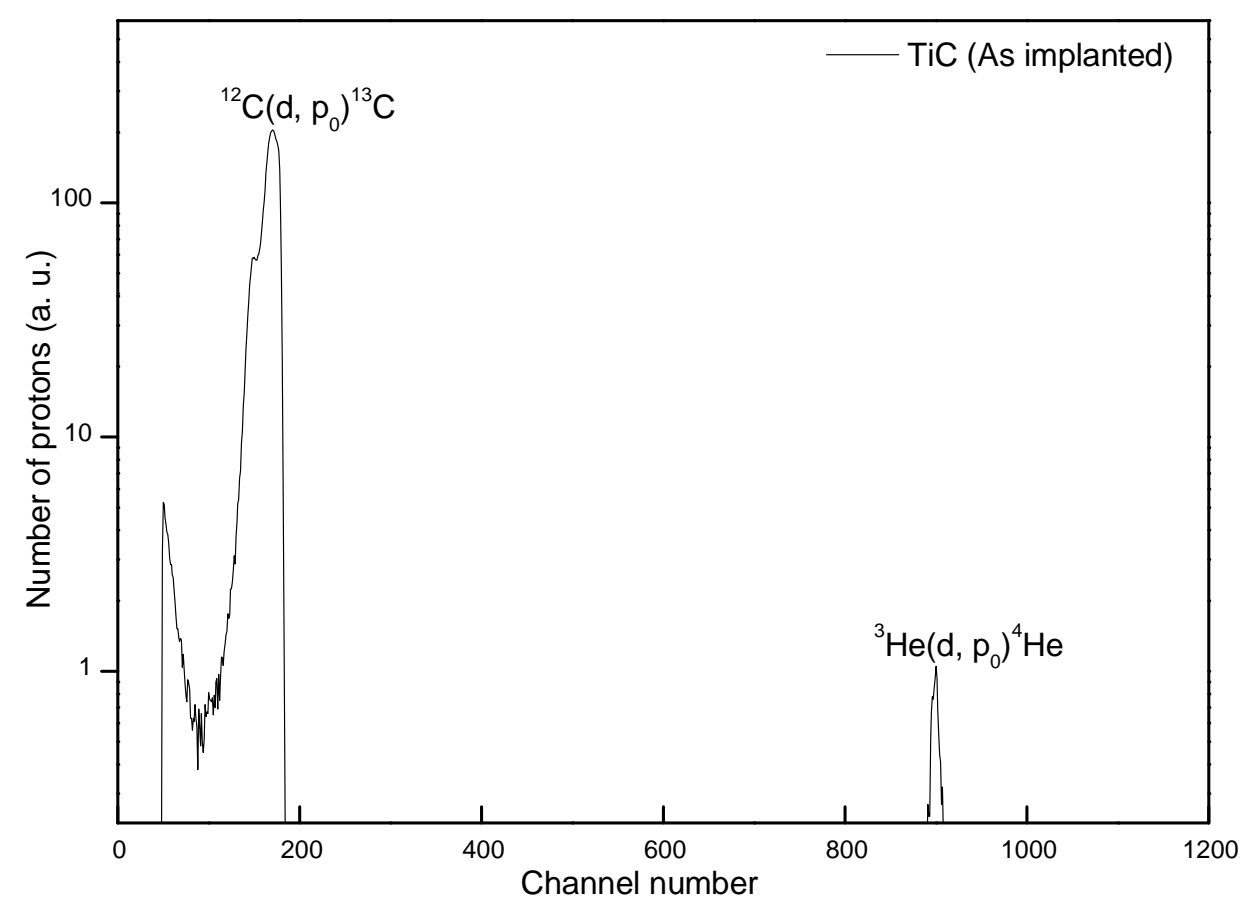

Figure 6.1a. The raw proton energy spectrum obtained with $1.3 \mathrm{MeV}$ deuteron energy for asimplanted TiC sample.

By plotting the variation of incident deuteron energy versus proton count at each energy, an excitation curve is obtained for $\mathrm{TiC}$ (see figure 6.1b). 


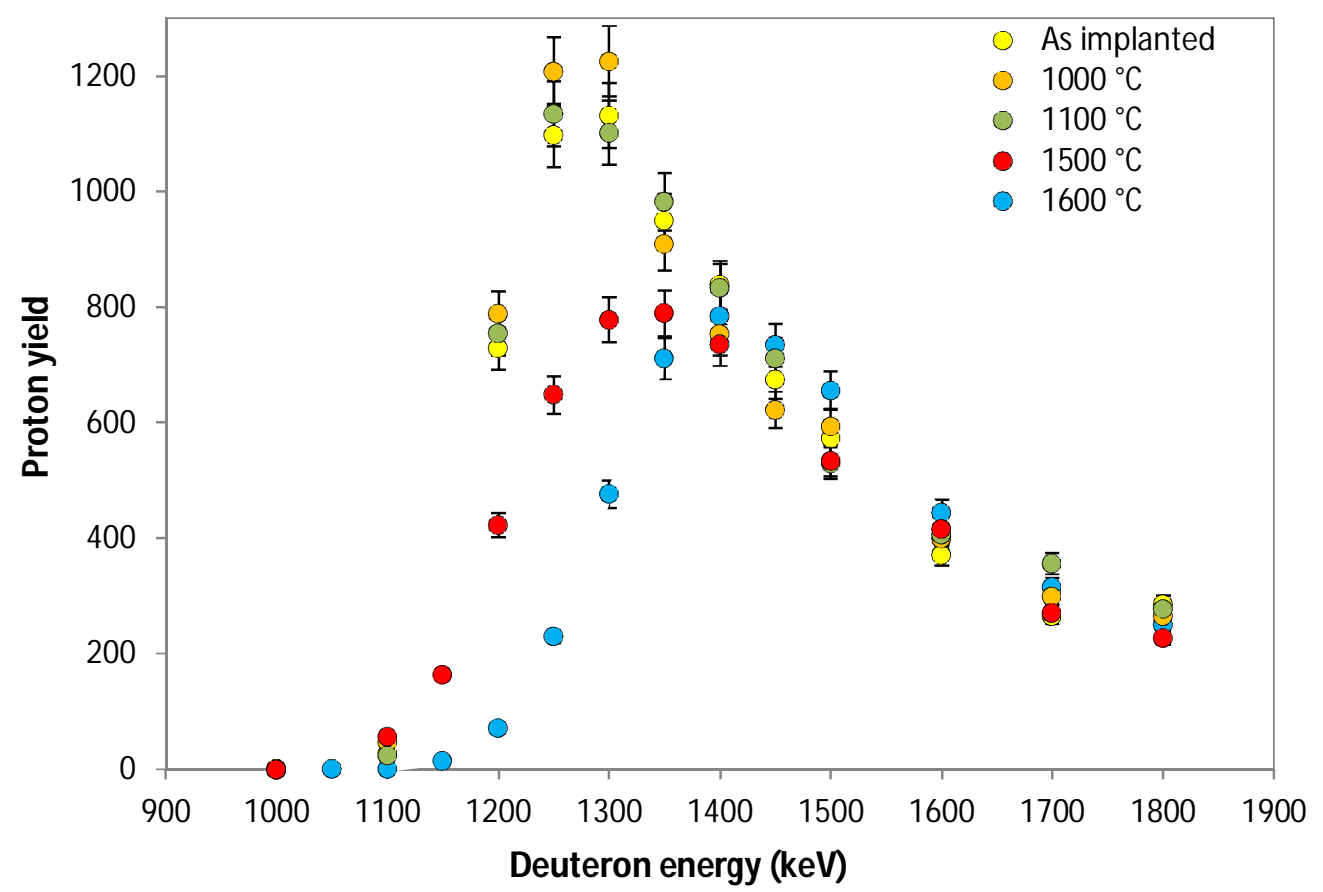

Figure 6.1b. Excitation curves (proton yield versus incident deuteron energy) measured for asimplanted and annealed TiC samples.

\section{A. Helium release}

For annealing temperature up to $1100{ }^{\circ} \mathrm{C}$ (see figure 6.1b) excitation curves are about the same within the experimental errors given by $\sqrt{N_{p}\left(E_{0}\right)}$ (where $\mathrm{N}_{\mathrm{p}}\left(\mathrm{E}_{0}\right)$ is the proton yield at energy $\mathrm{E}_{0}$ ). For annealing temperatures higher than $1100{ }^{\circ} \mathrm{C}$, a decrease in proton yield was observed. The proton yield decreases with increasing annealing temperature from $1100{ }^{\circ} \mathrm{C}$ to $1600{ }^{\circ} \mathrm{C}$. The direct comparison of the total area under the excitation curve obtained for the as-implanted and the annealed samples allowed us to evaluate the helium loss fraction and to describe its evolution with temperature.

As suggested by Costantini et al. in his study on helium behavior in yttria-stabilized-zirconia [1], we have assumed the helium release may obey 1 st order kinetics law (see figure 6.2). The decrease in the rate of helium concentration (C) in the sample is given by the following equation: 


$$
\mathrm{dC}(\mathrm{He}) / \mathrm{dt}=-\mathrm{C}(\mathrm{He}) v_{0} \exp \left(-\Delta \mathrm{H} / \mathrm{k}_{\mathrm{B}} \mathrm{T}\right)
$$

where $v_{0}$ is the classical frequency factor, $\Delta \mathrm{H}$ is the activation energy for helium release and $\mathrm{k}_{\mathrm{B}}$ is the Boltzmann constant. For a given annealing time $t_{a}$ and temperature $\mathrm{T}$, the integration of the above equation gives the value of helium lost fraction (f) [1]:

$$
\mathrm{f}=\mathrm{C}_{0}(\mathrm{He})-\mathrm{C}_{\mathrm{T}}(\mathrm{He})=1-\exp \left[-\alpha \exp \left(-\Delta \mathrm{H} / \mathrm{k}_{\mathrm{B}} \mathrm{T}\right)\right]
$$

where $\alpha$ is the pre-exponential factor which is equal to $v_{0} \cdot t_{\mathrm{a}}$. The helium lost fraction according to equation 6.2 was fitted by adjusting two parameters $\alpha$ and $\Delta \mathrm{H}$ and the optimized values obtained for these parameters were 74.58 and $0.89 \pm 0.09 \mathrm{eV}$, respectively. This value of activation energy for helium release is in good agreement with other materials like binary or complex oxides, minerals and metals $[2,3,4,5,6,7,8]$.

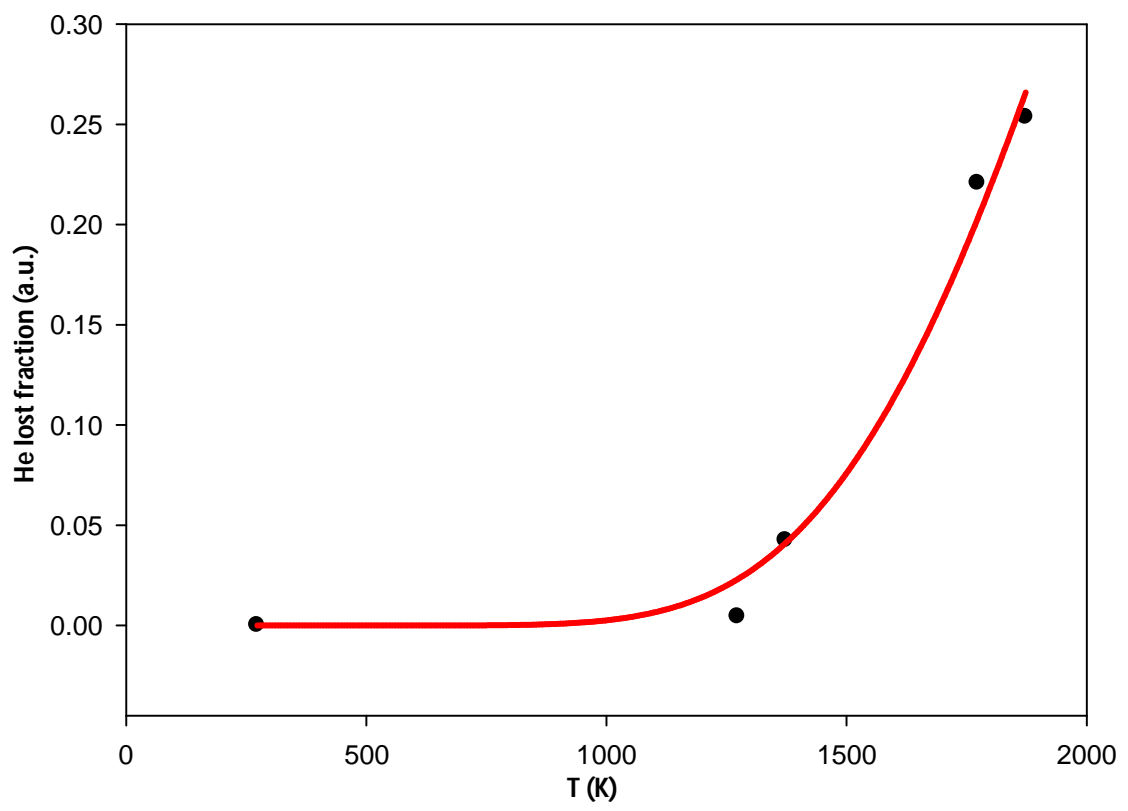

Figure 6.2. Helium lost fraction as a function of temperature fitted according to first order kinetics law in order to calculate activation energy for He release [1]. 
The excitation curve obtained for $\mathrm{TiC}$ annealed at $1600{ }^{\circ} \mathrm{C}$ (see figure $6.1 \mathrm{~b}$ ) exhibits a shift in the position of its maximum from $1300 \mathrm{keV}$ to $1400 \mathrm{keV}$. Complementary NRA measurements were carried out at $\mathrm{E}_{\mathrm{d}}=1.8 \mathrm{MeV}$ corresponding to the maximum cross section value for ${ }^{16} \mathrm{O}(\mathrm{d}$, $\left.\mathrm{p}_{\mathrm{o}}\right){ }^{17} \mathrm{O}$ reaction. Figure $6.3 \mathrm{a}$ displays the part of the spectrum coming from this reaction. The increase of the signal observed for the $1600{ }^{\circ} \mathrm{C}$ annealed sample indicates the sudden growth of a titanium oxide layer at the surface of TiC. The $100 \mathrm{keV}$ energy shift of the maximum of the excitation curve results from the additional energy loss that incident deuterons encounter for the sample annealed at $1600{ }^{\circ} \mathrm{C}$. Using the Pyrole code [9], we can derive the thickness of the titanium oxide layer grown at the surface of the $1600^{\circ} \mathrm{C}$ annealed sample which is about $1 \mu \mathrm{m}$.

The presence of $\mathrm{TiO}_{2}$ has been confirmed by using Raman spectroscopy technique and scanning electron microscope (see figures $6.3 \mathrm{~b}$ and $6.3 \mathrm{c}$ ). Figure $6.3 \mathrm{~b}$ clearly shows the presence of two very intense Raman bands located at $445 \mathrm{~cm}^{-1}$ and $610 \mathrm{~cm}^{-1}$ which are representative of the rutile phase of titanium oxide [10]. Figure $6.3 \mathrm{c}$ displays the picture taken by scanning electron microscope to show the crystals of $\mathrm{TiO}_{2}$ formed at the surface of $\mathrm{TiC}$ sample annealed at $1600{ }^{\circ} \mathrm{C}$.

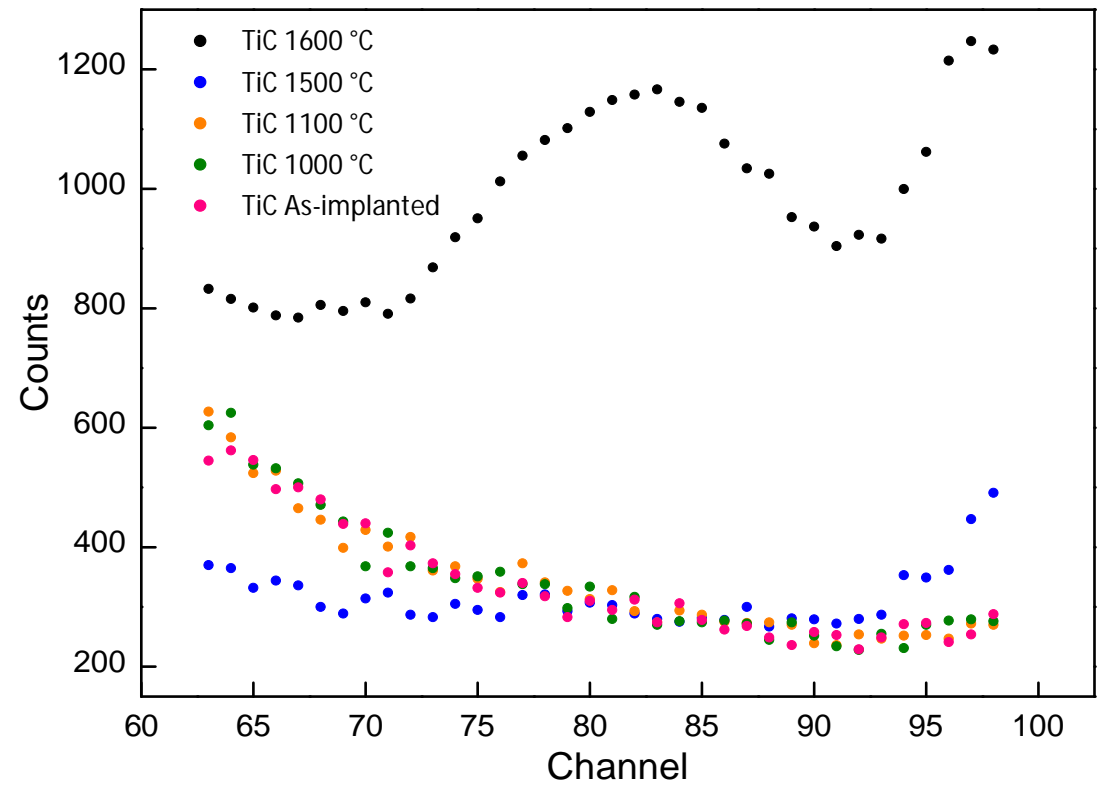

Figure 6.3a. NRA spectrum showing ${ }^{16} \mathrm{O}\left(\mathrm{d}, \mathrm{p}_{\mathrm{o}}\right)^{17} \mathrm{O}$ peak corresponding to $E_{d}=1.8 \mathrm{MeV}$ to confirm the sudden oxidation at the surface of TiC sample annealed at $1600{ }^{\circ} \mathrm{C}$. 


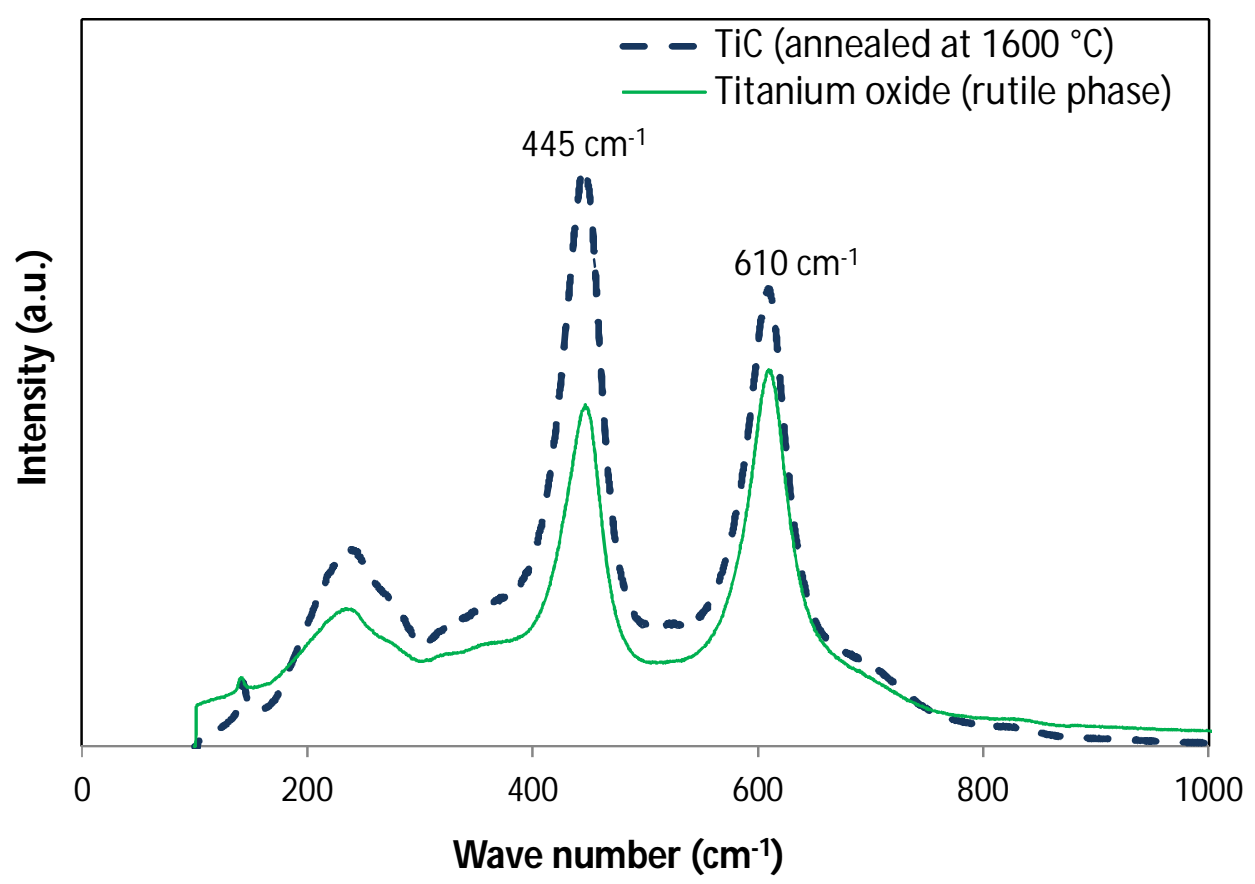

Figure 6.3b. Spectrum from Raman spectroscopy for TiC annealed at $1600{ }^{\circ} \mathrm{C}$ in order to confirm the formation of $\mathrm{TiO}_{2}$ at the surface.

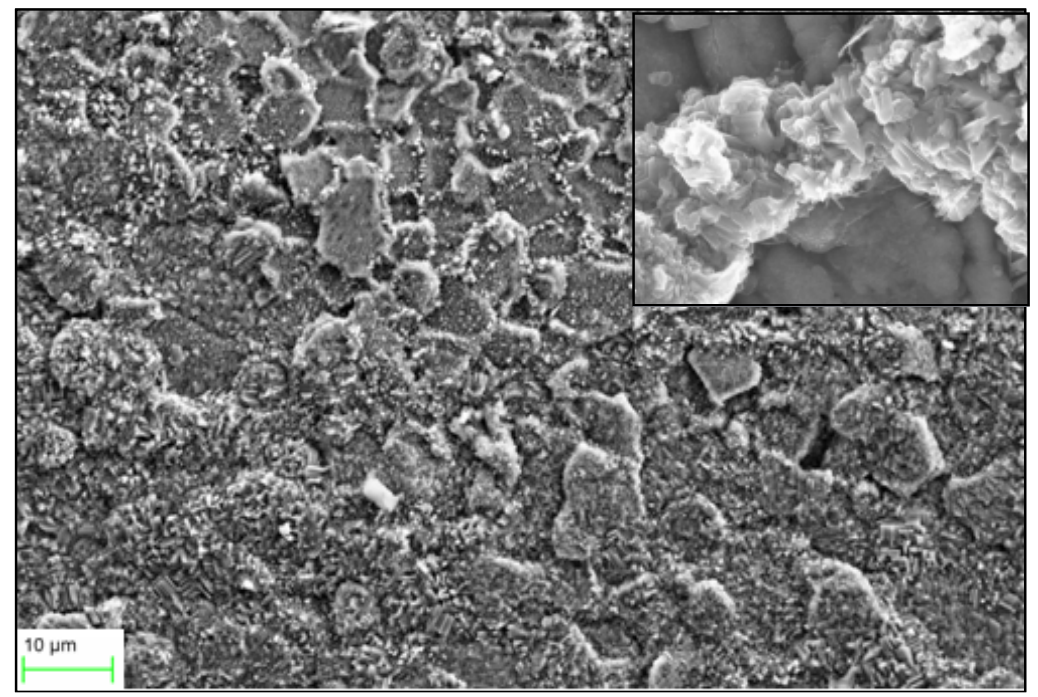

Figure 6.3c. Picture from scanning electron micro scopy to confirm the formation of $\mathrm{TiO}_{2}$ crystal at the surface of $\mathrm{TiC}$ annealed at $1600{ }^{\circ} \mathrm{C}$. Inset in the picture presents the magnification of $\mathrm{TiO}_{2}$ crystal. 


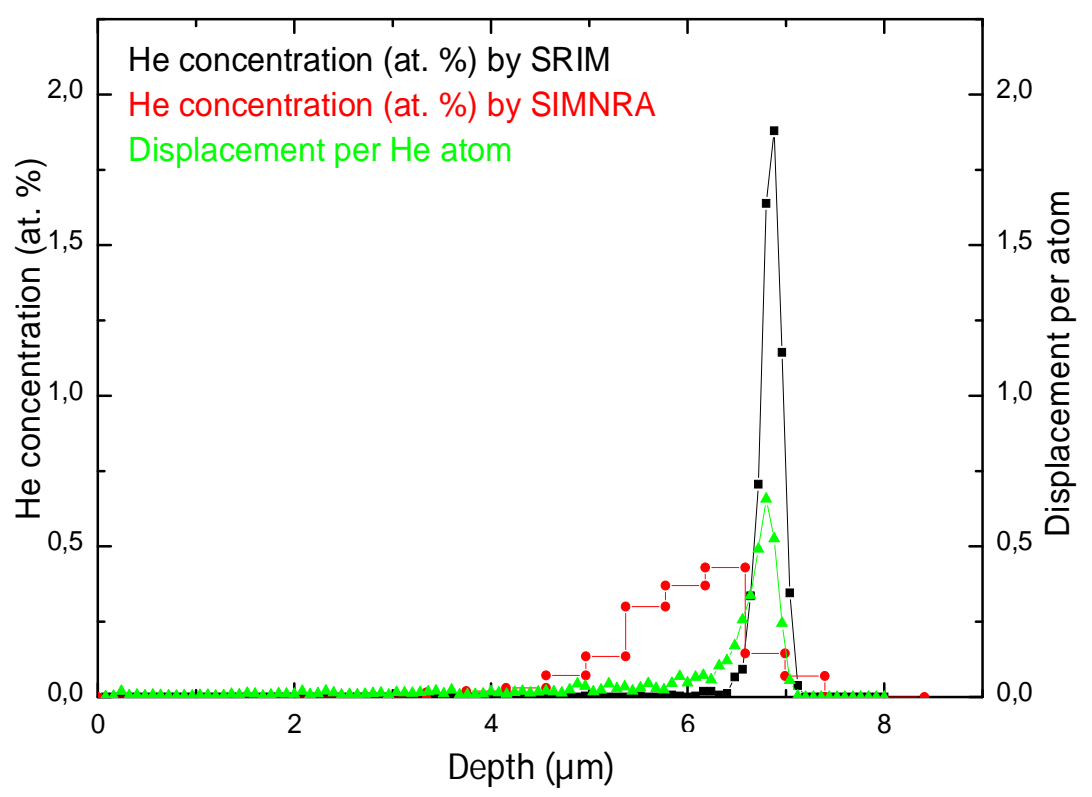

Figure 6.4. SRIM calculations and corresponding displacement per atom (or vacancy concentration per He atom taking a displacement threshold energy of Ti $=50 \mathrm{eV}, \mathrm{C}=30 \mathrm{eV}$ ) of the implantation profile of $3 \mathrm{MeV}{ }^{3} \mathrm{He}$ ions implanted at fluence $5 \times 10^{16} \mathrm{at} \mathrm{cm}^{-2}$ at room temperature in TiC. Comparison with experimentally obtained He profile obtained at $E_{d}=1.3$ MeV from SIMNRA.

\section{B. He distribution in as-implanted sample}

The maximum helium concentration $[\mathrm{He}]_{\max }$ in as-implanted $\mathrm{TiC}$ sample is about 1.8 at $\%$ at the depth of $6.78 \mu \mathrm{m}$ calculated by SRIM [11]. This theoretical helium distribution and vacancy defects created by helium ion implantation (calculated by SRIM software) along with the experimental helium distribution obtained from SIMNRA are shown in figure 6.4.

For the as-implanted sample, the area under the helium depth profile obtained experimentally is equal to the area under the theoretical helium depth profile obtained from SRIM. However, their shape and position depicts significant differences.

The experimentally obtained helium distribution profile in as-implanted sample exhibits a significant broadening and a shift towards the surface, meaning that the distribution could be affected by the backscattering of light elements at high energy. Hofker et al. showed clearly the 
deviation from Gaussian-shaped implantation profile of boron implanted into amorphous silicon at $30 \mathrm{keV}$ to Pearson-shaped distribution at $800 \mathrm{keV} \mathrm{[12].} \mathrm{However,} \mathrm{similar} \mathrm{helium}$ implantation profiles were obtained by Garcia et al. [13] and Martin et al. [14] in polycrystalline uranium dioxide where they explained the role of grain boundaries as effective short circuits for helium release and movement at all temperatures.

The grain diameter of polycrystalline uranium dioxide investigated by Garcia is of the same order of magnitude (6-9 $\mu \mathrm{m})$ as for the TiC samples studied here. Garcia showed the comparison of SEM and micro-NRA cartographies to demonstrate the heterogeneous helium distribution at the sample surface and preferential helium release from areas around the grain boundaries. For this purpose, we decided to follow a similar approach and performed micro-NRA cartography. NRA $\mu$-analysis was performed at nuclear microprobe of the LEEL at CEA Saclay using the ${ }^{3} \mathrm{He}\left(\mathrm{d}, \mathrm{p}_{0}\right){ }^{4} \mathrm{He}$ nuclear reaction [15]. The size and energy of incident deuteron beam were $(\sim 1 \mathrm{x} 1)$ $\mu \mathrm{m}^{2}$ and $1.3 \mathrm{MeV}$ respectively. Non-annealed samples were imaged by their electrostatic beam scanning on $(\sim 50 \mathrm{x} 50) \mu \mathrm{m}^{2}$ area in order to get helium spatial distributions. Figure $(6.5 \mathrm{a}$ and 6.5b) shows the spatial distribution of carbon and helium in non-annealed samples. The colour scale starts with white for the lowest counting rate and ends with green for the highest. Figure 6.5a exhibits the distribution of carbon in $\mathrm{TiC}$ with a homogeneous yellow colour while Figure $6.5 \mathrm{~b}$ clearly shows the heterogeneous $3-\mathrm{D}$ helium distribution, i.e. the colour scale now extends from blue to yellow. This heterogeneity seems to occur in the vicinity of grain boundaries and also in the interior of the grains due to the presence of porosity.

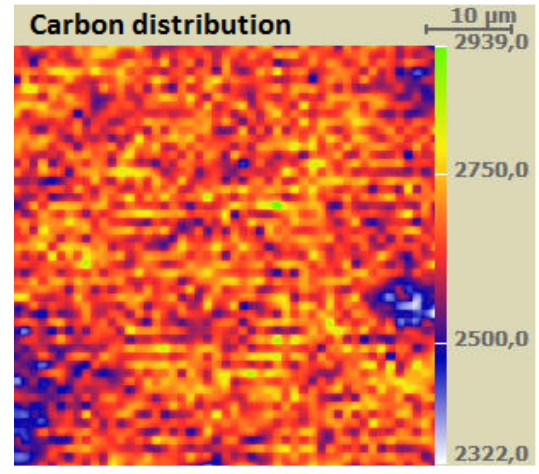

Figure 6.5a

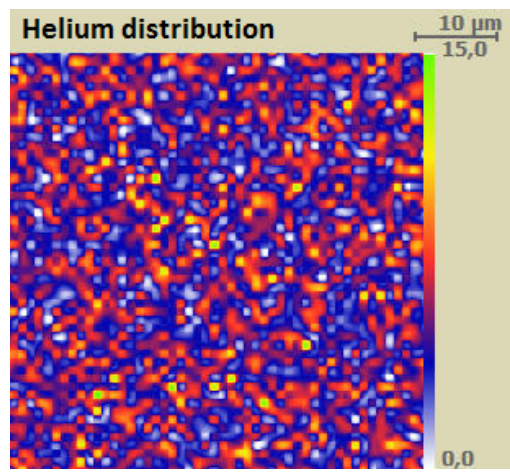

Figure 6.5b

Figure $6.5(\boldsymbol{a} \& \boldsymbol{b})$. NRA cartography to show carbon lateral distributions and helium distribution respectively, by rastering the beam over a $50 \times 50 \mu^{2}$ surface area of as-implanted TiC. 
Recently, Lefaix-Jeuland et al. explained the effect of grain microstructure on thermal helium desorption from pure iron [16]. They attributed the thermal shift and the higher desorption at low temperature to the higher density of grain boundaries present in the fine microstructure 2 $\mu \mathrm{m}$ grain size in comparison with the sample having a larger grain size (40 to $100 \mu \mathrm{m}$ ). The large number of grain boundaries acts as short-circuit for the migration of helium. It appears that perhaps, the tail towards the surface obtained in as-implanted helium profile seems to arise from the motion of helium towards the surface due to short diffusion paths created by grain boundaries along with contribution from backscattering of helium ions during implantation. However, role of native vacancies due to sub-stoichiometric $\mathrm{TiC}_{\mathrm{x}}(\mathrm{x}=0.96)$ is still unknown.

Also, figure 6.4 demonstrates that the position of the vacancy peak (displacement per atom) created by implanted helium ions does not lie over the position of experimentally obtained $\mathrm{He}$ profiles from SIMNRA. Therefore, it may suggest that helium is not trapped by the vacancies created during He implantation.

\section{Results from SIMNRA code}

Due to the presence of large tail towards surface for helium implantation profile, the asimplanted helium depth distributions obtained from SIMNRA code corresponding to $\mathrm{E}_{\mathrm{d}}=1.3$ MeV have been fitted by FITYK code into two Gaussians distributions (named as G1 and G2). For details on fitting, please refer to figure 5.11. Similar decomposition of helium profiles obtained at higher temperature was carried out. The characteristic parameters of the Gaussian distributions (G1 \& G2) for the helium depth distribution at different annealing temperatures have been summarized in table 6.1. The profiles fitted at temperature $1000{ }^{\circ} \mathrm{C}$ show the redistribution of helium atoms into the sample, for example the decrease in total area under G1 Gaussian curve at $1000{ }^{\circ} \mathrm{C}$ has been compensated by the increase in area under G2 Gaussian curve (see red curve in figure 6.6a), thus the sum of total area under two Gaussian curve (G1 + $\mathrm{G} 2)$ remains equal to total area $(\mathrm{G} 1+\mathrm{G} 2)$ for as-implanted profile. The same phenomenon has been also observed at $1100{ }^{\circ} \mathrm{C}$ (see green curve in figure 6.6a), where ${ }^{3} \mathrm{He}$ atoms from main peak (G1) moves to the tail towards the surface (with no release of helium from the surface) and perhaps at temperature higher than $1100{ }^{\circ} \mathrm{C}$ helium atoms follow the same path and finally are released from the surface of the sample. 


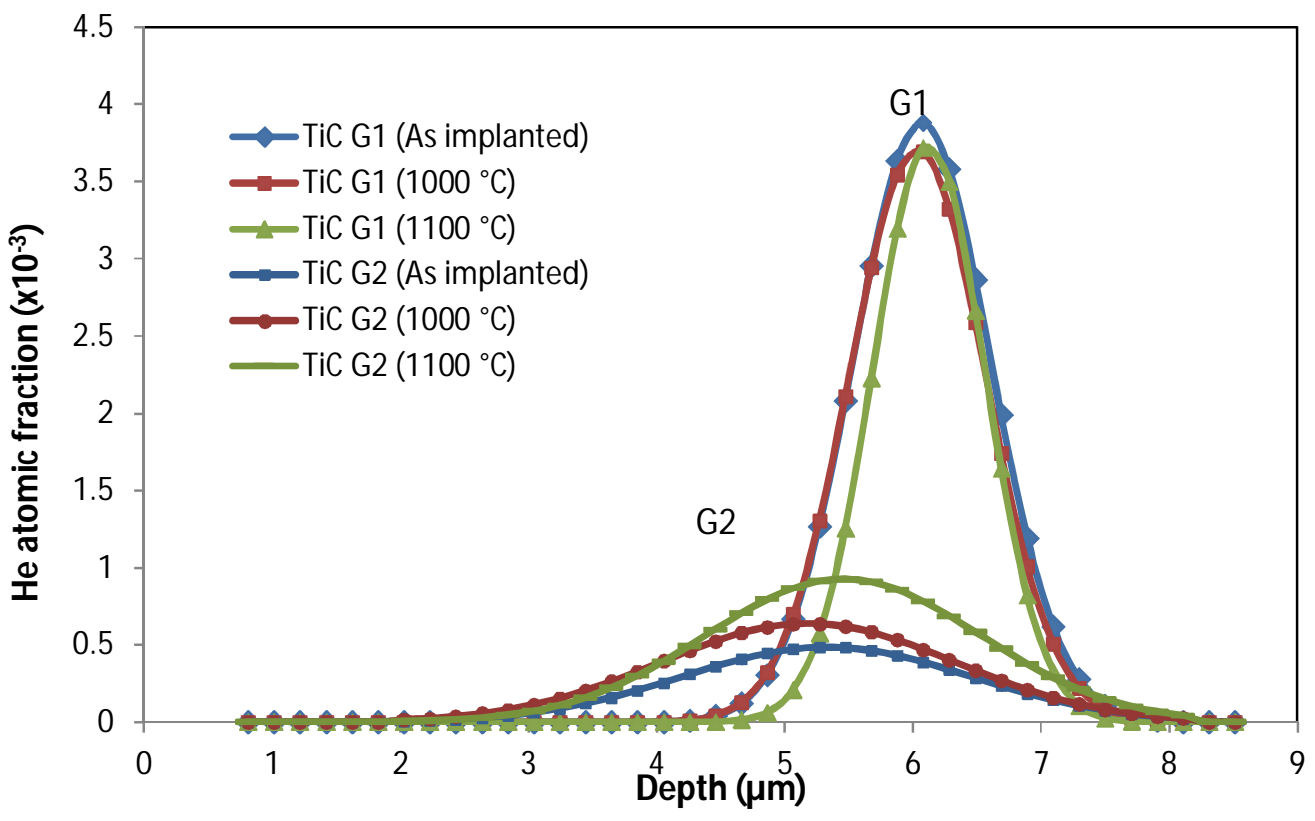

Figure 6.6a. Fitting of the He depth profiles obtained from SIMNRA by FYTIK software into two Gaussians (G1 \& G2) up to $1100{ }^{\circ} \mathrm{C}$. These profiles have been obtained corresponding to $E d=1.3 \mathrm{MeV}$.

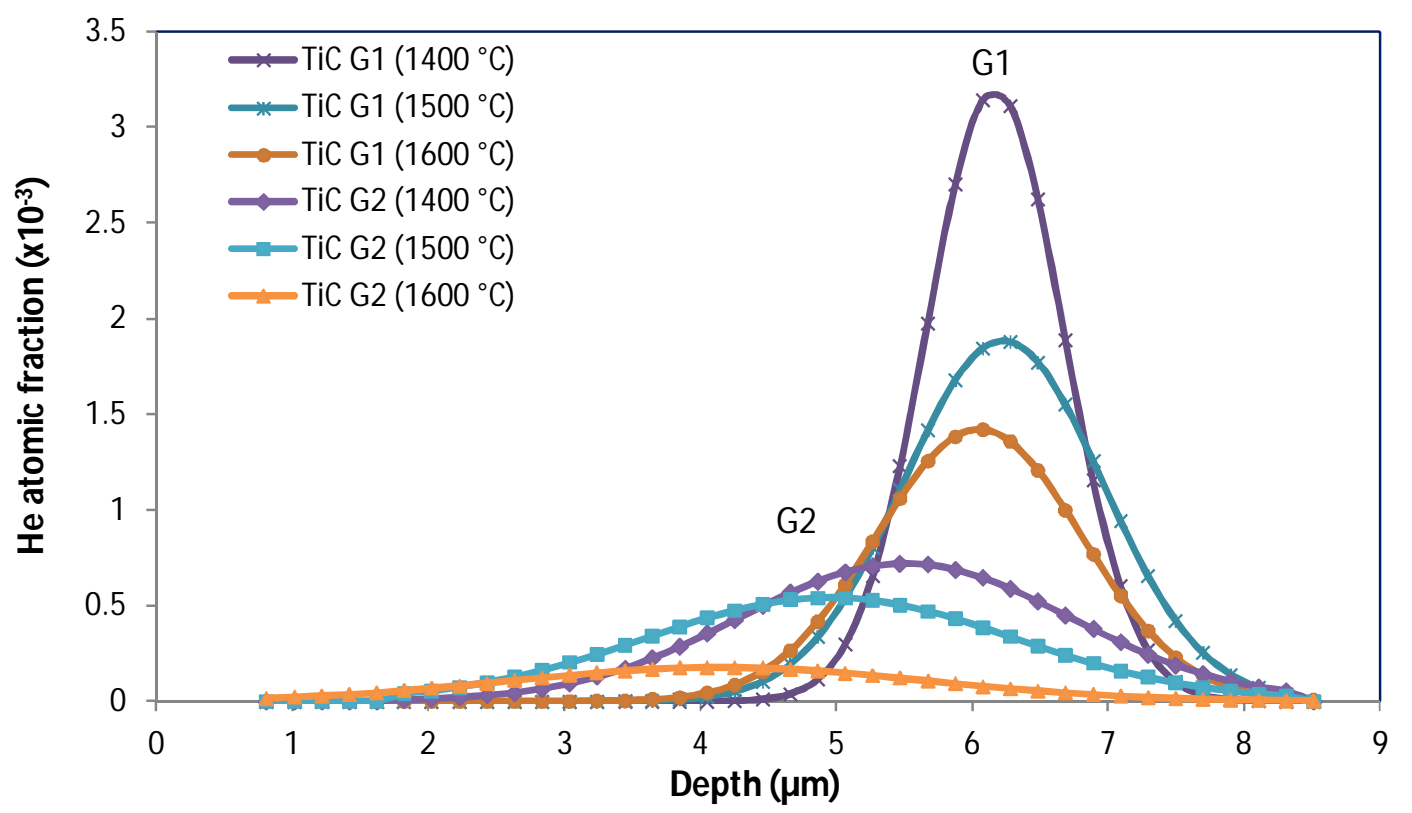

Figure 6.6b. Fitting of the He depth profiles obtained from SIMNRA by FYTIK software into two Gaussians $(G 1 \&$ \& $)$ above $1100{ }^{\circ} \mathrm{C}$. These profiles have been obtained corresponding to $E d=1.3 \mathrm{MeV}$. 


\begin{tabular}{|c|c|c|c|c|c|c|}
\hline $\begin{array}{c}\text { TiC } \\
\text { (Annealin } \\
\text { g Temp.) }\end{array}$ & $\begin{array}{c}\text { A } \\
\text { ( He at. fraction) }\end{array}$ & $\mathbf{x}_{\mathbf{c}}(\boldsymbol{\mu m})$ & $\mathbf{s}(\boldsymbol{\mu m})$ & $\begin{array}{c}\mathbf{A} \\
(\text { He at. fraction) }\end{array}$ & $\mathbf{x}_{\mathbf{c}}(\boldsymbol{\mu m})$ & $\mathbf{s}(\boldsymbol{\mu m})$ \\
\hline & \multicolumn{3}{|c|}{$\mathbf{G 1}$} & \multicolumn{3}{|c|}{$\mathbf{G 2}$} \\
\hline $\begin{array}{c}\text { As } \\
\text { implanted }\end{array}$ & $0.0038 \pm 0.0001$ & $6.05 \pm 0.6$ & $0.54 \pm 0.02$ & $0.0004 \pm 0.00004$ & $4.50 \pm 0.4$ & $1.13 \pm 0.1$ \\
\hline $\mathbf{1 0 0 0}^{\circ} \mathbf{C}$ & $0.0037 \pm 0.0001$ & $6.22 \pm 0.6$ & $0.53 \pm 0.02$ & $0.0006 \pm 0.00006$ & $4.96 \pm 0.4$ & $1.15 \pm 0.1$ \\
\hline $\mathbf{1 1 0 0}^{\circ} \mathbf{C}$ & $0.0036 \pm 0.0001$ & $6.16 \pm 0.6$ & $0.44 \pm 0.02$ & $0.0009 \pm 0.00009$ & $5.51 \pm 0.5$ & $1.02 \pm 0.1$ \\
\hline $\mathbf{1 4 0 0}^{\circ} \mathbf{C}$ & $0.0031 \pm 0.0001$ & $6.12 \pm 0.6$ & $0.50 \pm 0.02$ & $0.0007 \pm 0.00007$ & $5.45 \pm 0.5$ & $1.21 \pm 0.1$ \\
\hline $\mathbf{1 5 0 0}^{\circ} \mathbf{C}$ & $0.0018 \pm 0.00005$ & $6.03 \pm 0.6$ & $0.73 \pm 0.02$ & $0.0005 \pm 0.00005$ & $5.17 \pm 0.5$ & $1.36 \pm 0.1$ \\
\hline $\mathbf{1 6 0 0}^{\circ} \mathbf{C}$ & $0.0014 \pm 0.00005$ & $6.06 \pm 0.6$ & $0.75 \pm 0.02$ & $0.0002 \pm 0.00005$ & $5.33 \pm 0.5$ & $1.52 \pm 0.1$ \\
\hline
\end{tabular}

Table 6.1. Summary of the characteristic parameters of the Gaussian distributions (G1 \& G2) for the helium depth distribution at different annealing temperatures (for 2 hours) obtained from SIMNRA code and fitted by FYTIK code.

At temperature higher than $1100^{\circ} \mathrm{C}$, helium undergoes a thermal diffusion and release in $\mathrm{TiC}$. Helium depth profiles at higher temperature have been plotted in figure 6.6b. Helium profile obtained at $1600{ }^{\circ} \mathrm{C}$ was shifted $1 \mu \mathrm{m}$ towards the sample surface due to oxidation of sample (see section 6.1.2). It is important to mention that figure 6.6b presents the corrected helium profile for $1600{ }^{\circ} \mathrm{C}$.

Helium diffusion coefficient values for G1 population have been calculated by using classical Fick's law (see equation 5.3) which are presented in table 6.2 and plotted in figure 6.7. Over the temperature range $1100{ }^{\circ} \mathrm{C}-1600{ }^{\circ} \mathrm{C}$, the diffusion coefficient data for TiC exhibits a linear Arrhenius behaviour. This linear dependence gives an activation energy of $2.50 \pm 0.25 \mathrm{eV}$ for helium diffusion (see figure 6.7).

It seems difficult to imagine that helium has out-gassed directly from Gaussian curve G1. Instead it went out through the Gaussian curve G2. At temperature above $1100{ }^{\circ} \mathrm{C}$, it was not possible to estimate the decrease in area under G2 indicating helium release. Apart from helium release, the area under $\mathrm{G} 2$ also depends on the addition of area under the curve due to incoming helium atoms from G1 and further depends on either the fraction of these atoms would be trapped into G2 or released from G2. Therefore, it was difficult to calculate diffusion coefficient values and other migration parameters for G2 and, if calculated, these values show large incertitude. 


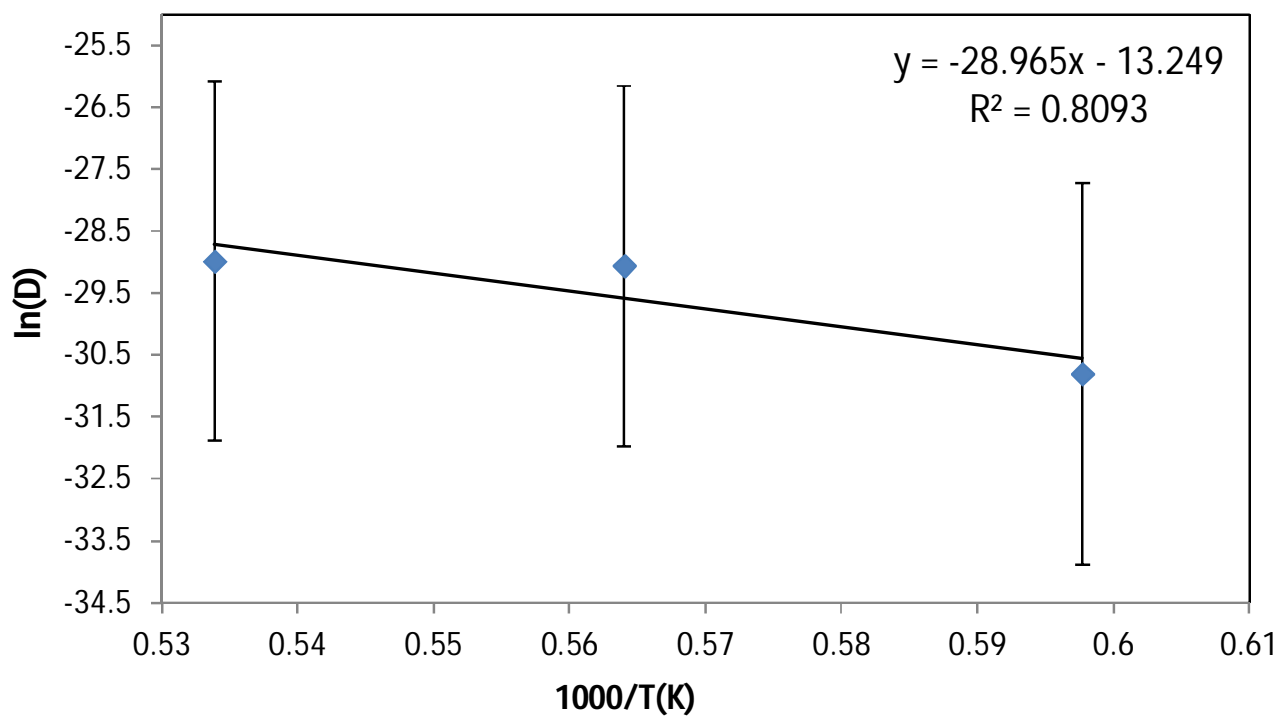

Figure 6.7. Effective diffusion coefficient variation versus temperature in TiC showing Arrhenius behavior.

\section{Results from AGEING code}

The error values obtained by using AGEING2 code are < (3)\%. Figure 6.8 shows an example the fitting of the excitation curve for TiC annealed at $1600{ }^{\circ} \mathrm{C}$ using AGEING2 code. Figure 6.9 shows the helium profile obtained by the AGEING2 code. The shapes closed to pseudoVoigt function have been obtained for samples annealed at temperature up to $1500{ }^{\circ} \mathrm{C}$. This shape represents the two populations of helium in the sample. The population P1 is represented by the concentration of helium present under the main peak, population P1 corresponds to G1 population in figure $6.6 \mathrm{a} \&$ figure $6.6 \mathrm{~b}$. Whereas population P2 is represented by the concentration of helium present under the two tails, population $\mathrm{P} 2$ corresponds to $\mathrm{G} 2$ population in figure $6.6 \mathrm{a} \&$ figure $6.6 \mathrm{~b}$. The enlargement of tails in the profile at $1000{ }^{\circ} \mathrm{C}$ and further at $1100{ }^{\circ} \mathrm{C}$ clearly shows an agreement with the result obtained from section 6.1.2A and 6.1.2B, which indicates the redistribution of $\mathrm{He}$ into the sample up to $1100{ }^{\circ} \mathrm{C}$. At $1500{ }^{\circ} \mathrm{C}$, there is almost a Gaussian shape and further at $1600{ }^{\circ} \mathrm{C}$, the tails seems to have completely disappeared indicating the presence of only one population P1. The position of helium depth profile at 1600 ${ }^{\circ} \mathrm{C}$ is shifted towards the right due to the formation of $\mathrm{TiO}_{2}$ at the surface as described before. The values of all migration parameters obtained are shown in table $6.2 \mathrm{a}$ and $6.2 \mathrm{~b}$. The values of diffusion coefficient for population $\mathrm{P} 2$ is higher as compared to population P1. Also, the 
population P2 completely disappears at $1600{ }^{\circ} \mathrm{C}$. Further development of the differential equation system would be necessary in order to represent more closely the experimental profile.

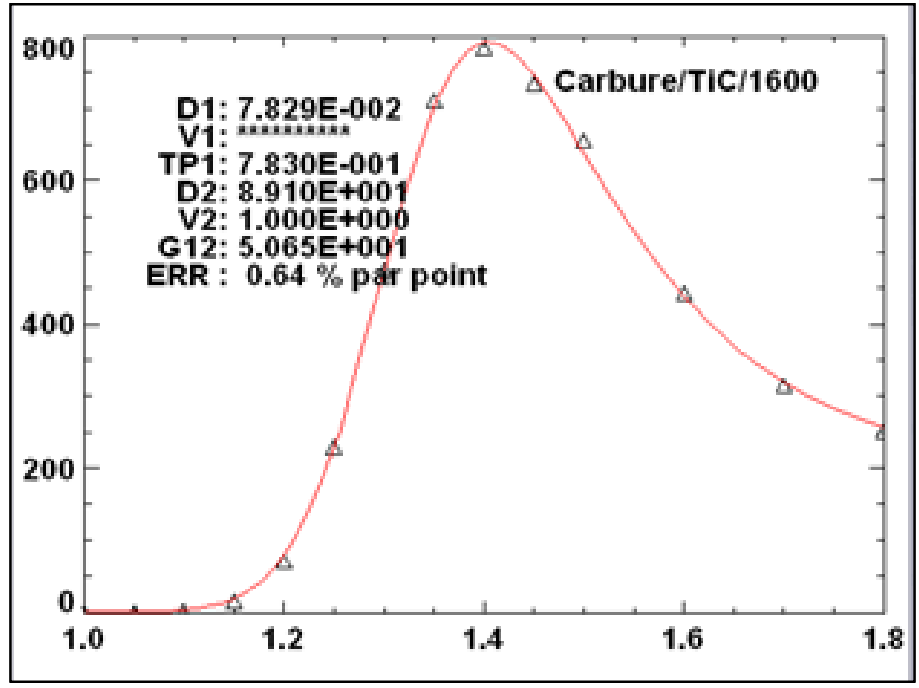

Figure 6.8. An example of the fitting of the excitation curve for TiC annealed at $1600{ }^{\circ} \mathrm{C}$ using AGEING2 code.

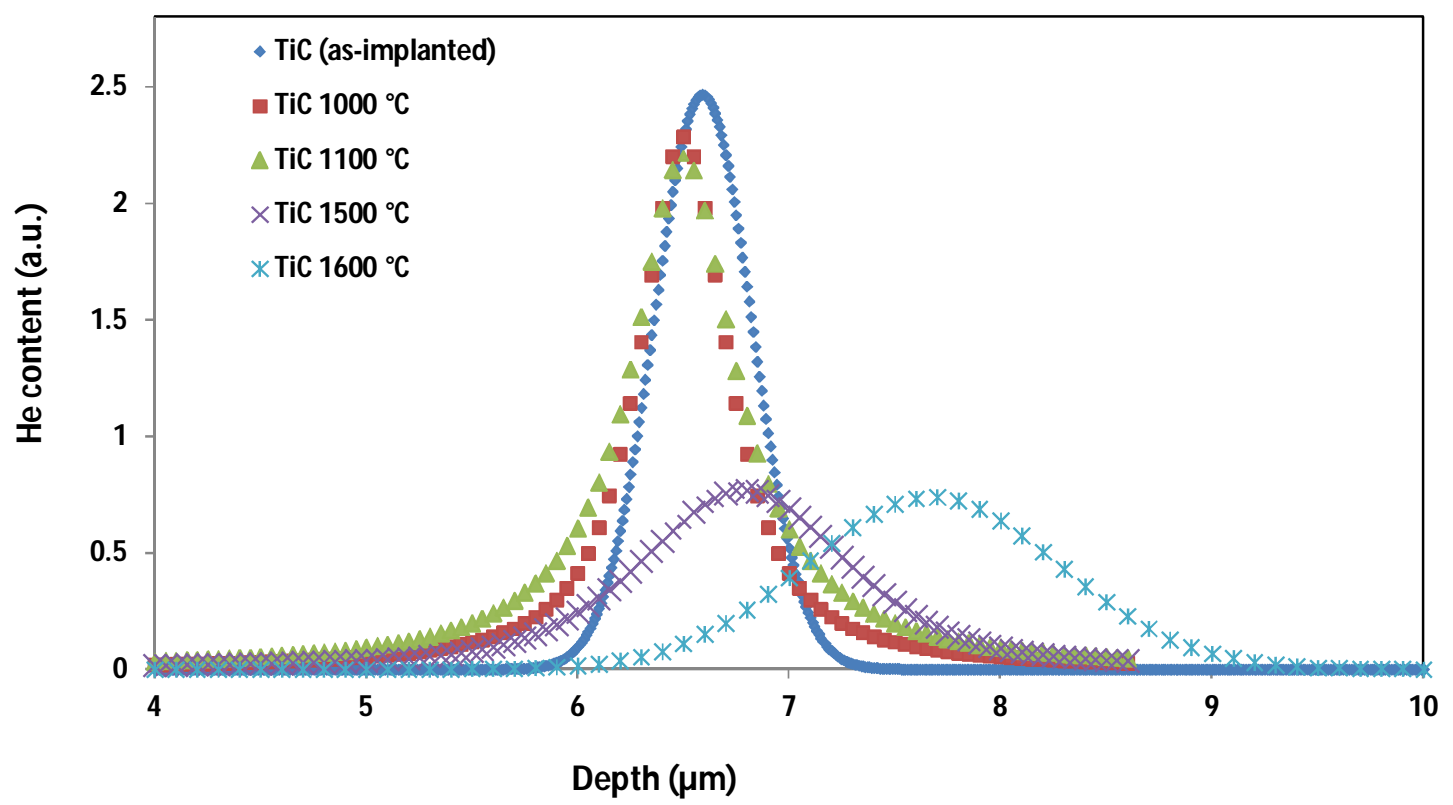

Figure 6.9. He depth profile obtained by AGEING code. 


\begin{tabular}{|l|l|l|l|}
\hline Temperature $\left({ }^{\circ} \mathbf{C}\right)$ & $\begin{array}{l}\text { Effective diffusion } \\
\text { coefficient for G1 } \\
\text { derived from SIMNRA } \\
\left(\mathbf{m}^{\mathbf{2}} \mathbf{s}^{-\mathbf{1}}\right)\end{array}$ & $\begin{array}{l}\text { Effective diffusion } \\
\text { coefficient }\left(\mathbf{D}_{\mathbf{1}}\right) \text { derived } \\
\text { from AGEING }\left(\mathbf{m}^{\mathbf{2}} \mathbf{~ s}^{-1}\right)\end{array}$ & $\begin{array}{l}\text { Effective diffusion } \\
\text { coefficient }\left(\mathbf{D}_{2}\right) \text { derived } \\
\text { from AGEING }\left(\mathbf{m}^{\mathbf{2}} \mathbf{~ s}^{-1}\right)\end{array}$ \\
\hline $1400^{*}$ & $(4.20 \pm 0.4) \times 10^{-18}$ & & \\
\hline 1500 & $(2.39 \pm 0.2) \times 10^{-17}$ & $(2.8 \pm 0.2) \times 10^{-17}$ & $(2.8 \pm 0.2) \times 10^{-14}$ \\
\hline $1600^{* *}$ & $(2.59 \pm 0.2) \times 10^{-17}$ & $(2.19 \pm 0.2) \times 10^{-17}$ & $(2.49 \pm 0.2) \times 10^{-14}$ \\
\hline
\end{tabular}

* For sample annealed at $1400^{\circ} \mathrm{C}, \mathrm{NRA}$ to plot excitation curve was not done, only one proton energy spectrum corresponding to Ed $=1300 \mathrm{keV}$ was taken to derive the values of migration parameters using SIMNRA code.

**Values of diffusion coefficient derived at $1600{ }^{\circ} \mathrm{C}$ using ageing code have large uncertainty due to sudden oxidation of sample.

Table 6.2a. Effective diffusion coefficients for ${ }^{3} \mathrm{He}$ in TiC derived from SIMNRA code as well as from AGEING code.

\begin{tabular}{|c|c|c|c|c|c|}
\hline $\mathbf{T}\left({ }^{\circ} \mathbf{C}\right)$ & $\mathbf{v}_{\mathbf{1}}(\boldsymbol{\mu m} / \mathbf{h})$ & $\mathbf{T P}_{\mathbf{1}}$ & $\begin{array}{c}\mathbf{g}_{\mathbf{1 2}} \\
\left(\mathbf{h}^{-\mathbf{1}}\right)\end{array}$ & $\mathbf{v}_{\mathbf{2}}(\boldsymbol{\mu \mathbf { m }} / \mathbf{h})$ & Error $(\boldsymbol{\%})$ \\
\hline 1000 & 0.02 & 1 & 51.24 & 0.90 & 2.87 \\
\hline 1100 & 0.02 & 1 & 52.01 & 0.90 & 1.35 \\
\hline 1500 & 0.02 & 0.82 & 50 & 1.79 & 2.25 \\
\hline $1600^{*}$ & 0.02 & 0.78 & 50.65 & 1 & 0.76 \\
\hline
\end{tabular}

*Values of migration parameters derived at $1600{ }^{\circ} \mathrm{C}$ using ageing code have large uncertainty due to sudden oxidation of sample.

Table 6.2b. Other ${ }^{3} \mathrm{He}$ diffusion parameters in TiC polycrystal annealed at different temperatures (for 2 hours) obtained by using AGEING code.

\subsubsection{General Discussion}

The presence of a very low density $(\sim 1 \%)$ of intragranular porosity in the samples indicates that the connecting channels (able to accelerate the gas release) formed from combinations of pores towards the surface are absent. After annealing up to $1400{ }^{\circ} \mathrm{C}$, no cracks or exfoliation on the surface have been observed but segregation of impurities at the grain boundaries is found. $\mathrm{X}$-ray diffraction studies (not displayed here) show the polycrystalline structure of $\mathrm{TiC}$ is randomly oriented indicating that no specific crystallographic orientation is responsible for $\mathrm{He}$ 
migration. Nevertheless, peak area measurement in annealed samples indicates that $37 \%$ of the total quantity of implanted helium has been released at $1600{ }^{\circ} \mathrm{C}$.

Helium diffusion in He-ion implanted materials at high temperature takes place either through a substitutional mechanism involving vacancy-assisted diffusion or a dissociative mechanism involving $\left(\mathrm{He}_{\mathrm{n}}-\mathrm{V}_{\mathrm{m}}\right)$ clusters in which He atoms are trapped. These clusters can act as nucleation centres for gas bubbles at large helium concentration (several tenths of atomic \%). [17]. Hojou showed the presence of bubbles in $\mathrm{TiC}$ at the fluence of $5 \times 10^{16} \mathrm{at} / \mathrm{cm}^{2}$ at room temperature [18]. This suggests the presence of stable $\left(\mathrm{He}_{\mathrm{n}}-\mathrm{V}_{\mathrm{m}}\right)$ clusters or bubbles in our sample.

Due to mixed bonding characteristics of $\mathrm{TiC}$, we have compared our results to both metallic and ceramic systems having a face centered cubic (fcc) crystal structure and finally results are compared with other materials.

For metallic systems, the presence of more than one population in the helium implanted samples has also been observed by Baskes and co-authors [19]. They calculated that the main defect after helium implantation at room temperature in copper was $\mathrm{He}_{6} \mathrm{~V}$ with a slight presence of $\mathrm{He}_{5} \mathrm{~V}$ and $\mathrm{He}_{4} \mathrm{~V}$. After annealing at higher temperature, the $\mathrm{He}_{6} \mathrm{~V}$ clusters broke into $\mathrm{He}_{2} \mathrm{~V}$ and $\mathrm{He}_{3} \mathrm{~V}$ clusters with release of helium atoms outside the sample. Further high temperature annealing was required to break stable $\mathrm{He}_{2} \mathrm{~V}$ and $\mathrm{He}_{3} \mathrm{~V}$ clusters.

For ceramic systems, Busker and co-workers [20] calculated vacancy cluster formation energies and dissociation energies of clusters with helium in magnesium oxide $(\mathrm{MgO})$. They showed that activation energies for dissociation of one helium atom from helium-filled vacancy depend on the helium-to-vacancy ratio $(\mathrm{n} / \mathrm{m})$ of clusters. The activation energy decreases with the increase in ratio. Therefore, less energy was required to dissociate clusters having high helium-to-vacancy ratio $(\mathrm{n} / \mathrm{m})$ than the small clusters having low helium-to-vacancy ratio.

These results provide a clear understanding of the origin and nature of the double-peak depth profile we can observe in fig. (6.6a, 6.6b, and 6.9). Hereafter, separate discussion is done on two populations:

Our measurement show that, as the higher annealing temperatures (above $1100{ }^{\circ} \mathrm{C}$ ) are reached, helium is de-trapped preferentially from the deeper part of the profile which apparently bind helium less strongly at the higher temperatures than do the finer scale of small clusters closer to the surface. This process of higher de-trapping from G1 population is observed up to $1500{ }^{\circ} \mathrm{C}$. Up to $1500{ }^{\circ} \mathrm{C}$, it appears that all the unstable large clusters (high helium to vacancy 
cluster ratio) present in deeper part of the profile may dissociate into stable small clusters (low helium to vacancy cluster ratio) and release helium atoms. At $1600{ }^{\circ} \mathrm{C}$, the release of helium atoms through de-trapping process continues in G1 but still a large amount of helium atoms remain trapped and thus a higher annealing temperature is required to release all helium atoms.

Until $1100^{\circ} \mathrm{C}$, it should be noted that almost no helium release is observed for G2 whereas there is an addition of helium atoms from $\mathrm{G} 1$ population (see figure $6.6 \mathrm{a}$ ). At $1500^{\circ} \mathrm{C}$, the $\mathrm{G} 2$ curve becomes wider with almost no change in the area under curve (see figure 6.6b). The similar behavior is also shown in figure 6.9 by AGEING code, where the area under tails exhibits very less change. At $1600{ }^{\circ} \mathrm{C}$, we observed the complete disappearance of helium atoms from the profile present close to the surface. The higher value of $D_{2}$ parameter than $D_{1}$ parameter and high drift velocity $(1.79 \mu \mathrm{m} / \mathrm{h})$ for $\mathrm{D}_{2}$ population indicates that the population present close to the surface would gradually out-gas from the sample through diffusion process rather than dissociation of clusters. The increase in helium drift velocity at higher temperature could be due to the annealing of the pre-existing defects such as dislocation lines. This disappearance of dislocation lines has been already observed in TiN [21]. To be discussed in the next chapter. In TEM investigation of $\mathrm{TiN}\left(3 \mathrm{MeV},{ }^{3} \mathrm{He}\right.$ implanted and post annealed at temperature $\geq 1400{ }^{\circ} \mathrm{C}$ ), dislocation lines vanished whereas they were clearly visible at lower temperature. This decrease in density of trapping sites perhaps contributes to the increase in drift velocity and further to helium release in TiC.

Blewer and co-author also observed the double-peak helium depth profile in vanadium [22]. After annealing the samples at higher temperature, the peak with greater trapping efficiency corresponds to the small clusters whereas the peak from which maximum helium has released corresponds to the presence of the large clusters. Recent computational studies on $\left(\mathrm{He}_{\mathrm{n}}-\mathrm{V}_{\mathrm{m}}\right)$ clusters in iron also showed that the He binding energy to the cluster is a decreasing function of the $\mathrm{n} / \mathrm{m}$ ratio [23]. The value of binding energy, $5.25 \mathrm{eV}$ for $\mathrm{n}=0$ changes to $1 \mathrm{eV}$, for $\mathrm{n} / \mathrm{m}$ $>6$ whereas vacancy binding increases with increase of $\mathrm{n} / \mathrm{m}$ ratio. When clusters have high $\mathrm{n} / \mathrm{m}$ ratio, it favours thermal emission of He atoms from clusters, whereas vacancies become more strongly trapped perhaps leading to the formation of highly stable bubbles and further decreasing $\mathrm{n} / \mathrm{m}$ ratio.

Similar observation about low dissociation energy of helium atoms from clusters with high $\mathrm{n} / \mathrm{m}$ ratio and stability of low $\mathrm{n} / \mathrm{m}$ ratio clusters have been given by many authors in different materials including both fcc and bcc crystal structure. Ao and co-workers showed the same 
phenomenon in aluminum [24], Wang and co-authors in titanium [25], Zhang and co-authors in vanadium [26]. The same phenomenon is expected to rule in our case, as to best of our knowledge no simulation or experimental study of helium migration in $\mathrm{TiC}$ has been done in the past.

Careful TEM investigations would clearly help us to decide the nature of helium association with defects in the two types of population.

\subsubsection{Conclusion}

Helium diffusion in TiC was studied with nuclear reaction analysis using ${ }^{3} \mathrm{He}\left(\mathrm{d}, \mathrm{p}_{0}\right)^{4} \mathrm{He}$ nuclear reaction. Polished slabs of TiC were implanted with $3 \mathrm{MeV}^{3} \mathrm{He}$ at a dose of $5 \times 10^{20}$ ${ }^{3} \mathrm{He} / \mathrm{m}^{2}$ and annealed over the temperature range $1000-1600{ }^{\circ} \mathrm{C}$ for 2 hours under low pressurized argon atmosphere. It is important to note that the diffusion coefficient determination for ${ }^{3} \mathrm{He}$ could be easily extended to know the value of the diffusion coefficient for ${ }^{4} \mathrm{He}[27,28]$. The conventional assumption is to consider the square root of the isotope mass ratio to deduce

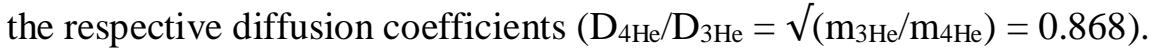

The main conclusions are summarized as follows:

1. Activation energy of He release is around $\sim 0.89 \mathrm{eV}$ whereas apparent value of activation energy for He diffusion is around $\sim 2.50 \mathrm{eV}$. Dissociative mechanism is supposed.

2. The helium implantation profile appears to be a non-Gaussian distribution. Therefore, the presence of two populations of helium is assumed. One population is present close to the surface in the form of stable clusters (with low He-to-vacancy ratio), whereas the other population is present deeper into the sample and contributes mainly to the total helium present in the sample, which has less stable clusters (with high He-to-vacancy ratio), and hence dissociates at higher annealing temperatures to release helium atoms. The diffusion coefficient value for this population varies from $4.20 \times 10^{-18}$ to $2.59 \times 10^{-}$ ${ }^{17} \mathrm{~m}^{2} \mathrm{~s}^{-1}$ and zero drift velocity towards the sample surface. The population present close to the surface has diffusion coefficient values around $2.48 \times 10^{-14} \mathrm{~m}^{2} \mathrm{~s}^{-1}$ and drift velocity varies from $0.90 \mu \mathrm{m} / \mathrm{h}$ to $1.79 \mu \mathrm{m} / \mathrm{h}$ towards the sample surface.

3. The values of diffusion coefficients and other migration parameters derived using the two codes are in good agreement. 
4. The presence of grain boundaries seems to affect largely the He-ion implantation profile, diffusion coefficient values and other migration parameters.

Data analysis by both AGEING and SIMNRA codes gives almost the same values for the diffusion coefficient. This double data processing method allows the description of the whole extent of the helium depth profile if a tailing phenomenon. Both the simulation shows the presence of two populations for He atoms. For oxidized samples, large incertitude in the migration parameters has been observed using both codes.

\section{References}

[1] J-M. Costantini, J-J. Grob, J. Haussy, P. Trocellier, Ph. Trouslard, J. Nucl. Mater. 321 (2003) 281-287.

[2] S. Miro, J-M. Costantini, J. Haussy, L. Beck, S. Vaubaillon, S. Pellegrino, C. Meis, J-J. Grob, Y. Zhang, W.J. Weber, J. Nucl. Mater. 415 (2011) 5-12.

[3] D.J. Cherniak, E.B. Watson, Chem. Geol. 288 (2011) 149-161.

[4] E. Oliviero, A. Van Veen, A.V. Fedorov, M-F. Beaufort, J-F. Barbot, Nucl. Instrum. Meth. Phys. Res. B186 (2002) 223-228.

[5] Y. Pramono, K. Sasaki, T. Yano, J. Nucl. Sci. Technol. 41 (2004) 751-755.

[6] Y. Pramono, T. Yano, J. Nucl. Mater. 329-333 (2004) 1170-1174.

[7] D. J. Cherniak, E. B. Watson, J. B. Thomas, Chem. Geol. 268 (2009) 155-166.

[8] D. J. Cherniak, E. B. Watson, Geochimica and Cosmochimica Acta.74 (2010) Supplement A173.

[9] P. Trouslard, Rapport CEA-R-5703, 1995.

[10] U. Balachandran, N. G. Eror, J. Solid State Chem. 42 (1982) 276.

[11] J. F. Ziegler, http://srim.org/SRIM/SRIM2011.htm.

[12] W. K. Hofker, H. W. Werner, D. P. Oosthoek, H. A. M. de Grefte, Appl. Phys. 2. 265-278 (1973).

[13] P. Garcia, G. Martin, P. Desgardin, G. Carlot, T. Sauvage, C. Sabathier, E. Castellier, H. Khodja, M.-F. Barthe, J. Nucl. Mater. 430 (2012) 156-165.

[14] G. Martin, P. Desgardin, T. Sauvage, P. Garcia, G. Carlot, H. Khodja, M. F. Barthe, , Nucl. Instrum. Meth. Phys. Res B 249 (2006) 509-512. 
[15] H. Khodja, E. Berthoumieux, L. Daudin, J-P Gallien, Nucl. Instrum. Meth. Phys. Res B $181(2001) 83-86$.

[16] H. Lefaix-Jeuland, S. Moll, T. Jourdan, F. Legendre, J. Nucl. Mater. 434 (2013) 152-157

[17] H. Trinkaus, B.N. Singh, J. Nucl. Mater. 323 (2003) 229 - 242.

[18] K. Hojou, H. Otsu, S. Furuno, K. Izui, T. Tsukamoto, J. Nucl. Mater. 212-215 (1994) 281286.

[19] M.I. Baskes and W.D. Wilson, J. Nucl. Mater. 63 (1976) 126-131.

[20] G. Busker, M. A. van Huis, R. W. Grimes, A. van Veen, Nucl. Instrum. Meth. Phys. Res. B 171 (2000) 528-536.

[21] S. Agarwal et al, Oral presentation to symposium EE, MRS Fall meeting, Boston, MA, USA, 2013 to be published.

[22] R.S. Blewer, R.A. Langley, J. Nucl. Mater. 63 (1976) 337-346.

[23] K. Morishita, R. Sugano, B. D. Wirth, T. Diaz de la Rubia, Nucl. Instrum. Meth. Phys. Res. B 202 (2003) 76-81.

[24] B.Y. Ao, J.Y. Yang, X.L. Wang, W.Y. Hu, J. Nucl. Mater. 350 (2006) 83-88.

[25] Y. Wang, S. Liu, L. Rong, Y. Wang, J. Nucl. Mater. 402 (2010) 55-59.

[26] P. Zhang, J. Zhao, Y. Qin, B. Wen, J. Nucl. Mater. 419 (2011) 1-8.

[27] T.W. Trull, M.D. Kurz, J. Mol. Struct. 485-486 (1999) 555-567.

[28] D.L. Schuster, K.A. Farley, J.M. Sisterson, D.S. Burnett, Earth. Planet. Sci. Lett. 217(2003) 19-32. 


\section{Part 2}

\subsection{Helium behavior under thermal environment in TiN}

Before presenting and discussing results for helium behavior under thermal environment in TiN, we have given a quick reminder of our experimental approach. The results shown in this section of chapter 6 are in process of publishing. Already two manuscripts have been written and are planned to be submitted in near future. These publications have the following title:

- 'When and how ion beam analysis (IBA) could be more effective than transmission electron microscopy (TEM)' to study helium behavior in materials. S. Agarwal, P. Trocellier, D. Brimbal, S. Vaubaillon.

-Mechanisms of helium bubble growth in TiN upon annealing. S. Agarwal, P. Trocellier, T. Jourdan, D. Brimbal, A. Barbu, S. Vaubaillon.

\subsubsection{Reminder of the experimental approach}

\begin{tabular}{|c|c|c|c|c|c|}
\hline (A) & $\begin{array}{c}\text { He implantation } \rightarrow \\
\text { in bulk TiN at RT } \\
\begin{array}{c}\text { 3 MeV, } \mathbf{F}_{1}=5 \times 10^{16} \mathrm{at} . / \mathrm{cm}^{2}, \\
\mathbf{R p}=6.16 \mu \mathrm{m})\end{array}\end{array}$ & $\begin{array}{c}\text { Thermal annealing } \\
\left(1000{ }^{\circ} \mathrm{C}, 1100{ }^{\circ} \mathrm{C},\right. \\
1400{ }^{\circ} \mathrm{C}, 1500{ }^{\circ} \mathrm{C}, \\
\left.1600{ }^{\circ} \mathrm{C}, 2 \mathrm{~h}\right)\end{array}$ & $\begin{array}{l}\rightarrow \text { NRA } \\
\text { (done on as- } \\
\text { implanted } \\
\text { and annealed } \\
\text { bulk samples) }\end{array}$ & $\begin{array}{c}\text { Cross section TEM } \\
\text { specimen made from } \\
\text { bulk annealed and as- } \\
\text { implanted samples } \\
\text { (with the help of FIB) }\end{array}$ & $\rightarrow \quad$ TEM Analysis \\
\hline (B) & $\begin{array}{l}\text { He implantation in three } \\
\text { TiN with three different } \\
\mathbf{F}_{1}=\mathbf{5} \times \mathbf{1 0}^{\mathbf{1 6}} \text { at. } / \mathbf{c m}^{\mathbf{2}} \\
\mathbf{F}_{\mathbf{2}}=\mathbf{0 . 7 3} \times \mathbf{1 0}^{\mathbf{1 6}} \text { at. } / \mathbf{c m}^{\mathbf{2}} \\
\mathbf{F}_{3}=\mathbf{0 . 2 3} \times \mathbf{1 0}^{\mathbf{1 6}} \text { at. } / \mathbf{c m}^{\mathbf{2}}\end{array}$ & $\begin{array}{l}\text { arge samples of } \rightarrow \\
\text { luences at } \mathbf{R T}: \\
; \mathbf{E}=\mathbf{3} \mathbf{M e V} \\
; \mathbf{E}=\mathbf{3} \mathbf{M e V} \\
; \mathbf{E}=\mathbf{3} \mathbf{M e V}\end{array}$ & $\begin{array}{l}\text { Thermal annealing } \\
\left(1100{ }^{\circ} \mathbf{C}, 1500{ }^{\circ} \mathrm{C},\right. \\
\text { 2h) }\end{array}$ & $\rightarrow \underset{\begin{array}{c}\text { NRA } \\
\text { (done on as- } \\
\text { implanted and } \\
\text { annealed bulk } \\
\text { samples) }\end{array}}{\rightarrow}$ & $\begin{array}{l}\text { Cross section TEM } \rightarrow \text { TEM } \\
\text { specimen made from } \\
\text { bulk annealed and as- } \\
\text { implanted samples } \\
\text { (with the help of FIB) }\end{array}$ \\
\hline
\end{tabular}

Apart from this reminder, some other points are important to mention here:

The results for $\mathrm{TiC}$ (see section 6.1) confirm that the two codes namely, SIMNRA and AGEING code for NRA data analysis agree with each other and the values of migration parameters and diffusion coefficients derived with the help of two codes resemble each other. Here, we have used both codes to verify the form of helium depth profiles but diffusion 
coefficients and other migration parameter values have been deduced only with the help of SIMNRA code.

It is also important to note that the value of fluence $\mathrm{F}_{1}$ used in experimental approach $\mathrm{B}$, is equal to the value of fluence $\mathrm{F}_{1}$ used in experimental approach $\mathrm{A}$.

\subsubsection{Results and Discussion}

In the next paragraph, results from experimental approach A on the specimen implanted with fluence $F_{1}$ and annealed at various temperatures $\left(T_{a}\right)$ are presented and discussed (Part A). Later on, results from experimental approach B on the role of implantation fluence on helium mobility are discussed (Part B).

\subsubsection{Specimens implanted with fluence $F_{1}$ and annealed at various $\mathbf{T}_{\mathbf{a}}(\operatorname{Part} \mathbf{A})$}

\section{A. Nuclear reaction analysis}

The experiments devoted to plot excitation curves were conducted by varying the deuteron energy $\left(\mathrm{E}_{\mathrm{D}}\right)$ from $0.8 \mathrm{MeV}$ to $1.8 \mathrm{MeV}$ on as-implanted and annealed TiN specimens at annealing temperature $\mathrm{T}_{\mathrm{a}}=1000{ }^{\circ} \mathrm{C}, 1100{ }^{\circ} \mathrm{C}, 1400{ }^{\circ} \mathrm{C}, 1500^{\circ} \mathrm{C}$ and $1600{ }^{\circ} \mathrm{C}$ (see figure $6.10 \mathrm{a}$ ). Similar to $\mathrm{TiC}$, the helium lost fraction (f) versus $\mathrm{T}_{\mathrm{a}}$ have been fitted by $1^{\text {st }}$ order kinetic law and the activation energy of helium release was obtained, $\Delta \mathrm{H}=(1.20 \pm 0.12) \mathrm{eV}$. This curve has been plotted in figure $6.10 \mathrm{~b}$. 


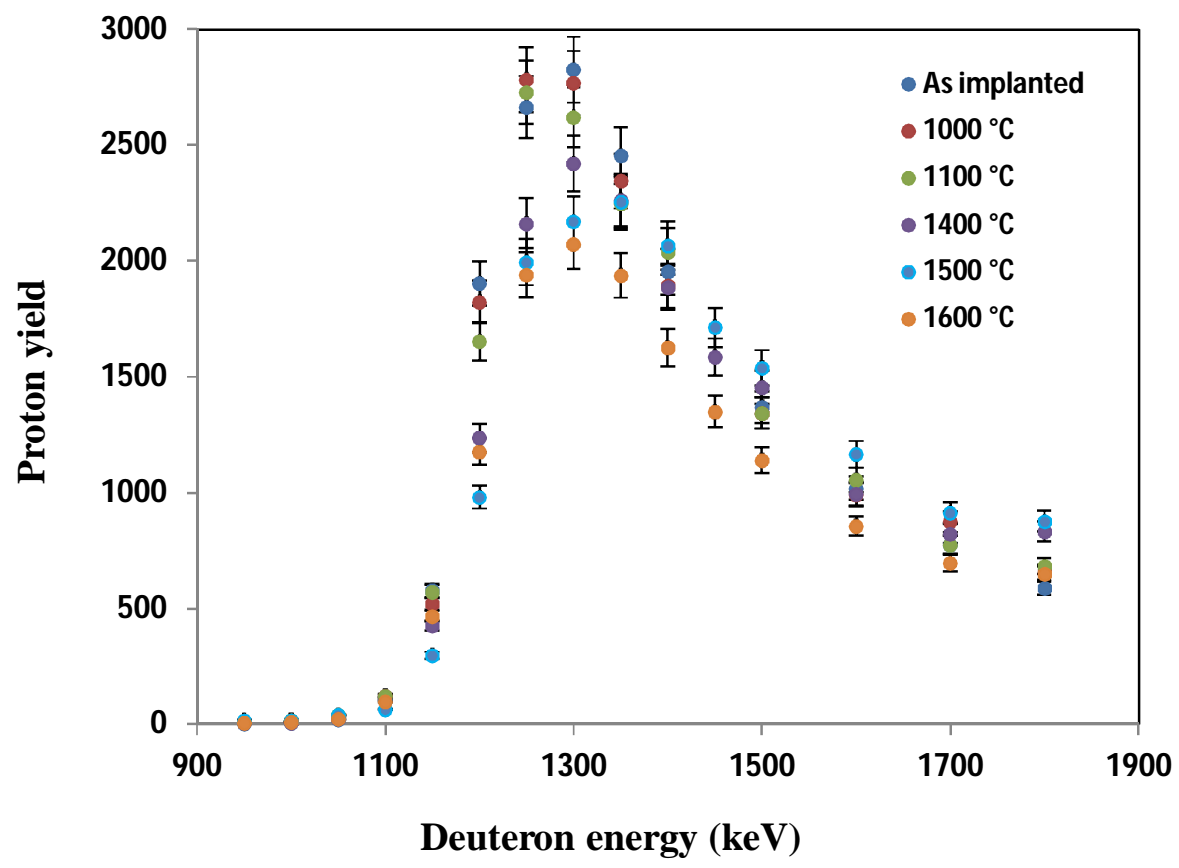

Figure 6.10a. Excitation curves (proton yield versus incident deuteron energy) measured for as-implanted and annealed TiN samples corresponding to $F_{1}$ fluence.

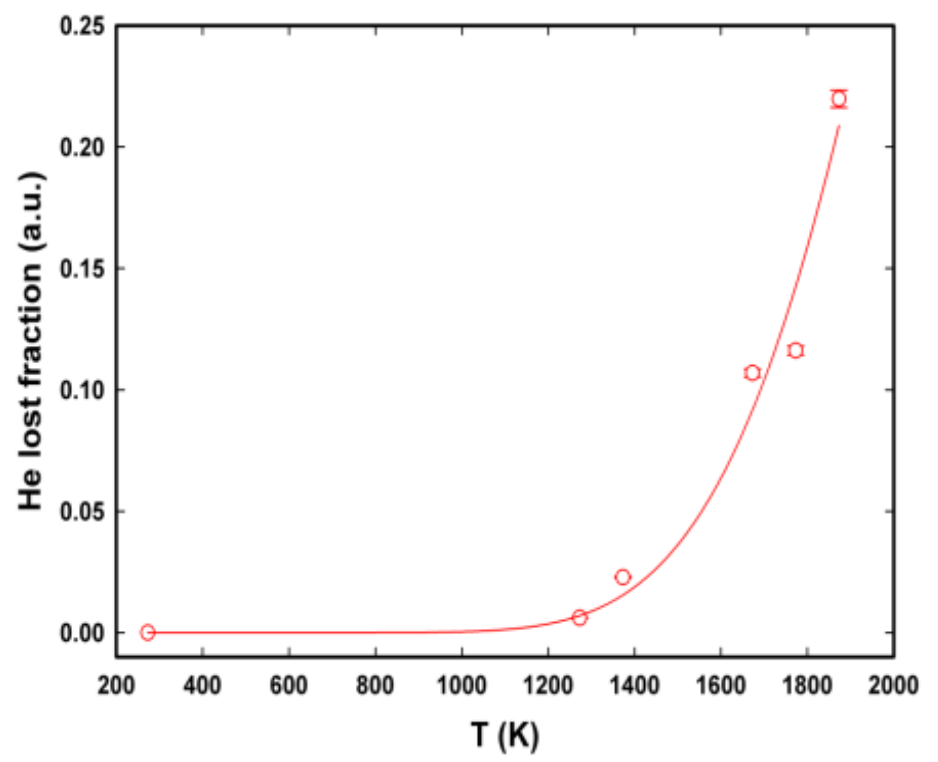

Figure 6.10b. Evolution of the ${ }^{3}$ He lost fraction $(f)$ versus annealing temperature for TiN. The equation of the fit obeys $f=1-\exp \left[-\alpha . \exp \left(-\Delta H / k_{B} . T\right)\right]$ with $\alpha=398.31$ and $\Delta H=(1.20 \pm$ $0.12) \mathrm{eV}$. 
Figure 6.10c shows helium depth profiles obtained for as-implanted and annealed specimens at $\mathrm{T}_{\mathrm{a}}=1000{ }^{\circ} \mathrm{C}, 1100{ }^{\circ} \mathrm{C}, 1400{ }^{\circ} \mathrm{C}, 1500{ }^{\circ} \mathrm{C}$ and $1600{ }^{\circ} \mathrm{C}$. These helium depth profiles have been obtained by using SIMNRA software corresponding to $\mathrm{E}_{\mathrm{d}}=1.3 \mathrm{MeV}$. The helium depth profiles obtained for as-implanted and annealed samples have no tailing effect towards the surface and could be fitted into single Gaussian shaped curve. At $\mathrm{T}_{\mathrm{a}} \leq 1100{ }^{\circ} \mathrm{C}$, the helium depth profiles overlap on each other within the measurement error. It implies no migration of helium atoms up to this $\mathrm{T}_{\mathrm{a}}=1100{ }^{\circ} \mathrm{C}$. Above temperatures of $1100{ }^{\circ} \mathrm{C}$, the peak of helium distribution decreases in magnitude (indicating helium release), but very little lateral spreading of the profile (as expected in Fick's law of diffusion) is observed at $\mathrm{T}_{\mathrm{a}} \geq 1400{ }^{\circ} \mathrm{C}$.

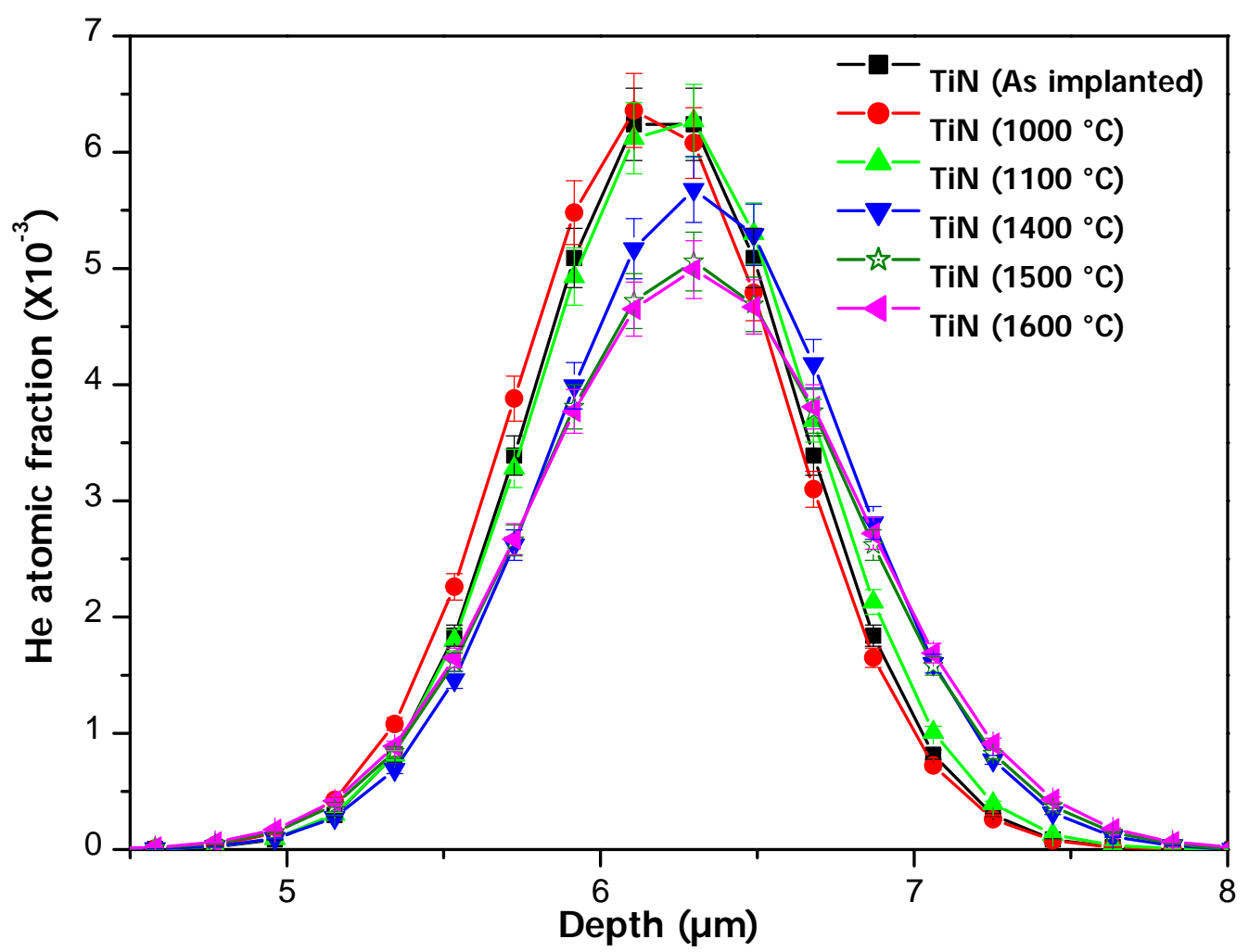

Figure 6.10c. Helium depth profiles obtained from nuclear reaction analysis for TiN samples implanted with fluence $F_{1}$ and annealed between $1000{ }^{\circ} \mathrm{C}-1600{ }^{\circ} \mathrm{C}$. These profiles have been obtained by SIMNRA code corresponding to $E_{d}=1.3 \mathrm{MeV}$ 
Table 6.3 presents the effective diffusion coefficient obtained for helium at $\mathrm{T}_{\mathrm{a}} \geq 1100{ }^{\circ} \mathrm{C}$ by using classical Fick's law formalism. Over the temperature range $1100{ }^{\circ} \mathrm{C}-1600{ }^{\circ} \mathrm{C}$, the effective diffusion coefficient data for TiN exhibits a linear Arrhenius behaviour. This linear dependence gives an activation energy of $E_{D}=1.05 \pm 0.2 \mathrm{eV}$ for effective helium diffusion (see figure 6.10d).

It should be noted that the effective diffusion coefficient obtained for $\mathrm{TiC}$ at all temperature is much higher than for TiN. Accordingly, the value of $\mathrm{E}_{\mathrm{D}}$ for TiC should be lower than for TiN. However, we have obtained the opposite, which is due to the poor regression factor obtained while employing Arrhenius law for TiC (see figure 6.7).

\begin{tabular}{|c|c|}
\hline $\begin{array}{c}\text { Temperature } \\
\left({ }^{\circ} \mathbf{C}\right)\end{array}$ & $\begin{array}{c}\text { Effective diffusion coefficient derived from } \\
\text { SIMNRA }\left(\mathbf{m}^{\mathbf{2}} \mathbf{~ s}^{\mathbf{1}}\right)\end{array}$ \\
\hline 1100 & $3.58 \mathrm{E}-19$ \\
\hline 1400 & $2.35057 \mathrm{E}-18$ \\
\hline 1500 & $2.86 \mathrm{E}-18$ \\
\hline 1600 & $5.92641 \mathrm{E}-18$ \\
\hline
\end{tabular}

Table 6.3. Effective diffusion coefficient obtained for helium at $T_{a} \geq 1100^{\circ} \mathrm{C}$ by using classical Fick's law.

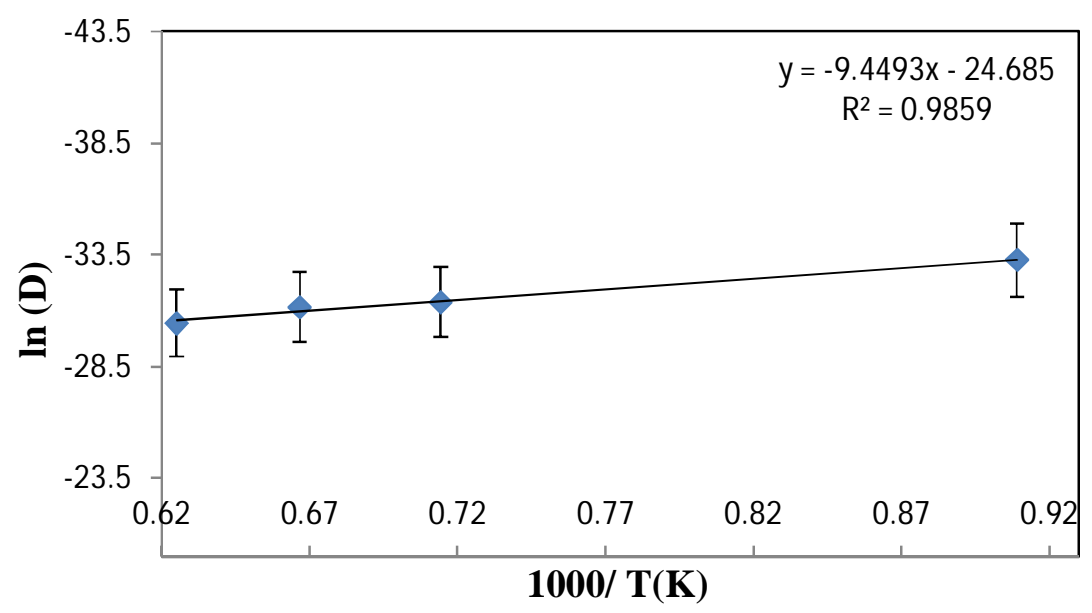

Figure 6.10d. Effective diffusion coefficient variation versus temperature in TiN following Arrhenius behavior. 
This small broadening (or slight lateral spreading) of helium depth profiles at higher temperature could be explained as if the helium atoms were trapped very strongly at (or near) its end-of-range location at room temperature and then released in fractions at progressively higher temperature. This behavior is similar to the G1 population in $\mathrm{TiC}$, where the helium is assumed to be trapped in $\mathrm{He}_{\mathrm{n}}-\mathrm{V}_{\mathrm{m}}$ clusters which are supposed to be large and unstable and releases $\mathrm{He}$ atoms to form stable cluster (having low $\mathrm{n} / \mathrm{m}$ ratios) at higher temperature. It was also assumed that large size of $\mathrm{He}_{\mathrm{n}}-\mathrm{V}_{\mathrm{m}}$ clusters is responsible for their less mobility and hence contributing to very small broadening. Evidences have been obtained by TEM which supports this hypothesis.

\section{B. TEM observation in grain interior (at the implantation zone)}

The microstructural changes were observed under TEM in the transverse FIB specimens of implanted and annealed samples. The transverse FIB specimen gives the entire depth distribution of damage caused by ion-implantation or other microstructural changes (for eg. bubbles in our case) from surface to the implantation zone.

Transverse FIB specimen of as-implanted samples revealed no unambiguous evidence for visible helium bubbles. This means that the majority of bubbles (He- $\mathrm{V}$ clusters) formed after implantation at room temperature have sizes below detection limit of the microscope.

The FIB specimen of samples annealed at $\mathrm{T}_{\mathrm{a}} \geq 1100{ }^{\circ} \mathrm{C}$, showed the presence of bubbles under TEM observation. TEM micrographs showing bubbles at implantation zone at $\mathrm{T}_{\mathrm{a}}=1100{ }^{\circ} \mathrm{C}$, $1400{ }^{\circ} \mathrm{C}, 1600{ }^{\circ} \mathrm{C}$ are shown in figure $6.11(\mathrm{a}, \mathrm{b}, \& \mathrm{c})$. 

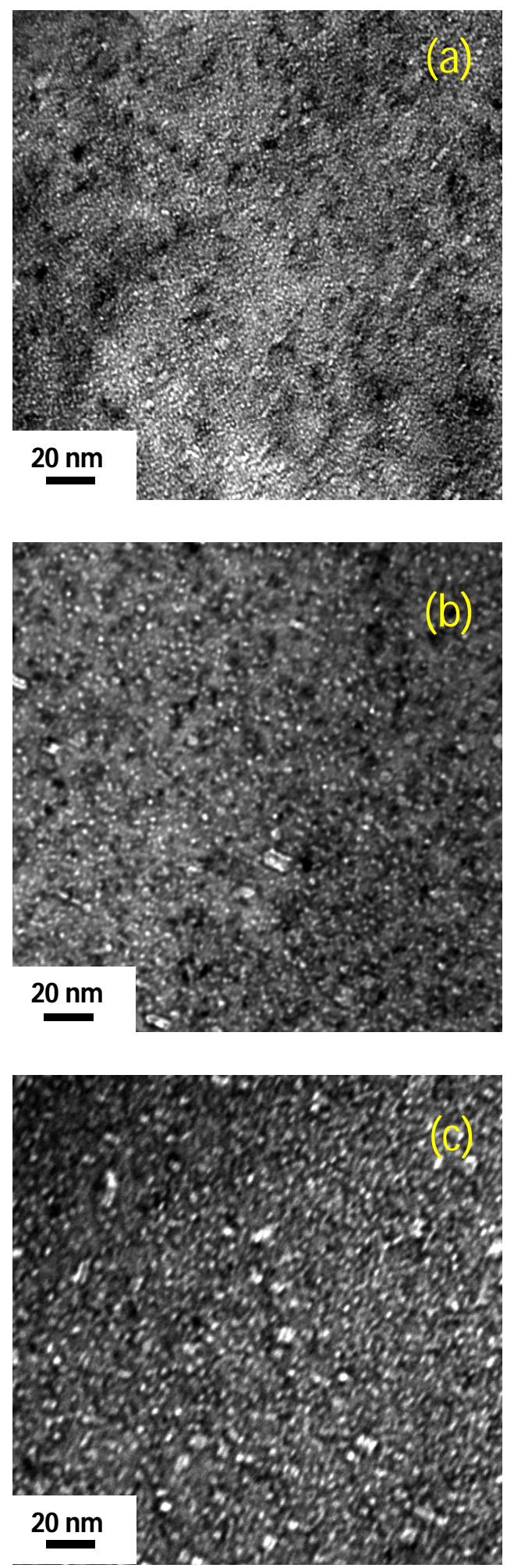

Figure 6.11. TEM micrographs of the implantation zone of TiN samples implanted with fluence $F_{1}$ and annealed at (a) $T_{a}=1100{ }^{\circ} \mathrm{C}$, (b) $T_{a}=1400{ }^{\circ} \mathrm{C}$, (c) $T_{a}=1600{ }^{\circ} \mathrm{C}$. The white contrast represent helium bubbles in under focus conditions (Bright field, Under focus $=-1100 \mathrm{~nm}$ ). 
The size distributions of the bubbles corresponding to figure 6.11 have been plotted in fig. $6.12(\mathrm{a}, \mathrm{b} \& \mathrm{c})$. The size distributions from figure $6.12 \mathrm{a}\left(\mathrm{at} \mathrm{T}_{\mathrm{a}}=1100{ }^{\circ} \mathrm{C}\right)$ to figure $6.12 \mathrm{c}\left(\mathrm{at} \mathrm{T}_{\mathrm{a}}\right.$ $=1600{ }^{\circ} \mathrm{C}$ ) show shift of the entire distribution towards higher value of mean bubble size. This shift suggests bubble growth.
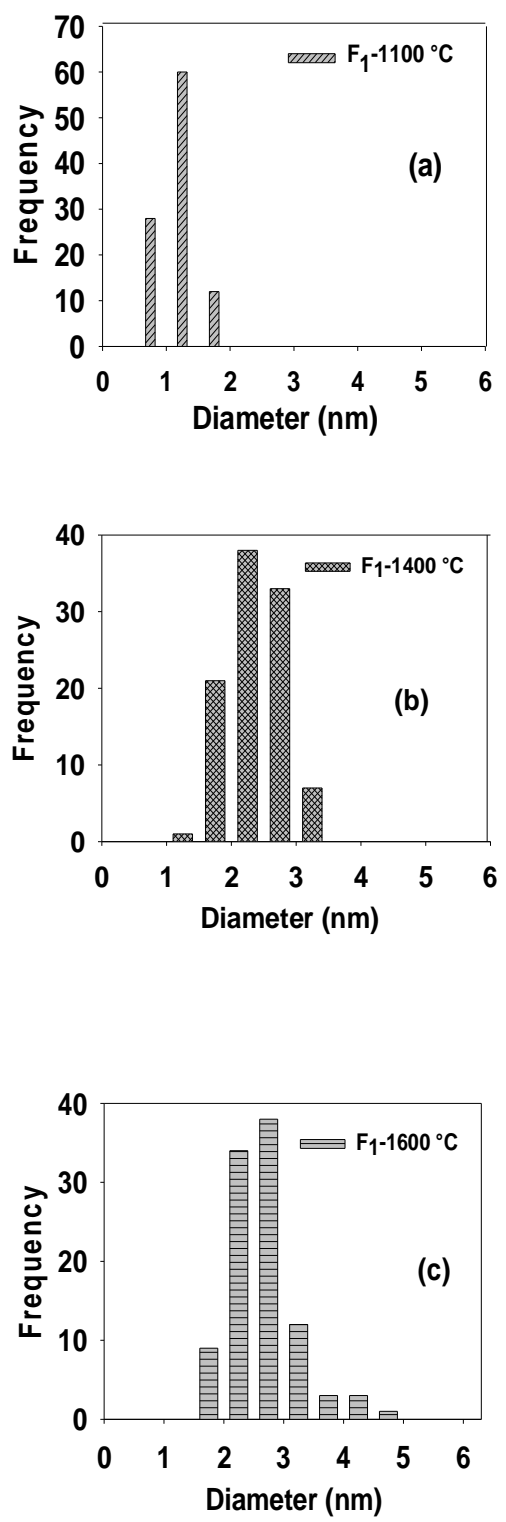

Figure 6.12. Size distribution of helium bubbles in the implanted zone of TiN annealed at (a) $1100{ }^{\circ} \mathrm{C}$ for $2 \mathrm{~h}(\mathrm{~b}) 1400{ }^{\circ} \mathrm{C}$ for $2 \mathrm{~h}(\mathrm{c}) 1600{ }^{\circ} \mathrm{C}$ for $2 \mathrm{~h}$.

The mean bubble radius $r_{B}$ versus $T_{a}$ is plotted in Arrhenius-type behavior (see figure 6.13). This plot gives an apparent activation energy of bubble growth $\mathrm{E}_{\mathrm{r}}=0.38 \pm 0.03 \mathrm{eV}$. The volume 157 
density of the bubbles $\left(\mathrm{D}_{\mathrm{B}}\right)$ decreased from $1100{ }^{\circ} \mathrm{C}$ to $1400{ }^{\circ} \mathrm{C}$ but did not evolve much from $\mathrm{T}_{\mathrm{a}}=1400{ }^{\circ} \mathrm{C}$ to $1600{ }^{\circ} \mathrm{C}$ and remained almost constant in the order of $\sim 1 \times 10^{17}$ bubbles $/ \mathrm{cm}^{3}$. Table 6.4a provides the precise values of density obtained at various annealing temperature. The containment spot separation method was used to measure the thickness of the FIB specimen at the same point on which the TEM micrographs were taken. The thickness value measured by this method contributes to $10 \%$ uncertainty in the volume density of the bubbles.

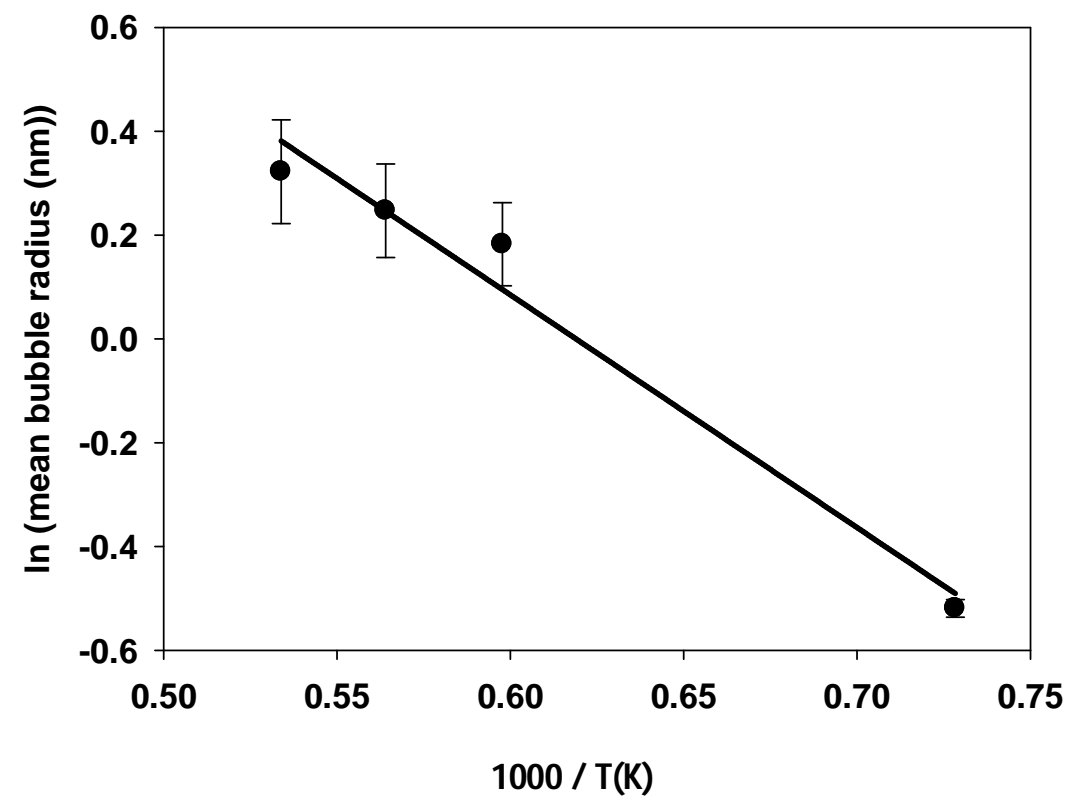

Figure 6.13. Arrhenius plot of bubble radius vs temperature to calculate the activation energy of bubble growth. 


\begin{tabular}{|c|c|}
\hline $\begin{array}{c}\text { Temperature } \\
\left({ }^{\circ} \mathrm{C}\right)\end{array}$ & $\begin{array}{c}\text { Bubble density } \\
\left(\text { bubbles } / \mathrm{cm}^{3}\right)\end{array}$ \\
\hline $1100{ }^{\circ} \mathrm{C}$ & $2.90 \mathrm{E}+17$ \\
\hline $1400{ }^{\circ} \mathrm{C}$ & $1.20 \mathrm{E}+17$ \\
\hline $1500^{\circ} \mathrm{C}$ & $1.00 \mathrm{E}+17$ \\
\hline $1600^{\circ} \mathrm{C}$ & $1.15 \mathrm{E}+17$ \\
\hline
\end{tabular}

Table 6.4a. Volume density of bubbles at different annealing temperatures for TiN implanted with fluence $F_{1}$.

\section{Determination of the pressure inside the bubbles at the implantation zone}

The equilibrium pressure inside the bubbles can be calculated by the equation $p=2 r / r$, where $\Upsilon$ is the surface free energy. Please refer to chapter 4.2.4 for more details. The equilibrium pressure values have been calculated for various values of $r_{B}$ (bubble radius) and have been plotted in figure 6.14 . The value of $\Upsilon$ for $\mathrm{TiN}$ is $1.2 \mathrm{~N} / \mathrm{m}$.

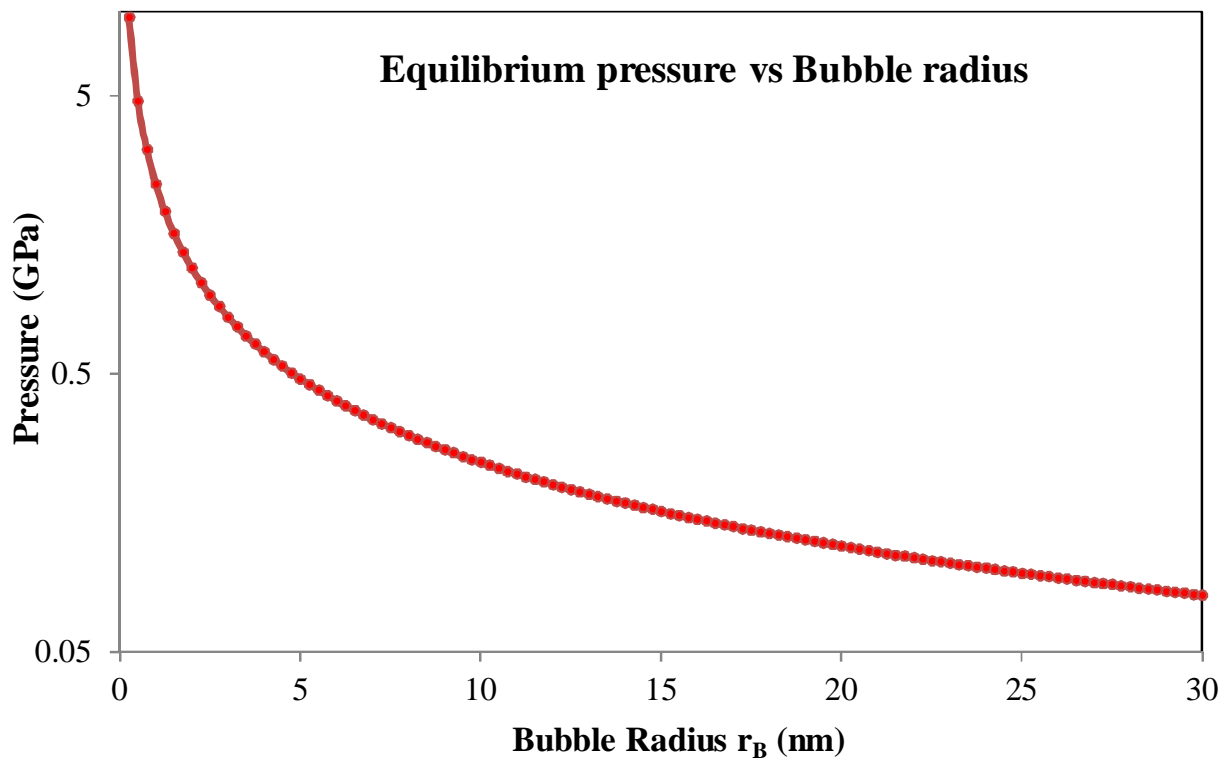

Figure 6.14. Plot of the equilibrium pressure $\left(P=2 r / r_{B}\right)$ vs $r_{B}$ for TiN. 
In this paragraph, the pressure values inside the bubbles have been calculated and compared with their corresponding equilibrium pressure values.

To calculate the pressure value inside the bubbles. We have to recall from section 4.2.4 that 'our aim is to find the reduced particle density $\rho=v_{l} / v$ '.

where value of $v_{l}$ (i.e. fluid volume upon freezing) can be calculated by the use of 'equation 4.6’.

where value of $v$ (i.e. volume per helium atom (in $\left.\AA^{3}\right)$ ) is calculated from the 'TEM micrographs'.

\section{Calculation of $v$ (i.e. volume per helium atom $\left(\right.$ in $\left.\AA^{3}\right)$ ):}

To explain, we consider a TEM micrograph (one from figure 6.11) corresponding to TiN implanted with ${ }^{3} \mathrm{He}$ and annealed at $\mathrm{T}_{\mathrm{a}}$. And we assume that 'all the implanted helium is present in the form of helium-vacancy (He-V) clusters'. However, it is important to mention that out of all He-V clusters, sizes of some clusters are below the detection limit of electron microscope and hence are not visible under TEM.

- Value of $\mathrm{C}_{\mathrm{He}}$ (the number of helium atoms per $\mathrm{nm}^{3}$ ) corresponding to TEM micrograph shown in figure 6.11 can be derived from its corresponding helium depth profile obtained from NRA of sample annealed at $\mathrm{T}_{\mathrm{a}}$ shown in fig. 6.10c.

- Value of $\mathrm{C}_{\mathrm{v}}$ (the number of vacancy per $\mathrm{nm}^{3}$ ) can be derived in the following manner:

Considering that,

vol. occupied by the bubble $\left(V_{B}\right)=$ vol. occupied by the vacancies in the bubble $\left(\mathrm{v}_{\mathrm{c}}\right)$

$$
\mathrm{V}_{\mathrm{B}}=\mathrm{V}_{\mathrm{c}}=\mathrm{n}_{\mathrm{v}} * \mathrm{~V}_{\mathrm{at}}
$$

where $\mathrm{n}_{\mathrm{v}}$ is the total number of vacancies in the bubble;

and $\mathrm{V}_{\mathrm{at}}$ is the volume occupied by one vacancy which is equal to the volume occupied by one atom;

- $\underline{\mathrm{C}}_{\mathrm{V}}$ (the number of vacancy per $\left.\mathrm{nm}^{3}\right)$ :

Applying eq. (6.3) to all the bubbles available in the TEM micrograph corresponding to $\mathrm{T}_{\mathrm{a}}$ shown in figure 6.11 ; 
Vol. occupied by total no. (or n) of bubbles $=$ Vol. occupied by the vacancies in 'n' bubbles $\left(\mathrm{V}_{\mathrm{c}}\right)$

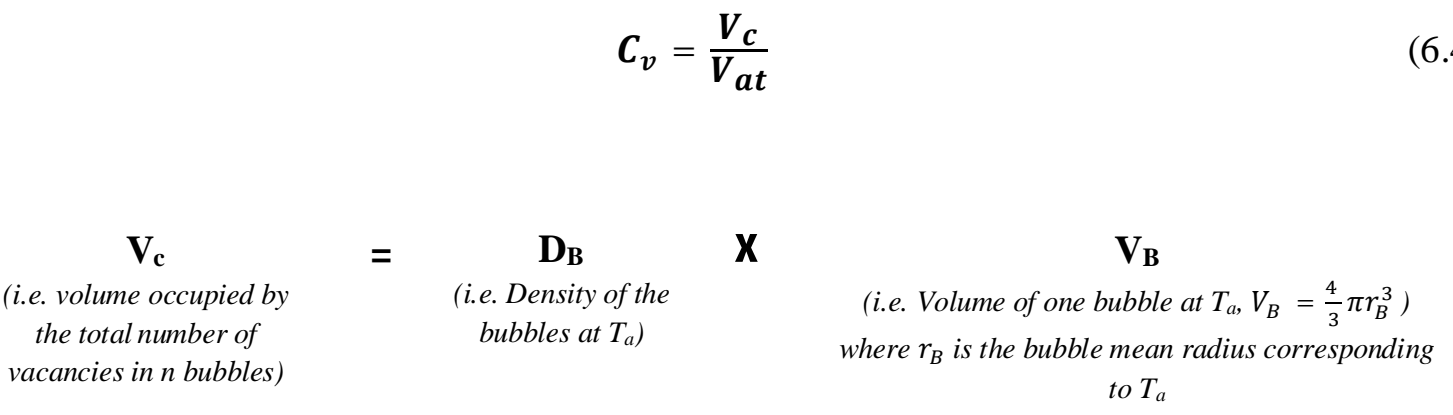

- Then, $\mathrm{C}_{\mathrm{He}} / \mathrm{C}_{\mathrm{v}}$ denotes the number of helium atoms per vacancy;

On multiplying $\mathrm{V}_{\text {at }}$ (i.e. the volume of one vacancy) at the denominator $\frac{C_{H e}}{C_{v^{*}} V_{a t}}$, we derive helium atoms per unit volume. And its reciprocal gives ' $v$ ' (i.e. volume per helium atom (in $\left.\AA^{3}\right)$ ).

- Finally, the value of $\rho=$ ' $v_{l} / v$ ' is derived and from eq. 4.5 compressibility factor ' $z$ ' is derived.

- And by putting the value of ' $z$ ' in real gas equation of state, pressure value inside the bubbles is derived.

The value of $\mathrm{C}_{\mathrm{He}} / \mathrm{C}_{\mathrm{v}}$ and the corresponding calculated pressure value are shown in Table $6.4 \mathrm{~b}$. Please refer to Annexe II for a more detailed example of pressure calculation.

\begin{tabular}{|c|c|c|c|c|}
\hline $\mathbf{T}$ & $\begin{array}{c}\mathbf{C}_{\mathbf{H e}} \\
\left({ }^{\circ} \mathrm{C}\right.\end{array}$ & $\mathbf{C}_{\mathbf{v}}$ & $\mathbf{C}_{\mathbf{H e}} / \mathbf{C}_{\mathbf{v}}$ & Pressure \\
& $\left(\right.$ atoms $\left./ \mathrm{nm}^{3}\right)$ & $\left(\right.$ Vacancy $\left./ \mathrm{nm}^{3}\right)$ & & $(\mathrm{GPa})$ \\
\hline 1100 & 0.67 & 0.012 & 54.6 & $\mathrm{P}>>240 \mathrm{GPa}^{*}$ \\
\hline 1400 & 0.58 & 0.043 & 13.5 & $\mathrm{P}>>240 \mathrm{GPa}^{*}$ \\
\hline 1500 & 0.52 & 0.067 & 7.85 & $\mathrm{P}=255 \mathrm{GPa}$ \\
\hline 1600 & 0.52 & 0.58 & 0.90 & $\mathrm{P}=2.29 \mathrm{GPa}$ \\
\hline
\end{tabular}

Table 6.4b. The pressure value inside the bubble at various $T_{a}$ calculated by an equation of state corresponding to $F_{1}$ fluence. 
The pressure values obtained at $\mathrm{T}_{\mathrm{a}}=1100{ }^{\circ} \mathrm{C}, 1400{ }^{\circ} \mathrm{C}$ and $1500^{\circ} \mathrm{C}$ are very high and close to solid state pressure values and are physically impossible. It is because, the calculated value of $\mathrm{C}_{\mathbf{v}}$ is underestimated due to the detection limit of TEM, where He-Vacancy clusters smaller than the size of $1 \mathrm{~nm}$ are not visible. Hence, it gives high uncertainty in bubble density values because here, $\mathrm{C}_{\mathrm{v}}$ is derived from the bubbles which are visible under TEM. It can also be said that the density $\left(\mathrm{D}_{\mathrm{B}}\right)$ calculated by TEM micrographs is an apparent density but not the real density of He-V cluster.

At $\mathrm{T}_{\mathrm{a}}=1500{ }^{\circ} \mathrm{C}$, the pressure inside the helium bubbles is close to shear modulus of TiN (i.e. $240 \mathrm{GPa}$ ) or mechanical stability limit of the material. This high pressure value is due to large $\mathrm{C}_{\mathrm{He}} / \mathrm{C}_{\mathrm{v}}$ values suggesting that even at $\mathrm{T}_{\mathrm{a}}=1500{ }^{\circ} \mathrm{C}$ some part of implanted helium is still present in the form of small He-V clusters which are invisible under TEM.

The pressure value at $\mathrm{T}_{\mathrm{a}}=1600{ }^{\circ} \mathrm{C}$ is close to the equilibrium pressure value of $\sim 2 \mathrm{GPa}$. It indicates that most of the helium implanted into sample is present in the form of visible bubbles. At $\mathrm{T}_{\mathrm{a}}=1600{ }^{\circ} \mathrm{C}$, the value $\mathrm{C}_{\mathrm{He}} / \mathrm{C}_{\mathrm{v}}$ is sufficiently low due to the higher value of denominator (i.e. $\mathrm{C}_{\mathrm{V}}$ ) which corresponds to the increase in $\mathrm{r}_{\mathrm{B}}$. And this low value of $\mathrm{C}_{\mathrm{He}} / \mathrm{C}_{\mathrm{v}}$ leads to the low pressure value (which is closer to equilibrium pressure value).

\section{GROWTH MECHANISM OF BUBBLES AT THE IMPLANTATION ZONE}

To predict the specific 'bubble growth mechanism' is extremely challenging in transition metal ceramics due to the presence of native vacancies. For TiN, its stoichiometric ratio has been verified which corresponds to $0.99 \pm 0.02$ within the measurement errors. Therefore, the contribution of native vacancies in total number of vacancies in the material cannot be neglected. It is assumed that these vacancies are not very mobile at low temperature because migration energy of vacancy ' $\mathbf{E}_{\mathbf{v}}$ ' is close to $3.8 \mathrm{eV}$ for TiN [1]. During helium implantation, these vacancies are trapping helium atoms to form small $\mathrm{He}_{1}-\mathrm{V}_{1}$ clusters.

On annealing, when temperature increases, mobility of $\mathrm{He}_{1}-\mathrm{V}_{1}$ clusters increases and they agglomerate to form $\mathrm{He}_{2}-\mathrm{V}_{2}$ or stable $\mathrm{He}_{\mathrm{n}}-\mathrm{V}_{\mathrm{m}}$ clusters (n, m denotes the number of helium atoms and vacancies, respectively) in the following manner:

$$
\mathrm{He}_{1}-\mathrm{V}_{1}+\mathrm{He}_{1}-\mathrm{V}_{1} \rightarrow \mathrm{He}_{2}-\mathrm{V}_{2}
$$




$$
\mathrm{He}_{2}-\mathrm{V}_{2}+\mathrm{He}_{2}-\mathrm{V}_{2} \rightarrow \mathrm{He}_{4}-\mathrm{V}_{4}
$$

$\mathrm{He}_{4}-\mathrm{V}_{4}+\mathrm{He}_{4}-\mathrm{V}_{4} \rightarrow \mathrm{He}_{8}-\mathrm{V}_{8} \rightarrow$ Formation of stable small $\mathrm{He}_{\mathrm{n}}-\mathrm{V}_{\mathrm{m}}$ cluster (or bubble nuclei)

Nucleation of the bubbles, i.e., the formation of stable He- $\mathrm{V}$ clusters occur at small sizes in the first size range, $r<10 \AA$. For Nickel, it is estimated that between 3 and 10 defects must be involved for the formation of stable $\mathrm{HeV}$ complexes (or HeVCs) [2]. To best of our knowledge, the no. of defects required to create stable HeVCs (in terms of $\mathrm{n}$ (helium atom) and $\mathrm{m}$ (vacancies)) in TiN is unknown. The radius of bubbles at $\mathrm{T}_{\mathrm{a}}=1100{ }^{\circ} \mathrm{C}$ is close to $0.75 \mathrm{~nm}$ and is in the size range of bubble nuclei estimated for nickel or other metals [2].

After the nucleation stage, the growth of bubbles or stable He-V complexes occurs. It is assumed due to the presence of large number of native vacancies in TiN, along with the stable $\mathrm{HeVCs}$, large number of helium atoms is present in the form of mono-vacancy clusters $\left(\mathrm{He}_{1^{-}}\right.$ $\left.\mathrm{V}_{1}\right)$ or di-vacancy $\left(\mathrm{He}_{2}-\mathrm{V}_{2}\right)$ clusters.

From $\mathrm{T}_{\mathrm{a}}=1100{ }^{\circ} \mathrm{C}$ to $1400{ }^{\circ} \mathrm{C}$, we have observed that the diameter of the bubbles have grown almost double in magnitude (see figure 6.12), however, the bubble density have almost reduced to half (see table 6.4). Due to the decrease in bubble density, the mechanism behind the bubble growth is not clear for us between $\mathrm{T}_{\mathrm{a}}=1100{ }^{\circ} \mathrm{C}$ to $1400{ }^{\circ} \mathrm{C}$.

From $\mathrm{T}_{\mathrm{a}} \geq 1400{ }^{\circ} \mathrm{C}$ (where $\mathrm{T}_{\mathrm{a}}$ is closed to $0.5 \mathrm{~T}_{\mathrm{m}}$ ), bubbles or stable He-V complexes grow by the absorption of mono (or di)-vacancy clusters. It is important to mention that due to high concentration of vacancies, their role on growth of bubbles cannot be neglected as well, particularly at higher temperature. This hypothesis is supported by the fact that; from $T_{a}=1400$ ${ }^{\circ} \mathrm{C}$ to $1600{ }^{\circ} \mathrm{C}$, there is no change in the bubble density within the measurement error, however, there is a significant change in bubble size.

Along with this, we have seen before, that $\sim 25 \%$ of helium has been lost at $\mathrm{T}_{\mathrm{a}}=1600{ }^{\circ} \mathrm{C}$. May be, this helium loss has also a strong role in decreasing the pressure value, but this point has to be explored further. The imaging of dislocation loops were not possible due to high damage caused during FIB preparation, otherwise information on dislocation loop density at the implantation zone could have further extended the explanation. 


\section{E. TEM OBSERVATION NEAR SURFACE}

Annealing of specimen at $\mathrm{T}_{\mathrm{a}}=1100{ }^{\circ} \mathrm{C}$ to $1600{ }^{\circ} \mathrm{C}$, results in formation of bubbles at the surface. The TEM micrographs are shown in figure $6.15(\mathrm{a}, \mathrm{b} \& \mathrm{c})$ and size distribution of bubbles are plotted in figure $6.16(\mathrm{a}, \mathrm{b} \& \mathrm{c})$. The mean bubble radius $\mathrm{r}_{\mathrm{B}}$ versus $\mathrm{T}_{\mathrm{a}}$ is plotted in the Arrhenius-type behavior (see figure 6.17). This plot gives an apparent activation energy of bubble growth $\mathrm{E}_{\mathrm{r}}=1.69 \pm 0.2 \mathrm{eV}$. The mean radius changed from $\sim 0.7 \mathrm{~nm}\left(\right.$ at $1100{ }^{\circ} \mathrm{C}$ ) to $\sim 45$ $\mathrm{nm}\left(\right.$ at $\left.1600{ }^{\circ} \mathrm{C}\right)$.

The transverse FIB specimen corresponding to $\mathrm{T}_{\mathrm{a}}=1100{ }^{\circ} \mathrm{C}$ to $1600{ }^{\circ} \mathrm{C}$ have been compared with transverse FIB specimen of as-implanted TiN, where neither the bubbles were present at the surface nor at the implantation zone. However, we observed that in as-implanted FIB specimen, the density of dislocation line at the surface was markedly high as compared to the density of dislocation lines in the matrix. This suggests that the surface of sample was damaged during the mechanical polishing and hence, the un-trapped helium, perhaps present in the form of small He-V clusters (which has high mobility) have escaped the implantation zone and further got trapped at the dislocation lines present at the surface. This hypothesis is also supported by fig. $6.16 \mathrm{c}$ where bubbles at the surface are aligned along the dislocation lines.

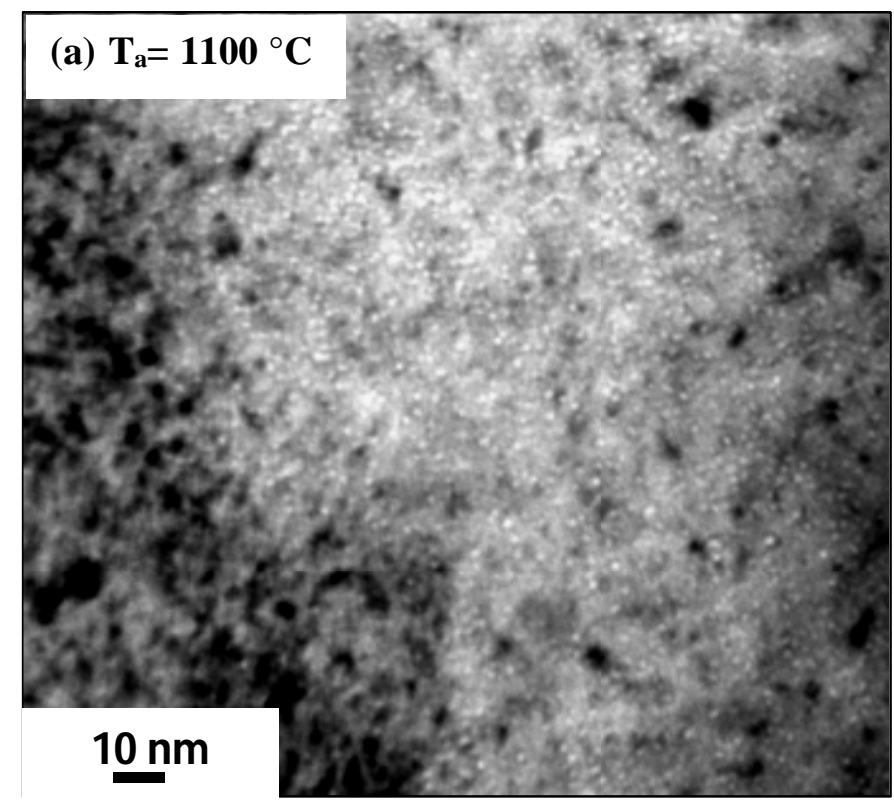



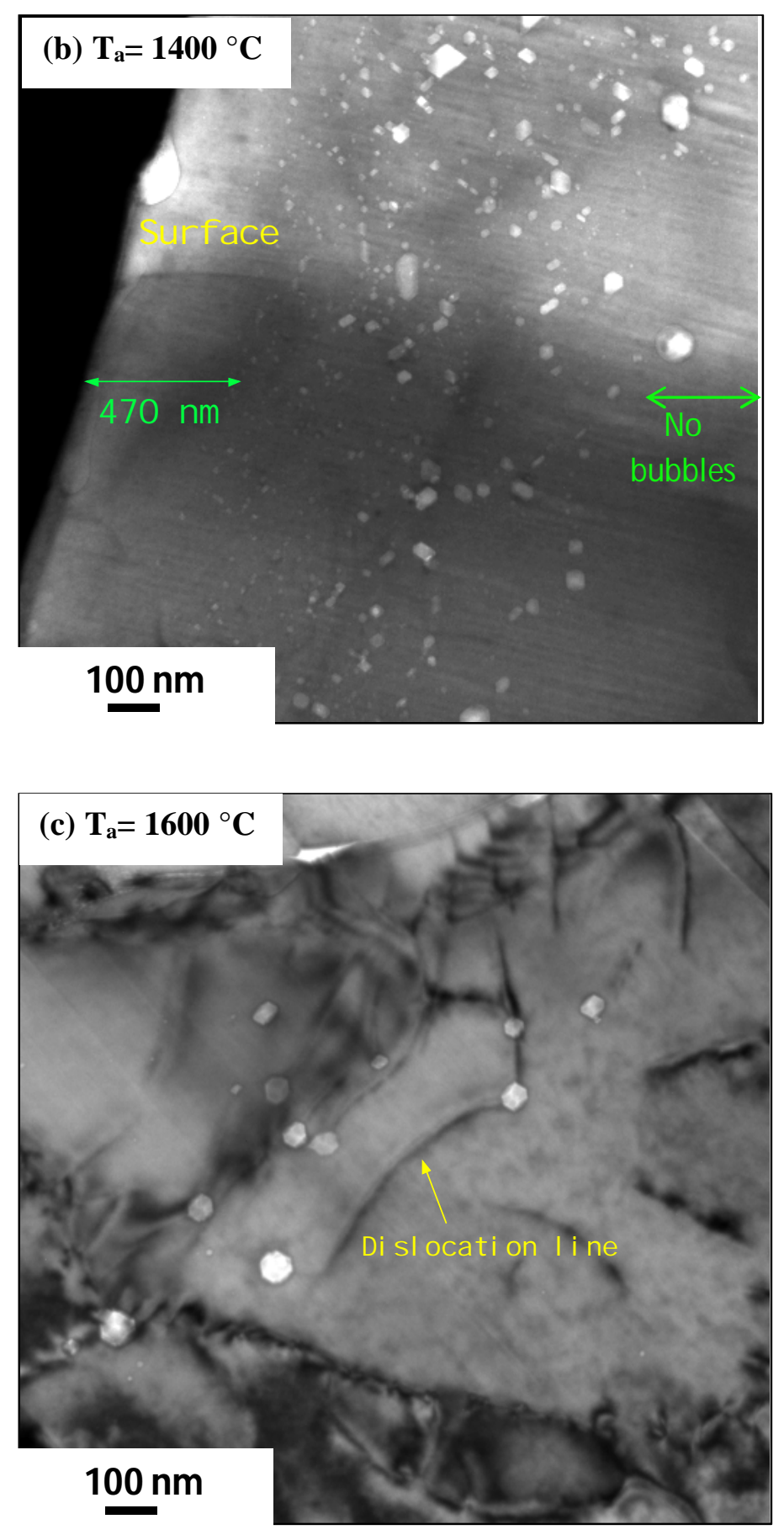

Figure $6.15(\boldsymbol{a}, \boldsymbol{b} \& \boldsymbol{c})$. Micrographs of the bubbles at the surface of samples implanted with fluence $F_{1}$ and annealed at $T_{a}=1100{ }^{\circ} \mathrm{C}, 1400{ }^{\circ} \mathrm{C}, 1600{ }^{\circ} \mathrm{C}$ respectively are shown. The second micrograph (b) also shows $\sim 500 \mathrm{~nm}$ denuded zone from the surface. And the third micrograph (c) shows the association of bubbles with dislocation lines. The white contrast represent helium bubbles in under focus conditions (Bright field, under focus $=-1000 \mathrm{~nm}$ ) 

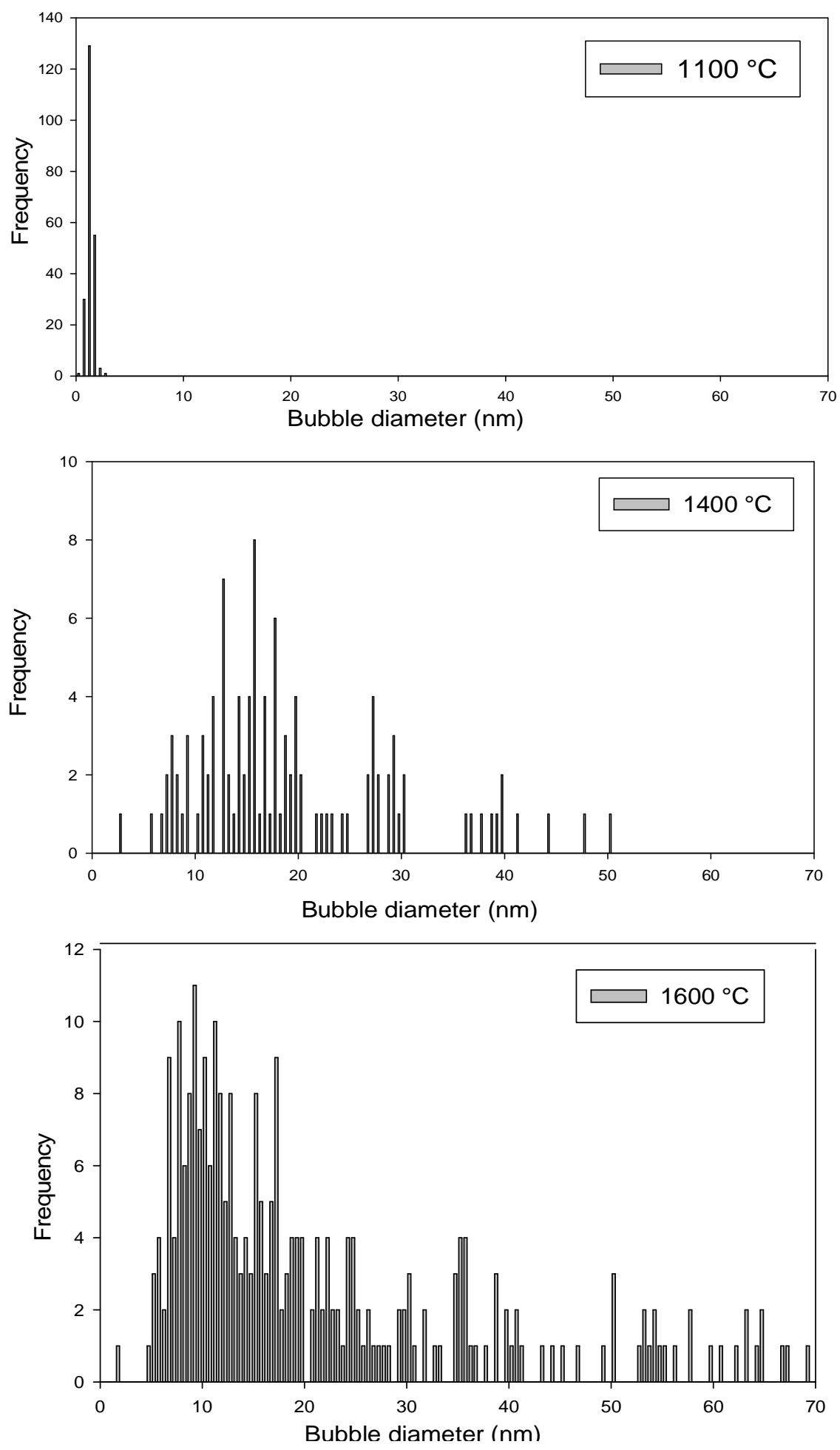

Figure 6.16 (a, b, c). Size distribution of helium bubbles in the implanted zone of TiN annealed at (a) $1100{ }^{\circ} \mathrm{C}$ for $2 \mathrm{~h} \mathrm{(b)} 1400{ }^{\circ} \mathrm{C}$ for $2 \mathrm{~h} \mathrm{(c)} 1600{ }^{\circ} \mathrm{C}$ for $2 \mathrm{~h}$. 


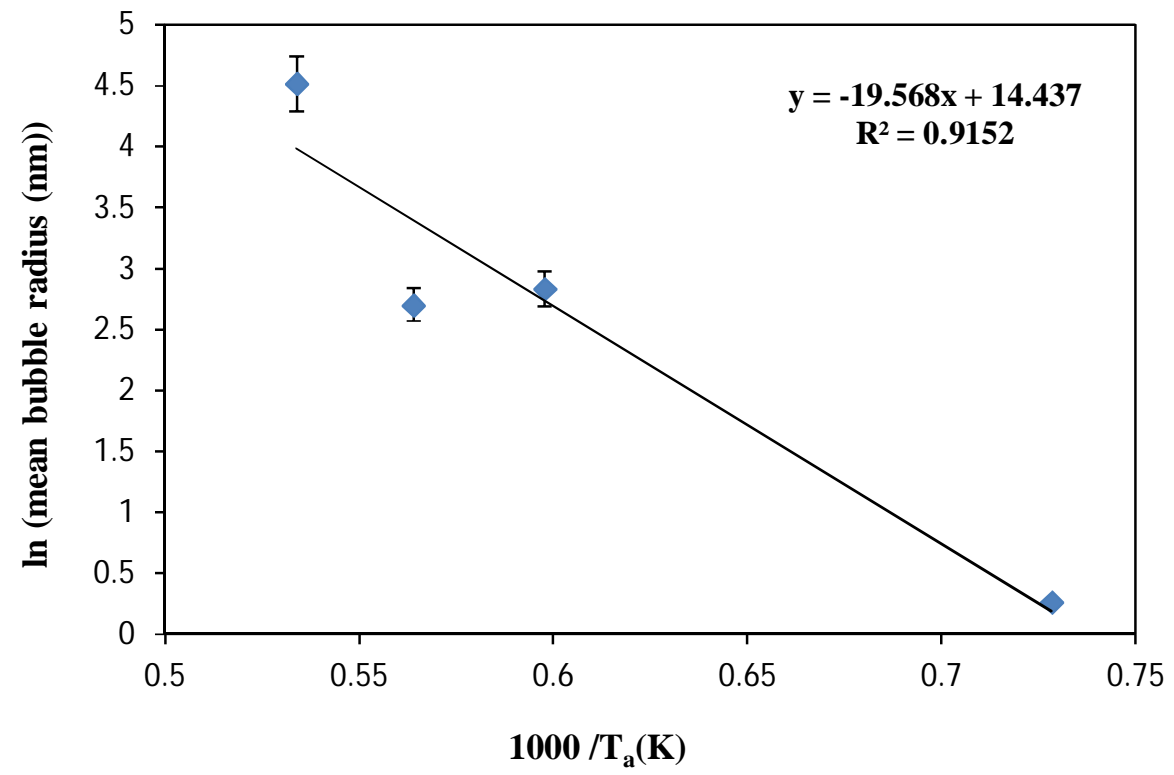

Figure 6.17. The Arrhenius plot of bubble radius vs temperature to calculate the activation energy of bubble growth at the surface of TiN.

The two foremost observations during bubble analysis at the surface were:

- Firstly, the presence of small $\sim 0.7 \mathrm{~nm}$ size bubble at $1100{ }^{\circ} \mathrm{C}$, which suggests that helium is present in very small clusters and further at high $T_{a}$, these bubbles grow up to $45 \mathrm{~nm}$.

This bubble growth can be explained in the following manner: Figure 6.10c shows that NRA profiles corresponding to as-implanted sample and at $\mathrm{T}_{\mathrm{a}}=1100{ }^{\circ} \mathrm{C}$ superimpose on each other within the measurement error. Therefore, the quantity of helium trapped at the surface is very less. This less quantity of helium is responsible for less density of $\mathrm{He}_{1}-\mathrm{V}_{1}$ clusters. This low density of $\mathrm{He}_{1}-\mathrm{V}_{1}$ clusters leads to formation of less density of stable HeVCs or nucleation centers (also known as stable $\mathrm{He}_{\mathrm{n}}-\mathrm{V}_{\mathrm{m}}$ cluster) which would later develop into big bubbles.

On high temperature annealing in such cases, the most low-cost energetically favorable process would be the absorption of $\mathrm{He}_{1}-\mathrm{V}_{1}$ clusters by existing nuclei rather than nucleating new stable nuclei. There is a large influx of the $\mathrm{He}_{1}-\mathrm{V}_{1}$ (or helium atoms that later develop into mono (or di) vacancy clusters) from the implantation zone.

In our case, as the number of stable He-V cluster (as suggested by small density of bubbles on surface at $\mathrm{T}_{\mathrm{a}}=1100{ }^{\circ} \mathrm{C}$ ) is very less, therefore on high temperature annealing at $\mathrm{T}_{\mathrm{a}}=1500{ }^{\circ} \mathrm{C}$, all the non-visible, small $\mathrm{He}_{1}-\mathrm{V}_{1}$ (or $\mathrm{He}_{2}-\mathrm{V}_{2}$ ) clusters are absorbed by few existing stable nuclei 
(or small sized bubbles at $\mathrm{T}_{\mathrm{a}}=1100{ }^{\circ} \mathrm{C}$ ) and have formed bigger bubbles. It is again important to mention that at high temperature, the effect of vacancy absorption on bubble growth cannot be neglected. Figure 6.15 (b \& c) shows formation of facetted bubbles at the surface.

- Secondly, $500 \mathrm{~nm}$ from the surface was denuded zone or defect free zone (absence of bubbles) and from denuded zone to $1 \mathrm{~nm}$ broad length, bubbles were present (see figure $6.15 \mathrm{~b}$ as an example at $\mathrm{T}_{\mathrm{a}}=1400{ }^{\circ} \mathrm{C}$ ) and after this distance, no bubbles were present up to implantation zone. The presence of $500 \mathrm{~nm}$ thick denuded zone could be due to recombination of defects at the zone close to the surface on high temperature annealing. The pressure inside the bubbles at the surface could not be calculated due to absence of data corresponding to ' $\boldsymbol{C}_{\boldsymbol{H}}$ ' at the surface. However, the facetted shape of the bubbles (or cavities) at $\mathrm{T}_{\mathrm{a}}=1400{ }^{\circ} \mathrm{C}$ to 1600 ${ }^{\circ} \mathrm{C}$ suggest that the bubbles were not over-pressurized.

\section{F. TEM OBSERVATION AT GRAIN BOUNDARIES}

After helium implantation at room-temperature, no defects were visible in grain boundaries (GB). At $\mathrm{T}_{\mathrm{a}}=1100{ }^{\circ} \mathrm{C}$, spherical bubbles (larger than size of the bubbles at matrix) appeared at grain boundaries. But interlinked facetted bubbles only appeared from $\mathrm{T}_{\mathrm{a}}=1400{ }^{\circ} \mathrm{C}$ to 1600 ${ }^{\circ} \mathrm{C}$. It is well established that interlinking of grain boundary bubble creates pathways towards surface for helium to release [3]. With increasing temperature the bubbles at GB's grew and their number density decreased.

A quantitative analysis of bubble evolution at GB's was difficult due to the dependence of bubble growth on the orientation of the grain boundaries. We did not observe a regular pattern in the evolution of bubbles at grain boundaries at different annealing temperatures. Therefore, role of grain boundaries to discharge bubbles from the implantation zone to the surface was not very clear, as in most of the cases, on following the GB from implantation zone to the surface, bubbles were only present on the GB located at (or near) the implantation zone. Bubbles were occasionally visible at the GB present between the surface and implantation zone (see figure $6.18 b)$.

Bubbles in the grain boundary and in the grain interior were well separated by defect free zones (this difference was more prominent at higher annealing temperature). TEM also revealed that in the regions which are in the vicinity of grain boundaries the bubble radii are larger (see 
figure 6.18c) and the bubble densities are smaller than the corresponding values for the bubbles in the grain interior. The quantitative analysis on these bubbles gave an activation energy for growth of bubble (present in the vicinity of GB) to be $E_{r}=(1.02 \pm 0.1) \mathrm{eV}$ by fitting the data with Arrhenius law (figure not displayed here).

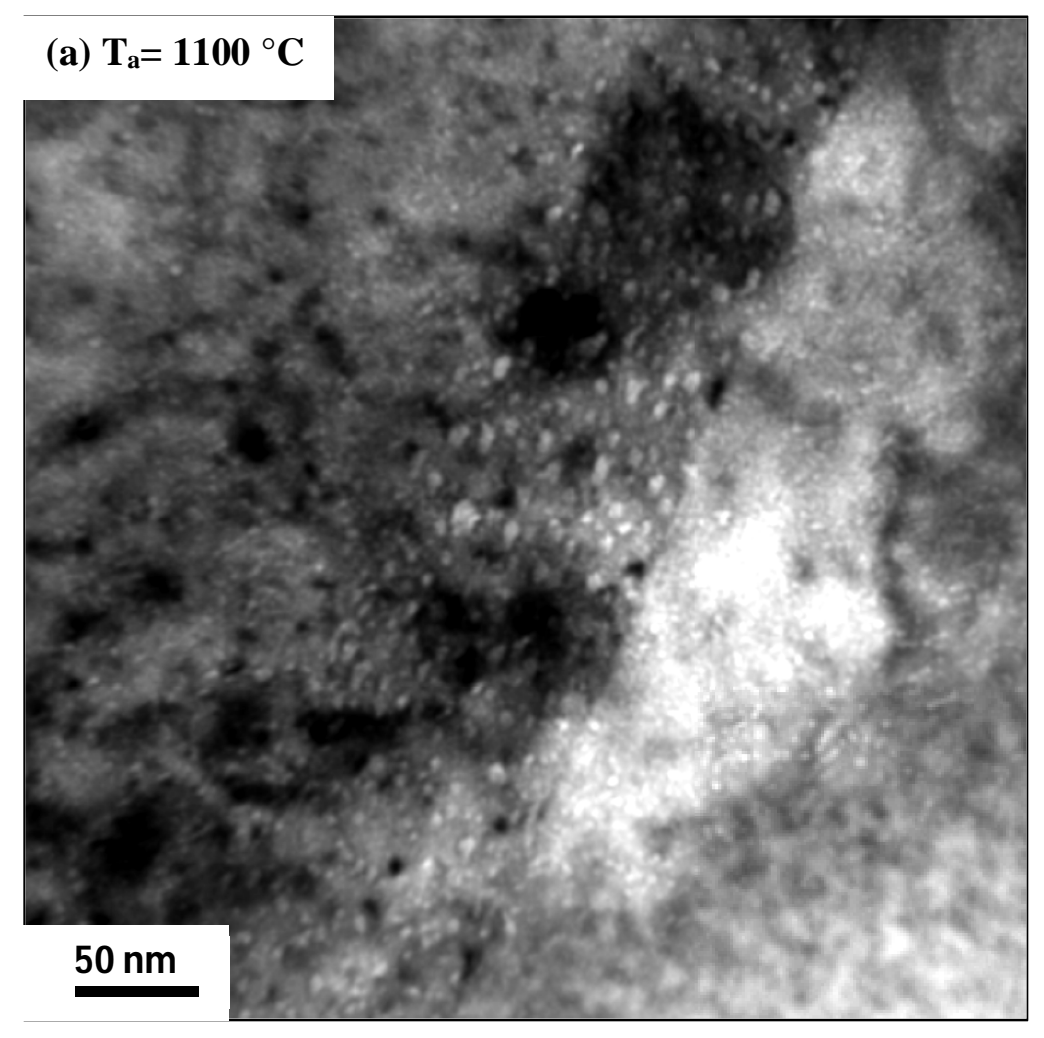



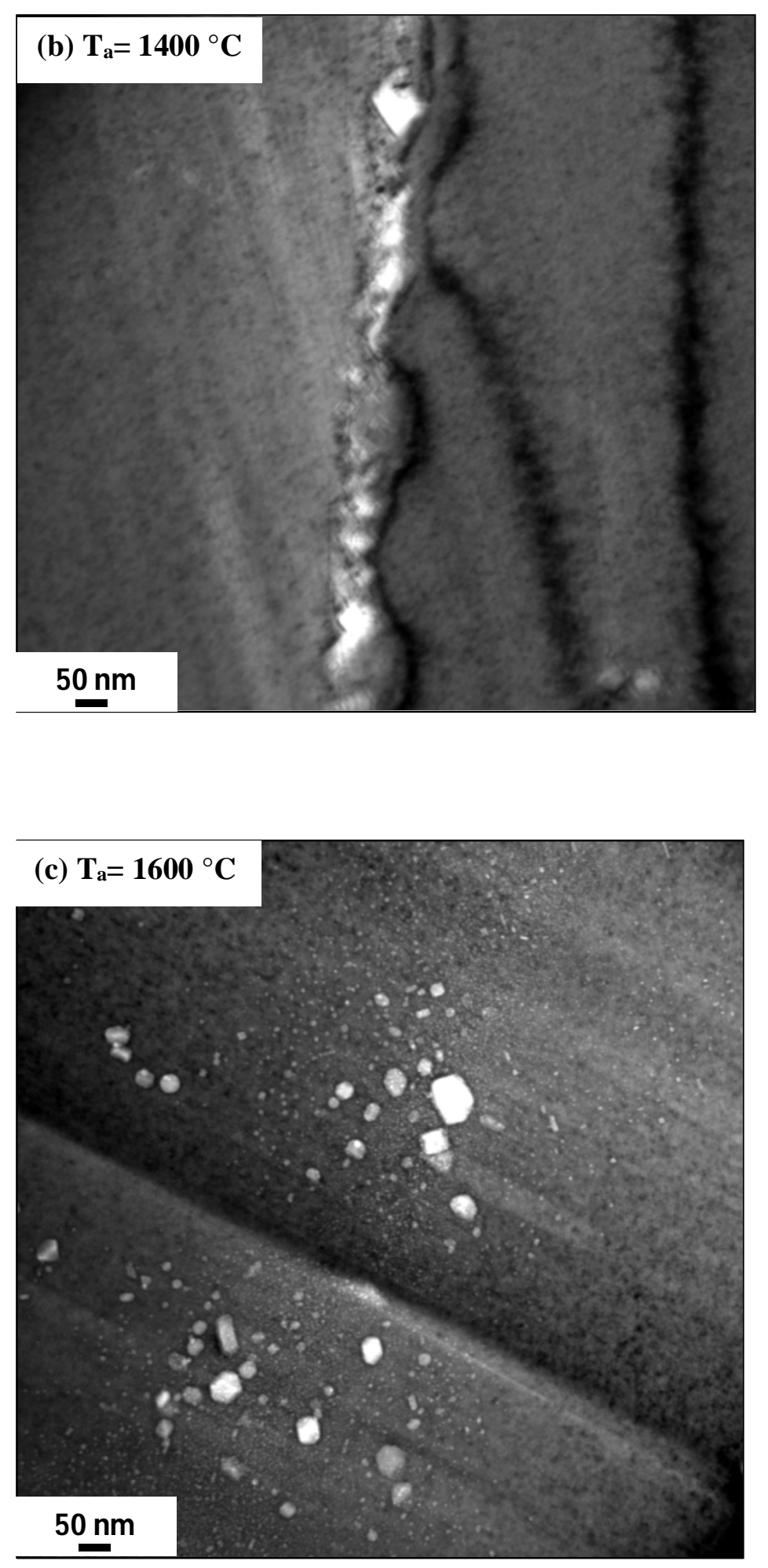

Figure 6.18. Few micrographs representing typical behavior of the bubbles at the grain boundaries are shown (a) The grain boundary filled with bubbles with the size of the bubbles greater than the bubbles at the matrix at $T_{a}=1100{ }^{\circ} \mathrm{C}$ is shown (b) The interlinking helium bubbles at the grain boundary, present between implantation zone and surface at $T_{a}=1400{ }^{\circ} \mathrm{C}$ is shown (c) The bigger bubbles in the vicinity of grain boundary at $T_{a}=1600{ }^{\circ} \mathrm{C}$ is shown. The white contrast represents the bubbles. 


\subsubsection{COMPARISON STUDY BETWEEN SPECIMENS IMPLANTED WITH FLUENCE F $1, F_{2}$ AND F $_{3}$ (Part B)}

\section{A. NUCLEAR REACTION ANALYSIS}

Excitation curves have been plotted for samples implanted with fluence $F_{2}$ and $F_{3}$, and subsequently annealed at $\mathrm{T}_{\mathrm{a}}=1100{ }^{\circ} \mathrm{C} \& 1500{ }^{\circ} \mathrm{C}$. The excitation curves are shown in figure $6.19 \mathrm{a} \& 6.19 \mathrm{~b}$. The incident deuteron energy varied from $1 \mathrm{MeV}$ to $1.8 \mathrm{MeV}$. Similar to $\mathrm{F}_{1}$ fluence, the maximum of excitation curves was found at $1.3 \mathrm{MeV}$ deuteron energy and helium depth profiles are extracted from the proton energy spectrum obtained at $\mathrm{E}_{\mathrm{D}}=1.3 \mathrm{MeV}$.

The most remarkable result that we obtained from figure 6.19a \& 6.19b are following: if we compare the excitation curves for fluence $F_{2}$ and $F_{3}$ and also with fluence $F_{1}$ (fig. 6.10a). We find that at $\mathrm{T}_{\mathrm{a}}=1100^{\circ} \mathrm{C}$, the excitation curve for $\mathrm{F}_{1}, \mathrm{~F}_{2} \& \mathrm{~F}_{3}$ superimpose on their corresponding as-implanted excitation curves within the measurement errors. At $\mathrm{T}_{\mathrm{a}}=1500{ }^{\circ} \mathrm{C}$, the excitation curves (or proton count) corresponding to $F_{1} \& F_{2}$ fluence have shifted downwards suggesting helium loss. However for lower value of fluence $\mathrm{F}_{3}$, the excitation curves at $\mathrm{T}_{\mathrm{a}}=1500{ }^{\circ} \mathrm{C}$ does not shift downwards and indicates zero loss of helium.

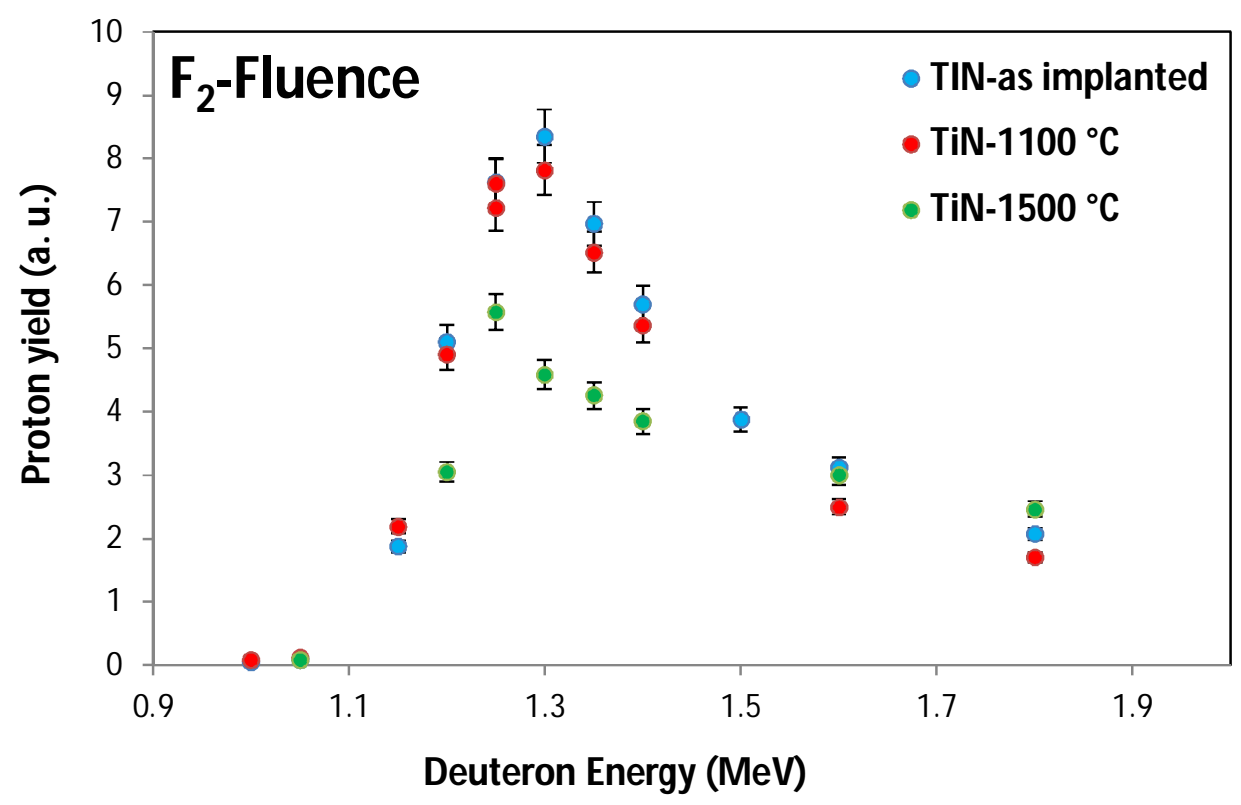

Figure 6.19a. Excitation curves (proton yield versus incident deuteron energy) measured for as-implanted and annealed TiN samples corresponding to $F_{2}$ fluence. 


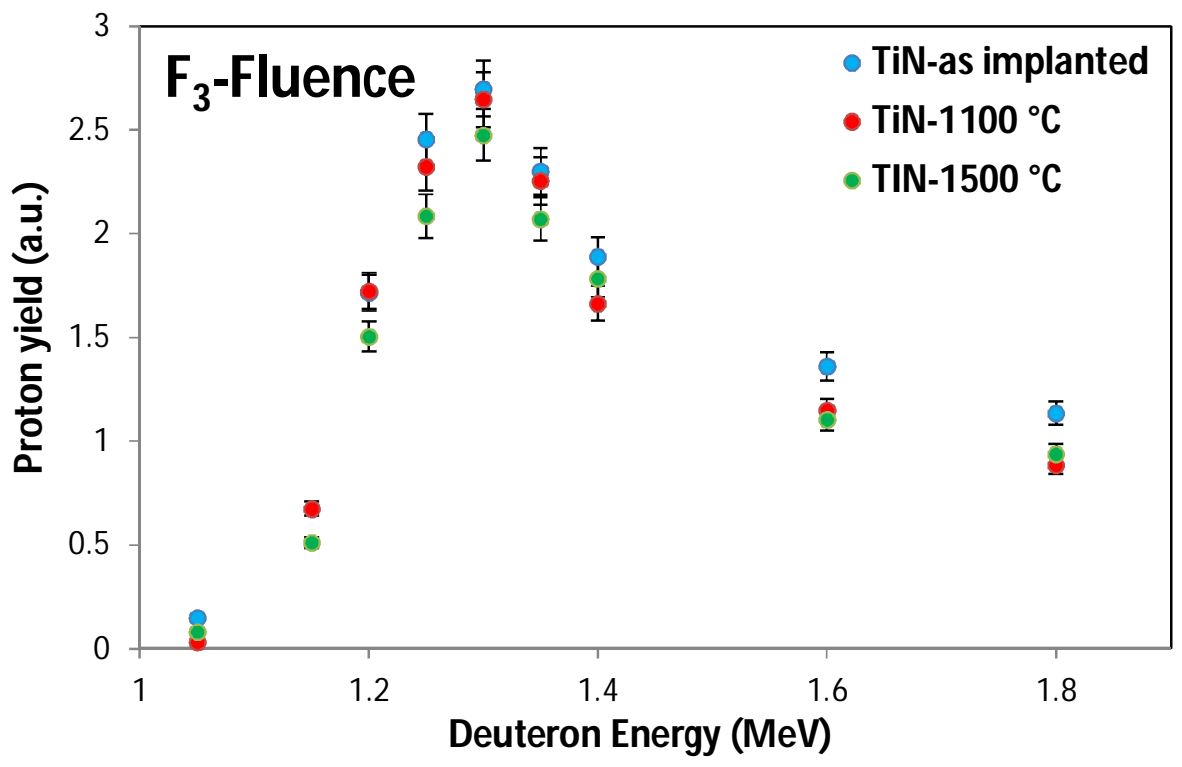

Figure 6.19b. Excitation curves (proton yield versus incident deuteron energy) measured for as-implanted and annealed TiN samples corresponding to $F_{3}$ fluence.

To investigate further, the comparison of helium depth profiles obtained for fluence $F_{1}, F_{2}$ and $\mathrm{F}_{3}$ at $\mathrm{T}_{\mathrm{a}}=1100{ }^{\circ} \mathrm{C} \& 1500^{\circ} \mathrm{C}$ with their corresponding as-implanted profile has been done. This comparison (in terms of height and FWHM) gives the information on helium loss and on range of migration of He-V clusters.

For high fluence values $\boldsymbol{F}_{1}$ and $\boldsymbol{F}_{2}$, at $\mathrm{T}_{\mathrm{a}}=1100{ }^{\circ} \mathrm{C}$, the helium distribution obtained from NRA superimposed (with in the error bars) on their respective helium distributions from asimplanted sample. At $\mathrm{T}_{\mathrm{a}}=1500{ }^{\circ} \mathrm{C}$, the peak of the helium distribution decreases in magnitude (indicating helium release), with slight lateral spreading of the profile (as expected in Fick's law). See figure $6.10 \mathrm{c}$ and $6.20 \mathrm{a}$.

But for lower fluence value $\boldsymbol{F}_{3}$, at $\mathrm{T}_{\mathrm{a}}=1100^{\circ} \mathrm{C} \& 1500{ }^{\circ} \mathrm{C}$, very large lateral spreading of the profile (as expected in Fick's law for diffusion) is observed. Nevertheless, the area under the curves is conserved (indicating no helium release) for both the temperatures correspon ding to low fluence value $F_{3}$. See figure $6.20 \mathrm{~b}$. 


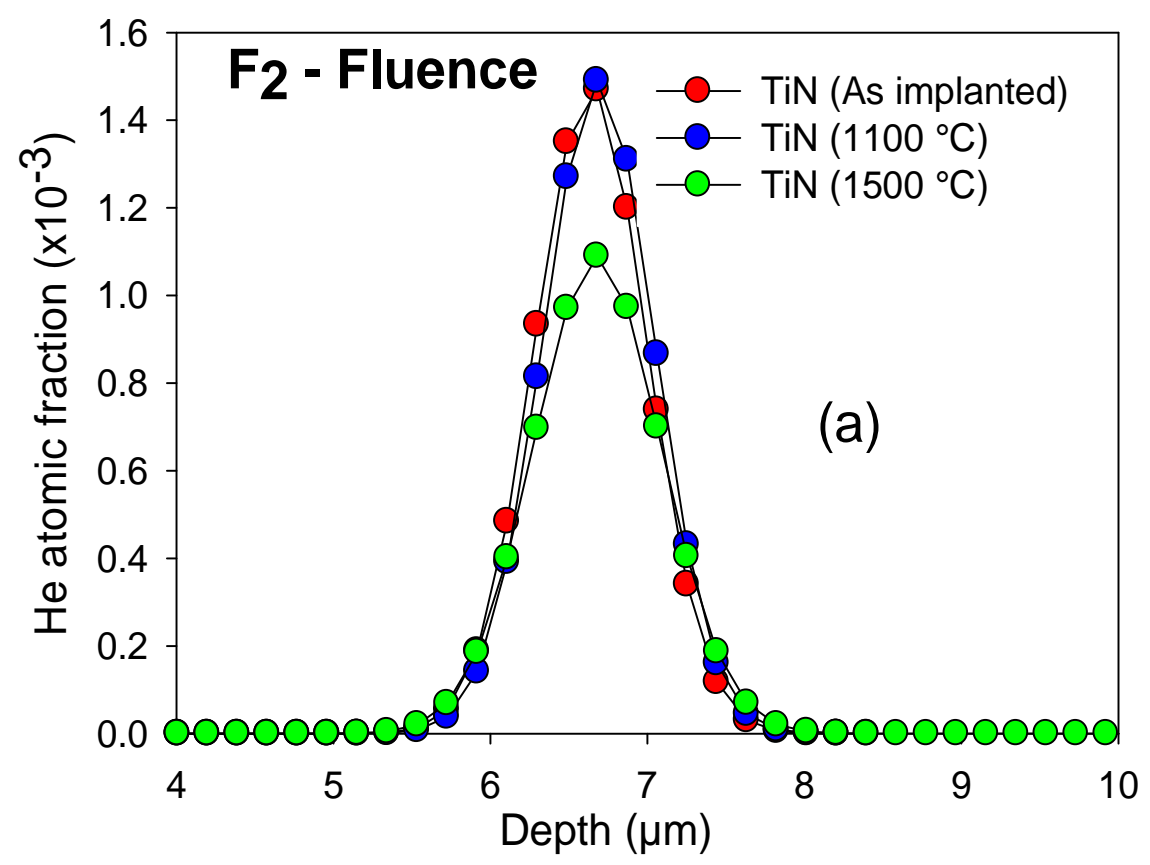

Figure 6.20a. Helium depth profiles obtained from nuclear reaction analysis for samples implanted with fluence $F_{2}$ and annealed at $T_{a}=1100{ }^{\circ} \mathrm{C} \& 1500{ }^{\circ} \mathrm{C}$. These profiles have been obtained by SIMNRA code corresponding to $E_{d}=1.3 \mathrm{MeV}$ and fitted into Gaussian function.

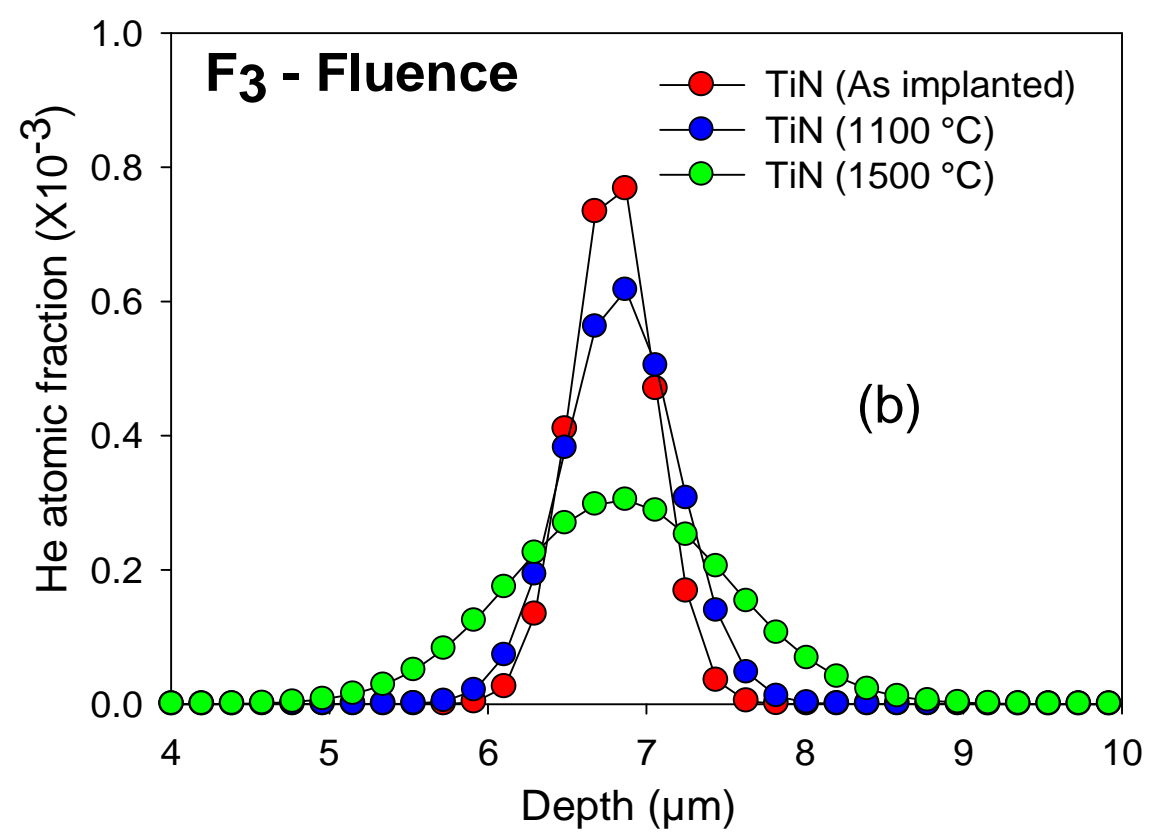

Figure 6.20b. Helium depth profiles obtained from nuclear reaction analysis for samples implanted with fluence $F_{3}$ and annealed at $T_{a}=1100{ }^{\circ} \mathrm{C} \& 1500{ }^{\circ} \mathrm{C}$. These profiles have been obtained by SIMNRA code corresponding to $E_{d}=1.3 \mathrm{MeV}$ and fitted into Gaussian function. 
Such long range diffusion in samples implanted with low fluence $\left(\mathrm{F}_{3}\right)$ indicates that there is a large amount of helium which is not trapped in the bubbles and is present in the form of small $\mathrm{He}-\mathrm{V}$ clusters which are mobile and diffuse to large distances. This interpretation has also been supported by TEM (to be further discussed in next section).

\section{B. TEM OBSERVATION ON GRAIN INTERIOR (AT THE IMPLANTATION ZONE)}

Similar to $\mathrm{F}_{1}$ fluence, soon after helium implantation with $\mathrm{F}_{2} \& \mathrm{~F}_{3}$ fluence at room temperature, no bubbles were observed in transverse FIB specimen of as-implanted samples.

In transverse FIB specimen of samples implanted with helium fluence $\left(\mathrm{F}_{2} \& \mathrm{~F}_{3}\right)$ and annealed at $\mathrm{T}_{\mathrm{a}} \geq 1100{ }^{\circ} \mathrm{C}$, bubbles were clearly seen under TEM. In the next paragraph, important findings are discussed and compared with fluence $F_{1}$.

\section{$\underline{\mathbf{T}_{\mathrm{a}}=1100^{\circ} \mathrm{C}:}$}

At $\mathrm{T}_{\mathrm{a}}=1100{ }^{\circ} \mathrm{C}$, for the three fluence values $\mathrm{F}_{1}, \mathrm{~F}_{2}$ and $\mathrm{F}_{3}$, the average bubble size stayed unvaried between 1-2 $\mathrm{nm}$. For comparison of density between different fluences (see figure 6.21 and 6.11a) and for size distribution (see figure $6.22(a, b$ \& $)$ ). 


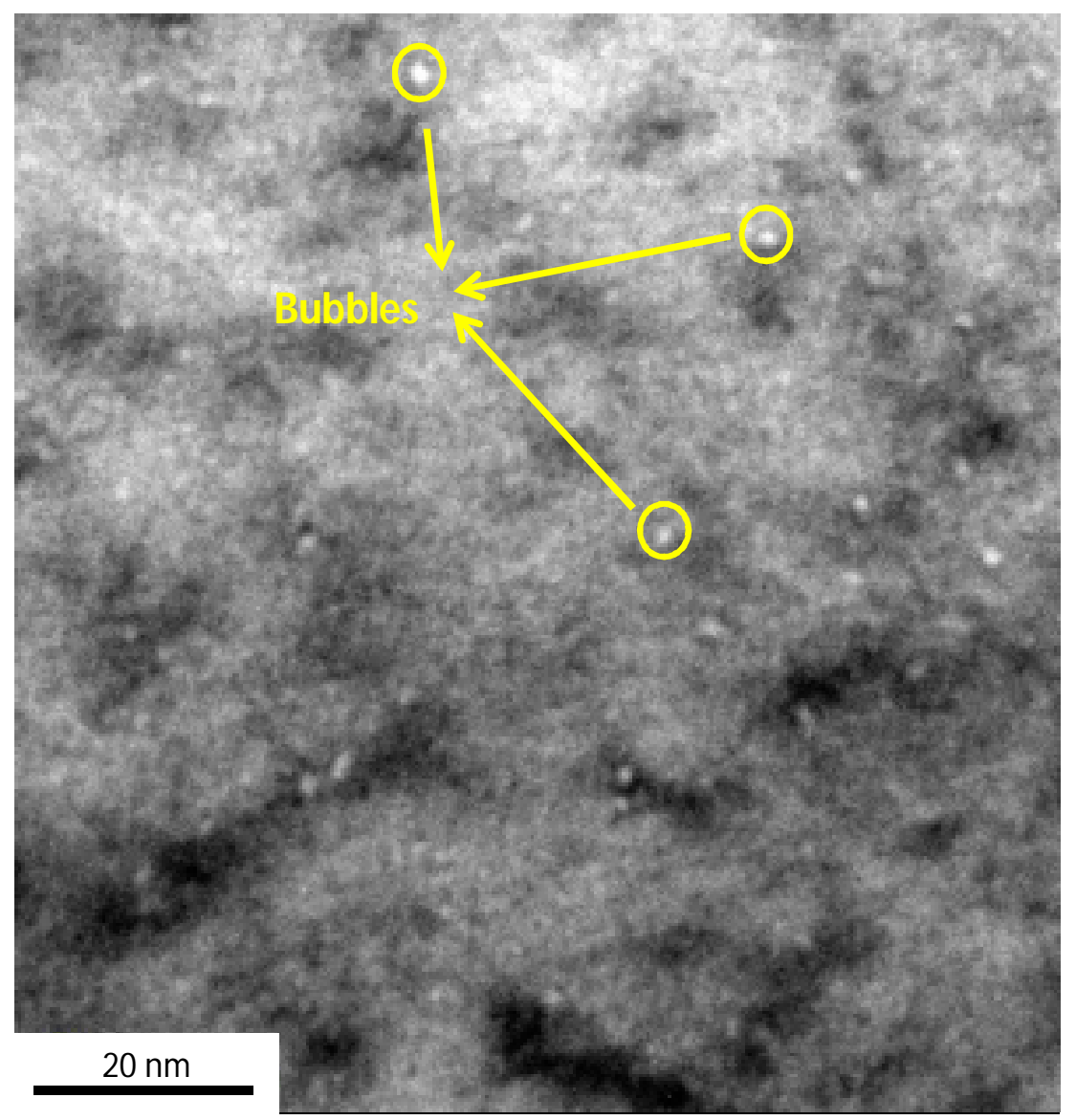

Figure 6.21. Micrographs of the implantation zone of samples implanted with fluence $F_{3}$ and annealed at $T_{a}=1100^{\circ} \mathrm{C}$. 

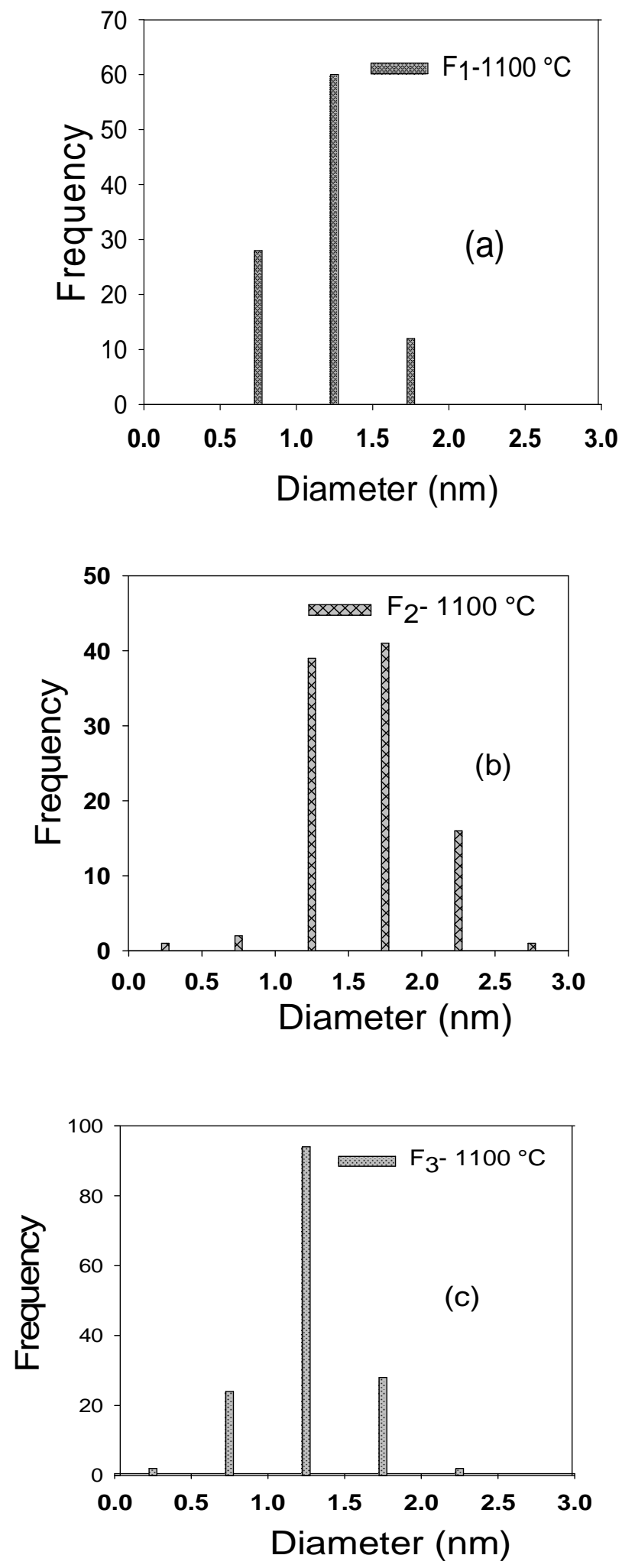

Figure 6.22. Size distribution of helium bubbles in the bulk of TiN annealed at (a) $1100{ }^{\circ} \mathrm{C}$ for $F_{1}(b) 1100{ }^{\circ} \mathrm{C}$ for $F_{2}(c) 1100{ }^{\circ} \mathrm{C}$ for $F_{3}$. 
At $\mathrm{T}_{\mathrm{a}}=1100{ }^{\circ} \mathrm{C}$, density of the bubbles was linearly proportional to the fluence (see red curve in figure 6.23). The similar bubble size but linear variation of bubble density with the implantation fluence supports our previous discussion (see section 6.2.2.1.F), where the quantity of bubble nuclei was supposed proportional to the quantity of helium.

It is well known that, the nucleation rate increases strongly with increasing concentration of helium atom until production rate $(\mathrm{P})$ during implantation and absorption rate $(\mathrm{A})$ of helium atom by existing nuclei balance each other approximately. The nucleation peak is reached for $\mathrm{P}=\mathrm{A}$, and for higher values of $\mathrm{P}$, the nucleation decreases [2]. Thus, the constant size of the bubbles and the linear variation of the bubble density versus the implanted fluence indicate that up to certain fluence the newly implanted gas atom is more likely to nucleate then to reach an existing nucleus. May be, further higher fluence is required to reach the nucleation peak and to increase the size of bubbles.

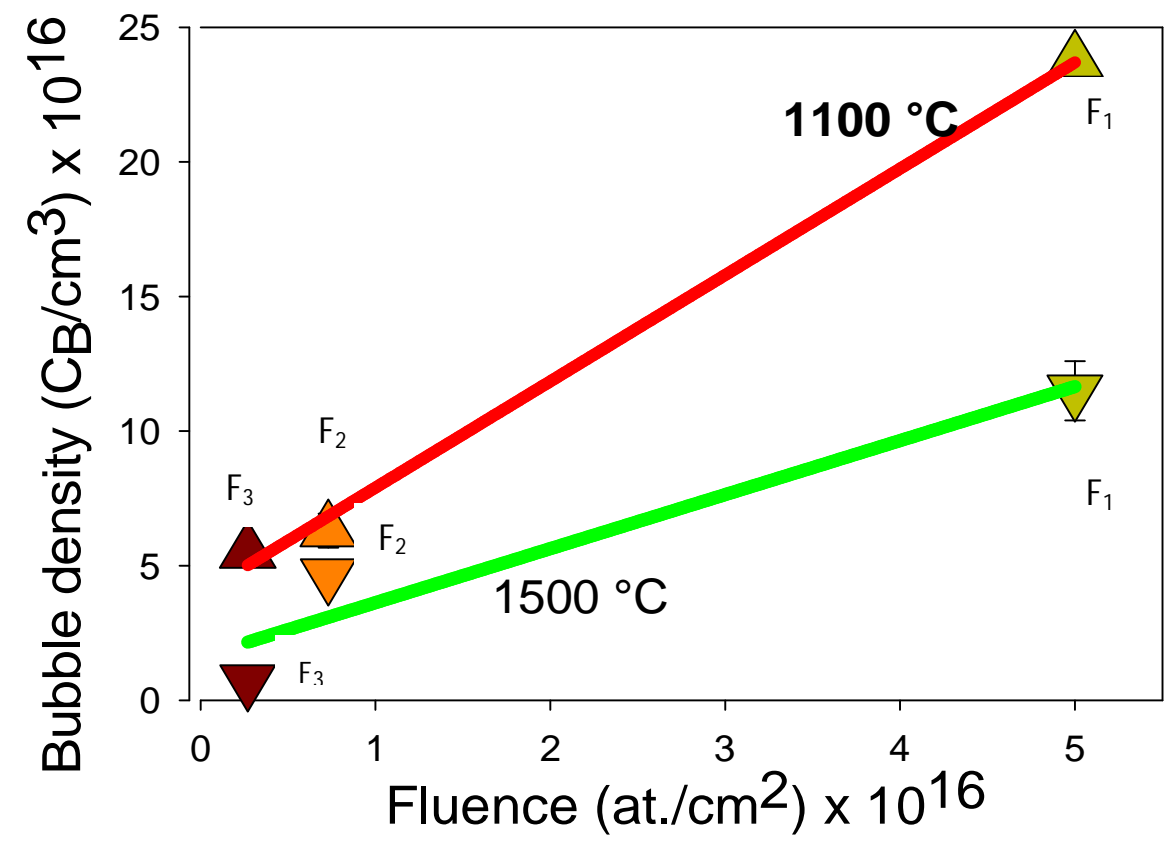

Figure 6.23. Variation of bubble density versus fluence at $1100{ }^{\circ} \mathrm{C}$ (by red line) \& at $1500{ }^{\circ} \mathrm{C}$ (by green line). The same curve can be used to see decrement in the bubble density with increasing $T_{a}$ for $F_{1}, F_{2}, F_{3}$ by color $(\Delta \nabla, \Delta \nabla, \Delta \nabla)$ respectively. 


\section{$\underline{\text { At } \mathbf{T}_{\mathrm{a}}=1500{ }^{\circ} \mathrm{C}:}$}

At $\mathrm{T}_{\mathrm{a}}=1500{ }^{\circ} \mathrm{C}$, the bubble size varied from $\mathrm{r}_{\mathrm{B}}=1.5 \mathrm{~nm}$ (for high $\mathrm{F}_{1}$ fluence) to $\mathrm{r}_{\mathrm{B}}=8 \mathrm{~nm}$ (for low $\mathrm{F}_{3}$ fluence). However, bubble density is again linearly proportional to fluence (see green curve in figure 6.23).

Figure 6.24 shows an increase in bubble size from $\mathrm{T}_{\mathrm{a}}=1100^{\circ} \mathrm{C}$ to $1500{ }^{\circ} \mathrm{C}$ for $\mathrm{F}_{2} \& \mathrm{~F}_{3}$ fluence. It is important to note that at $\mathrm{T}_{\mathrm{a}}=1500{ }^{\circ} \mathrm{C}$, the samples implanted with lower value of fluence $\left(\mathrm{F}_{3}\right)$ displays big bubbles as compared to samples implanted with higher value of fluence $\left(\mathrm{F}_{1}\right)$. This difference is more highlighted in figure 6.25.
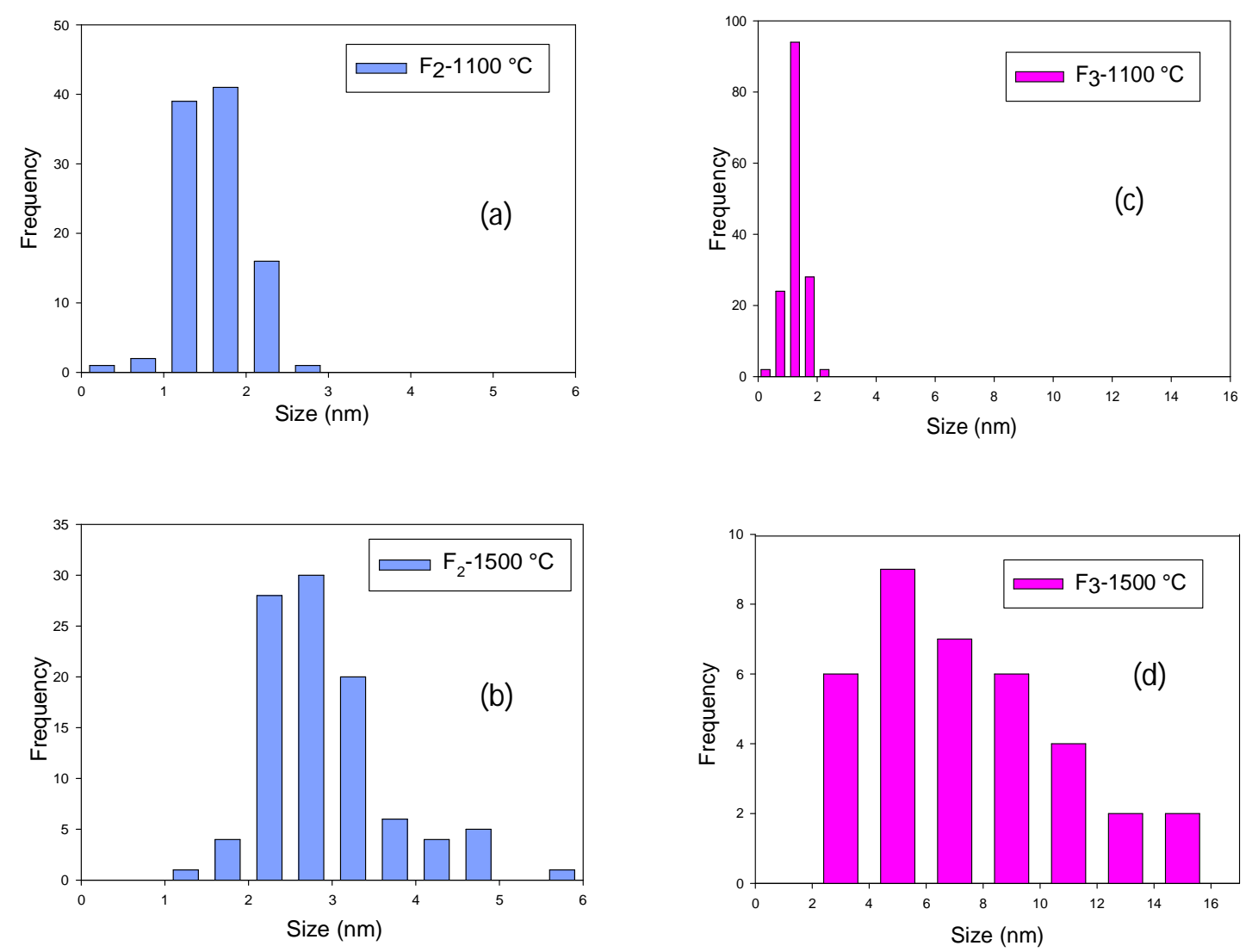

Figure 6.24. Size distribution of helium bubbles in the bulk of TiN annealed at (a) $1100{ }^{\circ} \mathrm{C}$ for $F_{2}(b) 1500{ }^{\circ} \mathrm{C}$ for $F_{2}(c) 1100{ }^{\circ} \mathrm{C}$ for $F_{3}(d) 1500{ }^{\circ} \mathrm{C}$ for $F_{3}$. 

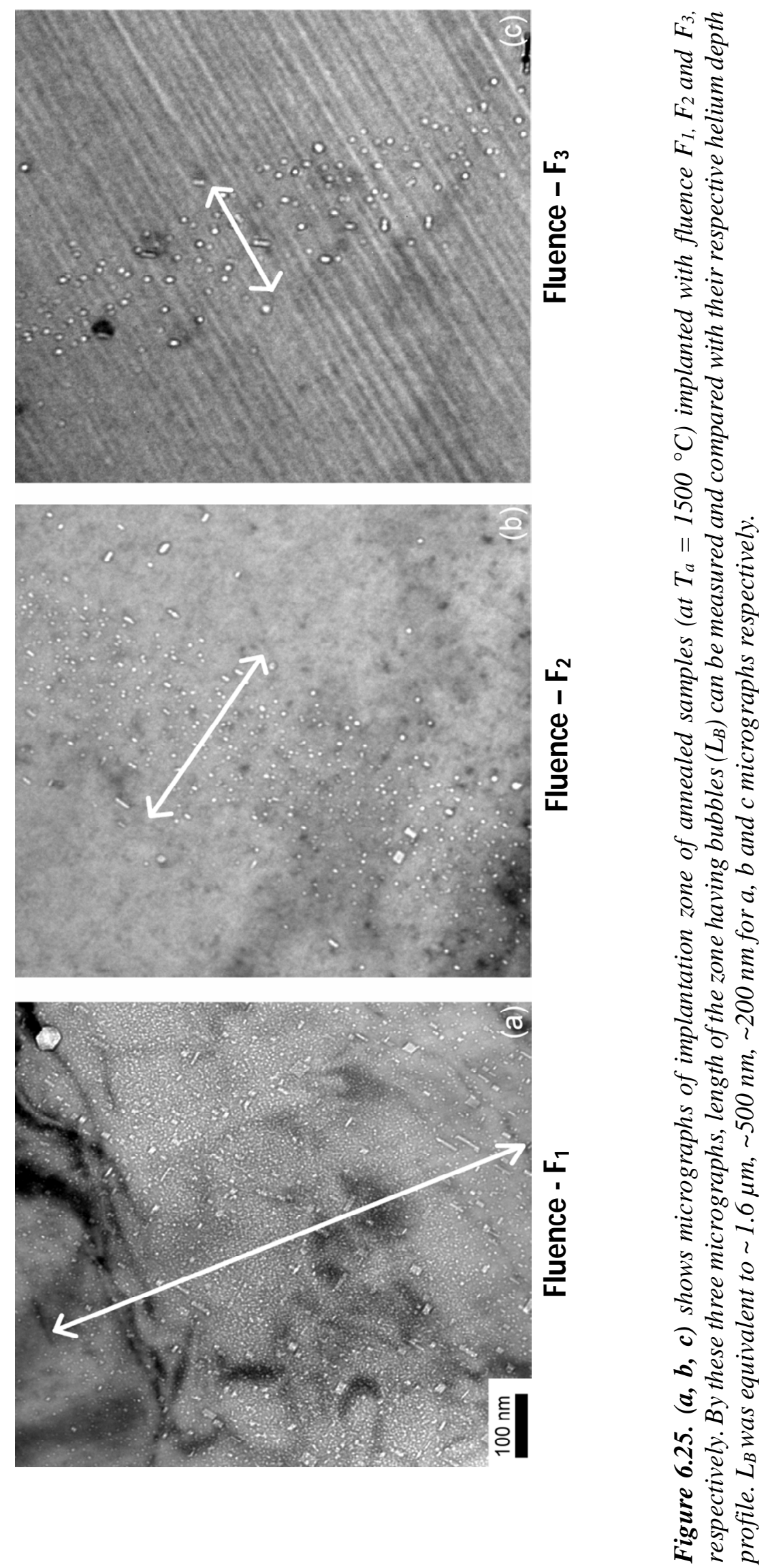
While trying to answer the question 'why under same annealing conditions (at $\boldsymbol{T}_{\boldsymbol{a}}=1500$ ${ }^{\circ}$ ), the samples implanted with lower concentration of helium have large sized bubbles?' we related the explanation with previous results, where bubbles with very large sizes were observed on the surface of the sample implanted with $F_{1}$ fluence (see section 6.2.2.1.F). It has already been mentioned that the numbers of bubble nuclei (or stable $\mathrm{He}_{\mathrm{n}}-\mathrm{V}_{\mathrm{m}}$ clusters) formed are proportional to the quantity of implanted helium. And here, this hypothesis has also been supported by TEM observation (see red curve in figure 6.23).

For samples implanted with lower fluence $\left(\mathrm{F}_{3}\right.$ fluence $)$ and annealed at $\mathrm{T}_{\mathrm{a}}=1500{ }^{\circ} \mathrm{C}$, it appears that due to less concentration of helium atoms, there are less nucleation centers (which have also been approved by very low density of small helium bubble at $\mathrm{T}_{\mathrm{a}}=1100{ }^{\circ} \mathrm{C}$ ). At $\mathrm{T}_{\mathrm{a}}=1500$ ${ }^{\circ} \mathrm{C}$, due to low density of nucleation centers, all the helium which is present in the form of invisible small mono-vacancy $\left(\mathrm{He}_{1}-\mathrm{V}_{1}\right)$ or di-vacancy $\left(\mathrm{He}_{2}-\mathrm{V}_{2}\right)$ which did not nucleate into stable nuclei would prefer to go to existing nuclei and therefore, increasing the size of bubbles. At $1500{ }^{\circ} \mathrm{C}$, the effect of vacancy absorption on bubble growth cannot be neglected, some native vacancies and vacancies created by irradiation may be absorbed by clusters, explaining the large sizes of helium bubbles.

However, for the samples which are implanted with higher fluence ( $F_{1}$ fluence), due to very high density of bubbles at $\mathrm{T}_{\mathrm{a}}=1100{ }^{\circ} \mathrm{C}$, all the invisible small mono (or di) vacancy clusters are partitioned among large concentration of small bubbles at $\mathrm{T}_{\mathrm{a}}=1100{ }^{\circ} \mathrm{C}$. This partitioning leads to the small bubble growth as compared to the samples implanted with lower concentration of helium.

We also revealed that in the samples which are implanted with lower concentration of helium, only very small fraction of implanted helium is visible in the form of bubbles and rest is present in the form of clusters which are too small in size to be visible under TEM. This has been observed by the superimposition of NRA profile on the TEM micrographs of samples implanted with $F_{1}, F_{2} \& F_{3}$ fluence annealed at $T_{a}=1500{ }^{\circ} \mathrm{C}$. We deduced that under same postimplantation annealing conditions, smaller the implantation fluence, larger is the proportion of small He-V cluster (which are invisible under TEM).

We revealed that during TEM analysis of sample implanted with $\mathrm{F}_{3}$ fluence and annealed at $1500{ }^{\circ} \mathrm{C}$, the total length in which helium bubbles (at the implantation zone) were present was $\sim 200 \mathrm{~nm}$ (see Annexe 3 for direct comparison) whereas the total length shown in NRA distribution was $3 \mu \mathrm{m}$. This confirms that the total implanted helium is not present in the form 
of bubbles, only helium present in $300 \mathrm{~nm}$ width (in the center of the Gaussian depth distribution) is present in the form of bubbles and rest is invisible under TEM. On precise calculation, only $30 \%$ of the implanted helium is present in the form of bubbles and rest $70 \%$ is present in the sample but cannot be observed under TEM. This statement also supports the interpretation in previous section where the long-range helium diffusion was considered due to small He-V cluster invisible under TEM.

Further on comparing, the difference in total length in which helium is present according to TEM micrographs and their respective NRA curves, seems to decrease with the increase in implantation fluence (see Annexe III). For samples corresponding to $\mathrm{F}_{2}$ fluence and annealed at $\mathrm{T}_{\mathrm{a}}=1500{ }^{\circ} \mathrm{C}$, we calculated that the more than half of the helium fraction is present in the form of small clusters which are invisible under TEM. However, for samples implanted with $\mathrm{F}_{1}$ fluence and annealed at $1500{ }^{\circ} \mathrm{C}$, the bubbles were almost present in the whole length of its respective NRA curve. These results concluded that, under same post-implantation annealing conditions, the larger the implantation fluence, the smaller the portion of the small He-V clusters (invisible under TEM).

\section{DETERMINATION OF PRESSURE INSIDE THE BUBBLES AT THE IMPLANTATION ZONE}

The pressure inside the bubble was calculated using the same procedure followed for $F_{1}$ fluence:

\begin{tabular}{|c|c|c|c|c|c|c|}
\hline Fluence & $\begin{array}{c}\mathbf{T} \\
\left({ }^{\circ} \mathbf{C}\right)\end{array}$ & $\begin{array}{c}\mathrm{C}_{\mathrm{He}} \\
(\text { atoms/nm } \\
\text { (nd })\end{array}$ & $\begin{array}{c}\mathrm{Cv} \\
\left(\text { vacancy } / \mathbf{n m}^{3}\right)\end{array}$ & $\mathbf{C}_{\mathrm{He}} / \mathrm{Cv}$ & $\begin{array}{c}\mathbf{P} \\
(\mathbf{G P a})\end{array}$ & $\begin{array}{c}\text { Corresponding } \\
\text { eq. pressure } \\
\left(2 \gamma / \mathbf{r}_{B}\right) \text { in }(\mathbf{G P a})\end{array}$ \\
\hline $\mathrm{F}_{2}$ & 1100 & 0.16 & 0.008 & 19.03 & 3335 & 5 \\
\hline$\overline{F_{2}}$ & 1500 & 0.12 & 0.038 & 3.03 & 23.7 & 2.86 \\
\hline $\mathrm{F}_{3}$ & 1100 & 0.06 & 0.003 & 18.5 & 3058 & 5 \\
\hline $\mathrm{F}_{3}$ & 1500 & 0.003 & 0.11 & 0.025 & 0.03 & 1 \\
\hline
\end{tabular}

Table 6.5. The pressure value inside the bubbles at various $T_{a}$ calculated by an equation of state corresponding to $F_{2}$ and $F_{3}$ fluence.

The pressure values falls at higher temperature for both the fluence values due to bubble growth. 
At $\mathrm{T}_{\mathrm{a}}=1500{ }^{\circ} \mathrm{C}$, for $\mathrm{F}_{3}$ fluence pressure inside the bubbles fall below the equilibrium pressure, this is also supported by the polygonal shape of bubbles seen under TEM (see figure $6.25 \mathrm{c}$ or 3a figure in Annex 3). We were not able to calculate activation energy of bubble growth $\left(\mathrm{E}_{\mathrm{r}}\right)$ by Arrhenius law due to only two annealing temperatures.

\section{TEM observation near grain boundaries and at surface}

The general behavior of the bubbles at the surface and grain boundaries was similar to the samples implanted with fluence $\mathrm{F}_{1}$. At $1100{ }^{\circ} \mathrm{C}$, bubbles were present at the surface, for both $\mathrm{F}_{2}$ and $\mathrm{F}_{3}$ fluence with $\sim 1 \mathrm{~nm}$. At $1500{ }^{\circ} \mathrm{C}$, bubbles grew upto $23 \mu \mathrm{m}$ and $15 \mu \mathrm{m}$ for $\mathrm{F}_{2}$ fluence respectively.

At GB, bubbles with different shapes (rod and faceted) are present at both temperatures corresponding to $F_{2}$ and $F_{3}$ fluence. Also, bubbles in the vicinity of GB were bigger in all the cases. The apparent energy calculation and other plots were not possible due to only two annealing temperatures $\mathrm{T}_{\mathrm{a}}$.

\subsubsection{Conclusion}

In this section important conclusions regarding the study of helium behavior under thermal environment in TiN have been presented. The major part of the study deals with calculation of effective helium diffusion coefficients and the microstructural evolution due to helium accumulation under the following experimental conditions: $3 \mathrm{MeV},{ }^{3} \mathrm{He}$ with $5 \times 10^{16}$ at. $/ \mathrm{cm}^{2}$ and samples annealed from $1000{ }^{\circ} \mathrm{C}-1600{ }^{\circ} \mathrm{C}$ for time period of $2 \mathrm{hrs}$ (Part A). And some part of the study is dedicated to understand the role of helium implantation fluence on helium mobility (Part B). Important conclusions from this study are:

\section{$\underline{\text { Part A }}$}

- The value of activation energy of helium release (obtained by fitting helium lost fraction (f) versus $\left.\mathrm{T}_{\mathrm{a}}\right)$ is $\Delta \mathrm{H}=(1.20 \pm 0.12) \mathrm{eV}$.

- Helium depth profiles obtained for annealed specimens from $\mathrm{T}_{\mathrm{a}}=1000{ }^{\circ} \mathrm{C}$ to $1600{ }^{\circ} \mathrm{C}$ showed very little lateral spreading with respect to as-implanted helium depth profile and the value of calculated effective diffusion coefficient varies from $(3.58 \mathrm{E}-19$ to $5.92641 \mathrm{E}-18) \mathrm{m}^{2} \mathrm{~s}^{-1}$. This 
small broadening (or slight lateral spreading) of helium depth profiles at higher temperature indicates that the helium atoms got trapped very strongly at (or near) its end-of-range location after helium implantation at room temperature.

- The value of activation energy of helium diffusion (derived by applying Arrhenius law on helium diffusion coefficient values vs $\mathrm{T}_{\mathrm{a}}$ ) is $\mathrm{E}_{\mathrm{D}}=1.05 \pm 0.2 \mathrm{eV}$.

- Transverse FIB specimen of as-implanted samples revealed no unambiguous evidence for visible helium bubbles. This means that the majority of bubbles (He-V clusters) formed after implantation at room temperature have sizes below detection limit of the microscope. The FIB specimen of samples annealed at $\mathrm{T}_{\mathrm{a}} \geq 1100^{\circ} \mathrm{C}$, showed the presence of bubbles under TEM and also revealed bubble growth from $\mathrm{T}_{\mathrm{a}}=1100{ }^{\circ} \mathrm{C}$ to $\mathrm{T}_{\mathrm{a}}=1600{ }^{\circ} \mathrm{C}$. The value of apparent activation energy $\left(E_{r}\right)$ of bubble growth was derived and is equal to $E_{r}=0.38 \pm 0.03 \mathrm{eV}$.

- The pressure values inside the bubbles obtained at $\mathrm{T}_{\mathrm{a}}=1100{ }^{\circ} \mathrm{C}, 1400{ }^{\circ} \mathrm{C}$ and $1500{ }^{\circ} \mathrm{C}$ are very high due to apparent density $\left(\mathrm{D}_{\mathrm{B}}\right)$ of He-V cluster calculated by TEM micrographs. At $\mathrm{T}_{\mathrm{a}}$ $=1500{ }^{\circ} \mathrm{C}$, the pressure inside the helium bubbles is close to shear modulus of TiN (i.e. 240 $\mathrm{GPa}$ ) or mechanical stability limit of the material. The pressure value at $\mathrm{T}_{\mathrm{a}}=1600{ }^{\circ} \mathrm{C}$ is close to the equilibrium pressure value of $\sim 2 \mathrm{GPa}$.

- From $\mathrm{T}_{\mathrm{a}} \geq 1400{ }^{\circ} \mathrm{C}$ (where $\mathrm{T}_{\mathrm{a}}$ is closed to $0.5 \mathrm{~T}_{\mathrm{m}}$ ), bubbles or stable He-V complexes grow by the absorption of mono (or di) vacancy clusters and native vacancies.

- Annealing of specimen from $\mathrm{T}_{\mathrm{a}}=1100{ }^{\circ} \mathrm{C}$ to $1600{ }^{\circ} \mathrm{C}$, results in formation of bubbles at the surface. An apparent activation energy of bubble growth has been derived and is equal to $\mathrm{E}_{\mathrm{r}}=$ $1.69 \pm 0.2 \mathrm{eV}$. The mean radius of bubbles increased from $\sim 0.7 \mathrm{~nm}$ (at $1100{ }^{\circ} \mathrm{C}$ ) to $\sim 45 \mathrm{~nm}$ (at $\left.1600{ }^{\circ} \mathrm{C}\right)$.

\section{$\underline{\text { Part B }}$}

- At $\mathrm{T}_{\mathrm{a}}=1500{ }^{\circ} \mathrm{C}$, helium loss have been observed corresponding to higher fluence $\left(\mathrm{F}_{1} \& \mathrm{~F}_{2}\right)$ values. However for lower value of fluence $F_{3}$, no helium loss has been observed.

- A long range helium diffusion in samples implanted with low fluence $\left(\mathrm{F}_{3}\right)$ have been observed which indicated that large amount of helium which was not trapped in the bubbles and was present in the form of small He- $\mathrm{V}$ clusters was mobile and diffused to large distances. Whereas the helium present in samples implanted with higher fluence $F_{1} \& F_{2}$ diffused to very small distances. 
- TEM investigations revealed that at $\mathrm{T}_{\mathrm{a}}=1100{ }^{\circ} \mathrm{C}$, density of the bubbles is linearly proportional to the fluence, however their size remained same. Under same annealing conditions (at $\mathrm{T}_{\mathrm{a}}=1500{ }^{\circ} \mathrm{C}$ ), the samples implanted with lower concentration of helium have very large sized bubbles.

- The difference in total length in which helium is present according to TEM micrographs and their respective NRA curves, decreases with the increase in implantation fluence value. We can also say that, under the same post-implantation annealing conditions, the larger the implantation fluence, the smaller the portion of the small He-V clusters (invisible under TEM).

\section{References}

[1] L. Tsetseris, N. Kalfagiannis, S. Logothetidis and S. T. Pantelides, PRL (2007) 99, 125503.

[2] H. Trinkaus, Rad. Effects (1983) 78, 189-211.

[3] J. Chen, P. Jung and H. Trinkaus, Physical Review B (2000) 01, 611. 


\section{Part 3}

\subsection{Helium behavior under thermal environment in $\mathrm{ZrC}$}

Similar to previous sections, before presenting and discussing results for helium behavior under thermal environment in $\mathrm{ZrC}$, we have given a quick reminder of the experimental approach.

The time spent in the result analysis for $\mathrm{ZrC}$ was the most fascinating period in the entire thesis due to very interesting microstructure properties of $\mathrm{ZrC}$. The two questions which were most inquired during the thesis are:

'What is the role of presence of native vacancies on helium diffusion and retention'?

'What is the role of grain boundaries on helium diffusion and retention'?

Due to very small grain size $(\sim 3$ to5 $\mu \mathrm{m})$ and due to the presence of large concentration of native vacancies (due to sub-stoichiometric ratio $=0.92 \pm 0.02$ ) in $\mathrm{ZrC}$. It was easy to study the role of native vacancies and grain boundaries and get significant information to answer the above mentioned questions.

\subsubsection{Reminder of the experimental approach}

\section{A. To understand the role of temperature}

\begin{tabular}{|c|c|c|c|c|c|}
\hline $\begin{array}{c}\text { He implantation } \\
\text { in bulk ZrC at } \mathrm{RT} \\
\mathrm{MeV}, \mathrm{F}_{1}=5 \times \mathbf{1 0} \mathbf{1 0}^{16} \text { at. } / \mathrm{cm}^{2}, \\
\mathbf{R p}=6.16 \mu \mathrm{m})\end{array}$ & $\rightarrow$ & $\begin{array}{c}\text { Thermal annealing } \\
\left(1000{ }^{\circ} \mathrm{C}, 1100{ }^{\circ} \mathrm{C},\right. \\
1500{ }^{\circ} \mathrm{C}, \\
\left.1600{ }^{\circ} \mathrm{C}, \mathbf{2 h}\right)\end{array}$ & $\begin{array}{l}\rightarrow \text { NRA } \\
\text { (done on as- } \\
\text { implanted } \\
\text { and annealed } \\
\text { bulk samples) }\end{array}$ & $\rightarrow$ & $\begin{array}{c}\text { Cross section TEM } \\
\text { specimen made from bulk } \\
\text { annealed and as-implanted } \\
\text { samples } \\
\text { (with the help of FIB) }\end{array}$ \\
\hline
\end{tabular}

B. To understand the role of implantation fluence

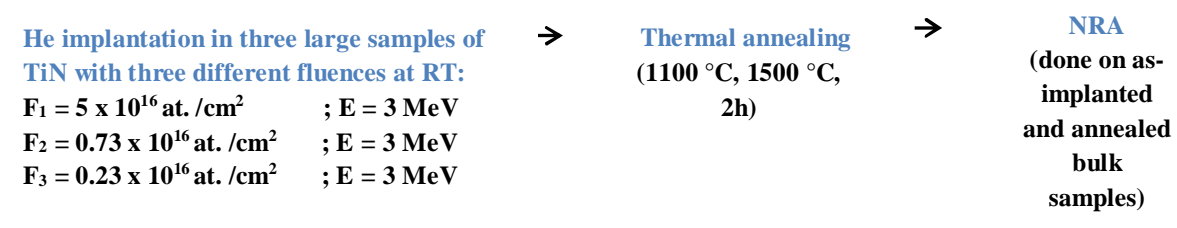




\subsubsection{Results and Discussion}

In the next paragraph, results from experimental approach A on the specimen implanted with fluence $F_{1}$ and annealed at various temperatures $\left(T_{a}\right)$ are presented and discussed (Part $A$ ). Following this, results from experimental approach B on the role of implantation fluence on helium mobility are discussed (Part B).

\subsubsection{Specimens implanted with fluence $F_{1}$ and annealed at various $\mathbf{T}_{\mathbf{a}}(\operatorname{Part} \mathbf{A})$}

\section{A. Nuclear reaction analysis}

The experiments to plot excitation curves were conducted by varying the deuteron energy $\left(\mathrm{E}_{\mathrm{D}}\right)$ from $0.8 \mathrm{MeV}$ to $1.8 \mathrm{MeV}$ on as-implanted and annealed $\mathrm{ZrC}$ specimens at temperature $\mathrm{T}_{\mathrm{a}}=$ $1000{ }^{\circ} \mathrm{C}, 1100{ }^{\circ} \mathrm{C}, 1500{ }^{\circ} \mathrm{C}$ and $1600{ }^{\circ} \mathrm{C}$ (see figure 6.26a). Similar to $\mathrm{TiC} \& \mathrm{TiN}$, the helium lost fraction (f) versus $\mathrm{T}_{\mathrm{a}}$ have been fitted by $1^{\text {st }}$ order kinetic law and the activation energy of helium release was obtained, $\Delta \mathrm{H}=(0.77 \pm 0.08) \mathrm{eV}$. This curve has been plotted in figure $6.26 b$.

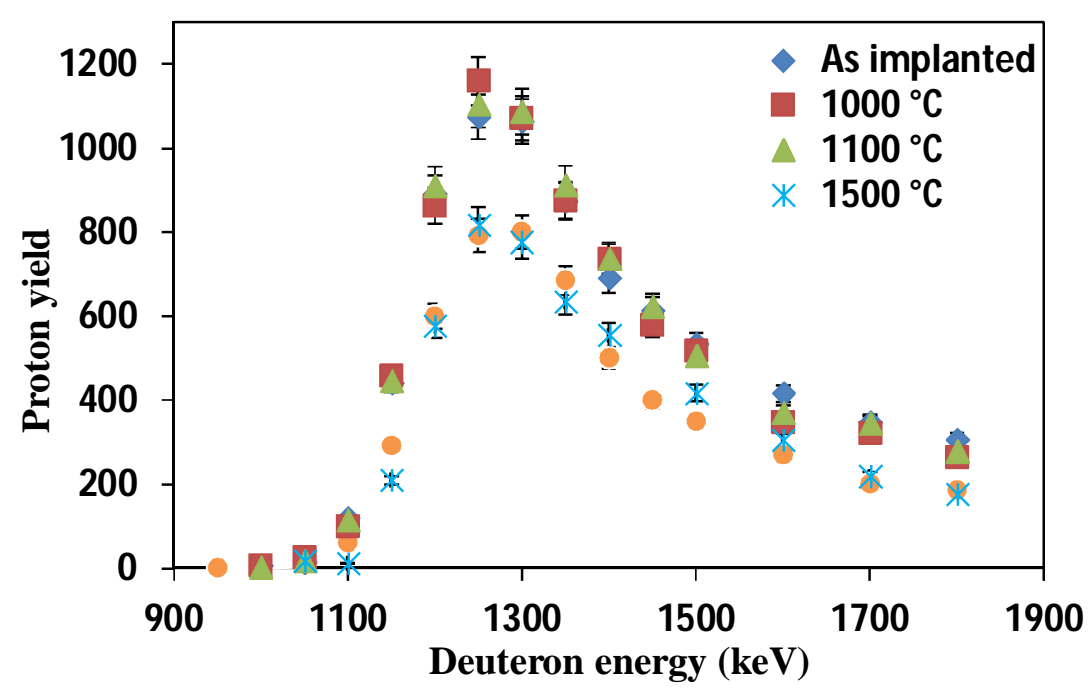

Figure 6.26a. Excitation curves (proton yield versus incident deuteron energy) plotted for asimplanted and annealed $\mathrm{ZrC}$ samples. 


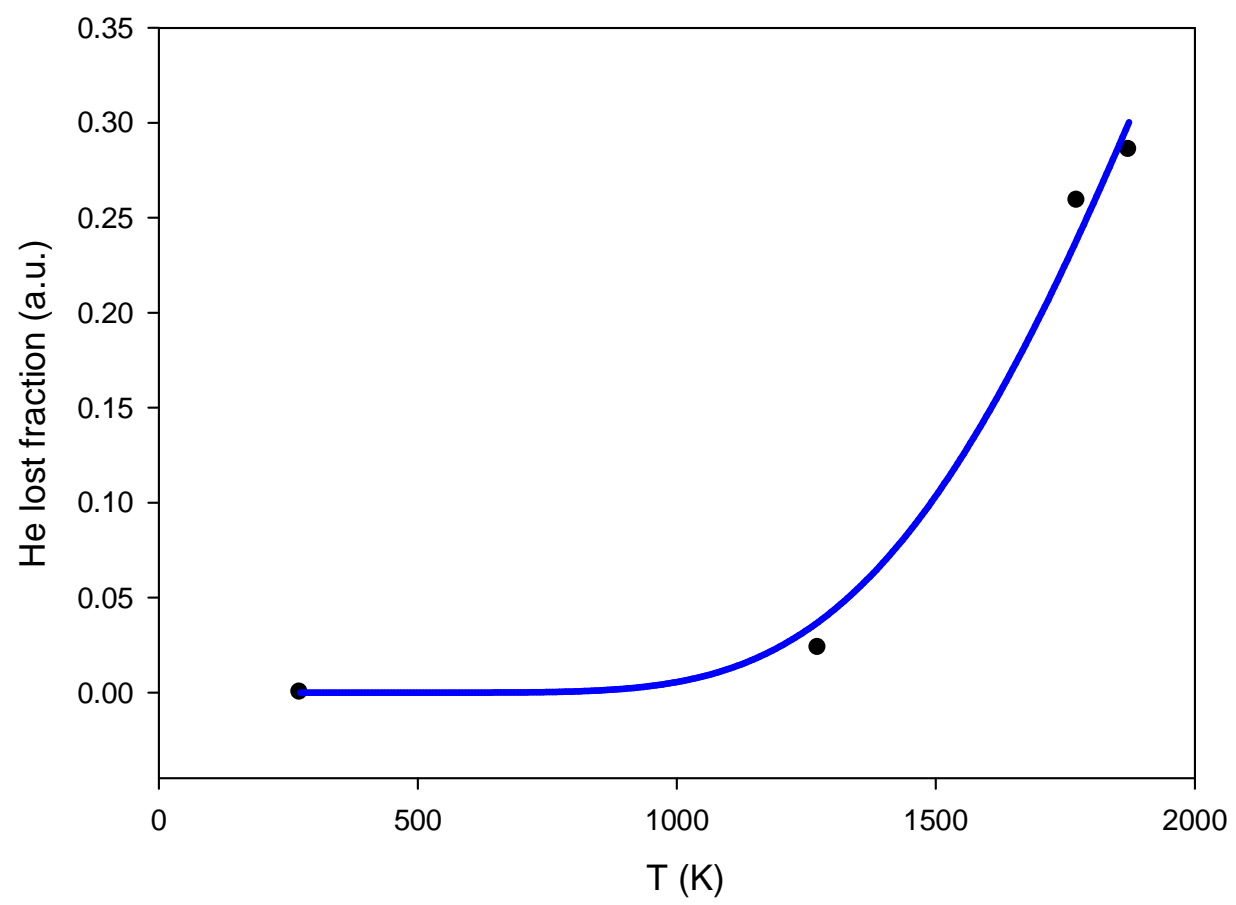

Figure 6.26b. Evolution of the ${ }^{3} \mathrm{He}$ lost fraction $(f)$ versus annealing temperature for TiN. The equation of the fit obeys $f=1-\exp \left[-\alpha . \exp \left(-\Delta H / k_{B} . T\right)\right]$ with $a=41.76$ and $\Delta H=(0.77 \pm$ 0.08) $\mathrm{eV}$.

Figure 6.26c shows helium depth profiles obtained for as-implanted and annealed specimens at $\mathrm{T}_{\mathrm{a}}=1000^{\circ} \mathrm{C}, 1100{ }^{\circ} \mathrm{C}, 1500{ }^{\circ} \mathrm{C}$ and $1600^{\circ} \mathrm{C}$. These helium depth profiles have been obtained by using SIMNRA software at $\mathrm{E}_{\mathrm{d}}=1.3 \mathrm{MeV}$. The helium depth profiles obtained for asimplanted and annealed samples have strong tailing effect towards the surface. Figure 6.26c shows that until $1100{ }^{\circ} \mathrm{C}$, there is no change in the positioning and total quantity of helium present in the sample. At $\mathrm{T}_{\mathrm{a}}=1500{ }^{\circ} \mathrm{C}$, instead of broadening (or lateral spreading), there is a shrinkage in the helium depth profile and also total area under curve does not remain constant, therefore confirming helium release. We did not fit these profiles into Gaussian shape, because fitting is required to accurately determine the diffusion coefficient values in case of helium depth profile broadening at higher temperature.

From our previous experimental study on $\mathrm{TiC}$ and $\mathrm{TiN}$, it appears that helium is strongly trapped inside the bubbles and due to extremely large number of native vacancies in $\mathrm{ZrC}$ $\left(\mathrm{ZrC}_{\mathrm{x}}, \mathrm{x}=0.92 \pm 0.02\right)$, the role of vacancies cannot be neglected. These vacancies seem to be responsible for large He- $\mathrm{V}$ cluster sizes which may have very less mobility. However, this is just a hypothesis, which needs to be confirmed by TEM. 


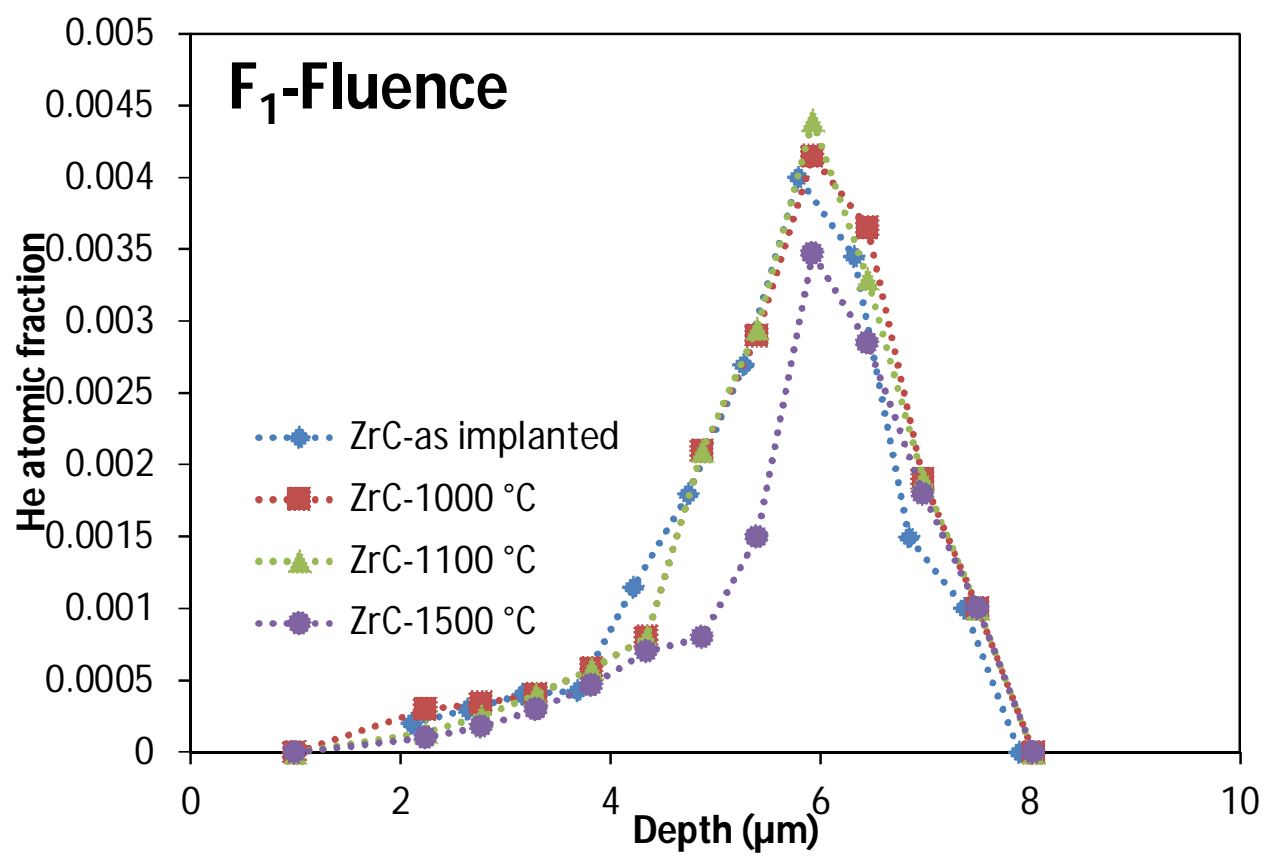

Figure 6.26c. Helium depth profiles obtained from nuclear reaction analysis for $\mathrm{ZrC}$ samples implanted with fluence $F_{1}$ and annealed between $1000{ }^{\circ} \mathrm{C}-1600{ }^{\circ} \mathrm{C}$. The dotted lines are to guide the eyes. These profiles have been obtained using SIMNRA code corresponding to $E_{d}=$ $1.3 \mathrm{MeV}$.

\section{B. Surface modification on post-annealing ZrC implanted with helium}

$\mathrm{ZrC}$ samples implanted with $\mathrm{He}$ and annealed at $\mathrm{T}_{\mathrm{a}}=1000{ }^{\circ} \mathrm{C}, 1100{ }^{\circ} \mathrm{C}, 1500{ }^{\circ} \mathrm{C} \& 1600{ }^{\circ} \mathrm{C}$ were observed under SEM. No surface changes were observed on as-implanted sample and sample annealed at $\mathrm{T}_{\mathrm{a}}=1000{ }^{\circ} \mathrm{C} \& 1100{ }^{\circ} \mathrm{C}$. However, samples annealed at $\mathrm{T}_{\mathrm{a}}=1500{ }^{\circ} \mathrm{C}$ showed large sized formation of blisters on the surface (see $6.26 \mathrm{~d} \& 6.26 \mathrm{e}$ ). 


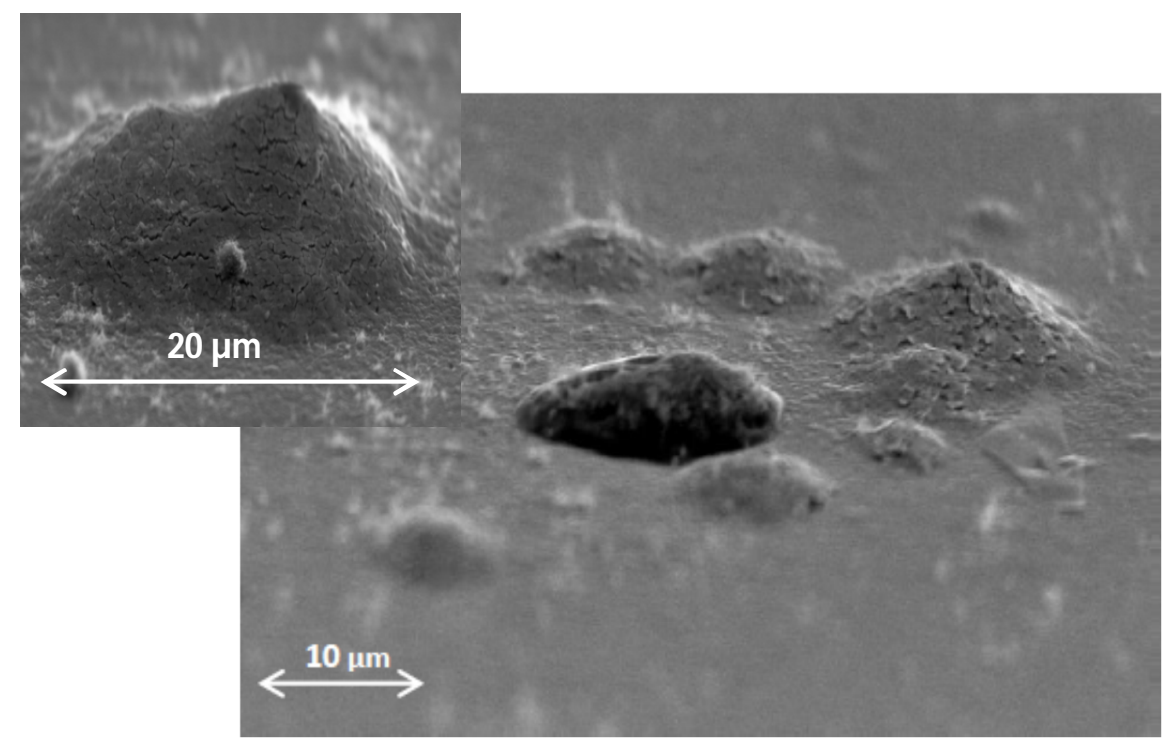

Figure 6.26d. Blister formation at the surface of $\mathrm{ZrC}$ after thermal annealing at $1500{ }^{\circ} \mathrm{C}$ observed by scanning electron microscopy. Picture on the left corner shows the zoom on a blister.

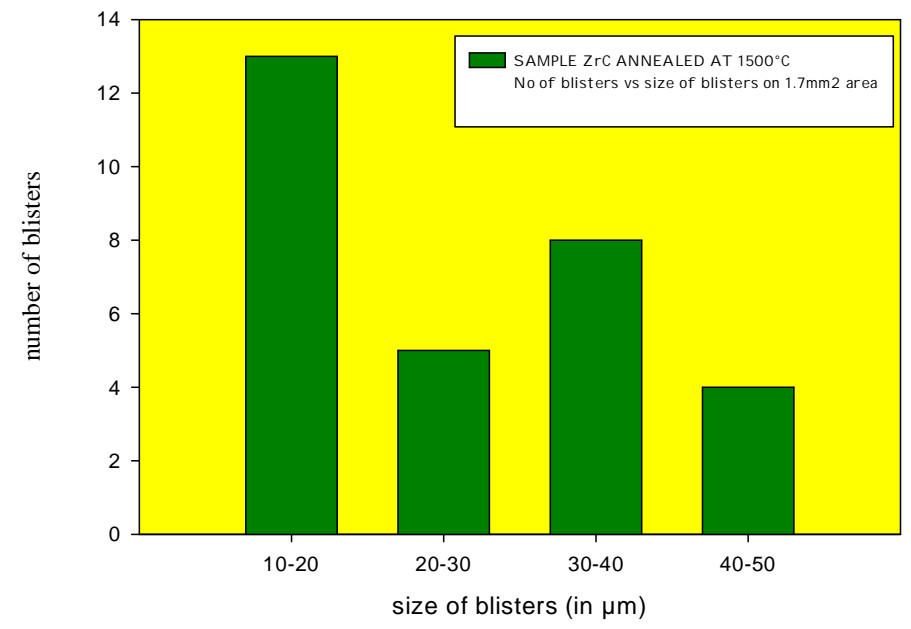

Figure 6.26e. Chart representing number of blisters and their size at the surface of ZrC after thermal annealing at $1500{ }^{\circ} \mathrm{C}$. 
The reason for blister formation was not very clear to us. However, to understand the reason behind blister formation, we did a survey on the available literature. In the next paragraph, we have quoted some important points:

Yadava and co-authors [1] clearly validates the existence of over pressurized bubbles and their coalescence to be an essential ingredient of a gas-driven blister formation mechanism. They explain that at temperatures lower than one third of the absolute melting temperature the bubbles have frequently aligned themselves in the form of superlattices having a structure identical and parallel to the host lattice. At higher temperatures (>0.35 $\mathrm{T}_{\mathrm{m}}$ ) annealing, bubble superlattices no longer exist and randomization occurs leading to a growth of lattice bubbles resulting in surface blistering. Evans [2] talks about transition from a blistered to a pinhole surface between 0.4 and 0.5 of the absolute melting point. In our case, upto $1600^{\circ} \mathrm{C}\left(0.45 \mathrm{~T}_{\mathrm{m}}\right)$ clear blisters are observed. Perhaps, blister formation at the surface of $\mathrm{ZrC}$ indicates the presence of highly pressurized He bubbles into the samples below $1500{ }^{\circ} \mathrm{C}$, which releases helium atoms from the implantation zone towards surface in order to decrease the pressure. However, TEM investigations are important to support this hypothesis.

In figure $6.26 \mathrm{c}$, helium depth profile obtained at $1600{ }^{\circ} \mathrm{C}$ is not shown, because after annealing sample at $\mathrm{T}_{\mathrm{a}}=1600^{\circ} \mathrm{C}$, surface had blisters along with the formation of oxidation layer on it. Due to this, corresponding helium depth profile obtained was shifted towards right and had distorted shape, therefore direct comparison with helium depth profiles at other temperature was not possible.

Figure 6.26f, shows the zoom over one of the blisters at $T_{a}=1600{ }^{\circ} \mathrm{C}$, covered with the oxidation layer. The chart of blister distribution at $\mathrm{T}_{\mathrm{a}}=1600{ }^{\circ} \mathrm{C}$ has not been plotted because some blister sizes were very small and only slight bump was visible due to the presence of oxidation layer on top of it. 


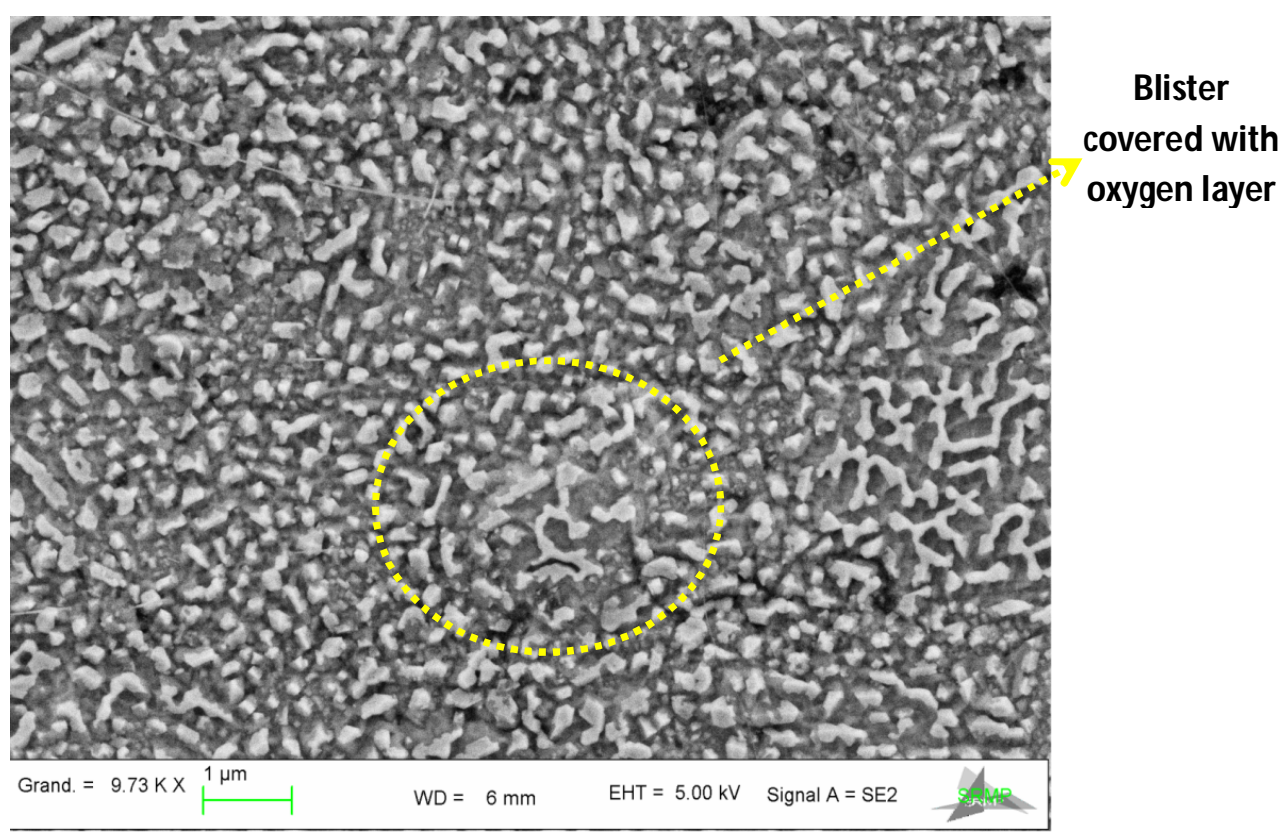

Figure 6.26f. Blister formation at the surface of $\mathrm{ZrC}$ after thermal annealing at $1600{ }^{\circ} \mathrm{C}$ observed by scanning electron microscopy.

\section{TEM OBSERVATION}

Similar to $\mathrm{TiN}$, transverse $\mathrm{FIB}$ specimen of as-implanted $\mathrm{ZrC}$ samples revealed no unambiguous evidence for visible helium bubbles. The FIB specimen of samples annealed at $\mathrm{T}_{\mathrm{a}} \geq 1100{ }^{\circ} \mathrm{C}$, showed that helium precipitates in the form of bubbles also in $\mathrm{ZrC}$. TEM micrographs showing bubbles at implantation zone at $\mathrm{T}_{\mathrm{a}}=1100^{\circ} \mathrm{C}, 1500^{\circ} \mathrm{C}$ are shown in figure 6. 27(a, b). The TEM micrographs show the growth of bubbles from $1100{ }^{\circ} \mathrm{C}$ to $1500{ }^{\circ} \mathrm{C}$.

The transverse FIB specimen also gave us the opportunity to take TEM micrographs on the transverse crossection (i.e. from the top to the bottom) of the blister. Figure 6.28a shows the interior of the blisters, there are interconnected structures (or cavities) which are present from the top to bottom of the blisters. It appears that these channels are gas-filled which are transfering helium from the implantation zone to the surface. We have also observed long tube like cavity at the interior of the grain boundary (see figure 6.28b). In most of the specimen, the tube like cavity in the grain boundary is directly linked to the channels in the blister. 

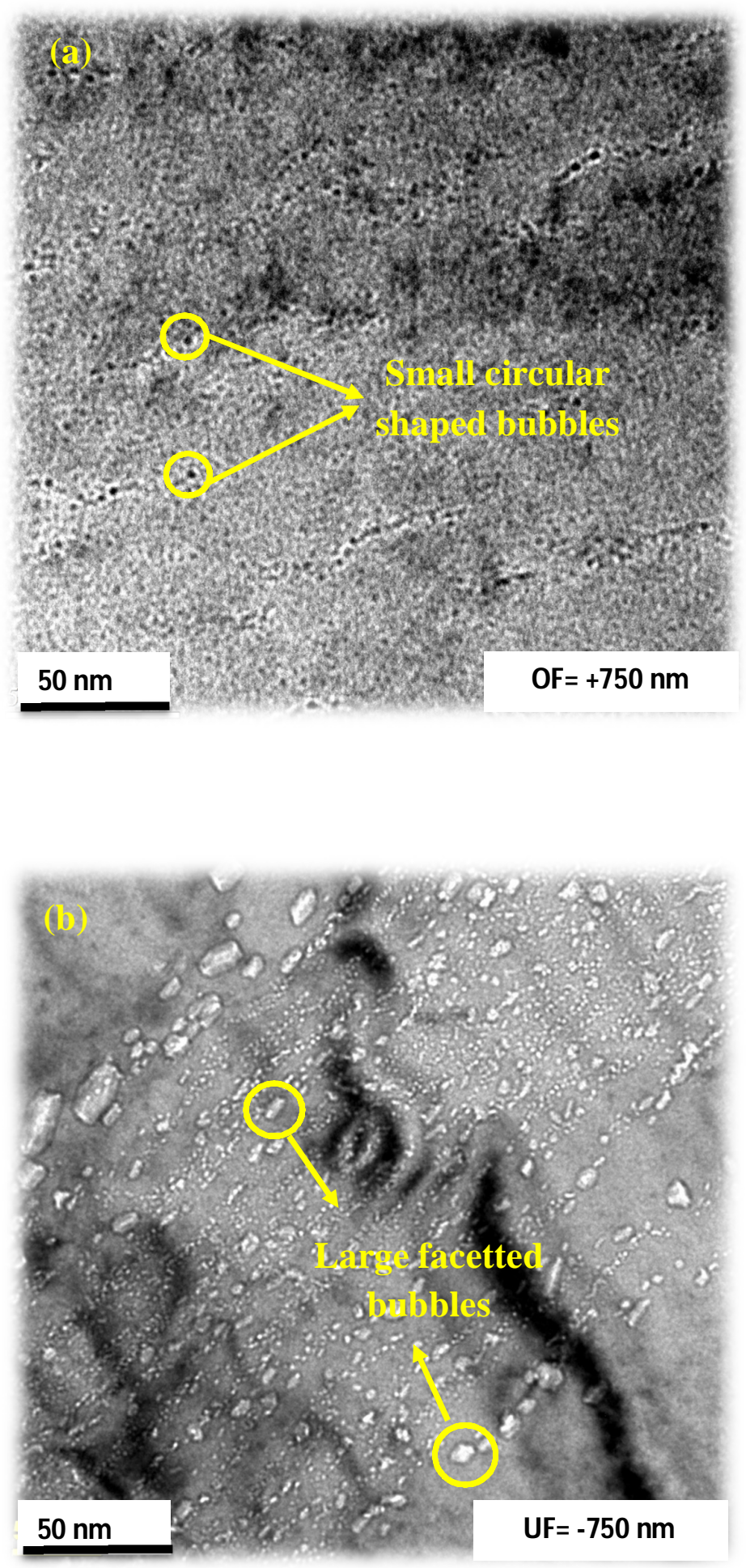

Fig. 6.27 (a) TEM micrographs of the implantation zone of $\mathrm{ZrC}$ samples implanted with fluence $F_{1}$ and annealed at (a) $T_{a}=1100{ }^{\circ} \mathrm{C}$, (b) $T_{a}=1500{ }^{\circ} \mathrm{C}$. The dark and white contrast in fig. $a \&$ $b$ represent helium bubbles in over and under focus conditions, respectively. 

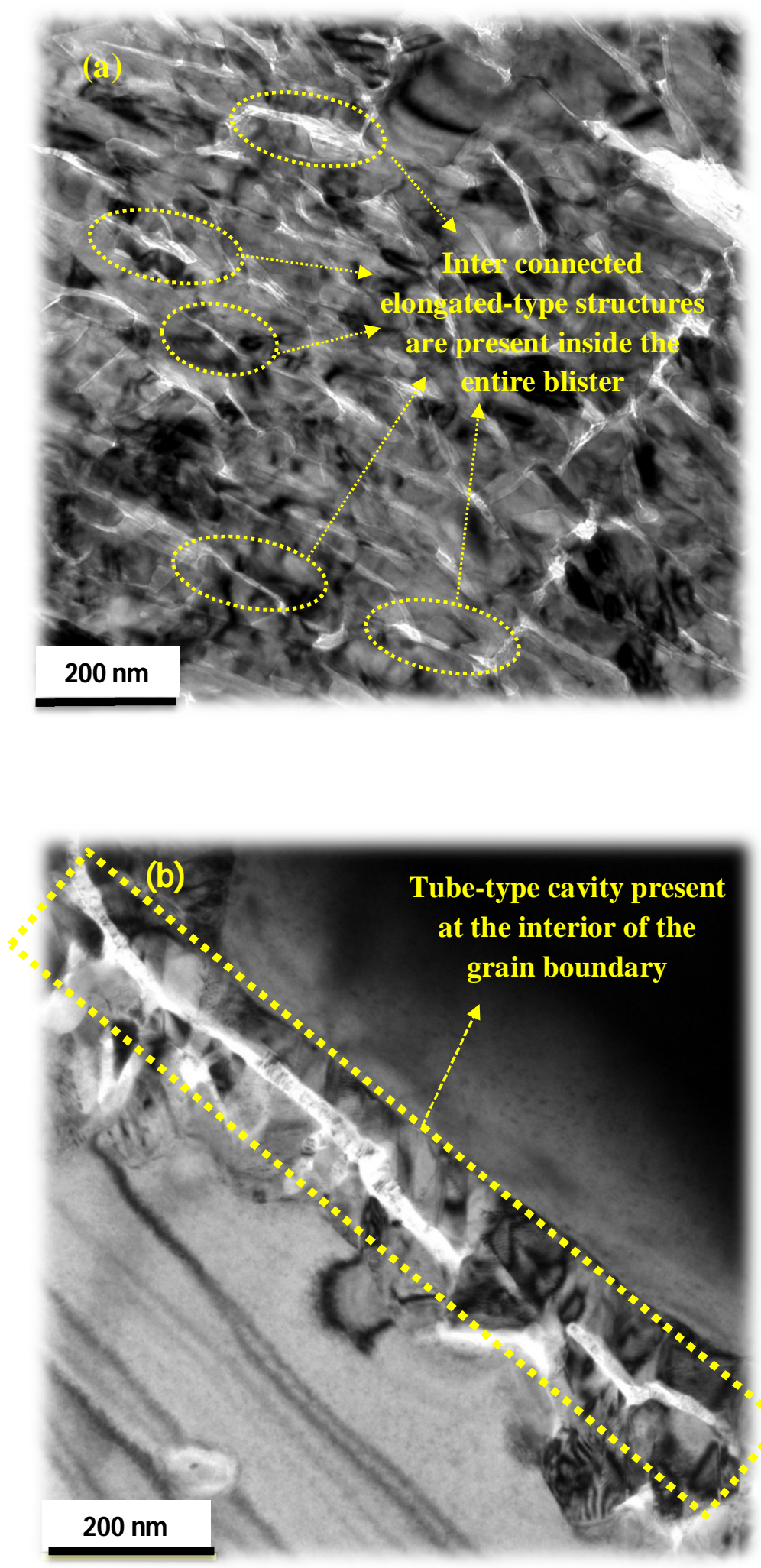

Fig. 6.28 (a) TEM micrograph taken on interior of the blister of $\mathrm{ZrC}$ samples implanted with fluence $F_{1}$ and annealed at $T_{a}=1500{ }^{\circ} \mathrm{C}$. (b) Enlongated tube shaped cavity present inside the grain boundary. 


\subsubsection{COMPARISON STUDY BETWEEN SPECIMENS IMPLANTED WITH FLUENCE F $\mathrm{F}_{1}, \mathrm{~F}_{2} \mathrm{AND}_{3}$ (Part B)}

\section{A. NUCLEAR REACTION ANALYSIS}

Excitation curves have been plotted for samples implanted with fluence $F_{2}$ and $F_{3}$, and subsequently annealed at $\mathrm{T}_{\mathrm{a}}=1100{ }^{\circ} \mathrm{C} \& 1500{ }^{\circ} \mathrm{C}$. The excitation curves are shown in figure $6.29 \mathrm{a} \& 6.29 \mathrm{~b}$, where the incident deuteron energy varies from $1 \mathrm{MeV}$ to $1.8 \mathrm{MeV}$. Similar to $F_{1}$ fluence, the maximum of excitation curves was found at $1.3 \mathrm{MeV}$ deuteron energy and helium depth profiles are extracted from the proton energy spectrum obtained at $\mathrm{E}_{\mathrm{D}}=1.3 \mathrm{MeV}$.

The most remarkable result that we obtained from figure $6.29 \mathrm{a} \& 6.29 \mathrm{~b}$ for $\mathrm{ZrC}$ are similar to the results obtained for TiN and are as follows: if we compare the excitation curves for fluence $F_{2}$ and $F_{3}$ and also with fluence $F_{1}$ (fig. 6.26a). We found that at $T_{a}=1100{ }^{\circ} \mathrm{C}$, the excitation curve for $F_{1}, F_{2} \& F_{3}$ superimpose on their corresponding as-implanted excitation curves within the measurement errors. At $\mathrm{T}_{\mathrm{a}}=1500^{\circ} \mathrm{C}$, the excitation curves (or proton count) corresponding to $F_{1} \& F_{2}$ fluence have shifted downwards suggesting helium loss. However for lower value of fluence $\mathrm{F}_{3}$, the excitation curves at $\mathrm{T}_{\mathrm{a}}=1500^{\circ} \mathrm{C}$ does not shift downwards and indicates zero loss of helium. 


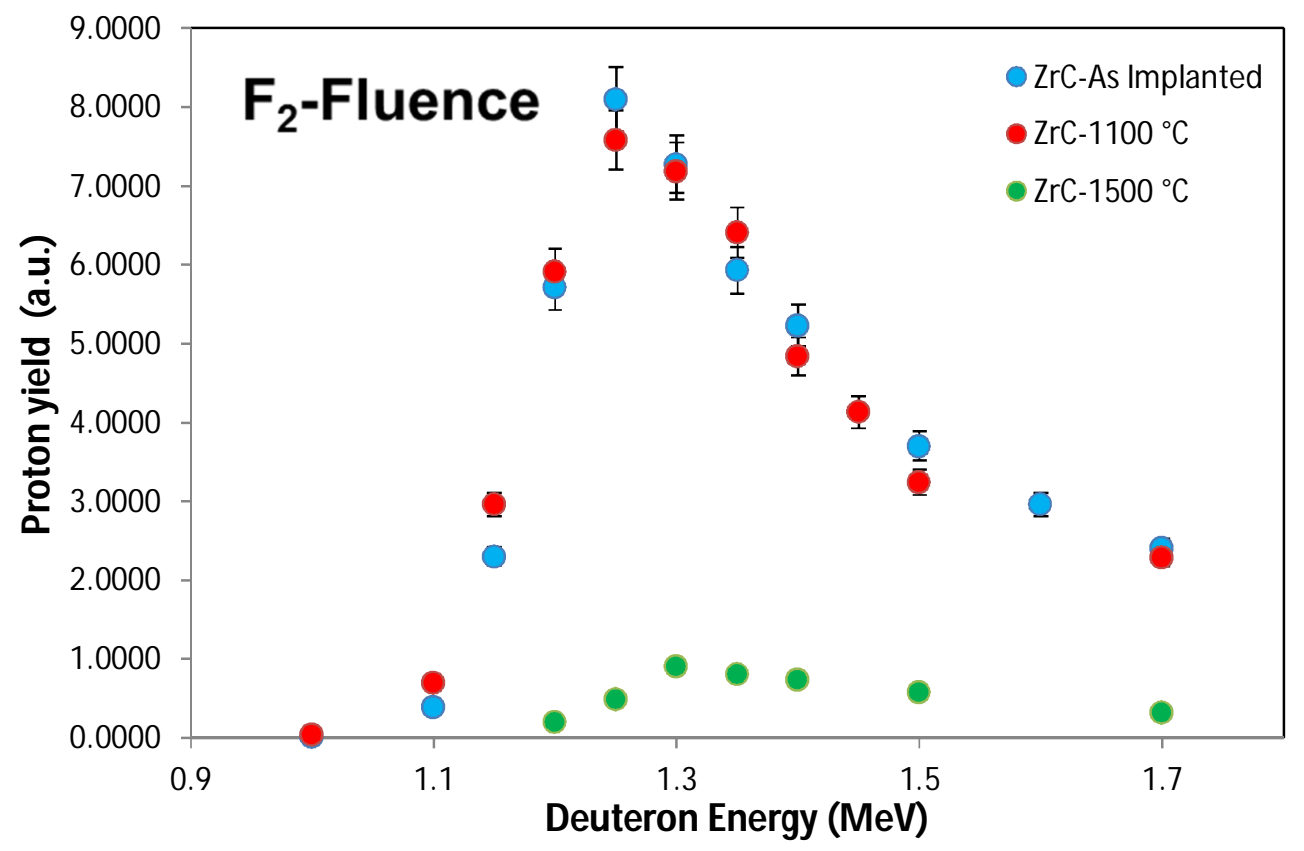

Figure 6.29a. Excitation curves (proton yield versus incident deuteron energy) measured for as-implanted and annealed $\mathrm{ZrC}$ samples corresponding to $F_{2}$ fluence.

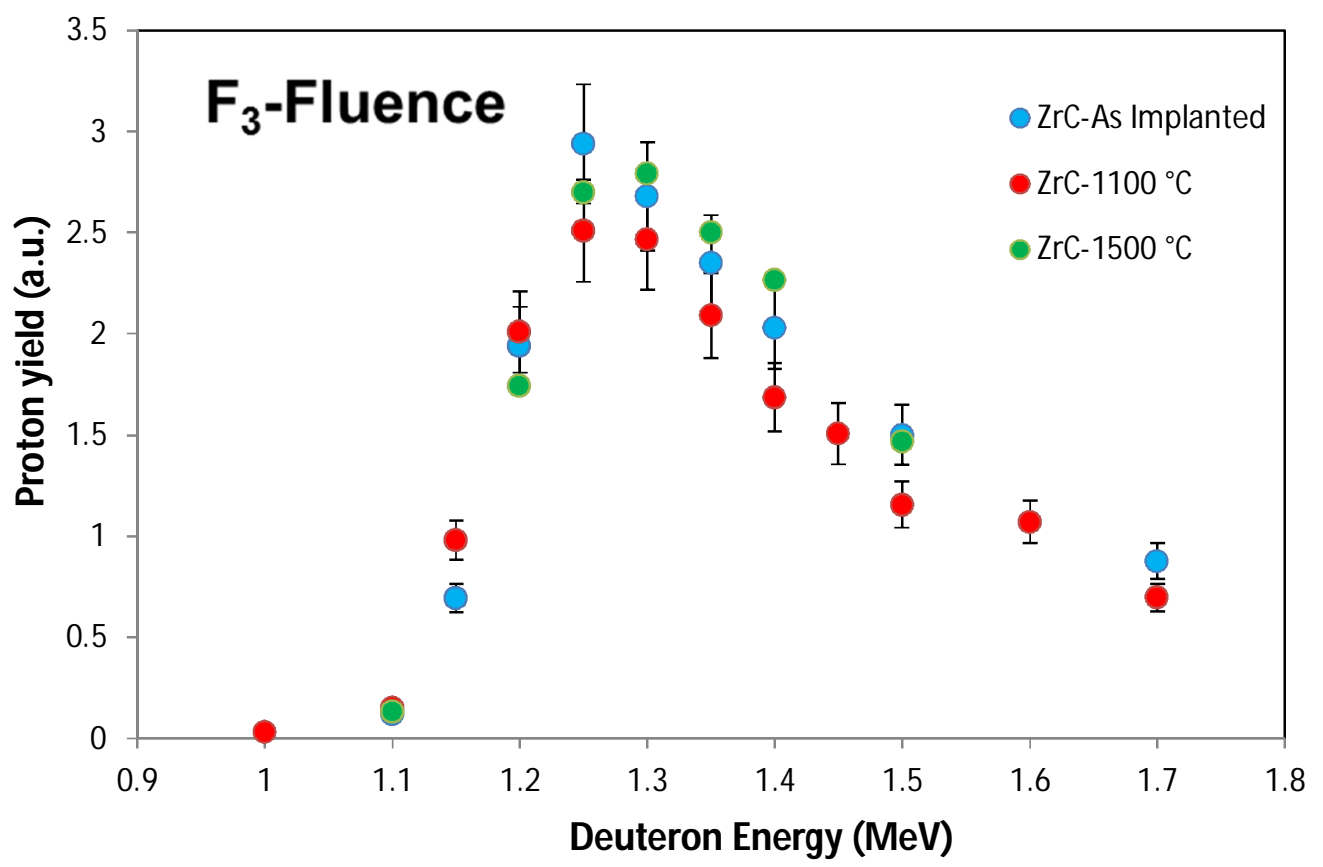

Figure 6.29b. Excitation curves (proton yield versus incident deuteron energy) measured for as-implanted and annealed $\mathrm{ZrC}$ samples corresponding to $F_{3}$ fluence. 
To investigate further, the comparison of helium depth profiles obtained for fluence $F_{1}, F_{2}$ and $\mathrm{F}_{3}$ at $\mathrm{T}_{\mathrm{a}}=1100{ }^{\circ} \mathrm{C} \& 1500{ }^{\circ} \mathrm{C}$ with their corresponding as-implanted profile has been done. As it has been already mentioned, this comparison (in terms of height and FWHM) gives the information on helium loss and on range of migration of He-V clusters.

\section{$\underline{\text { At } \mathbf{T}_{\mathrm{a}}=\mathbf{1 1 0 0}{ }^{\circ} \mathrm{C}:}$}

For all fluence values $\boldsymbol{F}_{1}, \boldsymbol{F}_{2} \& \boldsymbol{F}_{3}$, the helium distribution obtained from NRA (see fig. 6.30a), superimposed (with in the error bars) on their respective helium distributions from as-implanted sample.

\section{$\underline{\operatorname{At} T_{a}=1500{ }^{\circ} \mathbf{C}:}$}

For high fluence values $\boldsymbol{F}_{1}$ and $\boldsymbol{F}_{2}$, instead of broadening (or lateral spreading), there is a shrinkage in helium depth profile and also total area under curve does not remain constant, hence it confirms helium release (see fig. 6.30b). Surface blisters have been observed for sample implanted with $\mathrm{F}_{2}$ fluence as well.

However, for low fluence value $\boldsymbol{F}_{3}$, no change in helium depth profile was observed and it completely superimposed on its corresponding as-implanted helium depth profile.

The two most important points corresponding to $\mathrm{T}_{\mathrm{a}}=1500{ }^{\circ} \mathrm{C}$ are:

- Firstly, helium release occurs only for samples implanted with high fluence values $F_{1}$ and $F_{2}$. This release has been accompanied with the formation of blisters at the surface. This helium loss can be due to the formation of highly pressurized helium bubbles at $\mathrm{T}_{\mathrm{a}}<1500{ }^{\circ} \mathrm{C}$. For the samples implanted with low concentration of helium, neither the blisters are formed, nor has helium released.

- Secondly, positioning of helium atoms at $\mathrm{T}_{\mathrm{a}}=1500{ }^{\circ} \mathrm{C}$, has not changed in $\mathrm{ZrC}$ corresponding to all three helium fluence values. It appears that due to large number of native vacancies in $\mathrm{ZrC}$, the size of bubbles (or He-V clusters) is large and has less mobility. 


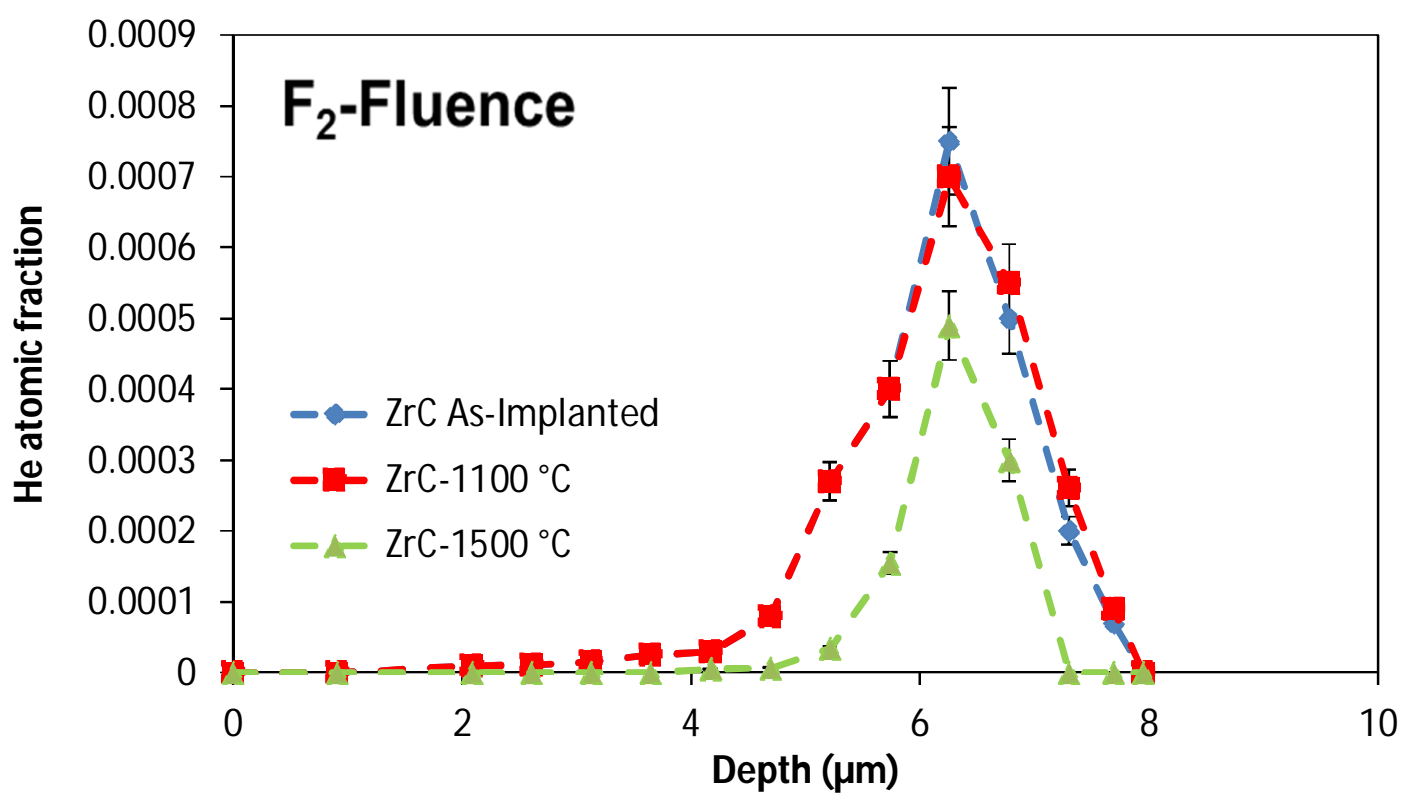

Figure 6.30a. Helium depth profiles obtained from nuclear reaction analysis for samples implanted with fluence $F_{2}$ and annealed at $T_{a}=1100{ }^{\circ} \mathrm{C} \& 1500{ }^{\circ} \mathrm{C}$. The dotted lines are to guide the eyes. These profiles have been obtained by SIMNRA code correspoing to $E_{d}=1.3$ $\mathrm{MeV}$.

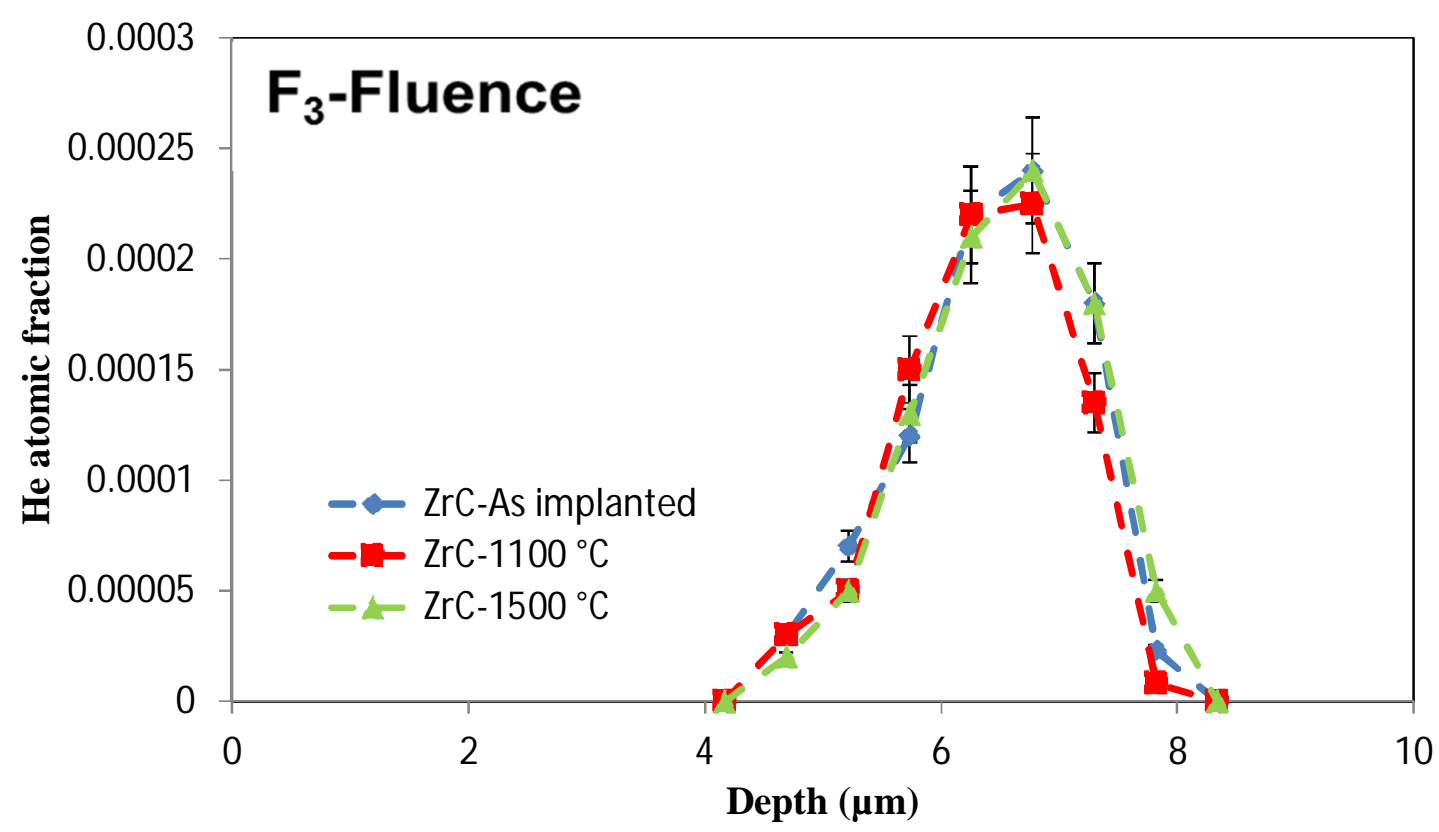

Figure 6.30b. Helium depth profiles obtained from nuclear reaction analysis for samples implanted with fluence $F_{3}$ and annealed at $T_{a}=1100{ }^{\circ} \mathrm{C} \& 1500{ }^{\circ} \mathrm{C}$. The dotted lines are to guide the eyes. These profiles have been obtained by SIMNRA code correspoing to $E_{d}=1.3$ $\mathrm{MeV}$. 


\subsubsection{Conclusion}

\section{$\underline{\text { Part A }}$}

- The helium lost fraction (f) versus $\mathrm{T}_{\mathrm{a}}$ have been fitted by $1^{\text {st }}$ order kinetic law and the activation energy of helium release was obtained and is equal to $\Delta \mathrm{H}=(0.77 \pm 0.08) \mathrm{eV}$.

- At $\mathrm{T}_{\mathrm{a}}=1500{ }^{\circ} \mathrm{C}$, instead of broadening (or lateral spreading), there is a shrinkage in the helium depth profile which is accompanied with helium release. It appears that helium is not mobile and is trapped in the form large $\mathrm{He}-\mathrm{V}$ clusters. Large number of vacancies in $\mathrm{ZrC}\left(\mathrm{ZrC}_{\mathrm{x}}\right.$, $\mathrm{x}=0.92 \pm 0.02$ ) seems to be responsible for large clusters. However, this is just a hypothesis, which needs to be confirmed by TEM.

- $\mathrm{ZrC}$ samples annealed at $\mathrm{T}_{\mathrm{a}}=1500{ }^{\circ} \mathrm{C}$ showed large sized formation of blisters on the surface. TEM micrographs shows the gas filled channels inside the blisters.

\section{$\underline{\text { Part B }}$}

- The role of implantation fluence on helium mobility in $\mathrm{ZrC}$ is similar to $\mathrm{TiN}$. We observed that the samples implanted with less quantity of helium $\left(\mathrm{F}_{3}\right)$ did not show helium release. However, under same annealing conditions (at $\mathrm{T}_{\mathrm{a}}=1500{ }^{\circ} \mathrm{C}$ ), the samples implanted with higher quantity of helium $\left(F_{1} \& F_{2}\right)$ showed helium release.

- For $\mathrm{ZrC}$, we did not observe broadening of helium depth profile for the samples implanted with less quantity of helium $\left(\mathrm{F}_{3}\right)$ as in TiN, when annealed at higher temperature equal to 1500 ${ }^{\circ} \mathrm{C}$.

\section{References}

[1] R.D. Yadava, J. Nucl. Mater. 98 (1981) 47-62.

[2] J.H. Evans, J. Nucl. Mater. 61 (1976) 1-7. 


\section{Chapter 7}

\section{Helium behavior under radiation environment}

In this chapter, important findings on 'helium behavior in transition metal ceramics under radiation environment' would be presented. As it has been previously mentioned, only $15 \%$ of time was devoted to conduct experiments and investigate important points on this part of the thesis.

\subsection{Reminder of experimental approach}

Damaging the material by self-ion implantation

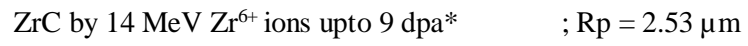

TiC by $14 \mathrm{MeV} \mathrm{Ti}{ }^{6+}$ ions upto $9 \mathrm{dpa} \& 27 \mathrm{dpa} ; \mathrm{Rp}=2.83 \mu \mathrm{m}$ TiN by $14 \mathrm{MeV} \mathrm{Ti}^{6+}$ ions upto $9 \mathrm{dpa} \& 27 \mathrm{dpa} ; \mathrm{Rp}=2.66 \mu \mathrm{m}$

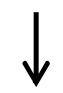

Sample characterization

after radiation damage

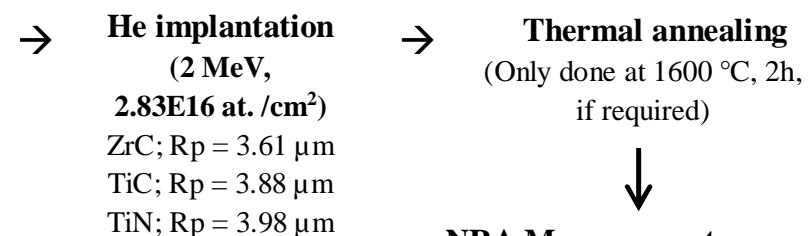

NRA Measurement

* All values of dpa have been calculated by SRIM using Full Damage Cascade option.

\subsection{Results and Discussion}

\subsubsection{Results of sample characterization after damaging the samples by their self-ions}

\section{A. Hardness measurements}

Nanoindentation techniques were used to measure the hardness induced in the samples after implantation of $14 \mathrm{MeV} \mathrm{Ti}^{6+}$ ions into $\mathrm{TiN} \& \mathrm{TiC}$ and $\mathrm{Zr}^{6+}$ ions into $\mathrm{ZrC}$ respectively. Before damaging the samples, the hardness varied in the following manner: $\mathbf{T i C}>\mathbf{Z r C}>\mathbf{T i N}$. After damaging the samples at $9 \mathrm{dpa}$, the hardness varied in the same manner with $\mathrm{TiC}$ being 
the hardest, followed by $\mathrm{ZrC}$ and $\mathrm{TiN}$ i.e. $\mathbf{T i C}>\mathbf{Z r C}>\mathbf{T i N}$. The hardness have been measured in the first micrometer of the sample from the surface.

At $27 \mathrm{dpa}$, the hardness measurement followed the same trend with $\mathrm{TiC}>\mathrm{TiN}$, however we could not predict the behavior of $\mathrm{ZrC}$ due to large experimental time required to damage $\mathrm{ZrC}$ at $27 \mathrm{dpa}$. Figure 7.1 shows the penetration depth versus loading for $\mathrm{TiN}, \mathrm{ZrC}$ and $\mathrm{TiC}$ damaged at 9 dpa.

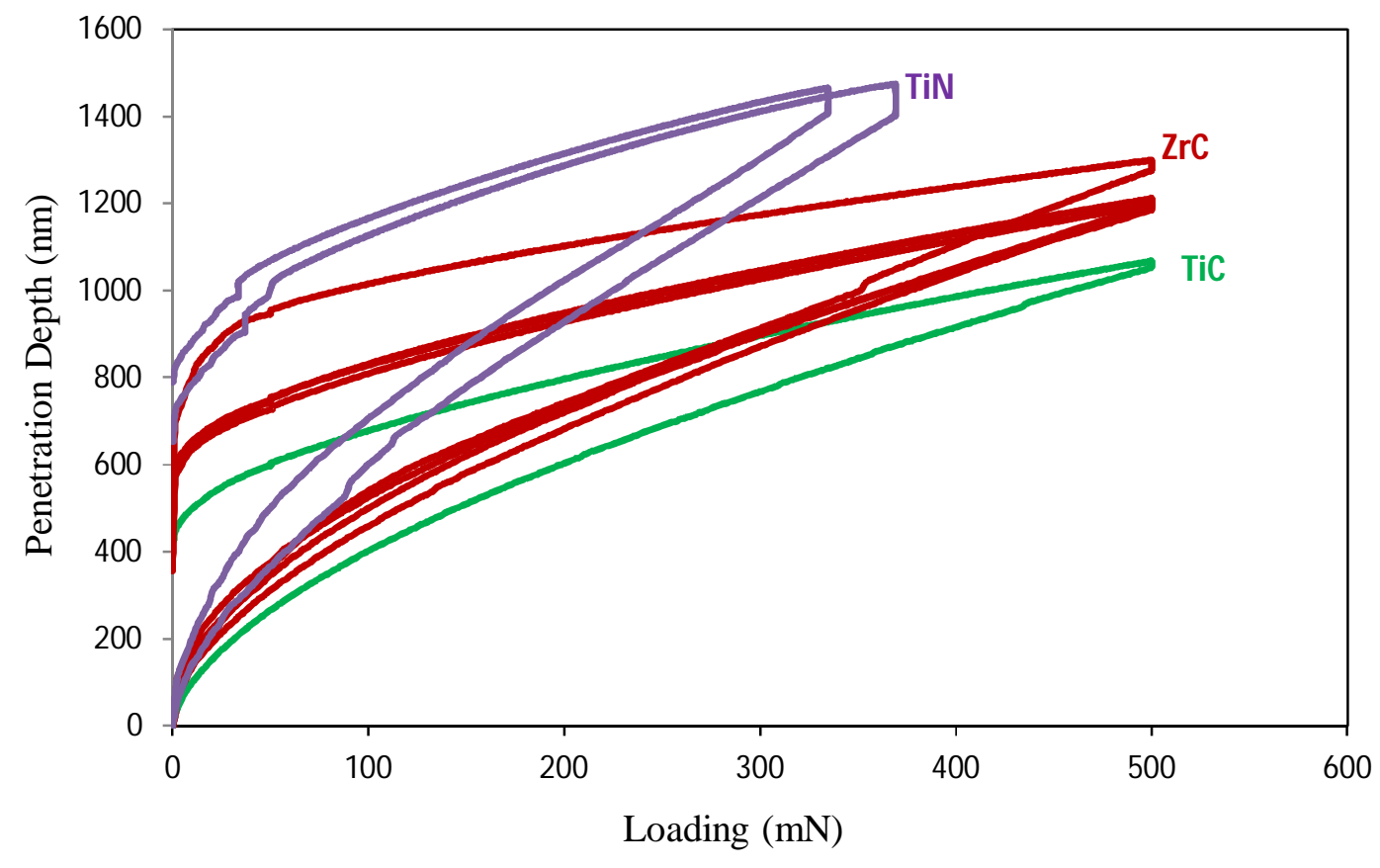

Figure 7.1. The plot of hardness measurement (penetration depth versus loading) for TiN, $\mathrm{ZrC}$ and TiC damaged at 9 dpa.

It is important to recall that during hardness measurement, the more the needle penetrates, lesser is the hardness measured. Figure 7.1 shows the cyclic loading for different materials and we can clearly observe that during loading needle penetrates most in TiN and least in TiC. This means $\mathrm{TiC}$ is hardest among all the investigated materials and does not allow deep penetration into its matrix as compared to other two materials.

We also revealed that the hardness of the transition metal ceramics $\mathrm{TiC}, \mathrm{ZrC}$ and $\mathrm{TiN}$ does not increase linearly with fluence. The hardness 'increases and then decreases' with the increase 
of fluence (see figure 7.2). For example in case of $\mathrm{TiC}$, TiC damaged at 9 dpa exhibit more hardness than TiC damaged at $27 \mathrm{dpa}$. Similar behavior has been observed for TiN. Additional fluence values must be investigated in order to localize the position of the maxima in the hardness curve. Due to only single point available for $\mathrm{ZrC}$ at $9 \mathrm{dpa}$, the hardness versus damage curve for $\mathrm{ZrC}$ has not been presented here.

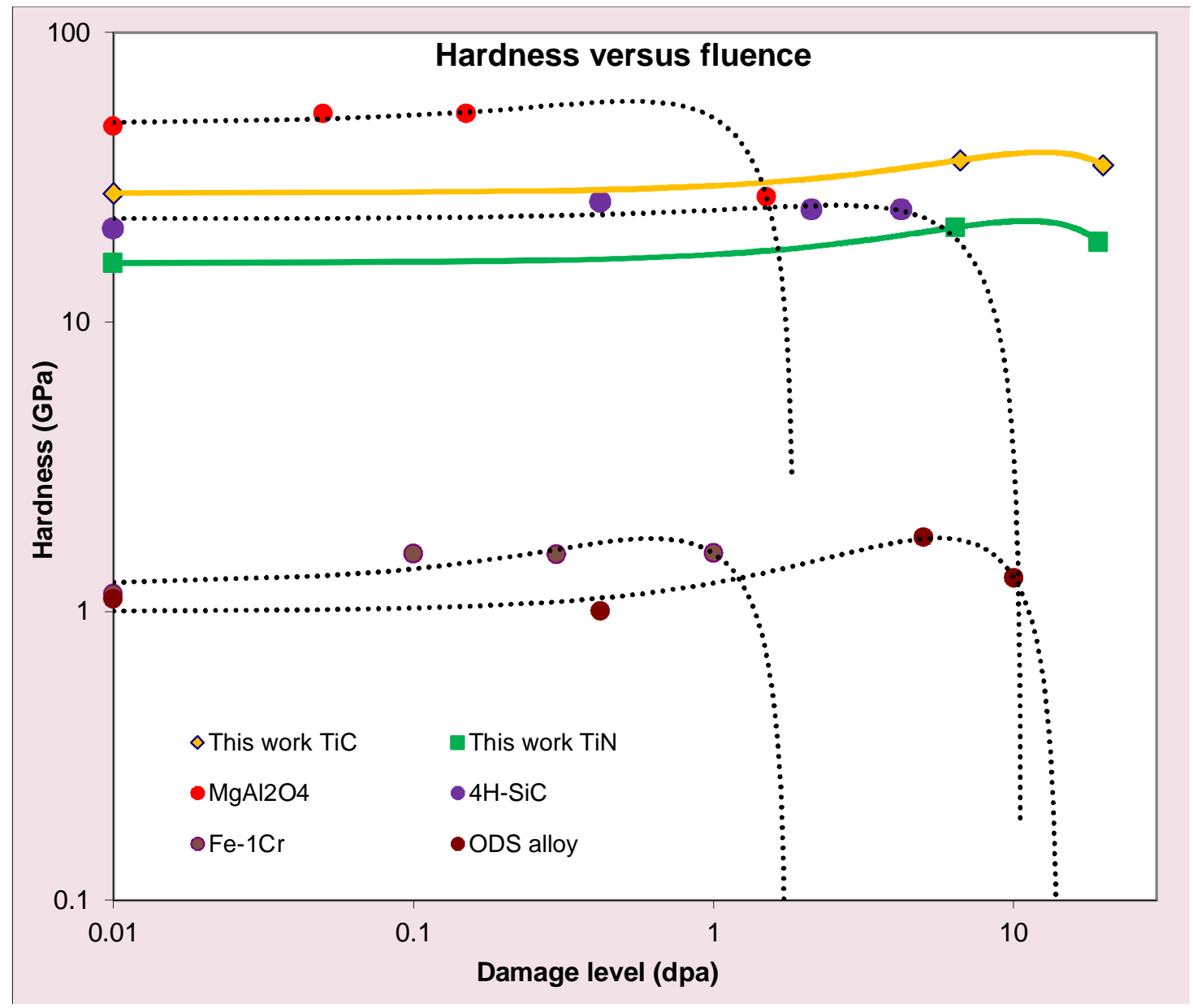

Figure 7.2. The plot of hardness versus dpa for TiC \& TiN (this work) in comparison with other materials from literature. The full and dotted lines are guide to the eyes.

\section{B. X-Ray diffraction investigations}

The lattice swelling was calculated for $\mathrm{TiC}$ and $\mathrm{ZrC}$ after implantation of $14 \mathrm{MeV} \mathrm{Ti}^{6+}$ ions or $\mathrm{Zr}^{6+}$ ions respectively by using $\mathrm{X}$-ray diffraction. X-ray diffraction experiments were performed 
at grazing incidences $\left(2\right.$ and then $\left.1^{\circ}\right)$ on virgin and damaged $\mathrm{TiC}, \mathrm{ZrC}$ at $9 \& 27 \mathrm{dpa}$. The diffraction diagrams were recorded at an ambient temperature with step size of $0.1^{\circ}$ from $20^{\circ}$ to $100^{\circ}$ in $2 \theta$ angle.

Figure 7.3 shows the comparison of the X-ray diffractograms obtained for a virgin and damaged TiC samples.

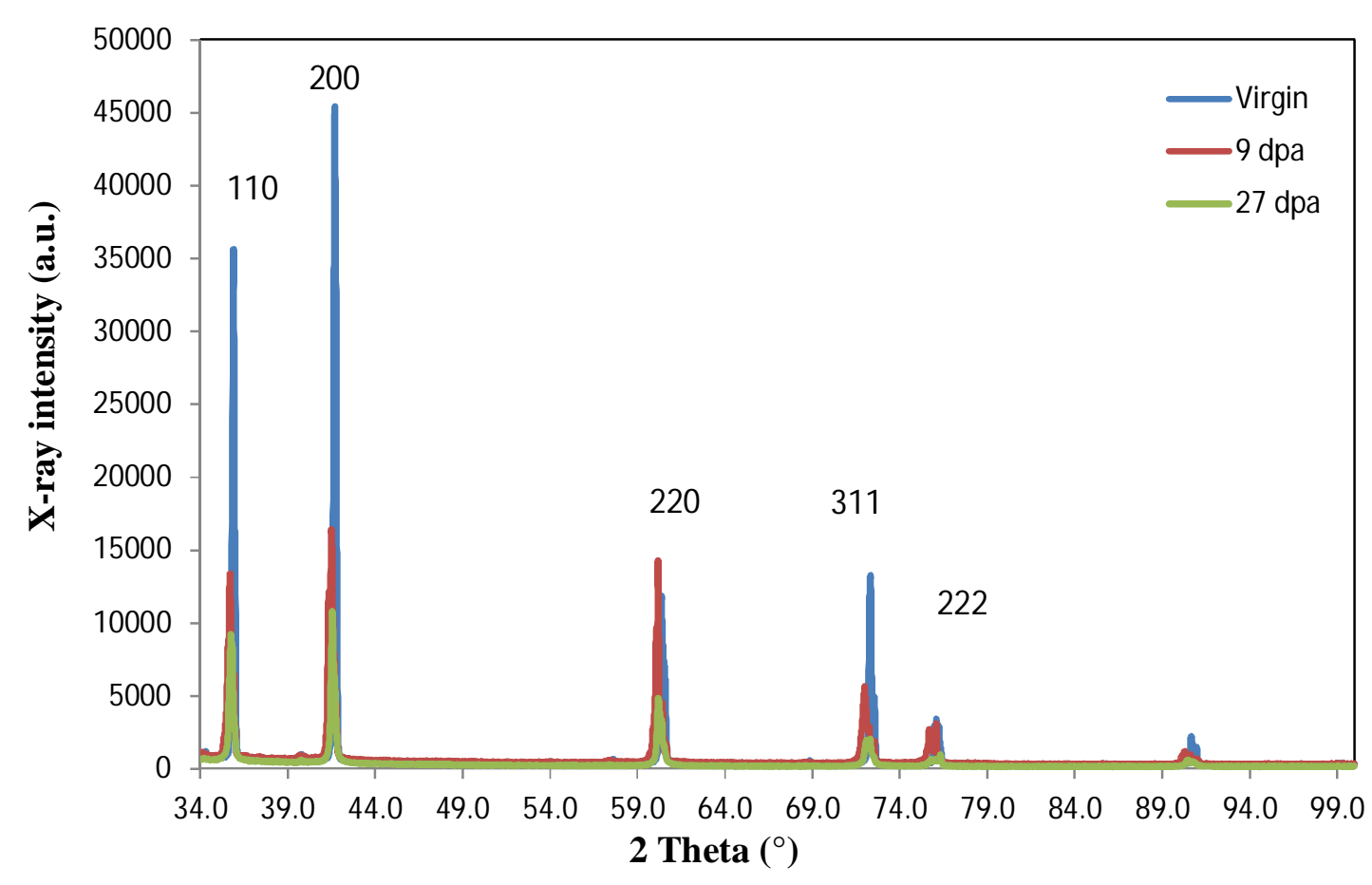

Figure 7.3. Comparison of the X-ray diffractograms obtained for a virgin and damaged TiC sample at 9 and 27 dpa.

Figure 7.4 shows the zoom on two peaks [110] and [200] of the diffractogram shown in figure 7.3 The peak position of the sample damaged at 9 dpa and $27 \mathrm{dpa}$ is little shifted towards left (towards decreasing $2 \theta$ values). To satisfy the condition of Bragg's law for constructive interference, normally if the value of $\theta$ decreases, the value of $\mathrm{d}$ increases $(n \lambda=2 d \sin \theta)$. Therefore, the shift in the peak position of damaged sample towards $\theta$ indicates lattice expansion. However, precise information on lattice expansion can be calculated by using a mathematical formula which has been previously mentioned in chapter 4 . 


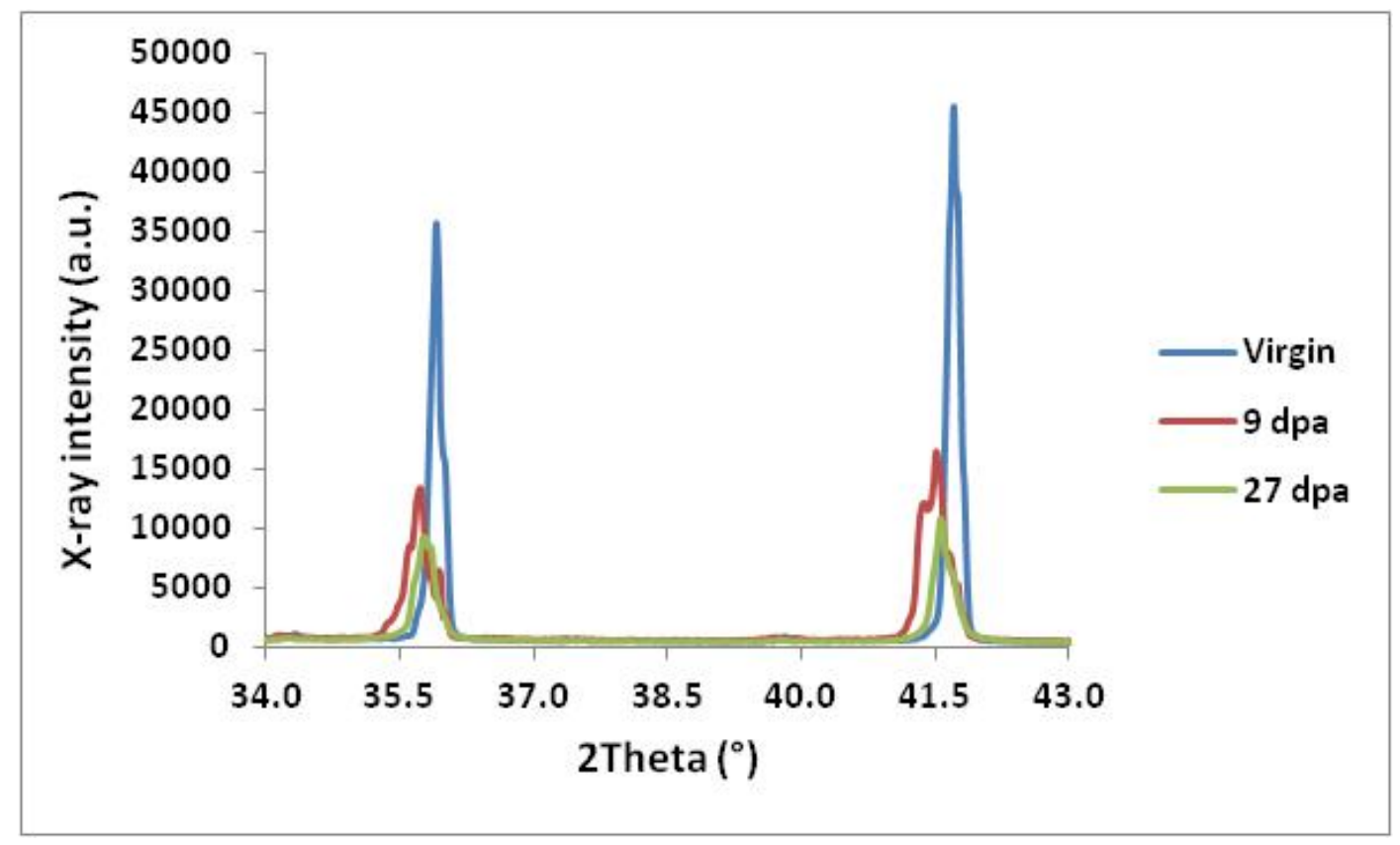

Figure 7.4. Zoom on both [110] and [200] peaks of the diffractogram. Comparison of the Xray diffractograms obtained for a virgin and damaged TiC sample at 9 and 27 dpa.

The difference between TiC samples damaged with 9 dpa \& 27 dpa is not significant in terms of change in $\theta$. Therefore, the difference in swelling between TiC sample damaged at 9 and 27 dpa could not be calculated. However, with the increase in dpa, the intensity of the damaged peak seems to decrease. It is possible that on further increasing the damage value (or dpa), these peaks completely disappear.

Similar curves were obtained for $\mathrm{ZrC}$. Table 7.1 presents the lattice parameter obtained for $\mathrm{TiC}$ and $\mathrm{ZrC}$. The lattice parameter expansion after radiation damage in terms of percentage has also been expressed in table 7.1. 


\begin{tabular}{|l|c|c|}
\hline & TiC & $\mathbf{Z r C}$ \\
\hline Lattice Parameter $(\AA)$ at 0 dpa & $\mathrm{a}=4.3300$ & $\mathrm{a}=4.6938$ \\
\hline Lattice Parameter $(\AA)$ at 9 dpa & $\mathrm{a}=4.3447$ & $\mathrm{a}=4.7064$ \\
\hline Change in lattice parameter & $\Delta \mathrm{a}=0.0146$ & $\Delta \mathrm{a}=0.0126$ \\
\hline Lattice expansion at 9 dpa & $0.34 \%$ & $0.27 \%$ \\
\hline
\end{tabular}

Table 7.1. The calculation of lattice expansion for $\mathrm{TiC}$ and $\mathrm{ZrC}$ after radiation damage.

\subsubsection{Results of NRA measurement}

After damaging the samples by self-ions, helium atoms were implanted at the distance of $\sim 1$ $\mu \mathrm{m}$ (towards the sample depth) from the damage zone to observe 'how damage (or vacancies) created by self-ions affect the mobility of helium'. We have also annealed the pre-damaged helium implanted samples at $1600{ }^{\circ} \mathrm{C}$ for $2 \mathrm{~h}$ to investigate the combine effect of thermal and radiation damage. To observe this, nuclear reaction analysis was carried out to know the position and quantity of helium atoms into pre-damaged samples.

The classical approach was followed during NRA experiments. The excitation curve were plotted for non-damaged samples implanted with helium in order to compare with pre-damaged samples implanted with helium atoms. It is important to mention, due to large experimental time required to obtain complete excitation curves, sometimes only single deuteron energy method (SDEM) was applied to obtain helium loss.

\section{A. Results of NRA measurement: TiN}

The excitation curves have been plotted for TiN implanted with $2 \mathrm{MeV}$ helium, TiN (predamaged with self-ions and implanted with helium), TiN (pre-damaged with self-ions, implanted with helium and annealed at $\left.1600{ }^{\circ} \mathrm{C}\right)$. The energy of deuteron $\left(\mathrm{E}_{\mathrm{d}}\right)$ was varied between $0.7 \mathrm{MeV}$ to $1.4 \mathrm{MeV}$.

If we carefully notice figure 7.5, the excitation curve for TiN implanted with $2 \mathrm{MeV}$ helium and TiN (pre-damaged with self-ions and implanted with helium) superimposed on each other with in the measurement errors. It suggests that proton count received from damaged and non- 
damaged sample implanted with helium do not change. Hence, radiation damage up to 9 dpa does not induce any change in helium retention behavior of the material. However, when these pre-damaged helium implanted TiN samples were annealed at $1600{ }^{\circ} \mathrm{C}$, there was $21 \%$ loss of helium. It is important to mention that we cannot compare this $21 \%$ loss with the study mention in previous chapter due to the difference in the value of helium implantation fluence and range.

The experiments on the samples damaged at $27 \mathrm{dpa}$ are planned in near future.

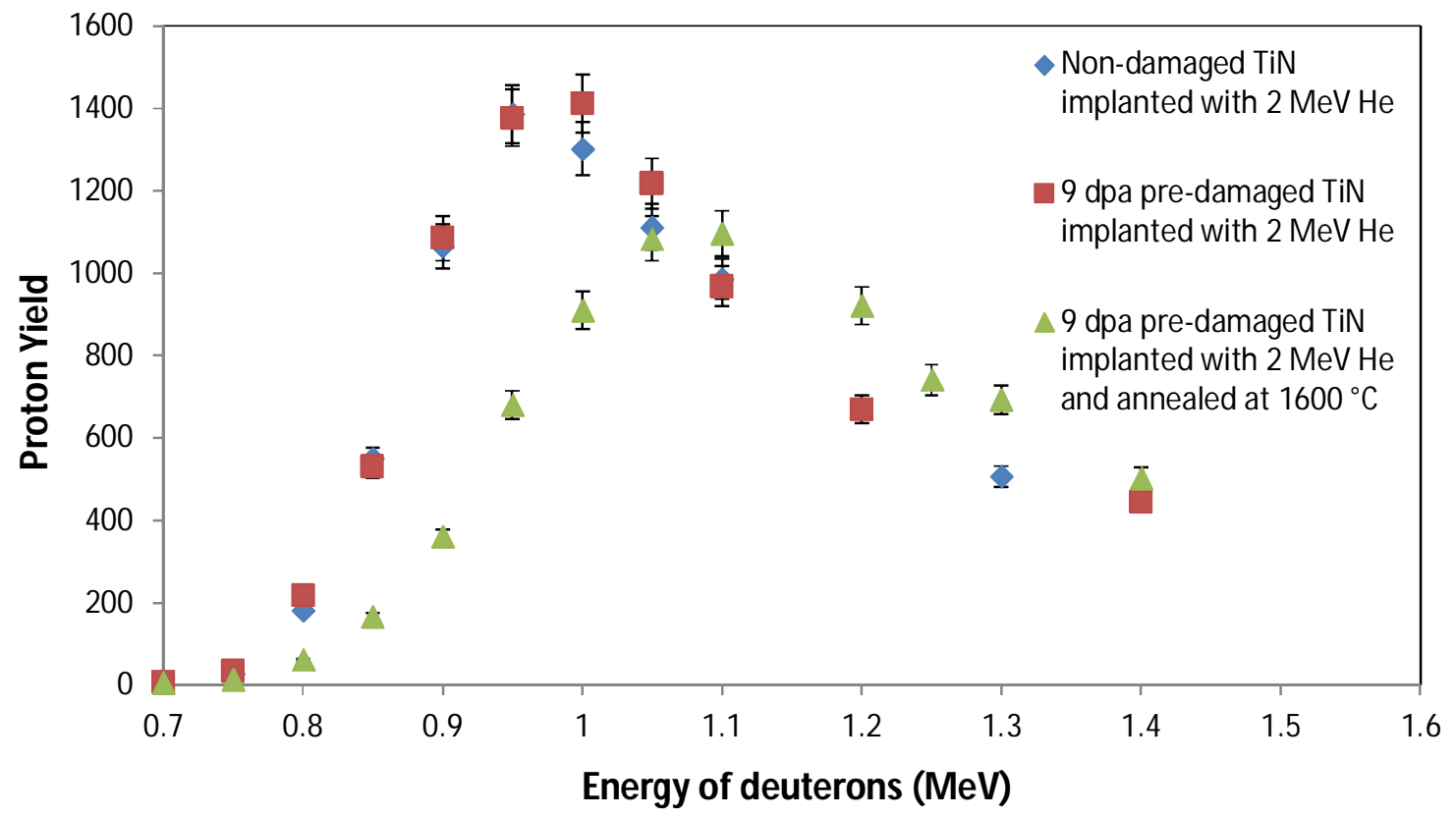

Figure 7.5. Excitation curves for TiN implanted with $2 \mathrm{MeV}$ helium, TiN (pre-damaged with self-ions and implanted with helium), TiN (pre-damaged with self-ions, implanted with helium and annealed at $1600^{\circ} \mathrm{C}$ ). 


\section{B. Results of NRA measurement: ZrC}

Due to large experimental time required to do analysis by excitation curve method approach, only single deuteron energy method (SDEM) was applied for NRA measurements for $\mathrm{ZrC}$. Figure 7.6 shows proton spectra obtained for deuteron energy $E_{d}=1 \mathrm{MeV}$ for $\mathrm{ZrC}$ implanted with $2 \mathrm{MeV}$ helium, $\mathrm{ZrC}$ (pre-damaged with self-ions and implanted with $2 \mathrm{MeV}$ helium), $\mathrm{ZrC}$ (pre-damaged with self-ions, implanted with helium and annealed at $1600{ }^{\circ} \mathrm{C}$ ).

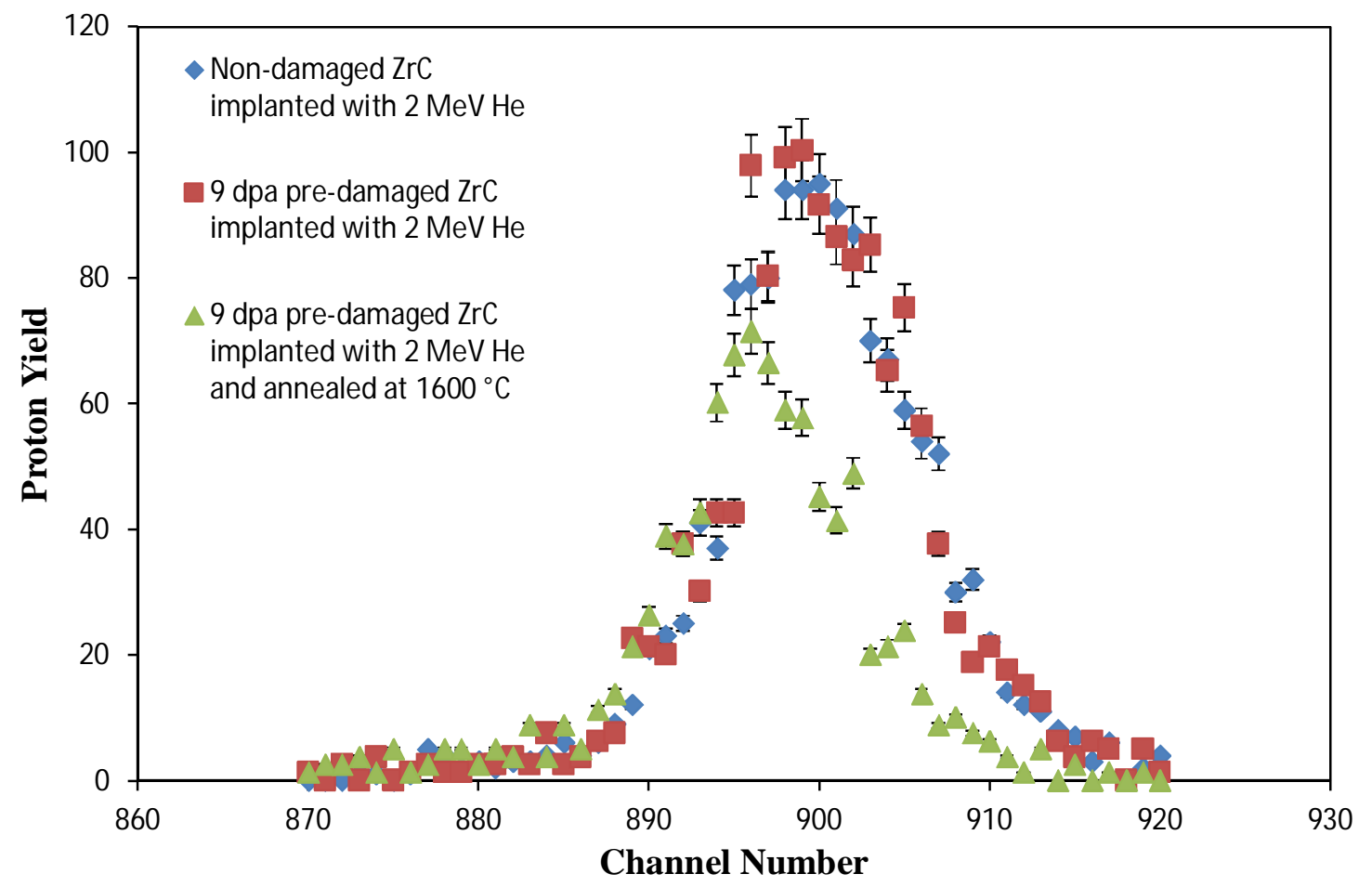

Figure 7.6. Proton spectra obtained for deuteron energy $E_{d}=1 \mathrm{MeV}$ for $\mathrm{ZrC}$ implanted with 2 $\mathrm{MeV}$ helium, $\mathrm{ZrC}$ (pre-damaged with self-ions and implanted with helium), $\mathrm{ZrC}$ (pre-damaged with self-ions, implanted with helium and annealed at $1600{ }^{\circ} \mathrm{C}$ ).

From the spectras plotted in figure 7.6, helium loss was calculated. It is evident from figure 7.6 that pre-damaging samples at 9 dpa does not induce any loss of helium atoms, however after annealing pre-damaged samples to $1600{ }^{\circ} \mathrm{C}$, about $33 \%$ of helium has been lost from the sample. 


\section{Results of NRA measurement: TiC}

Single deuteron energy method was also applied for measurements for TiC. Similar to TiN \& $\mathrm{ZrC}$, the quantity of helium retained in the pre-damaged sample and non-damaged sample was equal within the error bars. However after annealing at $1600{ }^{\circ} \mathrm{C}$, there was $38 \%$ of helium loss from the sample. The spectras corresponding to these observations are shown in figure 7.7.

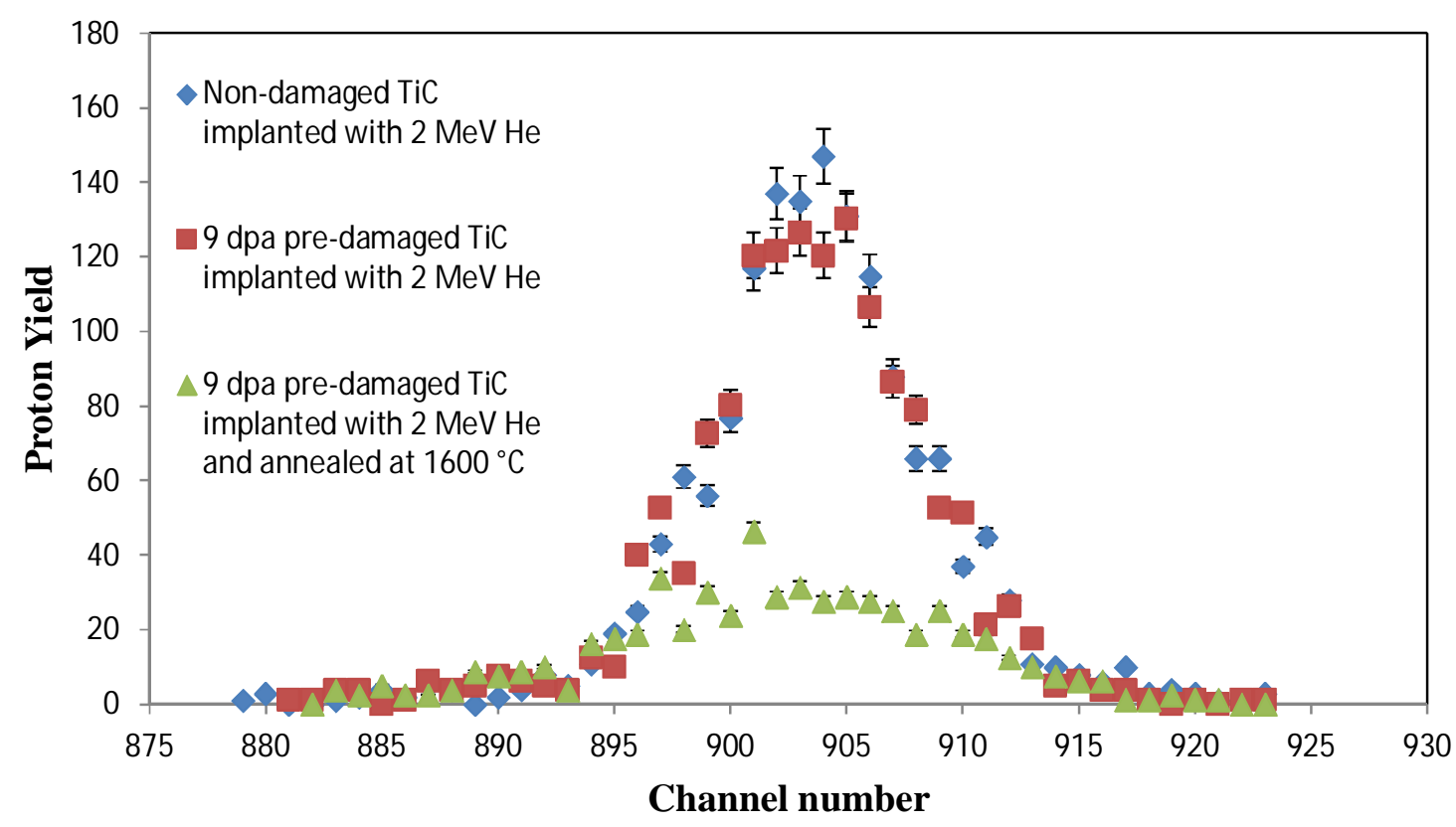

Figure 7.7. Proton spectras obtained for deuteron energy $E_{d}=1 \mathrm{MeV}$ for TiC implanted with 2 $\mathrm{MeV}$ helium, TiC (pre-damaged with self-ions and implanted with helium), TiC (pre-damaged with self-ions, implanted with helium and annealed at $1600{ }^{\circ} \mathrm{C}$ ).

\subsection{Conclusion}

(i) It is rather common to observe that the hardness of materials increases after radiation damage. It is typical to believe that gliding of dislocation in the matrix of the material is responsible for its ductile nature. After radiation damage, defects are formed for eg. vacancies, interstitial and their clusters etc. These defects acts as hindrance or resist the motion of dislocation and increases the hardness of the material. But the reason behind non-linear variation of hardness with fluence is still not clear.

(ii) It is also common to observe an increase in lattice parameter after radiation damage. However, it is remarkable to notice the presence of pointed peaks in the diffractograms obtained 
from the samples damaged at high doses corresponding to $9 \& 27 \mathrm{dpa}$. These pointed peaks corresponds to the crystalline nature of the samples and indicates that $\mathrm{TiC}$ and $\mathrm{ZrC}$ report no signs of amorphisation at damage level corresponding to $27 \mathrm{dpa}$. This observation helps in concluding that transition metal ceramics have high radiation tolerance. This statement is also supported by very low magnitude $(\leq 0.5 \%)$ of lattice swelling measured at $27 \mathrm{dpa}$.

(iii) The results obtained on helium mobility under radiation damage do not surprise us, because of the presence of large number of native vacancies in transition metal ceramics. We speculate from these experiments that the number of vacancies created by self-ion irradiation is not sufficient in comparison with already present large number of native vacancies to be able to induce any detectable effect on helium mobility. However, damaging the samples corresponding to higher dpa can bring modification in the mobility of helium. 


\section{Chapter 8}

\section{General Discussion}

In this chapter, we have compared and discussed important results on $\mathrm{TiN}, \mathrm{TiC}$ and $\mathrm{ZrC}$. At the end of this chapter, most important points are concluded. Some results shown in this chapter have already been published. This paper can be obtained from the citation given below:

Helium mobility in advanced nuclear ceramics, S. Agarwal, P. Trocellier, Y. Serruys, S. Vaubaillon, S. Miro, Nuclear Instruments \& Methods in Physics Research Section B, 327 (2014) 117-120.

\section{A. Helium release in $\mathrm{TiC}$, $\mathrm{TiN}$ and $\mathrm{ZrC}$}

Large pieces of polycrystalline $\mathrm{TiC}$, TiN and $\mathrm{ZrC}$ were implanted with $3 \mathrm{MeV}$ helium ions at the same time with fluence $\left(\mathrm{F}_{1}=5 \times 10^{16} \mathrm{at} . / \mathrm{cm}^{2}\right)$. These large samples were cut into small pieces and subsequently, sealed in quartz tube. Five sets containing three quartz tube (each containing one different type of sample) were heated at five different temperatures between $1000{ }^{\circ} \mathrm{C}-1600{ }^{\circ} \mathrm{C}$ for 2 hours. NRA was done on as-implanted and annealed samples to quantify and determine the position of helium atoms. He lost fraction versus annealing temperature for $\mathrm{TiC}$, TiN and $\mathrm{ZrC}$ have been plotted and fitted together in figure 8.1. These three curves are taken from figure $6.2,6.10 \mathrm{~b}$ and $6.26 \mathrm{~b}$. 


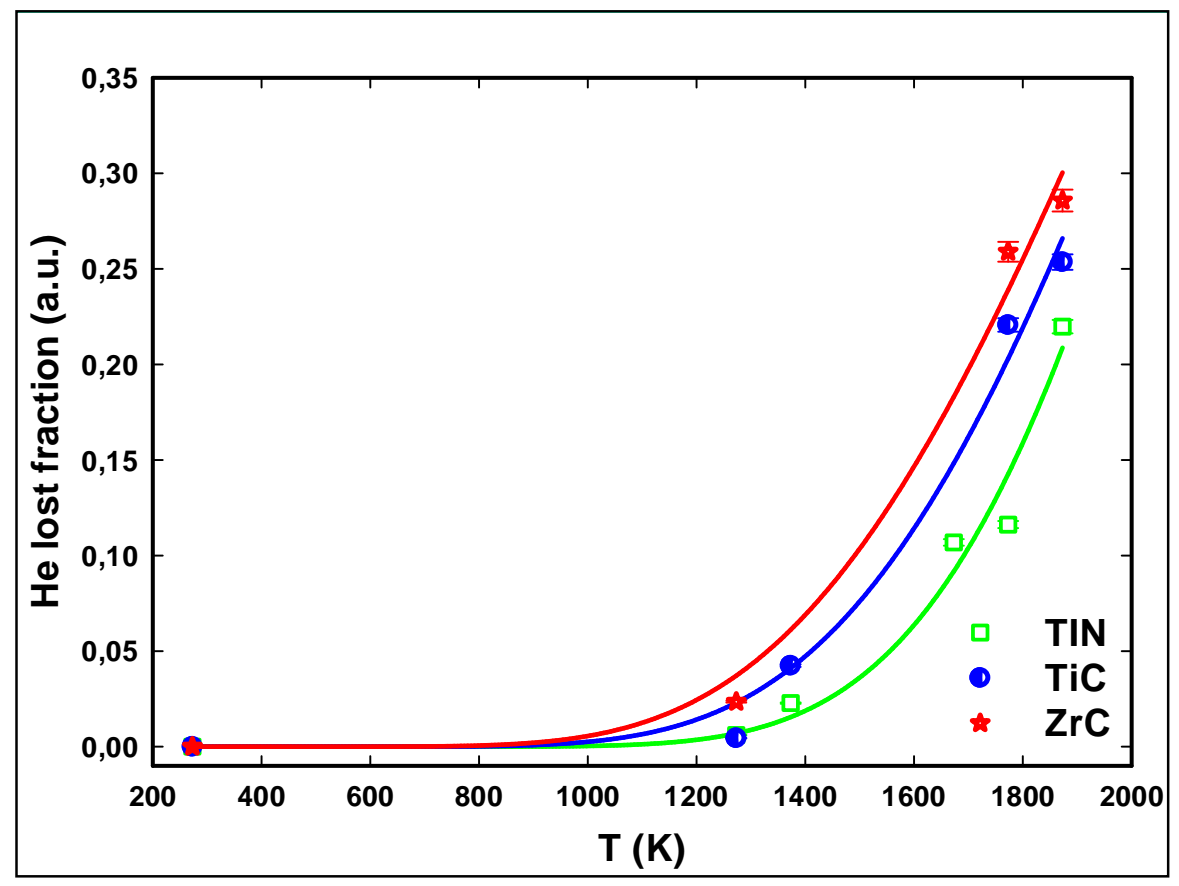

Figure 8.1. Helium lost fraction as a function of temperature fitted according to first order kinetics law in order to calculate activation energy for He release.

The values of activation energies derived from figure 8.1 are compiled in table 8.1.

\begin{tabular}{|c|c|c|}
\hline & $\boldsymbol{\alpha}$ & $\boldsymbol{\Delta H}(\mathbf{e V})$ \\
\hline $\mathbf{T i C}$ & 74.58 & $0.89 \pm 0.09$ \\
\hline TiN & 398.31 & $1.20 \pm 0.12$ \\
\hline ZrC & 41.76 & $0.77 \pm 0.08$ \\
\hline
\end{tabular}

Table 8.1. Comparison of activation energy for He release obtained for TiC, TiN and $\mathrm{ZrC}$.

The three microstructural parameters that appear to be responsible for different helium release in these samples are:

- Difference in grain boundary densities in three samples due to their different grain sizes.

- Difference in the concentration of native vacancies due to their different stoichiometric ratios.

- Difference in the type and concentration of porosities.

We have plotted the stoichiometric ratio of each sample versus their helium loss in figure 8.2. 


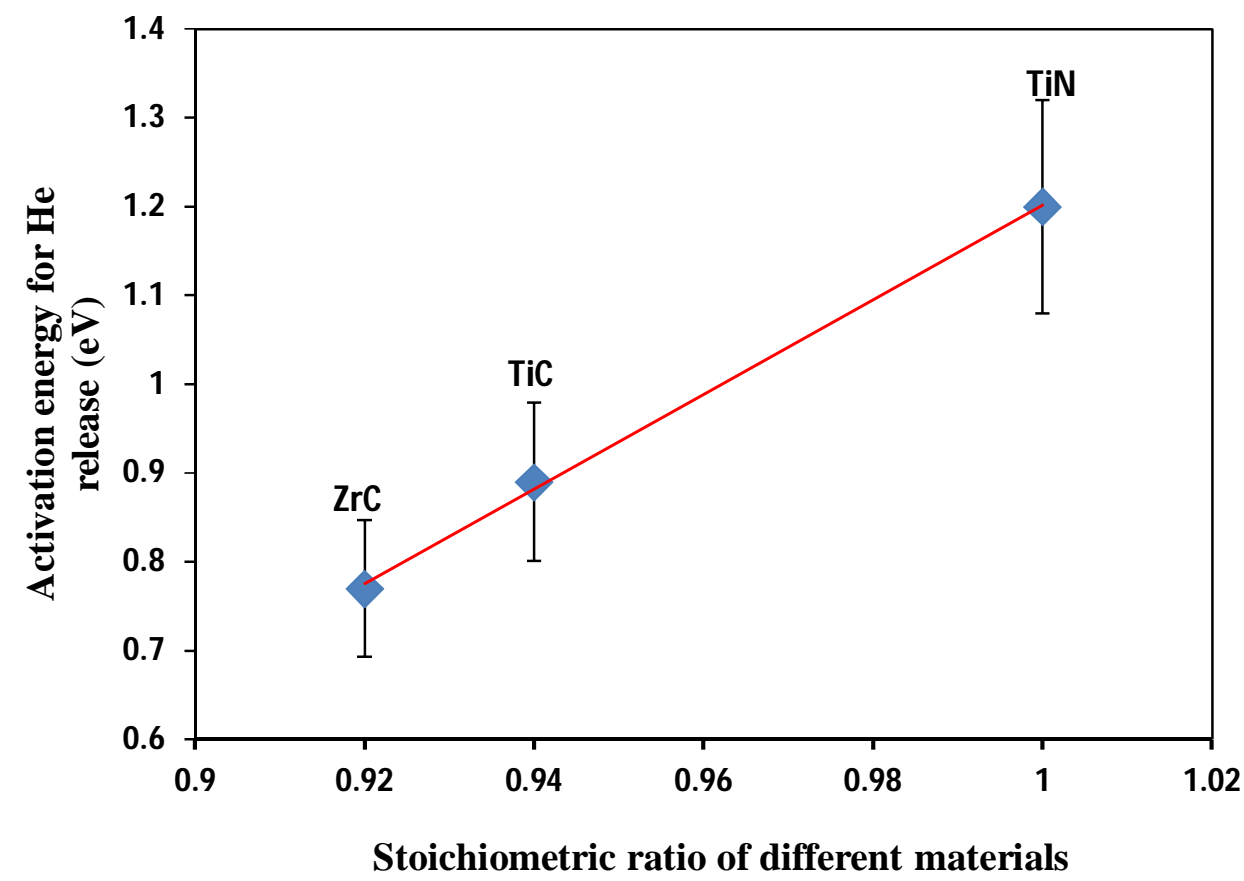

Figure 8.2. Linear variation of the activation energy of He release versus stoichiometric ratio of investigated materials.

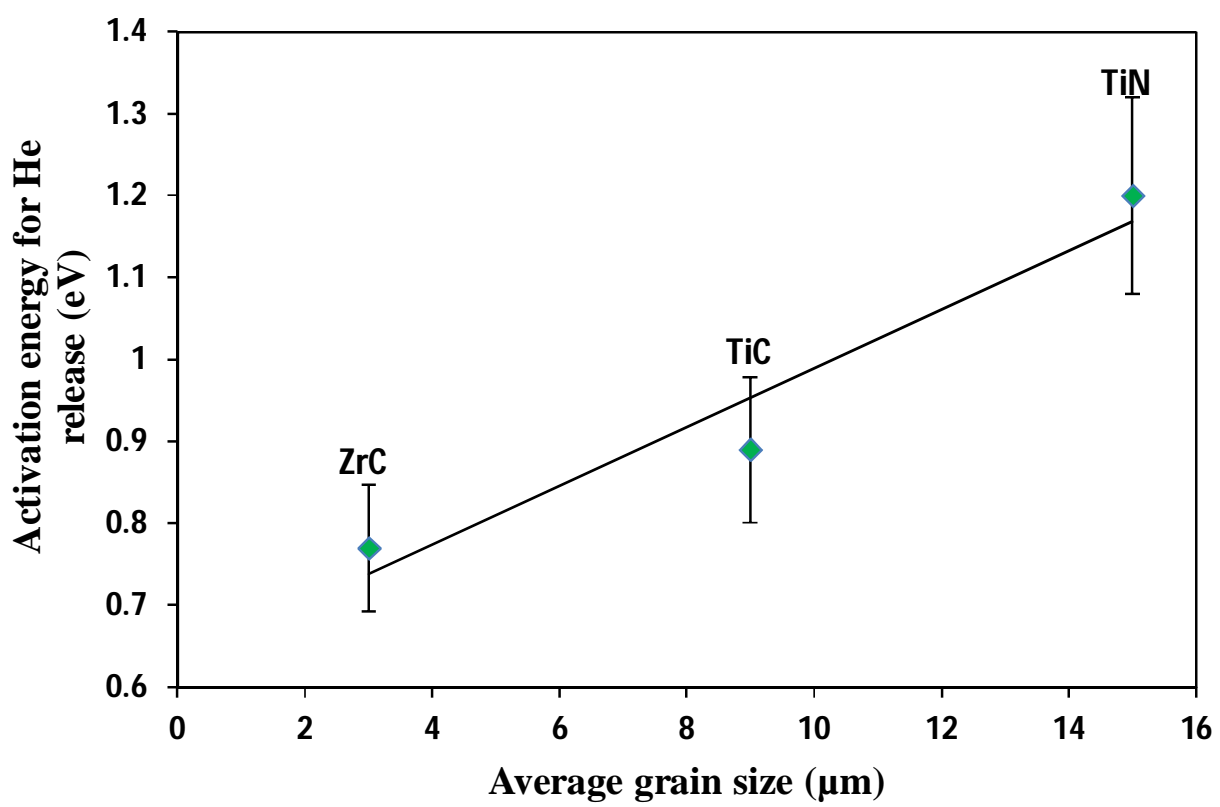

Figure 8.3. Linear variation of the activation energy of He release versus average grain size of investigated materials.

From figure 8.2 and 8.3 , it appears that helium release is directly proportional to the grain boundary densities (or inversely to the grain size) and also, directly proportional to the 211 
stoichiometric ratio. It seemed quite clear that samples with small grain size have large density of grain boundaries which provide large density of pathways for helium to release easily. But the role of stoichiometric ratio to release helium is not so clear. However, Askern in 1967 has reported the similar effect, the samples with low $\mathrm{C} / \mathrm{Zr}$ ratio released more gas as compared to the samples having $\mathrm{C} / \mathrm{Zr}$ ratio close to 1 . See p63 for more details.

From $\mu$-NRA experiments, we found that the helium was not homogeneously distributed inside the grains in as-implanted TiC \& TiN (result not displayed in this thesis). This heterogeneous distribution could be due to the excessive trapping of helium at (or near the intragranular porosities). But this is just a hypothesis, as the position of pores and the places where the helium is present in excess quantity cannot be compared.

Good quality transition metal ceramics are difficult to fabricate. We tried extremely hard to obtain the samples in which only one microstructural parameter varies, so that we can directly compare the results on these samples and conclude which sample has better helium retention and diffusion properties. Not only this, it was even difficult to obtain one type of sample (for e.g., $\mathrm{ZrC}$ or $\mathrm{TiC}$ or $\mathrm{TiN}$ ) in which the role of one parameter could be studied. For e.g. we wanted to study the role of native vacancies in $\mathrm{ZrC}$, we already had $\mathrm{ZrC}_{0.92}$, we were successful in obtaining $\mathrm{ZrC}_{0.95}$ and $\mathrm{ZrC}_{0.80}$ but surprisingly all the native vacancies were filled with $\mathrm{O}$ atoms. Therefore, it was not possible to study separately the role of one microstructur- al parameter on helium release.

But good news is that during this dissertation, we were able to conclude some common points regarding helium retention and diffusion in $\mathrm{TiN}, \mathrm{TiC}$ and $\mathrm{ZrC}$ which were not directly dependent on microstructural parameters (if varied in close interval). They include:

- 'No helium release takes place at the room temperature' as the helium implantation fluence was found equivalent to the total helium concentration present in as-implanted samples measured by NRA experiments conducted approximately two weeks after He implantation.

- 'Excitation curves at $T_{a}=1000{ }^{\circ} \mathrm{C} \& \mathrm{~T}_{a}=1100{ }^{\circ} \mathrm{C}$ superimposes on each other and then curves at $T_{a}=1500{ }^{\circ} \mathrm{C} \& T_{a}=1600{ }^{\circ} \mathrm{C}$ superimposes on each other with in the error bars in TiN, TiC and ZrC'. This indicates that in these type of materials, significant quantity of helium start releasing at $\mathrm{T}_{\mathrm{a}}=1100{ }^{\circ} \mathrm{C}$. However, once helium has started releasing, it is not directly proportional to the increase in temperature. It is important to note that here, we are comparing different annealing temperatures when time of annealing is kept same. 
- 'The helium retention behavior is almost same for all the three samples' as activation energy of helium release varies in the small interval between $(0.77 \pm 0.08)-(1.2 \pm 0.12) \mathrm{eV}$.

- The direct comparison of results obtained on helium retention behavior in $\mathrm{TiC}, \mathrm{TiN}$ and $\mathrm{ZrC}$ with the results on $\mathrm{SiC}$ in literature cannot be done due to different helium introduction conditions. For $3 \mathrm{MeV}$ energy of helium implantation in $\mathrm{SiC}$, some results are shown in table 8.2. corresponding to different grain sizes and different fluence values.

\begin{tabular}{|c|c|c|c|c|}
\hline $\begin{array}{l}\text { Grain Size } \\
\text { (SiC type) }\end{array}$ & $\begin{array}{c}\text { Energy \& Fluence } \\
\text { of He ions }\end{array}$ & $\begin{array}{c}\text { Annealing } \\
\text { Temperature }\left({ }^{\circ} \mathbf{C}\right)\end{array}$ & $\begin{array}{c}\text { Helium } \\
\text { release }(\%)\end{array}$ & References \\
\hline $\begin{array}{c}1 \mu \mathrm{m}-100 \mathrm{~nm} \\
(3 \mathrm{C}-\mathrm{SiC})\end{array}$ & $3 \mathrm{MeV}, 5 \times 10^{16}$ at. $/ \mathrm{cm}^{2}$ & $1100{ }^{\circ} \mathrm{C}$ & $40 \%$ & See Annex 4 \\
\hline $\begin{array}{c}3 \mu \mathrm{m} \\
(3 \mathrm{C}-\mathrm{SiC})\end{array}$ & $3 \mathrm{MeV}, 5 \times 10^{16}$ at. $/ \mathrm{cm}^{2}$ & $1100{ }^{\circ} \mathrm{C}$ & No helium release & See Annex 4 \\
\hline $\begin{array}{c}\text { Single crystal } \\
(4 \mathrm{H}-\mathrm{SiC}, 6 \mathrm{H}-\mathrm{SiC})\end{array}$ & $3 \mathrm{MeV}, 1 \times 100^{16}$ at. $/ \mathrm{cm}^{2}$ & $1150{ }^{\circ} \mathrm{C}$ & More than $40 \%$ & [1] \\
\hline
\end{tabular}

Table 8.2. Summary of some work on helium retention in $\mathrm{SiC}$.

From table 8.2, the work mentioned in $1^{\text {st }}$ and $2^{\text {nd }}$ row are done by our group and could be directly compare with the results on $\mathrm{TiN}, \mathrm{TiC}$ and $\mathrm{ZrC}$. We can clearly see from this table that the samples with small grain sizes $(1 \mu \mathrm{m}-100 \mathrm{~nm})$ releases large amount of helium at $1100{ }^{\circ} \mathrm{C}$, however sample implanted with large grain size $(3 \mu \mathrm{m})$ do not release helium at $1100{ }^{\circ} \mathrm{C}$.

\section{B. Helium diffusion in $\mathrm{TiC}$, TiN and $\mathrm{ZrC}$}

\section{B.1. Position of helium in as-implanted samples}

He depth profiles for as-implanted $\mathrm{TiC}$, TiN and $\mathrm{ZrC}$ have been taken from fig. 6.6a, 6.10c, $6.26 \mathrm{c}$ and have been plotted together in figure 8.4. 
From figure 8.4, it appears that the tailing effect in helium depth profiles increases from TiN to $\mathrm{TiC}$, followed by $\mathrm{ZrC}$. In the same order, both stoichiometric ratio and grain size varies among these samples.

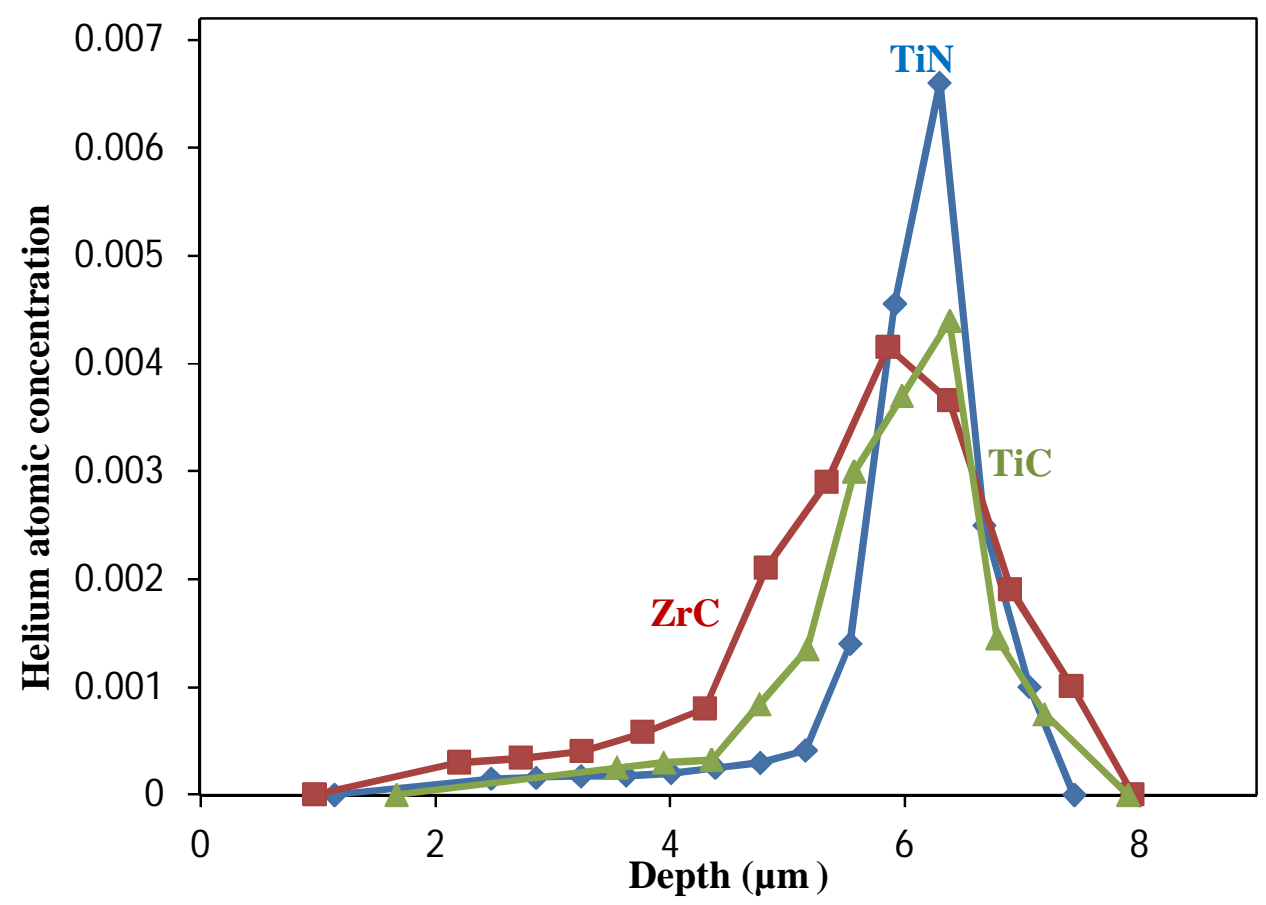

Figure 8.4. Comparison of helium depth profile obtained corresponding to as-implanted samples.

From previous discussion in their respective chapters, we speculate that the tails corresponds to the small stable He-V clusters. For TiN, even these clusters which are present in tails were too small to be visible under TEM and only the big He- $\mathrm{V}$ clusters present in the main peak were visible as bubbles. It is perhaps possible that the combination of large GB density and native vacancies is responsible for large tailing effect (or double population) in studied samples especially in $\mathrm{ZrC}$. Due to large number of native vacancies in $\mathrm{ZrC}$, there are large number of small mono-vacancy (or di-vacancy) cluster, which are either captured at GBs (or drifted by GBs) towards sample surface.

\section{B.2. Helium diffusion in annealed samples}

Our group is not the first one to say that "helium is present in the form of double peaks". This has been previously observed experimentally in 1976 at Sandia National laboratory by 
R.S. Blewer and L.A. Langley [2] and was verified by using simulations. Following this, it has been observed by many groups in CEA $[1,3]$.

However, the most interesting is the similar type of diffusion behavior observed by Blewer and Langley. They verified that peak (or the tail) that is present closed to the surface retained the helium during which the main peak has started releasing it. We have observed the same behavior in $\mathrm{TiC}$ and $\mathrm{ZrC}$, the first helium release starts from peak close to the end-of-range (EOR). For $\mathrm{ZrC}$, up to $1600{ }^{\circ} \mathrm{C}$, there was no helium release from the tail during which the large amount of helium released from the main peak. For TiC, until $1500{ }^{\circ} \mathrm{C}$, there was no loss of helium from the tail present close to the surface. However, to simplify our study, we neglected the tail in TiN. Blewer and Langley speculated that the helium present in tails (or the peak closer to the surface) have smaller He-V clusters, however, the main peak present at the end-of the range have large He-Vclusters. Our study is also built on the similar hypothesis.

It is important to note "that the values of diffusion coefficient derived from the application of fick's law are not the true diffusion coefficient values of ${ }^{3} \mathrm{He}$ in the material". These are the effective (or apparent) diffusion coefficient values where the mobility of ${ }^{3} \mathrm{He}$ is affected by material's microstructure (such as native vacancies, grain boundaries, porosities, dislocation lines etc.) and also by implantation induced defects. For TiN and TiC, due to the broadening of helium depth profiles at higher temperature, we were successful in calculating effective helium diffusion coefficient values; conversely, due to the shrinkage of helium depth profile at higher temperature for $\mathrm{ZrC}$, it was not possible to calculate effective helium diffusion coefficient values.

Overall, this study gave an important interval in which effective helium diffusion coefficient varies for TiN and TiC.

For TiN: $D_{\mathrm{He}}=3.58 \mathrm{E}-19 \mathrm{~m}^{2} \mathrm{~s}^{-1}$ to $5.296 \mathrm{E}-18 \mathrm{~m}^{2} \mathrm{~s}^{-1}\left(\right.$ from $\mathrm{T}_{\mathrm{a}}=1100{ }^{\circ} \mathrm{C}$ to $\left.1600{ }^{\circ} \mathrm{C}\right)$.

For TiC: $D_{\mathrm{He}}=4.20 \mathrm{E}-18 \mathrm{~m}^{2} \mathrm{~s}^{-1}$ to $2.59 \mathrm{E}-17 \mathrm{~m}^{2} \mathrm{~s}^{-1}\left(\right.$ from $\mathrm{T}_{\mathrm{a}}=1100{ }^{\circ} \mathrm{C}$ to $\left.1600{ }^{\circ} \mathrm{C}\right)$.

\section{B.3. He interaction with defects}

Upon introduction into the bulk material, helium atom undergoes three distinct processes: diffusion (or transport), bubble nucleation and bubble growth. The diffusion is the result of 
random jumps from one stable or meta-stable lattice site to another and is the key ingredient for bubble nucleation and growth.

From literature on TiC [4] and TEM experiments on TiN, for helium implantation fluence high annealing temperature equal to $5 \times 10^{16}$ at. $/ \mathrm{cm}^{2}$ and $1100{ }^{\circ} \mathrm{C}$, respectively, major quantity of helium trapped in the form of bubbles (or stable He-V clusters) with the size from $0.75 \mathrm{~nm}$ to $1 \mathrm{~nm}$ have been observed. Therefore, it can be concluded that in the studied material most of the helium atom undergoes dissociation mechanism where a He atom in a vacancy (or He- $\mathrm{V}$ clusters) is dissociated from its position and diffuses interstitially until re-trapped by another vacancy (or clusters). Our preliminary TEM observation on $\mathrm{ZrC}$, also revealed the formation of bubbles but detailed results and discussion on $\mathrm{ZrC}$ can be done, once all the TEM experiments our completed.

Regarding helium bubble nucleation and growth, we can discusss in detail with respect to observations only on TiN. The presence of native vacancies in TiN have complexed our explanation on helium bubble growth. Our hypothesis after many discussions and experiments is following: Like in other nuclear materials, helium upon introduction interacts with vacancies (they could be either native vacancies plus the vacancies created during helium implantation). In TiN, due to presence of large number of native vacancies, the net concentration of vacancies is high, due to which all the implanted helium interacts with single vacancies to helium mono (or di-vacancy clusters) which are small and very stable. On annealing, these small clusters start to agglomerate (or join together) and grow to a size which is bigger and stable and can be called as bubble nuclei. It is assumed that the number of bubble nuclei is proportional to the concentration of initially formed (mono or di) He-V clusters. These bubble nuclei are very stable and generally can be seen under TEM and have the size between (0.5-1) nm. We believe that the very small bubble seen at $1100{ }^{\circ} \mathrm{C}$ in TiN corresponds to the bubble nuclei. Following this, these bubble nuclei have grown to bigger bubbles. The growth of bubble nuclei in TiN seems to be a temperature dependent phenomenon which is sometimes accompanied by decrease in bubble density (at $\mathrm{T}_{\mathrm{a}}=1100{ }^{\circ} \mathrm{C}$ to $1400{ }^{\circ} \mathrm{C}$ ) and sometimes the density has remained constant (from $\mathrm{T}_{\mathrm{a}}=1400{ }^{\circ} \mathrm{C}$ to $1600{ }^{\circ} \mathrm{C}$ ).

It is also important to consider that even at temperatures where the bubbles can be observed under TEM, there is significant concentration of helium which is present in the form of small clusters having size below the detection limit of the microscope. And, at high annealing 
temperature, they get absorb and therefore, leading to growth of bubbles. However, there is a role of vacancy absorption during bubble growth, which cannot be neglected.

Regarding the pressure calculation inside the bubbles, applying Trinkaus equation of state is an effective procedure, but few points are important to keep in mind:

- Firstly, the concentration of helium should be known (or measured) corresponding to the position from where the TEM micrographs of bubbles are taken for pressure calculation.

- Secondly, the approach is more accurate at higher annealing temperatures, because in this case, most of the helium is present in the clusters having sizes which are enough to be detected under TEM.

\section{He fluence effect}

Helium diffusion mechanisms and interaction of helium with the material defects depends on the quantity of helium introduced in the material.

For both $\mathrm{TiN}$ and $\mathrm{ZrC}$, we observed that the helium retention properties of the material are altered when the quantity of implanted helium is modified. In both samples, $100 \%$ helium has been retained into the material when the quantity of helium is less. However, under the same annealing conditions, helium release has been observed for samples implanted with higher concentration of helium.

From TEM and NRA experiments, we concluded that when the quantity of introduced helium is less, upon post-implantation annealing large portion of this quantity remains in the form of small clusters, which are too small to be visible under TEM and perhaps due to their small size, they diffuse slowly through substitutional mechanism (where helium atoms jumps from one substitutional position to another) and hence their release from the material is delayed.

However, when the quantity of introduced helium is large, upon post-implantation annealing, most of the helium is present in the form of bubbles, these bubbles can be highly pressurized (or can be made up of large unstable He-V clusters) which releases helium atom either to reduce pressure or become stable. These helium atoms either can get re-trapped by another bubbles or He- $\mathrm{V}$ clusters or could be released out of the sample through interstitial spaces. 


\section{Helium behavior under radiation damage}

Transition metal carbides and nitrides are stable on wide range of stoichiometric ratios. Therefore, it is reasonable to expect a large stability of these materials under ion irradiation due to conservation of their structure with large number of vacancies. The results obtained on helium mobility under radiation damage do not surprise us, because of the presence of large number of native vacancies in transition metal ceramics. We speculate from the experiments conducted to study helium behavior under radiation damage that the number of vacancies created by self-ion irradiation is not sufficient in comparison with already present large number of native vacancies to be able to induce any detectable effect on helium mobility. However, damaging the samples higher than 9 dpa can bring modification in the mobility of helium.

We have observed the hardness and increase in lattice parameter of materials increases after radiation damage. Hardness is believed to occur due to resistance in the gliding of dislocation in the material matrix. Defects formed after radiation damage for eg., vacancies, interstitial and their clusters etc. acts as hindrance or resist the motion of dislocation and increases the hardness of the material. But the reason behind non-linear variation of hardness with fluence is still not clear.

We have also observed the presence of pointed peaks in the diffractograms obtained from the samples damaged at high doses corresponding to $9 \& 27 \mathrm{dpa}$ for $\mathrm{TiC}$ and $\mathrm{ZrC}$. This confirms no signs of amorphisation at $27 \mathrm{dpa}$. This observation helps in concluding that transition metal ceramics have high radiation tolerance. This statement is also supported by very low magnitude $(\leq 0.5 \%)$ of lattice swelling measured at $27 \mathrm{dpa}$.

\section{References}

[1] S. Miro, J.M. Costantini, J. Haussy, L. Beck, S. Vaubaillon, S. Pellegrino, C. Meis, J.J. Grob, Y. Zhang, W.J. Weber, Nuclear reaction analysis of helium migration in silicon carbide, J. Nucl. Mater. 415 (2011) 5-12.

[2] R.S. Blewer, R.A. Langley, J. Nucl. Mater. 63 (1976) 337-346. 
[3] D. Gosset, P. Trocellier, Determination of the helium thermal diffusion coefficient in britholite using a NRA method: New results, J. Nucl. Mater. 336 (2005) 140-144.

[4] K. Hojou, H. Otsu, S. Furuno, K. Izui, T. Tsukamoto, J. Nucl. Mater. 212-215 (1994) 281-286. 


\section{Conclusions and Perspectives}

\section{Important Conclusions}

This dissertation is focused on the study of helium behavior in advanced nuclear ceramics which are candidates for fuel coatings in GFR and have been considered as potential cladding materials for SFR. The most promising candidates for ceramic coatings are $\mathrm{ZrN}, \mathrm{ZrC}$, TiN, TiC $\& \mathrm{SiC}$ due to a combination of neutronic performance, thermal properties, chemical behavior, crystal structure, and physical properties.

This study can also be extended to fusion energy systems due to the presence of helium in fusion reactors and the use of $\mathrm{TiC} \& \mathrm{TiN}$ as coatings on materials used for permeation barrier against tritium.

The main objectives of this $\mathrm{PhD}$ work includes: i) to calculate diffusion and migration energies of helium under different experimental conditions by applying theoretical models on experimental data. ii) to investigate the microstructural evolution due to helium accumulation and conversely, identifying the role of microstructure such as grain boundaries, native vacancies and porosities on helium release. iii) to know the role of helium introduction conditions on helium diffusion. iv) to establish and validate an approach to calculate pressure built by helium gas inside the bubbles and to verify if the pressure approaches the mechanical stability limit.

To accomplish the objectives which are mentioned above, $3 \mathrm{MeV}^{3} \mathrm{He}^{+}$ions were implanted with fluence of $5 \times 10^{16}$ at./ $\mathrm{cm}^{2}$ (corresponding to $~ 1.7-2$ at.\%) into polycrystalline samples of $\mathrm{TiC}$, TiN and ZrC. Subsequently, thermal annealing at various temperatures between $1000{ }^{\circ} \mathrm{C}$ and $1600{ }^{\circ} \mathrm{C}$ for the time period of 2 hours was carried out. He depth profiling experiments were conducted on as-implanted and annealed samples using the ${ }^{3} \mathrm{He}\left(\mathrm{d}, \mathrm{p}_{0}\right)^{4} \mathrm{He}$ nuclear reaction and mathematical models like AGEING and SIMNRA were used to calculate various helium migration parameters. TEM experiments were conducted to observe the microstructural evolution, for eg., formation of helium bubbles in the implantation zone and grain boundaries, etc. The samples were also implanted with various values of helium fluence to study the role of helium introduction condition on diffusion and retention of helium. 
We concluded that the helium retention behavior is almost same for all the three samples. The activation energy of helium release varies in the small interval between $(0.77 \pm 0.08) \mathrm{eV}-(1.2$ $\pm 0.12) \mathrm{eV}$. This small variation in the activation energy is directly related to their microstructural parameters such as grain boundary densities and stoichiometric ratios. However, exclusively, blister formations due to helium release have been only observed at the surface of $\mathrm{ZrC}$.

We have obtained doubly peak helium depth profile for as-implanted and annealed samples. The first peak is present at the end-of-range region and holds major portion of the implanted helium, whereas the second peak is the tail which is present towards the surface and holds very less quantity of helium. We speculated that the tails corresponds to the small stable $\mathrm{He}-\mathrm{V}$ clusters and up to certain temperature, it retained the helium during which the main peak start releasing it. The helium release from main peak is attributed to the dissociation mechanism which is confirmed by the presence of bubbles under TEM; however the helium release in the tail has been delayed and perhaps corresponds to the substitutional vacncy type diffusion mechanism.

The following values of effective helium diffusion coefficient have been derived using Fick's law:

\section{For TiN: $D_{\mathrm{He}}=3.58 \mathrm{E}-19 \mathrm{~m}^{2} \mathrm{~s}^{-1}$ to $5.296 \mathrm{E}-18 \mathrm{~m}^{2} \mathrm{~s}^{-1}\left(\right.$ from $\mathrm{T}_{\mathrm{a}}=1100{ }^{\circ} \mathrm{C}$ to $\left.1600{ }^{\circ} \mathrm{C}\right)$.} For TiC: $D_{\mathrm{He}}=4.20 \mathrm{E}-18 \mathrm{~m}^{2} \mathrm{~s}^{-1}$ to $2.59 \mathrm{E}-17 \mathrm{~m}^{2} \mathrm{~s}^{-1}\left(\right.$ from $\mathrm{T}_{\mathrm{a}}=1100{ }^{\circ} \mathrm{C}$ to $\left.1600{ }^{\circ} \mathrm{C}\right)$.

The values of activation energy of helium diffusion derived by fitting above values from Arrhenius law are $2.50 \pm 0.25 \mathrm{eV}$ and $1.05 \pm 0.2 \mathrm{eV}$ for TiC and TiN, respectively.

We also revealed the presence of bubbles and their growth under TEM on TiN samples annealed at $\mathrm{T}_{\mathrm{a}} \geq 1100{ }^{\circ} \mathrm{C}$. The value of apparent activation energy $\left(\mathrm{E}_{\mathrm{r}}\right)$ of bubble growth was derived and is equal to $\mathrm{E}_{\mathrm{r}}=0.38 \pm 0.03 \mathrm{eV}$. This value is in agreement with the apparent activation energy of helium bubble growth in other nuclear materials. The pressure values inside the helium bubbles formed in $\mathrm{TiN}$ annealed at $\mathrm{T}_{\mathrm{a}} \geq 1100{ }^{\circ} \mathrm{C}$ were calculated by applying Trinkaus equation of state. The pressure value at $\mathrm{T}_{\mathrm{a}}=1600{ }^{\circ} \mathrm{C}$ is close to the equilibrium pressure value of $\sim 2 \mathrm{GPa}$. However, the pressure values calculated at $\mathrm{T}_{\mathrm{a}} \leq 1500{ }^{\circ} \mathrm{C}$, had lot of uncertainity because large fraction of the bubbles at these temperatures have sizes below the resolution of TEM which has contributed to large errors in the density calculation of bubbles. 
While investigating the role of helium introduction condition on diffusion in TiN, TEM investigations revealed that the samples implanted with lower concentration of helium diffuses to longer distances as compared to the samples implanted with higher concentration of helium. TEM investigations also revealed that the density of the bubbles is linearly proportional to the fluence, however their size did not evolve with fluence and remained closed to the size of bubble nuclei. These observations were made at $\mathrm{T}_{\mathrm{a}}=1100{ }^{\circ} \mathrm{C}$. At higher temperature $\left(\mathrm{T}_{\mathrm{a}}=1500{ }^{\circ} \mathrm{C}\right)$, because of bubble growth, the density of the bubbles is not proportional to the fluence and their sizes were also different. The role of implantation fluence on helium mobility in $\mathrm{ZrC}$ is similar to TiN.

We did not observe any detectable change in helium mobility under radiation damage. It could be because the vacancies created during helium implantation and radiation damage are very less as compared to already present large number of native vacancies in transition metal ceramics.

Finally, we can conclude that $\mathrm{TiN}, \mathrm{TiC}$ and $\mathrm{ZrC}$ have excellent and similar helum retention property. The only remarkable difference was observed in terms of different surface changes on these samples. Like in other nuclear materials, helium precipitates in the form of bubbles in the implantation zone and phenomenas such as grain boundary cavitation have also been observed in these samples. The pressure inside the bubbles at higher temperature is closed to equilibrium pressure value. We also concluded that helium retention and diffusion properties depends on helium introduction conditions for e.g., samples implanted with lower concentration showed better helium retention properties. 


\section{Perspectives}

We believe that more experiments can be conducted in the future to explore more scientific information related to this topic. Some of which are:

- To implant helium very close to the surface and to study helium release (or de-trapping) from He-V clusters through THDS (Thermal desorption Spectrometry). By this technique, we can separate the activation energies corresponding to each type of He-V clusters. ERDA (Elastic recoil detection analysis) experiments which are known for better depth resolution can also be done on samples implanted with helium very close to the surface to obtain helium depth profiles.

- Insitu annealing during helium implantation can be done to obtain more information on the role of temperature on bubble nucleation during helium supply. These experiments can also give information on role of implantation temperature on helium release, because implantation at higher temperature can lead to recombination of defects and hence reducing the number of vacancies for helium to interact.

- Samples can be annealed to temperatures higher than $1600{ }^{\circ} \mathrm{C}$ to know the role of helium release on bubble growth and blister formation. However, the facility to heat samples more that $1600{ }^{\circ} \mathrm{C}$ is rarely available.

- Insitu annealing can also be done during TEM experiments on as-implanted FIB foils, this kind of experiments will help in reducing errors while calculating activation energies of bubble growth, because same set of bubbles are followed during their growth from low temperature to high temperature.

- Raman spectroscopy can be done on FIB specimens of as-implanted and annealed samples to obtain the entire depth distribution of defects.

- The similar kind of experiments can be used to study similar material like $\mathrm{ZrN}$, HfC and HfN and can also be extended to study carbonitrides and borides.

- One can also compare helium depth profiles obtained (by dual beam experiments in which the simultaneous implantation of ${ }^{3} \mathrm{He}$ takes place with heavy ions for example, self ions or gold ions) with the profiles obtained on helium implanted pre-damaged samples. 
- The similar set of experiments could be planned to study the thermal/radiation behavior of hydrogen in the same type of ceramics. The study of hydrogen migration is crucial in these type of materials due to their candidature as coating materials in fusion reactors.

- Due to the fact that both hydrogen and helium are produced in large quantites in the core of fusion reactors, simultaneous dual implantation study of $\mathrm{He}$ and $\mathrm{H}$ can also be done. 


\section{$\underline{\text { ANNEX } 1}$ \\ COMPRESSIBILITY FACTOR}

Let us recall what is the compressibility factor?

The compressibility factor is a measure of how much the thermodynamic properties of a real gas deviate from those expected of an ideal gas.

It may be thought of as the ratio of the actual volume of a real gas to the volume predicted by the ideal gas at the same temperature and pressure as the actual volume.

The ideal gas law is defined as: $\mathrm{PV}_{\mathrm{m}}=\mathrm{RT}$

And the ideal gas corrected for non-ideality is defined as: $\mathrm{PV}_{\mathrm{m}}=\mathrm{ZRT}$

where $\mathrm{P}$ is the pressure, $\mathrm{V}_{\mathrm{m}}$ is the molar volume, $Z$ is the compressibility factor, $\mathrm{R}$ is the universal gas constant, $\mathrm{T}$ is the temperature.

The compressibility factor, as mentioned earlier, may also be expressed as:

$$
\mathrm{Z}=\frac{\text { Vactual }}{\text { Vreal }}
$$

It is important to note that:

1. the value of $Z$ tends toward 1 as the gas pressure approaches 0 , where all gases tend toward ideal behavior.

2. the value of $\boldsymbol{Z}$ is less than 1 at intermediate pressures because the intermolecular forces of attraction causes the actual volumes to be less than the ideal values.

3. the value of $\boldsymbol{Z}$ is greater than $\mathbf{I}$ and ultimately tends toward infinity at high pressure because the intermolecular repulsive forces cause the actual volumes to be greater than the ideal values. 


\section{$\underline{\text { ANNEX } 2}$}

In this annex, an example which details 'the calculation of pressure inside the bubbles' has been provided. To illustrate this point, we have calculated the pressure inside the bubbles formed in TiN implanted with $5 \times 10^{16}$ helium atoms $/ \mathrm{cm}^{2}$ and annealed at $\mathrm{T}_{\mathrm{a}}=1600{ }^{\circ} \mathrm{C}$.

\section{STEP 1: To calculate $C_{H e}$ i.e. the number of helium atoms per $\mathbf{n m}^{3}$.}

To complete this step, the maximum of helium depth profile obtained for $\mathrm{TiN}$ at $\mathrm{T}_{\mathrm{a}}=1600{ }^{\circ} \mathrm{C}$ has been taken:

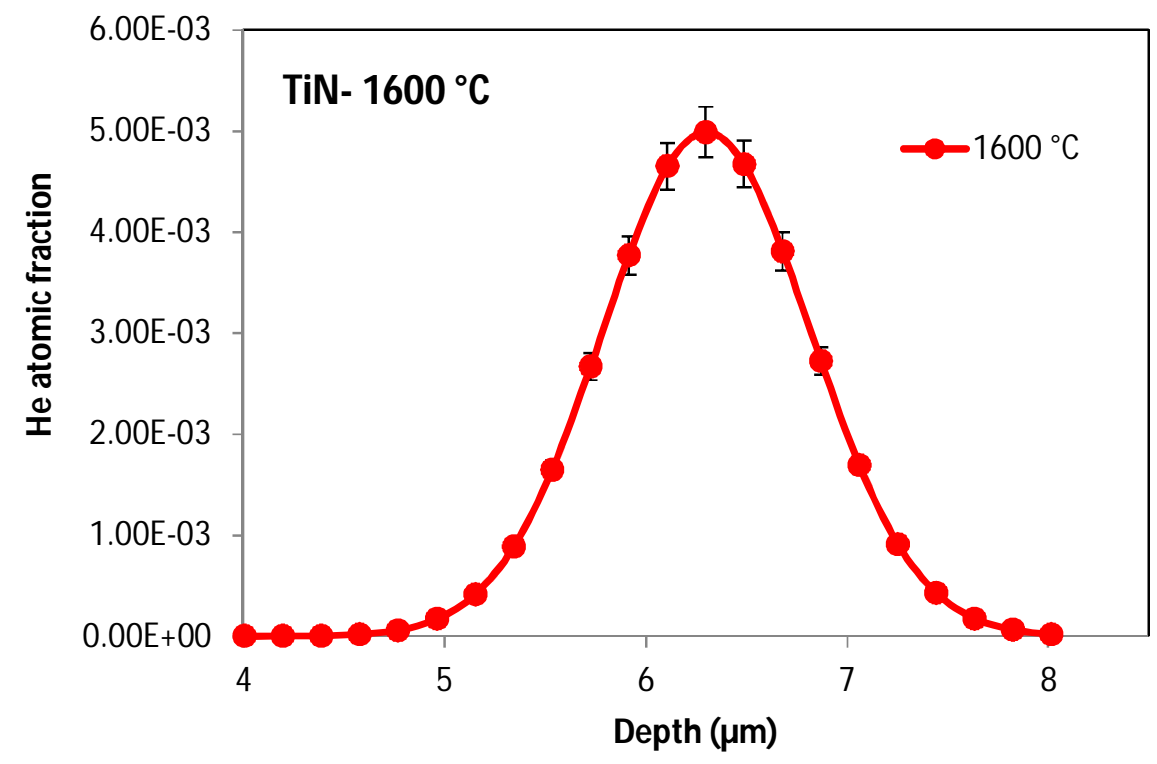

Figure AII.1. Helium depth profile obtained from nuclear reaction analysis for samples implanted with fluence $F_{1}$ and annealed at $1600{ }^{\circ} \mathrm{C}$.

The maxima of this curve denotes the maximum helium atomic fraction present in TiN after annealing at $\mathrm{T}_{\mathrm{a}}=1600{ }^{\circ} \mathrm{C}$. This quantity can be easily converted into helium atoms $/ \mathrm{nm}^{3}$ by dividing it with total number of TiN atoms present per $\mathrm{nm}^{3}$.

From the above curve and density of atoms in TiN $\left(10.48 \mathrm{E} 22\right.$ atoms $\left./ \mathrm{cm}^{3}\right)$. We get:

$C_{H e}$ i.e. the number of helium atoms per $\mathrm{nm}^{3}=0.524$ atoms $/ \mathrm{nm}^{3}$. 


\section{STEP 2: To calculate $C_{V}$ i.e. the number of vacancy per $\mathbf{n m}^{3}$.}

To complete this step, we take the TEM micrograph taken at the distance of $6.29 \mu \mathrm{m}$ (corresponds to the center of the helium depth profile shown in fig. 1) from the surface of the sample (or transverse FIB specimen).

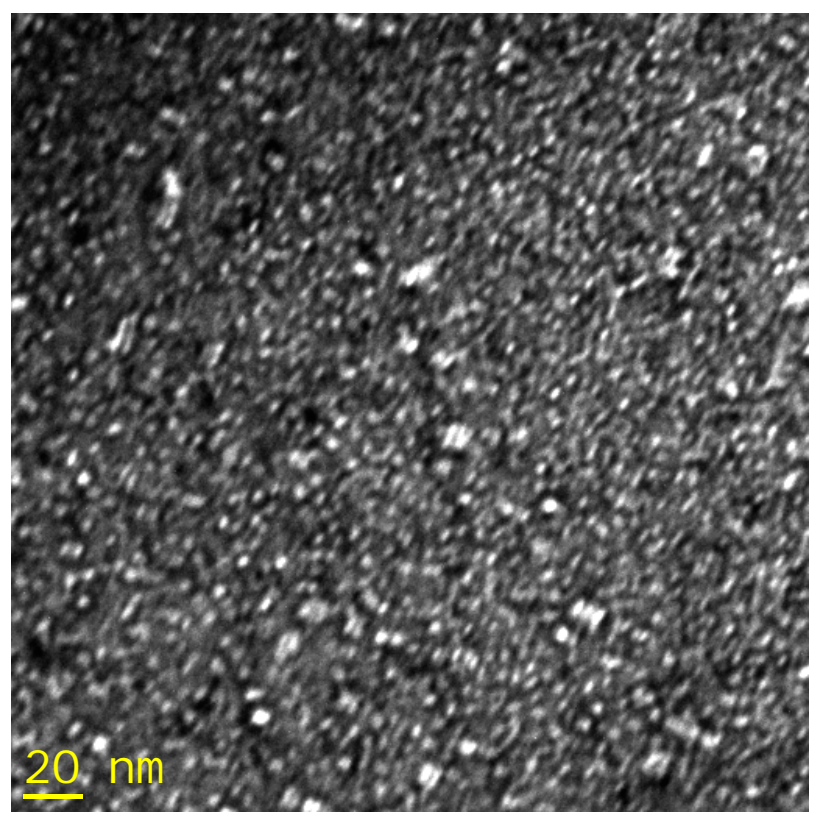

Figure AII.2. TEM micrograph showing bubbles at the center of implantation zone of TiN (implanted with fluence $F_{1}$ and annealed at $T_{a}=1600{ }^{\circ} \mathrm{C}$ ). The white contrast represt the bubbles

From this TEM picture, we calculated the bubble density and mean size. The bubble density and the mean diameter came out to be $1.15 \mathrm{E}-04$ bubbles $/ \mathrm{nm}^{3}$ and $2.75 \mathrm{~nm}$.

Vol. occupied by the total number of vacancy $(\mathrm{Vc})=$ Density of the bubble $x \mathrm{~V}_{\text {в }}$ (vol. of the bubble) (II.1)

By multiplying $\mathbf{V}_{\mathbf{B}}\left(V_{B}=\frac{4}{3} \pi r_{B}^{3}\right)$ with density.

We get, $V c=0.0011283$ 
To improve the accuracy of the above measurement, complete integration of the size distribution (corresponding to TEM micrograph at $\mathrm{T}_{\mathrm{a}}=1600{ }^{\circ} \mathrm{C}$ ) can be done. We can also multiply, the density of the bubble in each bar of the histogram with the corresponding volume of the bubble and finally it could be added to find the total volume occupied by the vacancy.

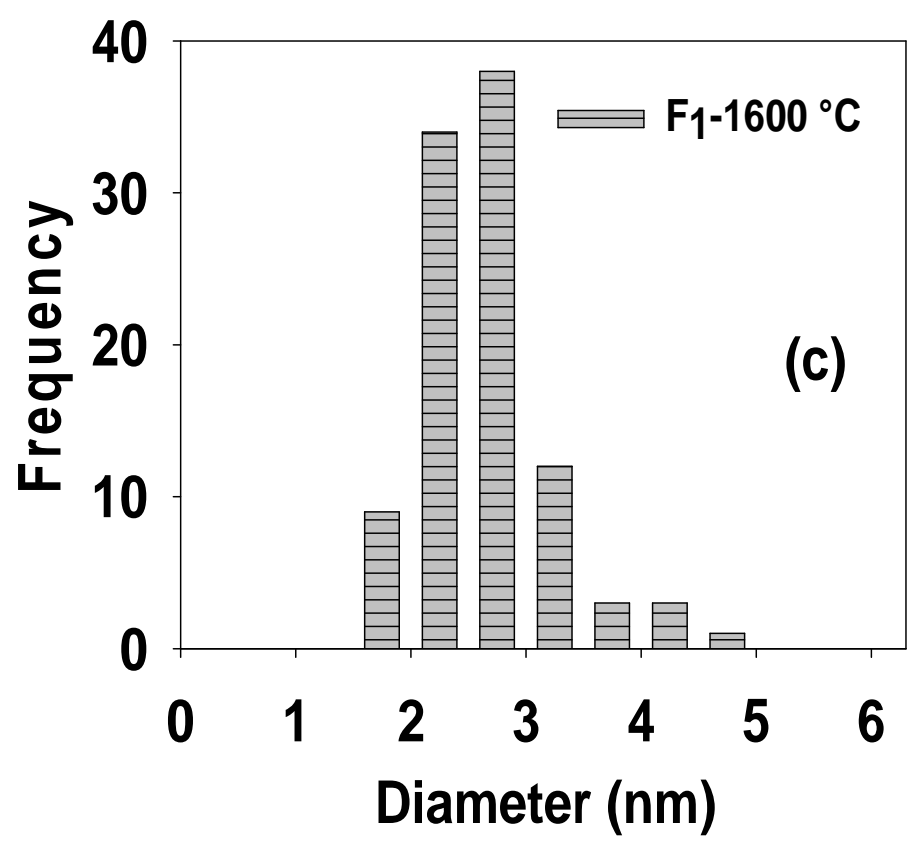

Figure AII.3. Size distribution of helium bubbles in the implanted zone of TiN annealed at $1600{ }^{\circ} \mathrm{C}$ for $2 h$.

In the above size distribution, there are 7 vertical bars. But the major contribution of the bubbles come from $2^{\text {nd }}, 3^{\text {rd }}$ and $4^{\text {th }}$ vertical bar. In the table below, we have calculated the contribution of Vc from each bar separately. 


\begin{tabular}{|c|c|c|c|c|c|c|}
\hline$n^{\text {th }}$ bar & $\begin{array}{c}\text { Diameter } \\
\text { (nm) }\end{array}$ & $\begin{array}{c}\text { Volume of the } \\
\text { bubble } \\
V_{B}=\frac{4}{3} \pi \frac{D_{n}^{3}}{8}\end{array}$ & $\begin{array}{l}\text { No of } \\
\text { bubbles }\end{array}$ & $\begin{array}{c}\text { Fraction of } \\
\text { bubbles } \\
\text { No. of bubble } \\
\text { (correspondin } \\
\mathrm{g} \text { to } \mathrm{n}^{\text {th }} \text { bar)/ } \\
\text { total no. of } \\
\text { bubble) }\end{array}$ & $\begin{array}{c}\text { Density fraction } \\
\text { (Fraction of bubbles } \\
\text { x total density) } \\
\text { Total density = } \\
1.15 \mathrm{E}-04 \\
\text { bubbles } / \mathrm{nm}^{3}\end{array}$ & $\begin{array}{l}\text { Volume fraction } \\
\text { occupied by } \\
\text { bubble in } n^{\text {th }} \text { bar } \\
\qquad\left(d_{B} \times V_{B}\right)\end{array}$ \\
\hline $2^{\text {nd }}$ & $D_{2}=2.25$ & 5.964112266 & 34 & 0.4047619 & $\mathrm{~d}_{2}=4.65476 \mathrm{E}-05$ & Vol. $_{2}=0.000277615$ \\
\hline $3^{\text {rd }}$ & $D_{3}=2.75$ & 10.88920909 & 38 & 0.45238095 & $d_{3}=5.20238 E-05$ & Vol. $_{3}=0.000566498$ \\
\hline $4^{\text {th }}$ & $D_{4}=3.25$ & 17.97414904 & 12 & 0.14285714 & $\mathrm{~d}_{4}=1.64286 \mathrm{E}-05$ & Vol. $_{4}=0.00029529$ \\
\hline \multicolumn{7}{|c|}{ Vol. occupied by the vacancy in total number of bubbles $(\mathrm{Vc})=\sum \mathrm{Vol}_{.2}+\mathrm{Vol}_{.3}+\mathrm{Vol}_{.4}=0.0011394$} \\
\hline
\end{tabular}

Table AII.1 Calculation of Vc by the integration of the histogram shown in figure AII.3.

If we consider that the volume occupied by each vacancy is equal to the volume occupied by each atom.

Considering the fact that, TiN has fcc crystal structure:

The volume occupied by one atom in $\operatorname{TiN}\left(\mathrm{V}_{\mathrm{at}}\right)=\mathrm{a}^{3} / 4$

where $\mathrm{a}$ is the unit cell edge length (or lattice parameter).

For TiN, a $=4.2407 \mathrm{E}-4 \AA$ 位erefore, vol. occupied by one atom in $\operatorname{TiN}\left(\mathrm{V}_{\mathrm{at}}\right)=19.0656958 \AA^{3}$

Now, if we divide, the total volume occupied by the vacancies by the volume occupied by one vacancy i.e. $\left(\mathrm{V}_{\mathrm{C}} / \mathrm{Vat}\right)$, we obtain the concentration of vacancy i.e. $\mathrm{Cv}$.

Finally, we get $C v=\frac{V c}{V a t}=0.58132804$ Vacancy $/ \mathrm{nm}^{3}$.

STEP 3: Calculation of v (i.e. volume per helium atom (in $\AA^{3}$ )) 
By dividing $\mathrm{C}_{\mathrm{He}} / \mathrm{C}_{\mathrm{v}}$, it will denote the number of helium atoms per vacancy;

On multiplying $\mathrm{V}_{\text {at }}$ at the denominator $\frac{C_{H e}}{C_{v^{*}} V_{a t}}$, we derive helium atoms per unit volume.

And reciprocal of this gives $v$ (i.e. volume per helium atom $\left(\right.$ in $\left.\AA^{3}\right)$ ).

For TiN annealed at $1600{ }^{\circ} \mathrm{C}$, we get $\mathrm{C}_{\mathrm{He}} / \mathrm{C}_{\mathrm{v}}=0.90138446$

And finally we obtained, $v$ (i.e. volume per helium atom (in $\AA^{3}$ ))

$$
v\left(\AA^{3}\right)=21.15157024
$$

\section{STEP 4: Calculation of the reduced particle density $\rho=v_{l} / v$}

We already found the value of $v$ (i.e. volume per helium atom $\left(\right.$ in $\left.\AA^{3}\right)$ )

The value of $v_{l}$ could be derived by the following equation:

$v_{l}$ the fluid volume upon freezing; $v_{l}=56 T_{m}^{-1 / 4} \exp \left(-0.145 T_{m}^{+1 / 4}\right)\left(\right.$ in $\left.\AA^{3}\right)$

here $\mathrm{T}_{\mathrm{m}}$ corresponds to the melting point of $\mathrm{TiN}, \mathrm{T}_{\mathrm{m}}=3203 \mathrm{~K}$

For TiN annealed at $1600^{\circ} \mathrm{C}$, we obtained $\rho=0.118226423$

\section{STEP 5: Calculation of the compressibility factor $Z$.}

- The compressibility factor from Trinkaus equation of state of helium can be expanded into:

$$
z=(1-\rho)\left(1+\rho-2 \rho^{2}\right)+(1-\rho)^{2} \rho \frac{B}{v_{l}}+(3-2 \rho) \rho^{2} z_{l}+(1-\rho) \rho^{2} z_{l}^{\prime} v_{l}
$$

To solve this equation we already calculated the value of ' $\rho$ '.

- $\mathrm{B}(\mathrm{T})$ the constant is defined as;

$B(T)=170 T^{-1 / 3}-\frac{1750}{T}\left(\right.$ in $\left.\AA^{3}\right)$

Here $\mathrm{T}$ is the annealing temperature, here $\mathrm{T}=1600{ }^{\circ} \mathrm{C}$ ( or $1973 \mathrm{~K}$ ).

On solving we get, $\mathrm{B}(\mathrm{T})=13.2076903$ 
- $z_{l}$ is the compressibility factor on freezing;

$$
z_{l}=0.1225 v_{l} T_{m}^{0.555}
$$

Here $\mathrm{T}_{\mathrm{m}}$ is the melting point of $\mathrm{TiN}$ and $v_{l}$ has been already defined in eq. AII.2

On solving we get, $z_{l}=27.02572504$

- $z_{l}^{\prime} v_{l}=\left(\frac{\partial z}{\partial} \ln v\right) l \approx-50$; the quasi-harmonic approximation on freezing appears to be rather constant along the melting curve between $100 \mathrm{~K}$ and $1000 \mathrm{~K}$.

Finally, by putting all the value in equation (AII.3), we get; $z=1.874568589$

\section{STEP 6: Calculation of pressure inside the bubble}

In the previous annexe, we have already defined that, the ideal gas corrected for non-ideality is defined as:

$$
\mathbf{P V}=\mathbf{z K T}
$$

where $\mathrm{P}$ is the pressure,

$\mathrm{V}$ is the volume,

$\mathrm{Z}$ is the compressibility factor (see Annexe I),

$\mathrm{K}$ is the Boltzmann constant,

and $\mathrm{T}$ is the temperature,

For TiN implanted with $5 \times 10^{16}$ helium atoms $/ \mathrm{cm}^{2}$ and annealed at $T_{a}=1600{ }^{\circ} \mathrm{C}$ :

we calculated,

$z($ the compressibility factor $)=1.874568589$

$v($ i.e. volume per helium atom $)=21.15157024\left(\right.$ in $\left.\left.\AA^{3}\right)\right)=2.11516 E-29 \mathrm{~m}^{3}$

and we know the values of:

$T=1873 \mathrm{~K}$

$K=1.38065 E-23 \mathrm{~J} / \mathrm{K}$

Therefore, by putting all the values in eq. AII.6, we get:

$$
P=2.29 E+09 P a
$$




\section{$\underline{\text { ANNEX } 3}$}

In this annexe, the comparison of the helium depth profiles obtained under same annealing condition for different fluence values with their corresponding TEM micrographs has been done.
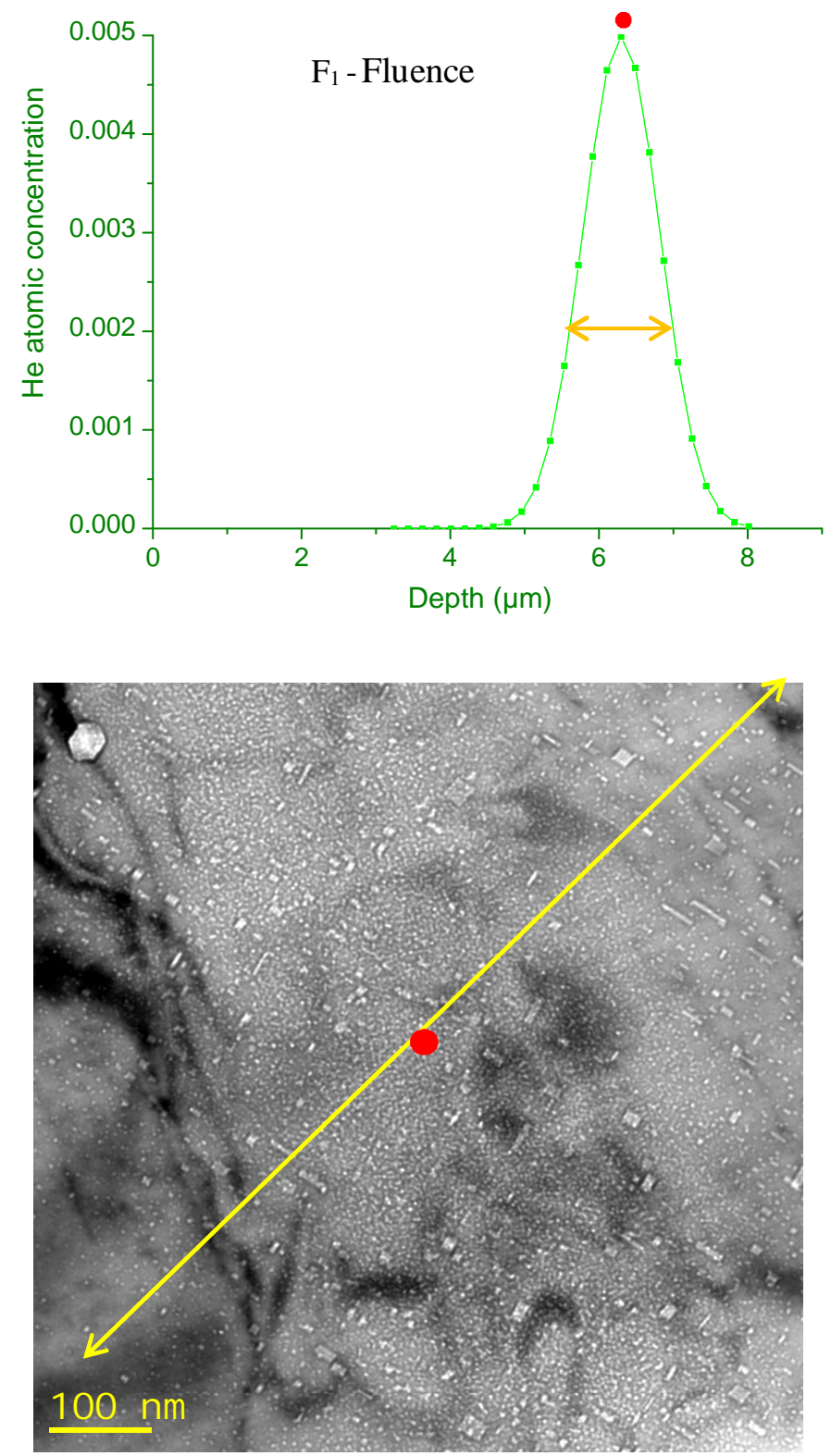

Figure AIII.1 (a) The helium depth profile obtained for TiN implanted at $F_{1}$ fluence and annealed at $T_{a}=1500{ }^{\circ} \mathrm{C}(\mathrm{b}) \mathrm{TEM}$ picture taken at $\sim 6.1 \mu \mathrm{m}$ from the surface. The red point in 
both figures indicates the common point which is approximately $6.1 \mu \mathrm{m}$ deep into the sample from the surface. The white contrast represent the bubbles.
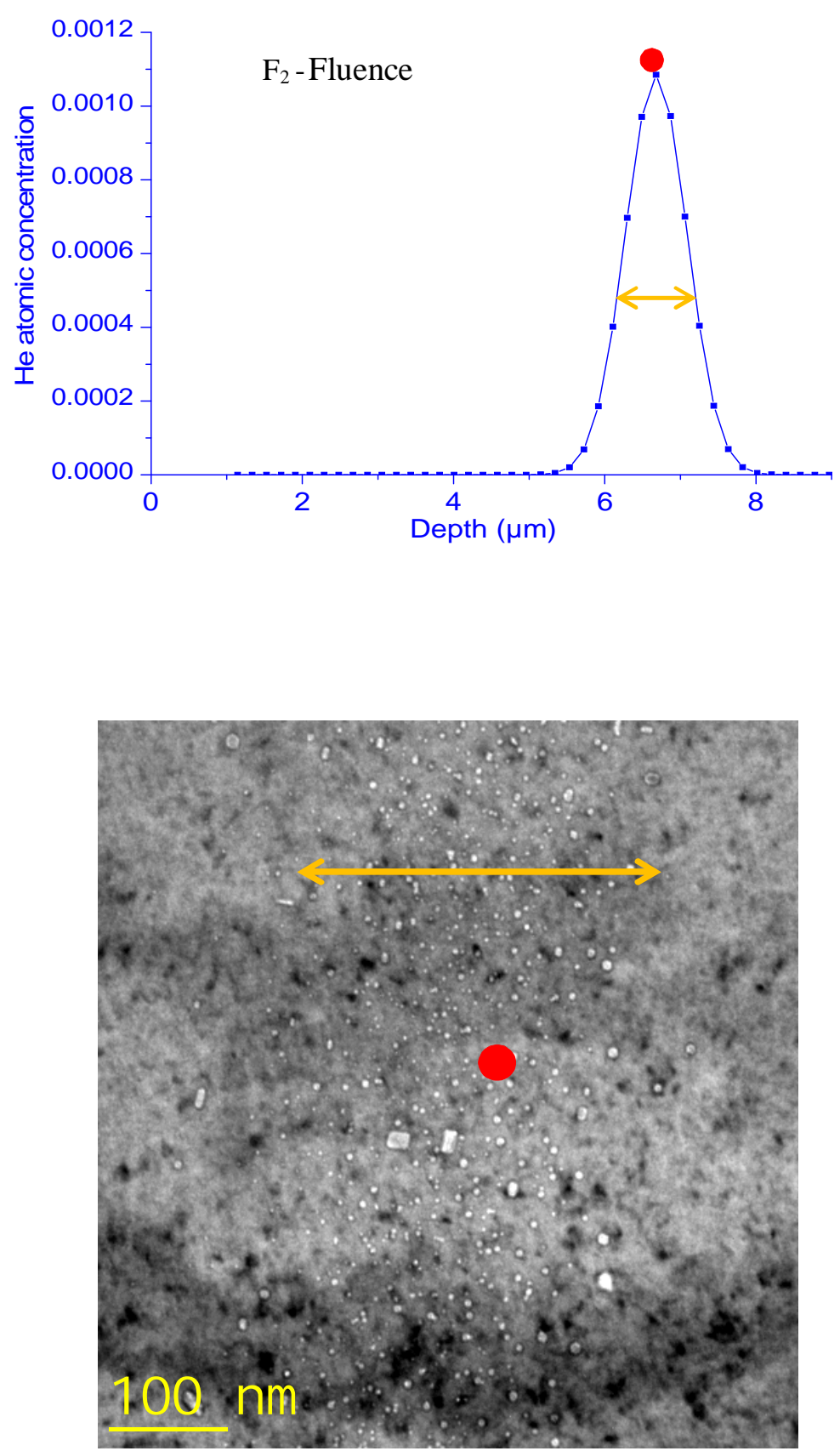

Figure AIII.2 (a) The helium depth profile obtained for TiN implanted at $F_{2}$ fluence and annealed at $T_{a}=1500{ }^{\circ} \mathrm{C}(\mathrm{b}) \mathrm{TEM}$ picture taken at $\sim 6.1 \mu \mathrm{m}$ from the surface. The red point in both figures indicates the common point which is approximately $6.1 \mu \mathrm{m}$ deep into the sample from the surface. The white contrast represent the bubbles. 

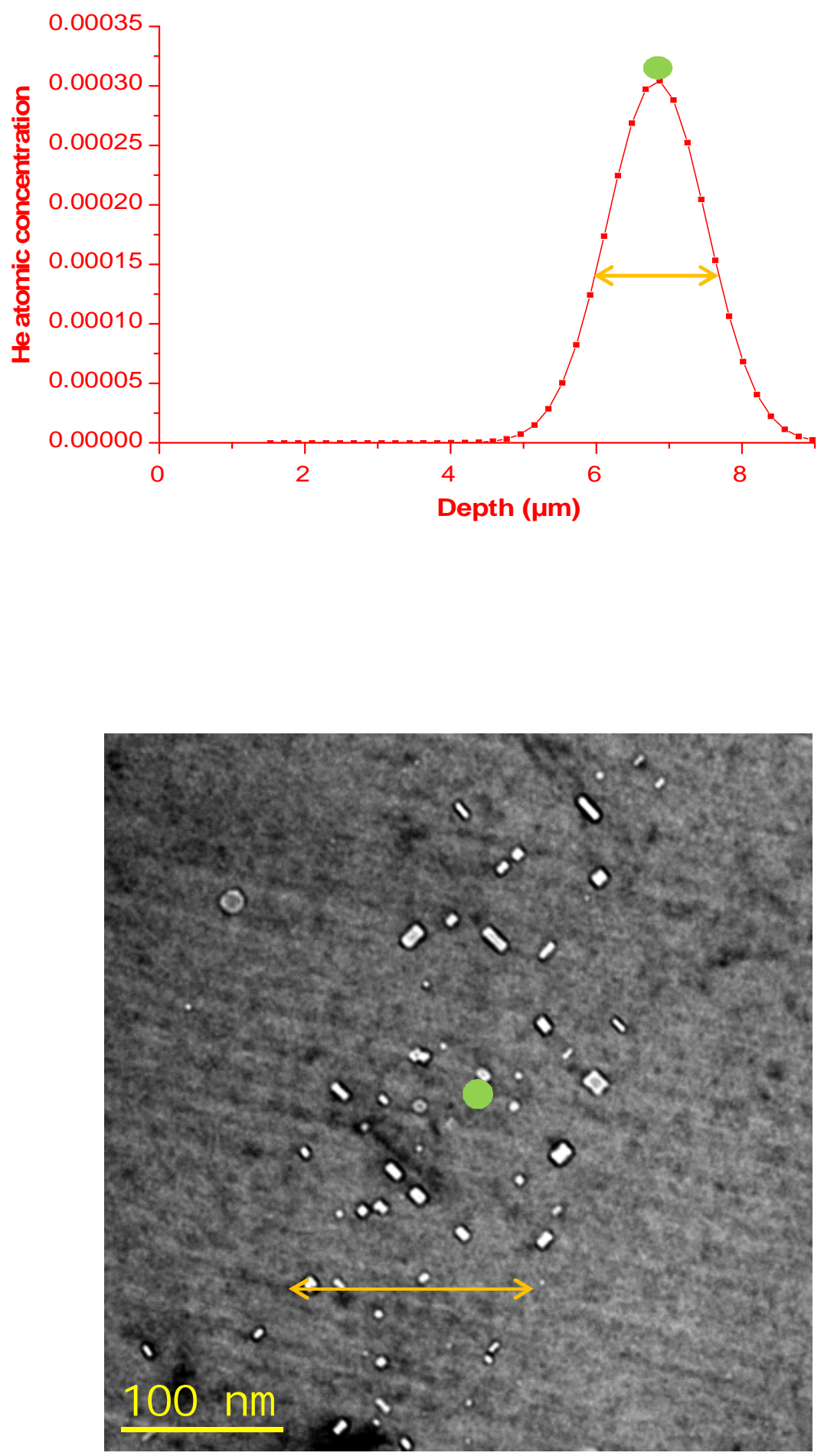

AIII.3 (a) The helium depth profile obtained for TiN implanted at $F_{3}$ fluence and annealed at $T_{a}=1500{ }^{\circ} \mathrm{C}(b)$ TEM picture taken at $\sim 6.1 \mu \mathrm{m}$ from the surface. The green point in both figures indicates the common point which is approximately $6.1 \mu \mathrm{m}$ deep into the sample from the surface. The white contrast represent the bubbles. 
After adjusting the scale of NRA profile and TEM micrograph shown in figure 1 and after superimposing NRA curve on TEM micrograph (AIII.4). We deduced that only the helium which is present in the central part of the NRA profile is present in the form of bubbles. The central part of the NRA profile which is visible under TEM is highlighted by yellow color in figure AIII.4. No bubbles were seen in the area corresponding to the tails of NRA profile. For samples implanted with $\mathrm{F}_{1}$ fluence and annealed at $1500{ }^{\circ} \mathrm{C}$, the entire width of the region where helium is present by NRA is $2.8 \mu \mathrm{m}$, however only the central $1.6 \mu \mathrm{m}$ of total $2.8 \mu \mathrm{m}$ of the helium depth profile is seen in the form of bubbles under TEM.

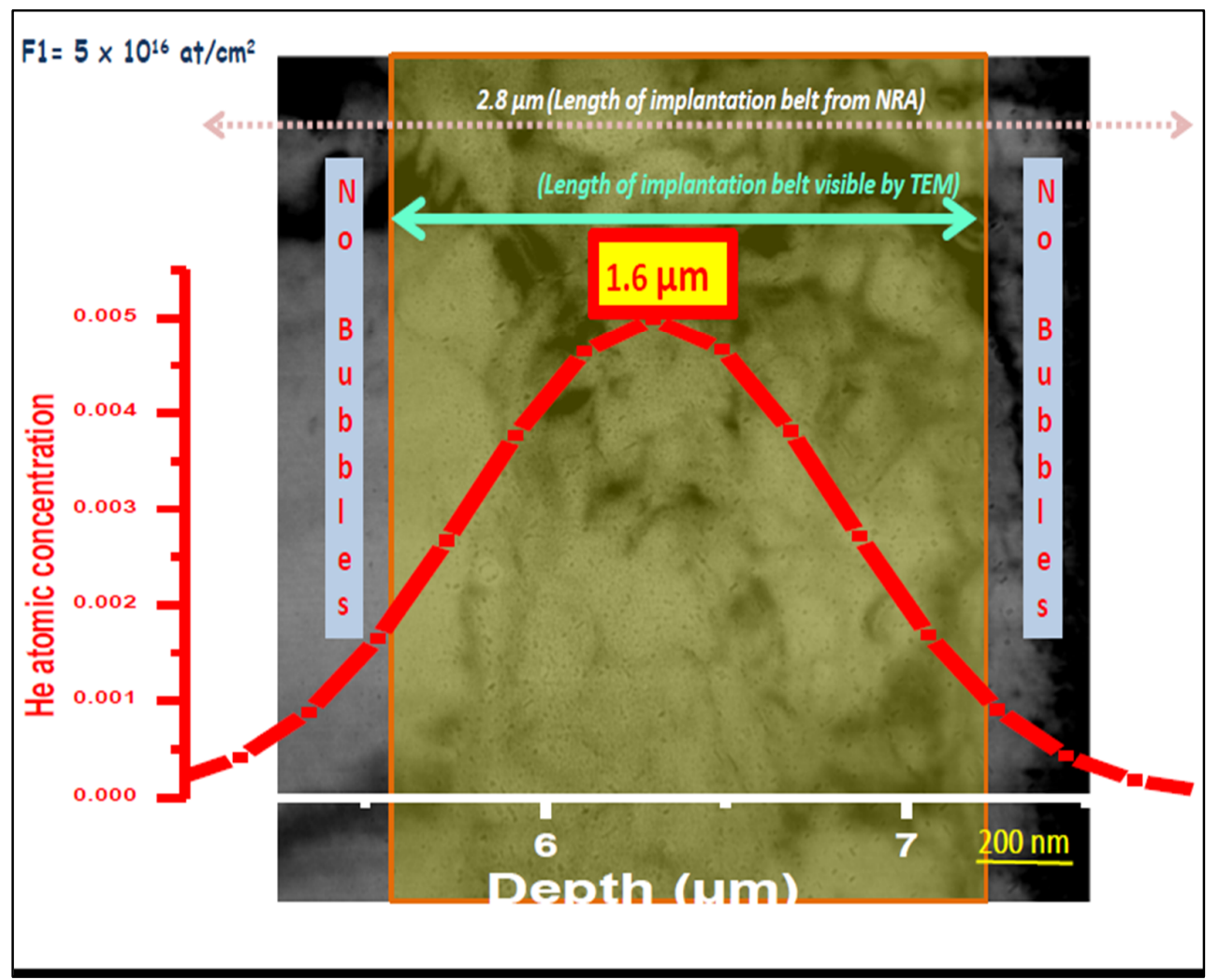

Figure AIII.4. The superimposition of NRA curve obtained for sample implanted with $F_{1}$ fluence and annealed at Ta $=1500{ }^{\circ} \mathrm{C}$ on its corresponding TEM micrograph. In the TEM micrograph, black dots (obtained in over focus conditions) represent the bubbles. 
For samples implanted with $\mathrm{F}_{2}$ fluence and annealed at $1600{ }^{\circ} \mathrm{C}$, the entire width of the region where helium is present by NRA is $2.6 \mu \mathrm{m}$, however only the central $500 \mathrm{~nm}$ of total $2.6 \mu \mathrm{m}$ of the helium depth profile is seen in the form of bubbles under TEM.

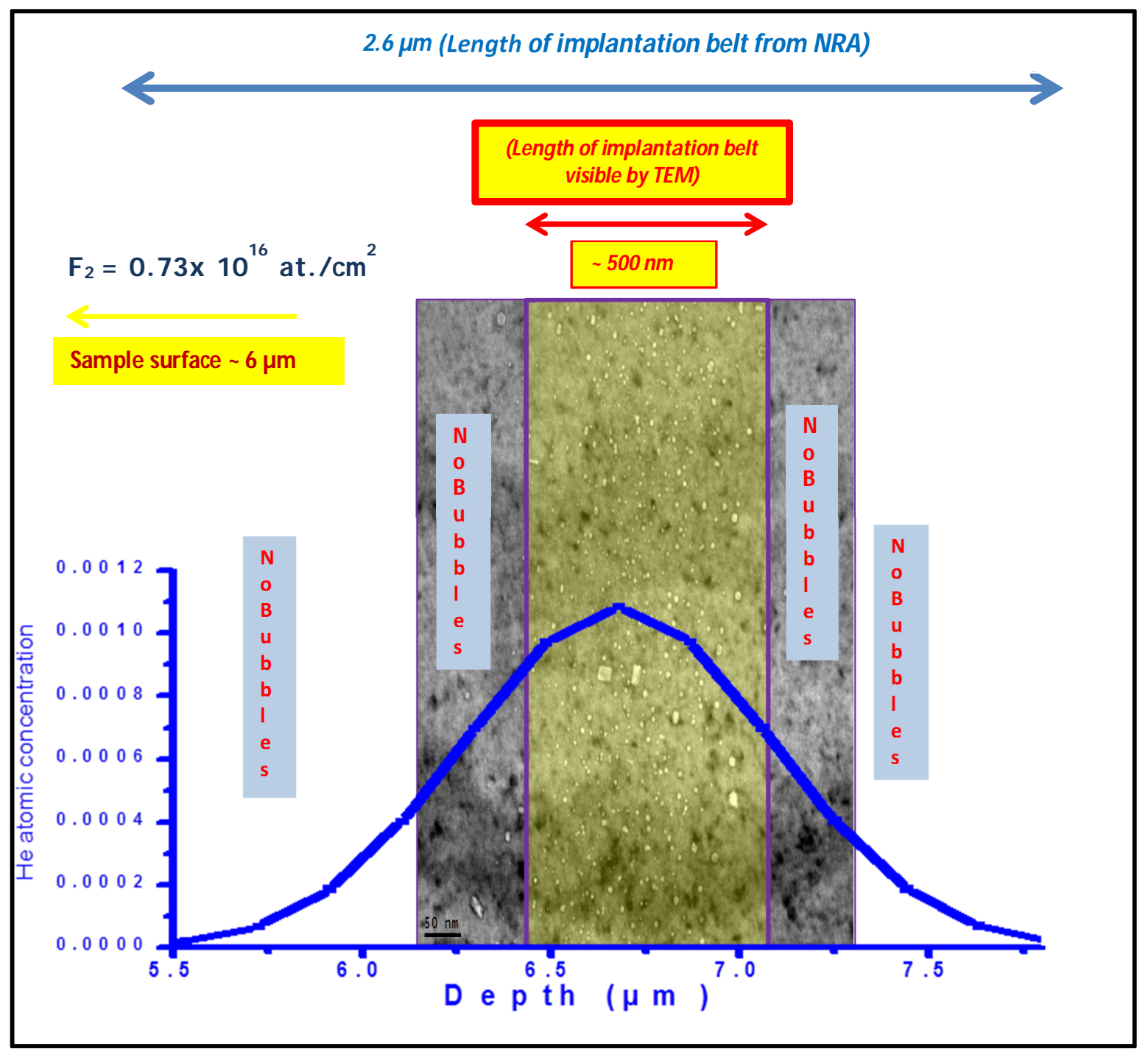

Figure AIII.5 The superimposition of NRA curve obtained for sample implanted with $F_{2}$ fluence and annealed at $\mathrm{Ta}=1500^{\circ} \mathrm{C}$ on its corresponding TEM micrograph. In the TEM micrograph, white dots (obtained in under focus conditions) represent the bubbles. 
For samples implanted with $\mathrm{F}_{3}$ fluence and annealed at $1600{ }^{\circ} \mathrm{C}$, the entire width of the region where helium is present by NRA is $3 \mu \mathrm{m}$, however only the central $200 \mathrm{~nm}$ of total $3 \mu \mathrm{m}$ of the helium depth profile is seen in the form of bubbles under TEM.

From figures A.III.4, A.III.5, A.III.6, we concluded that concentration of helium is an important parameter for bubble nucleation. We can easily observe in all the three figures, that in the region where the helium is present in small quantity, the helium vacancy clusters have not grown into the size which is visible under TEM.

And comparing the total quantity of helium visible under TEM, we observed that for higher fluence value almost $90 \%$ of the helium is present into the form of bubbles, however, under the same annealing conditions, for low fluence value, only $30 \%$ of helium is present in the form of visible bubbles and all the rest of helium is present in the form of invisible small clusters. And this also seems to be the reason, why helium implanted with low fluence show long range diffusion (as expected in Fick's law). Therefore, lower the quantity of helium, the probability of the bubbles to nucleate into stable bubbles reduces. However, one should not confuse this with size of the bubbles. As already explained in section 6.2, when there are few nucleation centers, there are high chances for them to grow into relatively big sizes. 


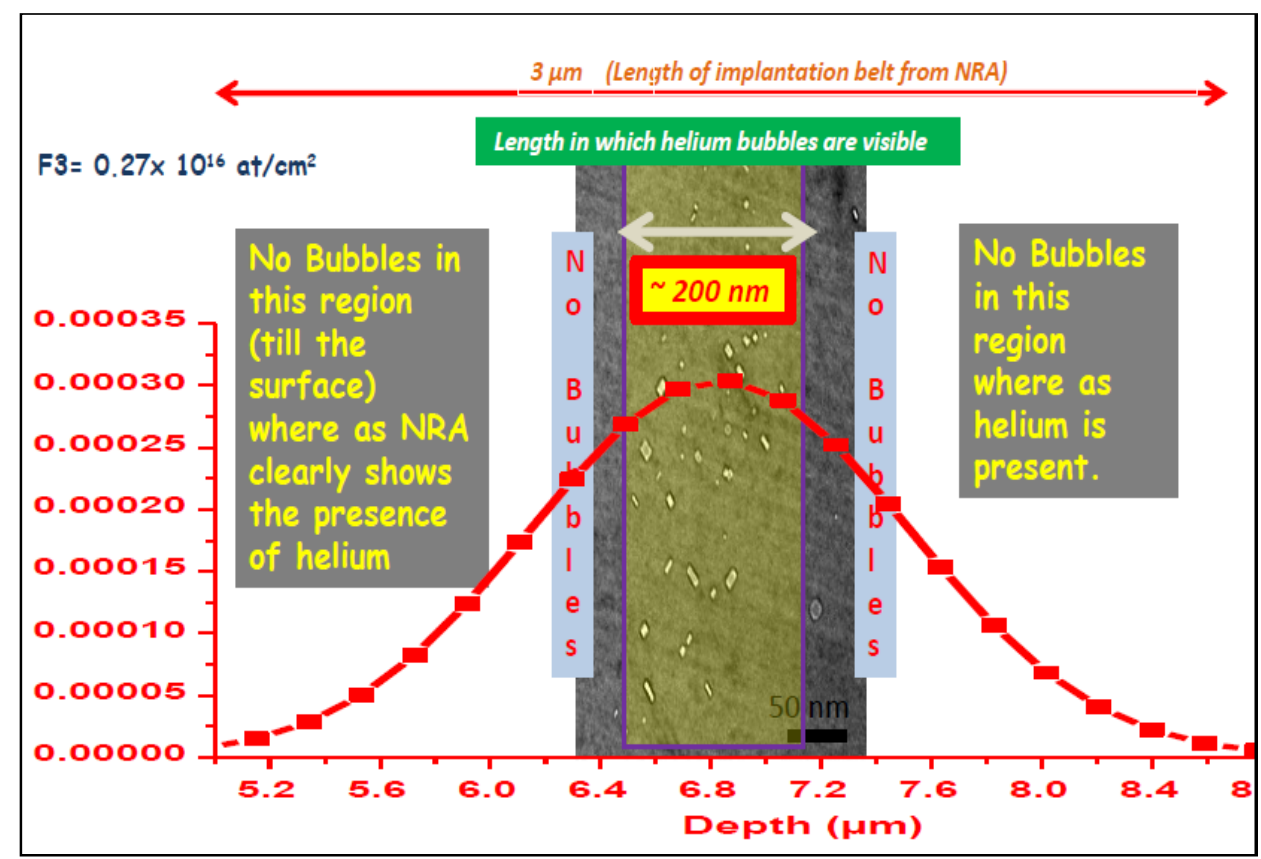

Figure AIII.6 The superimposition of NRA curve obtained for sample implanted with $F_{3}$ fluence and annealed at $\mathrm{Ta}=1500^{\circ} \mathrm{C}$ on its corresponding TEM micrograph. In the TEM micrograph, white dots (obtained in under focus conditions) represent the bubbles.

All the results are summarized in Table A.III.1:

\begin{tabular}{|l|c|c|}
\hline \multicolumn{1}{|c|}{ Samples } & $\begin{array}{c}\text { Total length in } \\
\text { which He is } \\
\text { present } \\
\text { calculated } \\
\text { by NRA }\end{array}$ & $\begin{array}{c}\text { Total length in which } \\
\text { He seems to be present } \\
\text { calculated by TEM }\end{array}$ \\
\hline $\begin{array}{l}\text { TiN implanted with } \boldsymbol{F}_{\mathbf{1}} \text { fluence } \\
\text { and annealed at } \boldsymbol{T}_{\boldsymbol{a}}=\mathbf{1 5 0 0}^{\circ} \boldsymbol{C}\end{array}$ & $2.8 \mu \mathrm{m}$ & $1.6 \mu \mathrm{m}$ \\
\hline $\begin{array}{l}\text { TiN implanted with } \boldsymbol{F}_{\mathbf{2}} \text { fluence } \\
\text { and annealed at } \boldsymbol{T}_{\boldsymbol{a}}=\mathbf{1 5 0 0}^{\circ} \boldsymbol{C}\end{array}$ & $2.6 \mu \mathrm{m}$ & $500 \mathrm{~nm}$ \\
\hline $\begin{array}{l}\text { TiN implanted with } \boldsymbol{F}_{\mathbf{3}} \text { fluence } \\
\text { and annealed at } \boldsymbol{T}_{\boldsymbol{a}}=\mathbf{1 5 0 0}^{\circ} \boldsymbol{C}\end{array}$ & $3 \mu \mathrm{m}$ & $200 \mathrm{~nm}$ \\
\hline
\end{tabular}




\section{$\underline{\text { ANNEX } 4}$}

Two type of polycrystalline 3C-SiC (E68 \& F90*), one having grain size between $(100 \mathrm{~nm}$ $1 \mu \mathrm{m}$ ) and other having grain size around $3 \mu \mathrm{m}$, respectively were implanted with $3 \mathrm{MeV}$ helium ions at the same time with fluence $\left(\mathrm{F}_{1}=5 \times 10^{16} \mathrm{at} . / \mathrm{cm}^{2}\right)$. These large samples were cut into small pieces and subsequently, sealed in quartz tube. Two sets containing two quartz tube (each containing one different type of sample) were heated at two different temperatures $\left(1000{ }^{\circ} \mathrm{C} \&\right.$ $1100{ }^{\circ} \mathrm{C}$ ) for $2 \mathrm{~h}$. NRA was done on as-implanted and annealed samples to quantify and determine the position of helium atoms. Excitation curves are plotted in figure A.IV1 and A.IV2 for samples with code F90 \& E68 respectively. From these excitation curves, we can clearly see that the samples with large grain size (F90) have better helium retention properties as the excitation curves corresponding to $1000{ }^{\circ} \mathrm{C} \& 1100{ }^{\circ} \mathrm{C}$, superimpose with in the measurement errors on the excitation curve obtained for as-implanted samples. However, samples with small grain size have lost more than $40 \%$ of helium at $1100{ }^{\circ} \mathrm{C}$ (see figure A.IV2). These results confirm the role of grainboundaries on helium release.

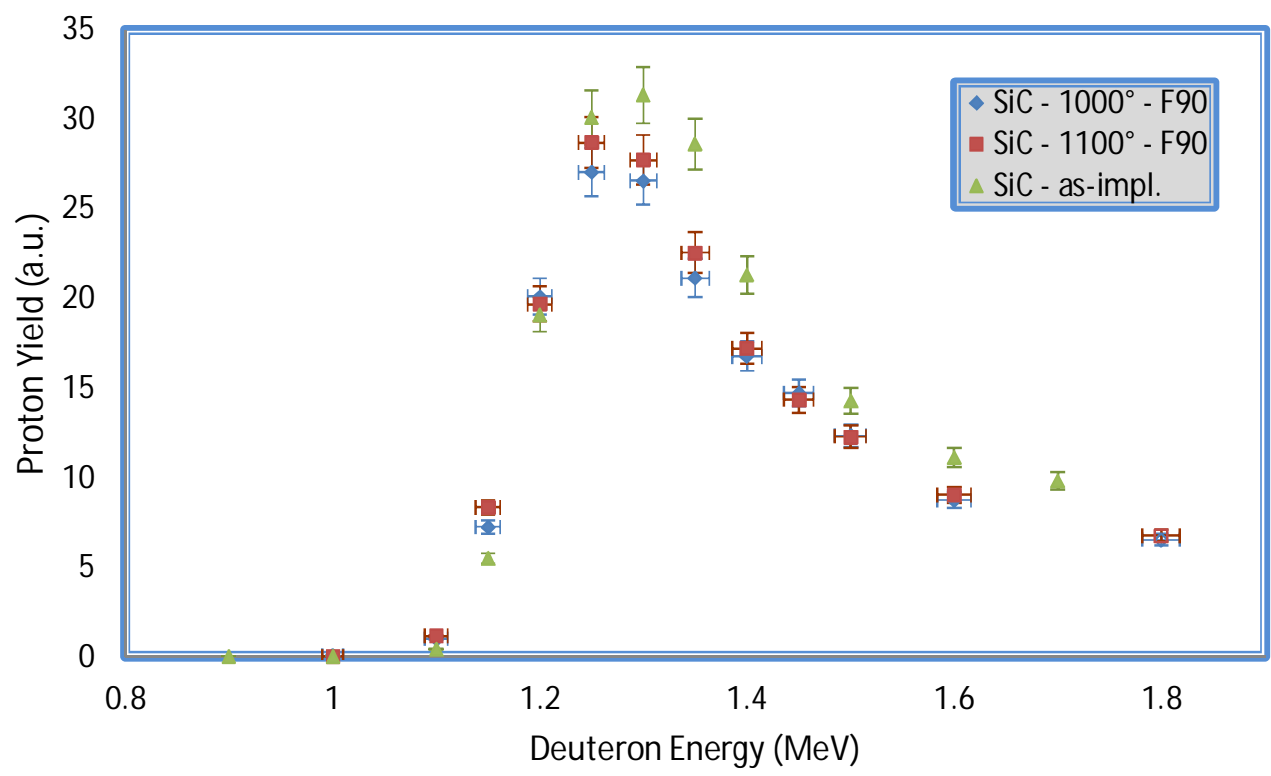

Figure A.IV1. Excitation curves (proton yield versus incident deuteron energy) measured for as-implanted and annealed 3C-SiC (F90) samples.

\footnotetext{
* These samples are fabricated in Department of Nuclear Materials, CEA Saclay and have been given these codes.
} 


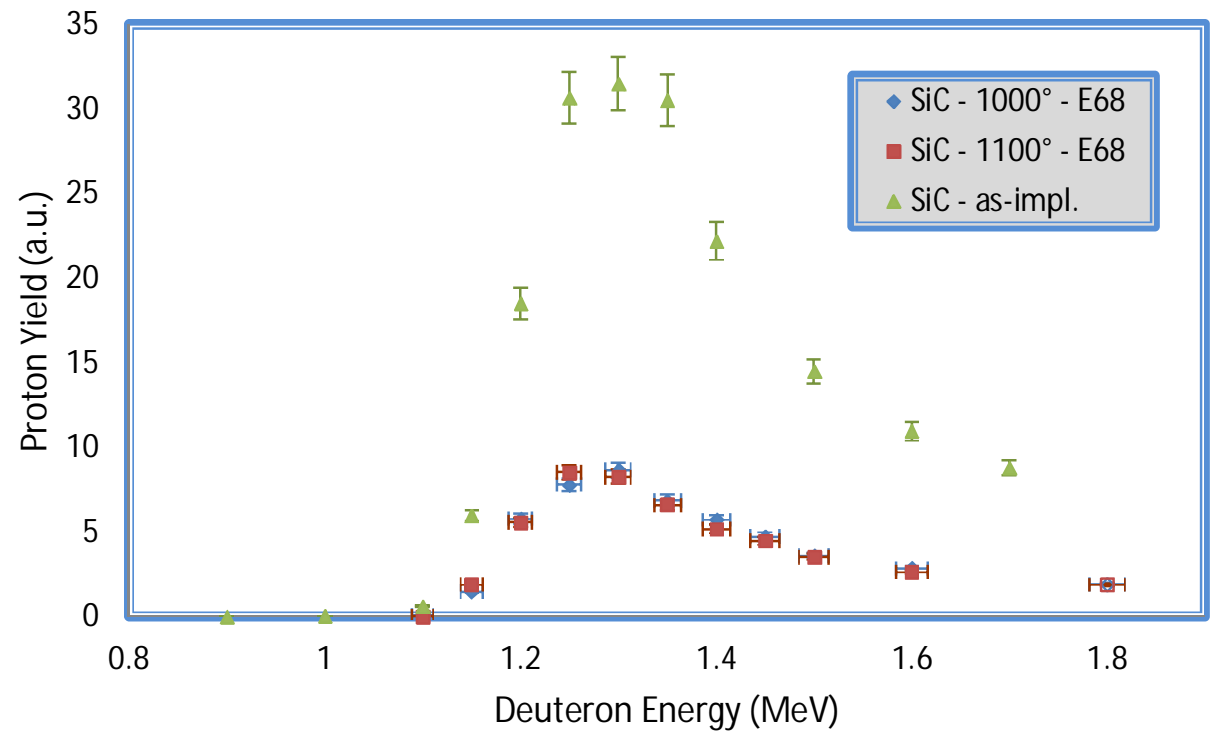

Figure AIV2. Excitation curves (proton yield versus incident deuteron energy) measured for as-implanted and annealed 3C-SiC (E68) samples. 
